\title{
STORM SIGNATURES IN COASTAL PONDS AND MARSHES OVER THE LATE HOLOCENE
}

by

\author{
Katherine A. Castagno \\ B.A., Smith College (2012) \\ M.A., University of Rhode Island (2014) \\ Submitted in partial fulfillment of the requirements for the degree of \\ Doctor of Philosophy \\ at the \\ MASSACHUSETTS INSTITUTE OF TECHNOLOGY \\ and the \\ WOODS HOLE OCEANOGRAPHIC INSTITUTION
}

September 2019

C2019 Katherine A. Castagno. All rights reserved.

The author hereby grants to MIT and WHOI permission to reproduce and to distribute publicly paper and electronic copies of this thesis document in whole or in part in any medium now known or hereafter created.

Author

Joint Program in Oceanography/Applied Ocean Science \& Engineering

Massachusetts Institute of Technology \& Woods Hole Oceanographic Institution

June 24, 2019

Certified by.

Dr. Jeffrey P. Donnelly

Senior Scientist in Geology \& Geophysics

Woods Hole Oceanographic Institution

Thesis Supervisor

Accepted by

Dr. Daniel McCorkle

Senior Scientist in Geology \& Geophysics

Woods Hole Oceanographic Institution

Chair, Joint Committee for Marine Geology \& Geophysics 


\title{
STORM SIGNATURES IN COASTAL PONDS AND MARSHES OVER THE LATE HOLOCENE
}

by

\author{
Katherine A. Castagno \\ Submitted to the MIT-WHOI Joint Program in Oceanography and Applied Ocean Science and \\ Engineering on June 24, 2019, in Partial Fulfilment of the Requirements for the Degree of \\ Doctor of Philosophy in Geology and Geophysics.
}

Tropical cyclones pose a growing threat to coastal populations, especially as both populations and infrastructure are increasingly concentrated along the eastern coast of the United States. This thesis seeks to characterize the impacts of storms on coastal ponds and marshes along the eastern coast of the United States. Tropical cyclones and other storms have been shown to cause a spectrum of effects on these coastal systems, ranging from widespread erosion to deposition of thick sediment deposits. Sediments deposited and preserved in coastal ponds and marshes can provide a proxy for tropical cyclone landfall, the development and interpretation of which is imperative to understanding past climate trends and informing decisions for the future. This thesis uses a variety of methods to quantify the spatiotemporal signatures of tropical cyclone events in coastal, marsh, bay, and pond systems in Massachusetts, Connecticut, and Virginia. Trends in grain-size distribution and sediment coarse fraction are used to broaden our understanding of deposition and sediment sources during tropical cyclone events. The complexity of how storms interact with these systems requires a process-based, whole-site analysis to adequately develop a storm record. Given the many nuances to storm deposition in these systems (including reverse grading trends and apparent spatiotemporal variation in sediment source), the potential utility and caveats to inversely modeling storm intensity from deposit grain-size characteristics is discussed. Finally, the question of whether hurricanes can produce widespread erosion of marsh platforms is addressed through both field and modeling techniques. While storms typically deposit sediment, field evidence suggests that marshes have the potential to be eroded by a series of storms over time-a deviation from our traditional understanding of marsh evolution. Deposition and erosion of sediment during major storms remain complex, emphasizing the importance of contextualizing storm signatures within a broader view of the study area. This provides an opportunity to strengthen both paleo-reconstructions of storm activity and our ability to make informed decisions for coastal management in response to potential future changes in storminess.

Thesis Supervisor: Dr. Jeffrey P. Donnelly

Title: Senior Scientist in Geology \& Geophysics

Woods Hole Oceanographic Institution 


\section{Acknowledgements}

I am extremely grateful to have completed this thesis under the guidance of my advisor, Jeff Donnelly, whose enthusiasm for and dedication to the field of paleotempestology is an inspiration. Many thanks to Jeff and the rest of Donnelly lab, present and former: Jimmy Bramante, Nicole D'Entremont, Kelly McKeon, Stephanie Madsen, Sam Muñoz, Richard Sullivan, Jessie Pearl, Lizzie Wallace, and Charlotte Wiman.

Many more thanks to my collaborators and the members of my committee: Sergio Fagherazzi, Jon Woodruff, Ning Lin, Taylor Perron, David McGee, Chris Piecuch, and Rob Evans.

Thank you to Doug Beach and Jon Woodruff at UMass Amherst for time and instruction on the Camsizer, as well as to NOSAMS for radiocarbon analysis. I also wish to express much gratitude for the Academic Programs Office at WHOI, as well as the G\&G administrators-this thesis could not have been possible without your help. Funding for this work was provided by the Norman C. Rasmussen Fellowship Fund, Woods Hole Sea Grant, and the Ray Dalio Family Foundation.

I am grateful to have had the help of many interns throughout my five years at WHOI. These interns have braved field expeditions and repetitive sieving procedures alike, without which this thesis could not be possible: Max Besser, Bethany Bowen, David Carter, Miranda Cashman, Dan Chamberlain, Michelle Chen, Margaret DiGiorno, Charmille Dizon, Kristin Esser, Rachel Gold, Alexandra Good, Matt Hemler, Laura Jack, Emma Keeler, Ali LaBella, Jake Light, Dan Litchmore, Abby Llona, Mollie McDowell, Michelle O’Donnell, Patrick Orenstein, Sophie Ruehr, Lizzy Soranno, and Mitchell Starr.

Finally, a great thank you is in order for my friends and family-and all the four-legged furry companions — who were ceaselessly there for me throughout this journey. 


\section{Contents}

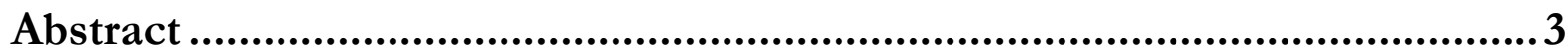

Acknowledgements..................................................................................5

List of Figures ............................................................................................11

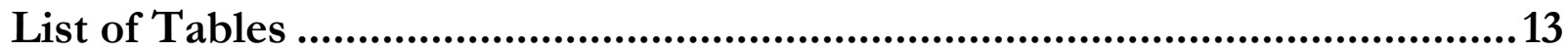

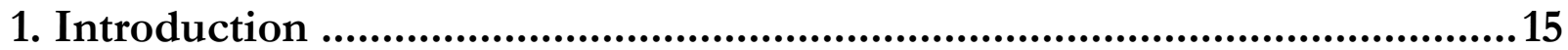

2. Storm processes and salt marsh dynamics................................................19

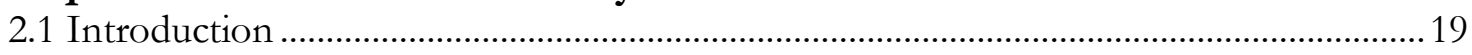

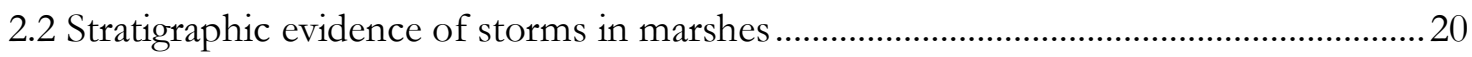

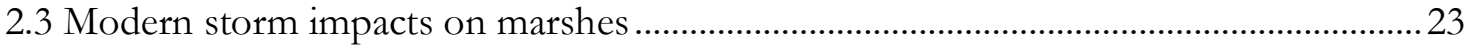

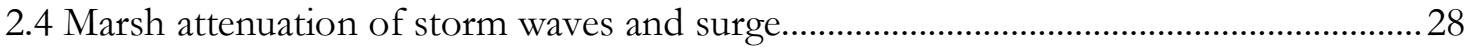

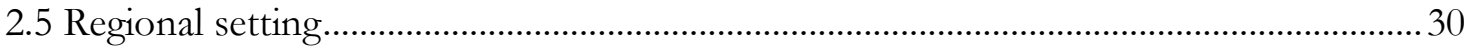

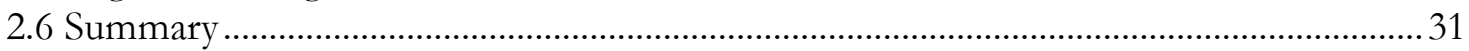

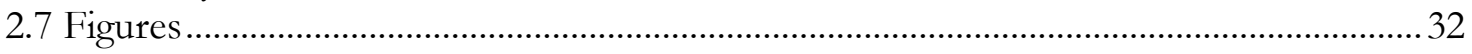

3. Spatial and temporal stratigraphic analysis of hurricane activity in a coastal

New England pond ........................................................................................39

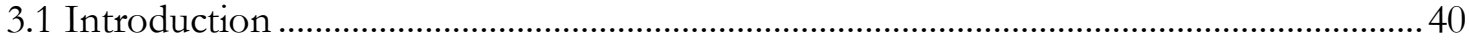

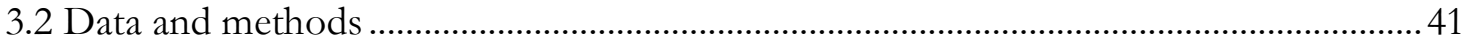

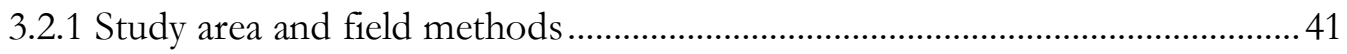

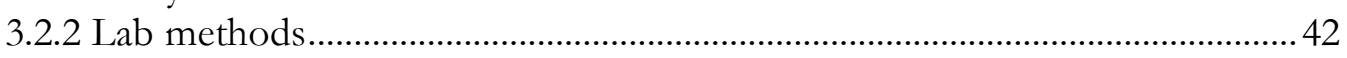

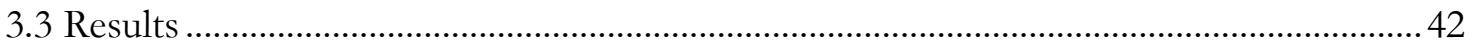

3.3.1 Correlation across transect and application to study cores .............................. 42

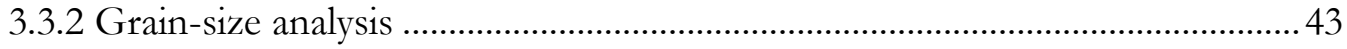

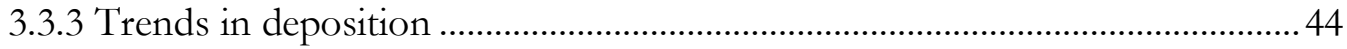

3.3.3.1 Spatial trends in deposition ................................................................ 44

3.3.3.2 Temporal trends in deposition........................................................... 44

3.3.3.3 Spatiotemporal trends in deposition ................................................. 44

3.3.4 Relationship between coarse fraction and grain size ....................................... 45

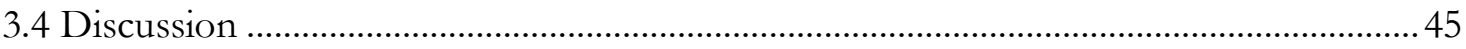

3.4.1 Updated Salt Pond chronology ………….......................................................... 45

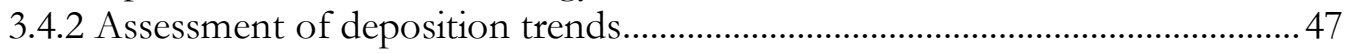

3.4.3 Relationship between coarse fraction and grain size ......................................... 49

3.5 Conclusions

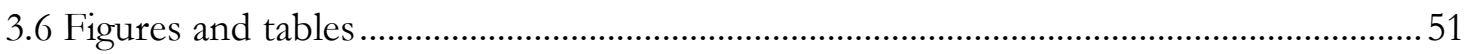




\section{Grain-size analysis of hurricane-induced event beds in a New England salt marsh.................................................................................................65

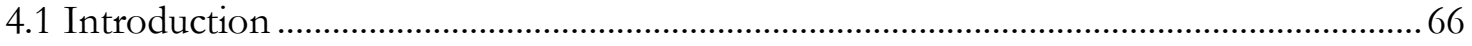

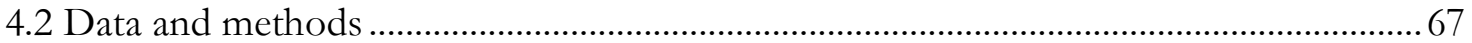

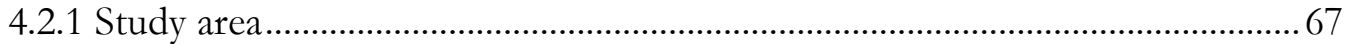

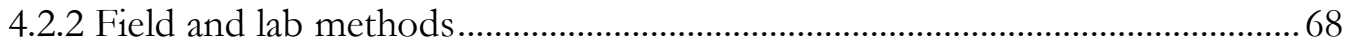

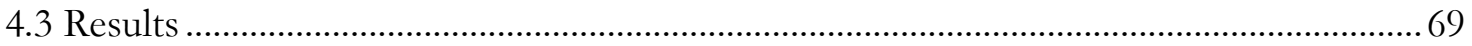

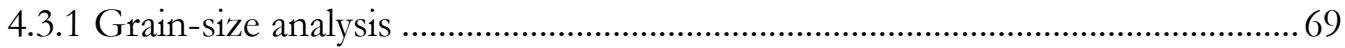

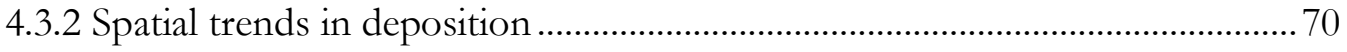

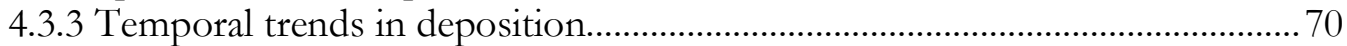

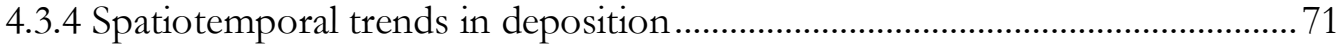

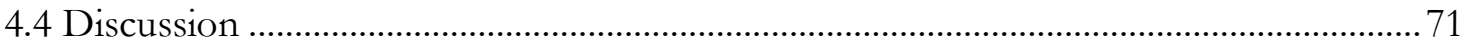

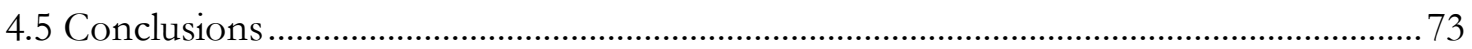

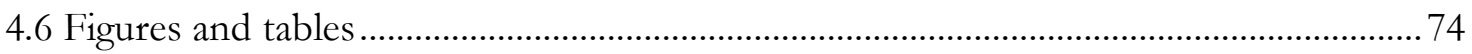

\section{Applications and caveats of inverse modeling to reconstruct tropical}

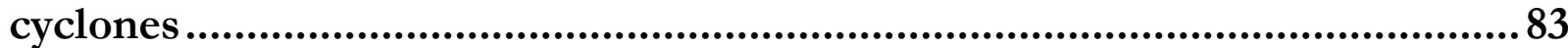

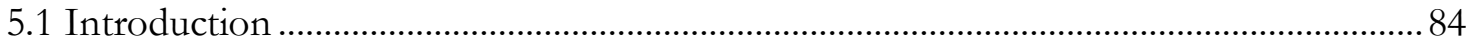

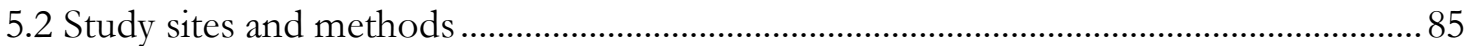

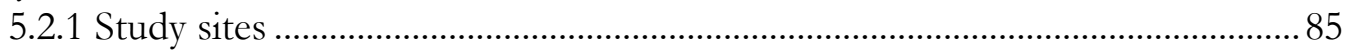

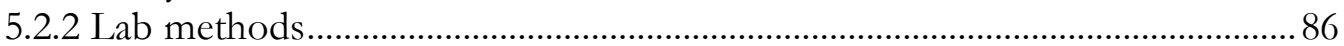

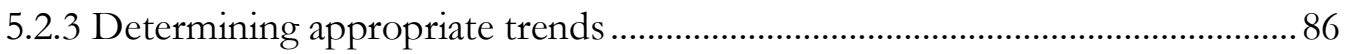

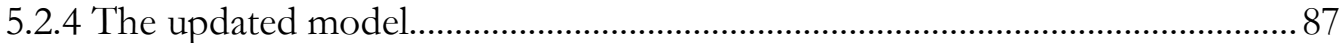

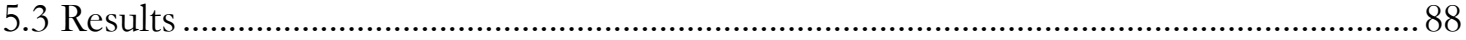

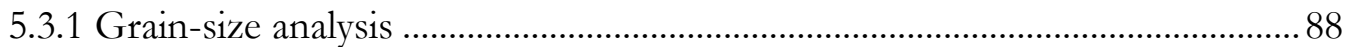

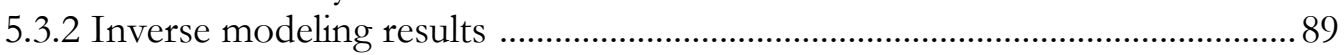

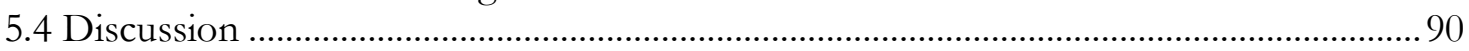

5.4.1 Comparison to the original inverse modeling technique ................................... 90

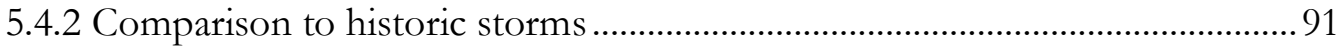

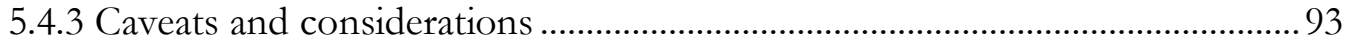

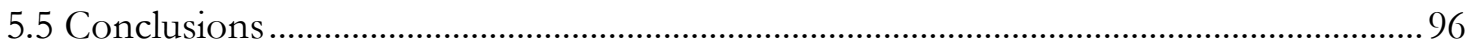

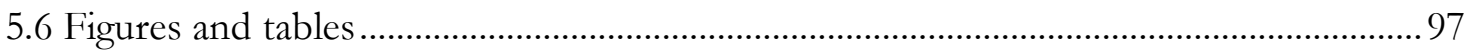

\section{Impacts of hurricane events on form and function of a Connecticut salt}

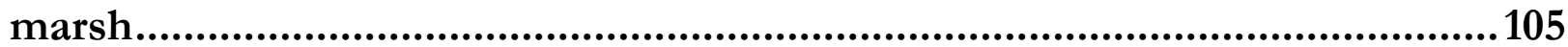

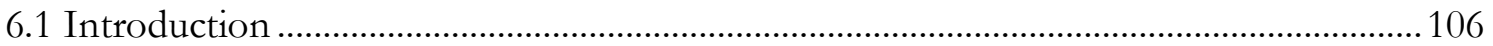

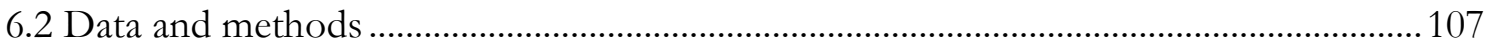

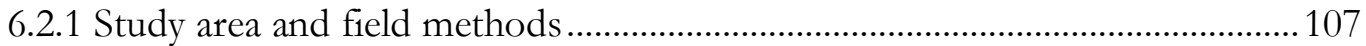

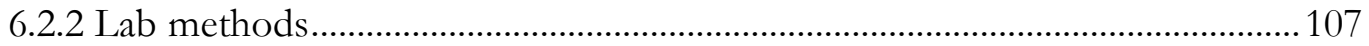

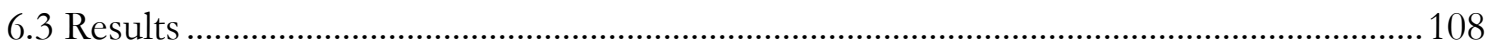

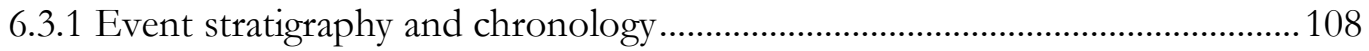

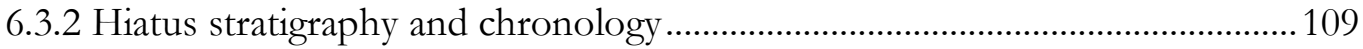

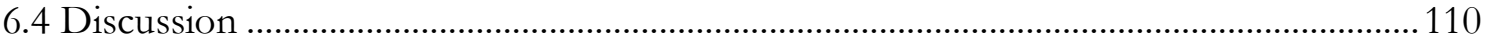

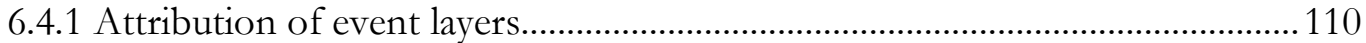

6.4.2 Testing the van de Plassche et al. (2006) hypothesis ..............................................111

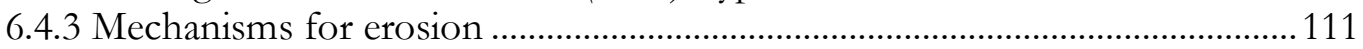




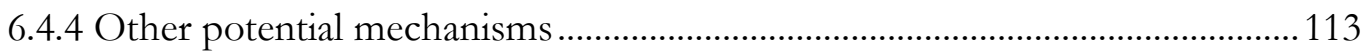

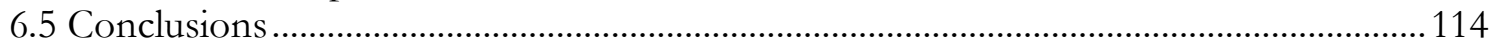

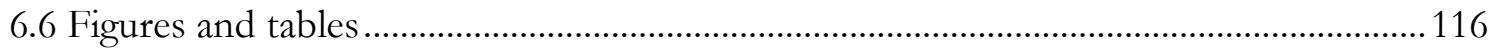

7. Intense storms increase the stability of tidal bays .....................................123

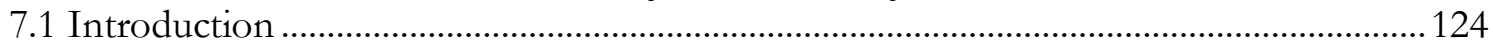

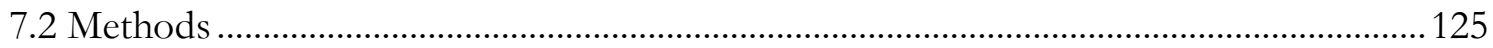

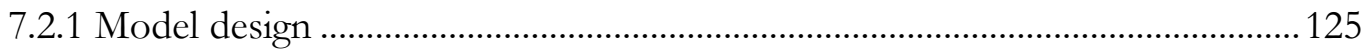

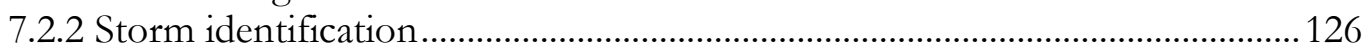

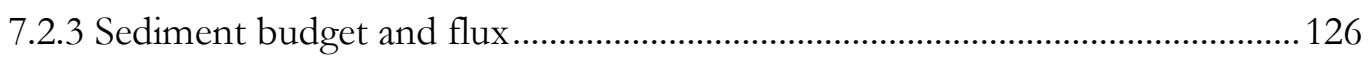

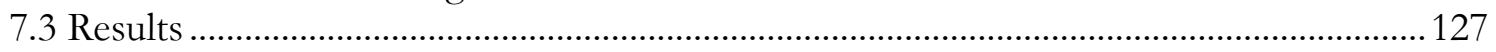

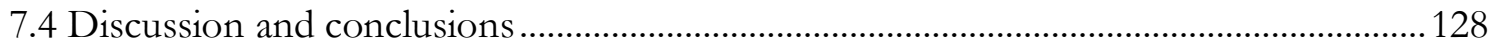

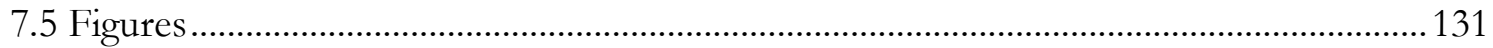

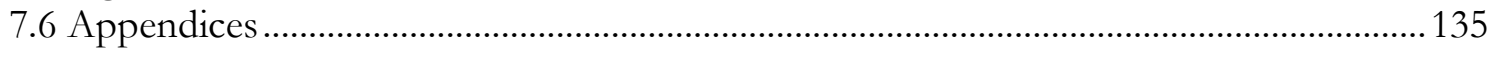

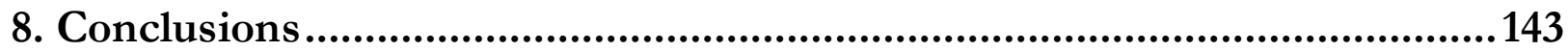

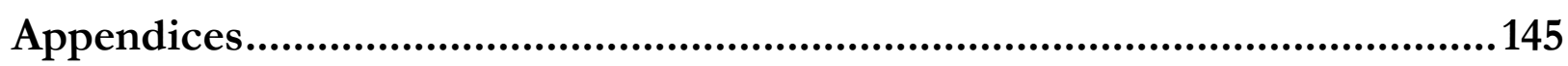

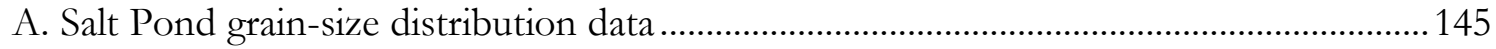

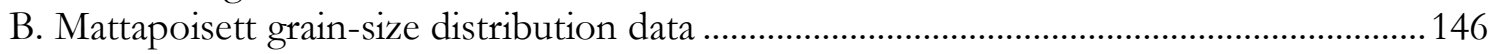

C. Pattagansett coarse-fraction data ..................................................................................... 148

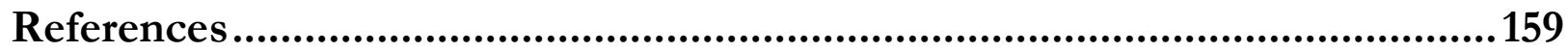




\section{List of Figures}

Figure 2.1 Research locations of storm impacts on salt marshes.................................................... 32

Figure 2.2 Theoretical salt marsh structure per Redfield (1972). ................................................... 33

Figure 2.3 Updated theoretical salt marsh structure........................................................................... 33

Figure 2.4 Field photos of depositional impacts of storms on marshes. .......................................... 34

Figure 2.5 Field photos of erosional impacts of storms on marshes.............................................. 35

Figure 2.6 Evidence of erosion and deposition in the same marsh core. ........................................ 36

Figure 2.7 Evidence of continued storm activity and marsh persistence......................................... 36

Figure 2.8 Changes in sea level and storminess over the past 2,000 years.................................... 37

Figure 2.9 Processes that impact marsh stability............................................................................... 38

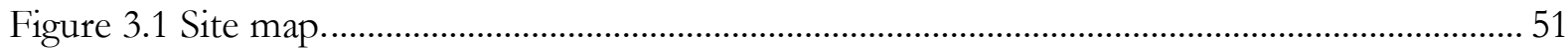

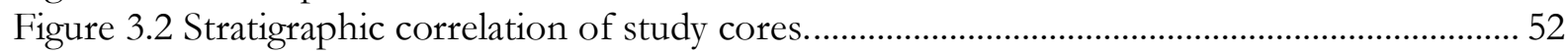

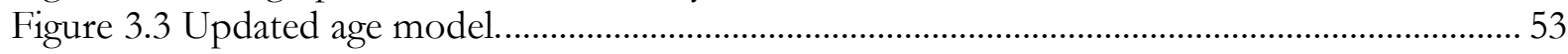

Figure 3.4 Updated age models and event frequencies.................................................................. 54

Figure 3.5 Coarse fractions for historic events. ............................................................................ 55

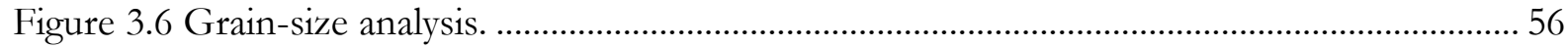

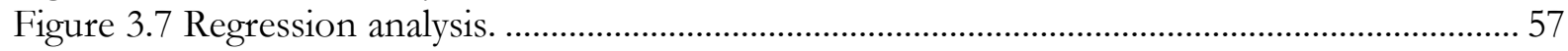

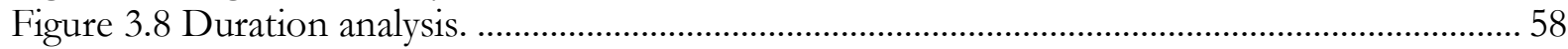

Figure 3.9 Relationship of coarse fraction to maximum grain size for historic events.................. 59

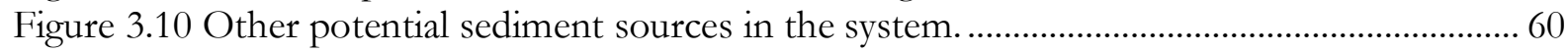

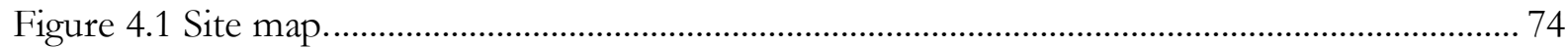

Figure 4.2 Core radiographs and event beds................................................................................ 75

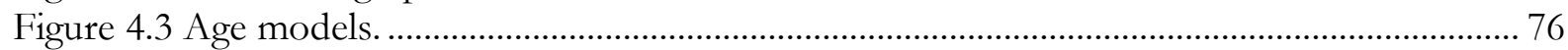

Figure 4.4 Relationships between grain size, particle number, and coarse fraction. ...................... 77

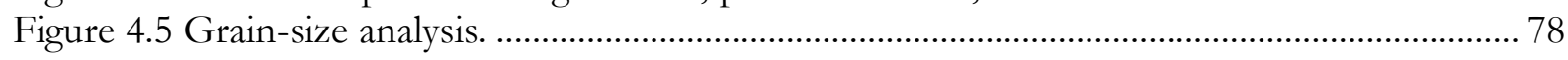

Figure 4.6 Radiographs and maximum grain sizes of study events................................................. 79

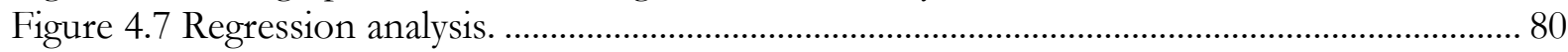

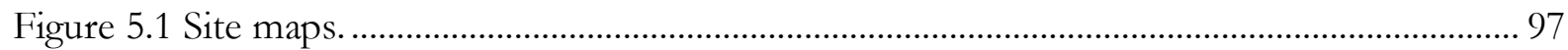

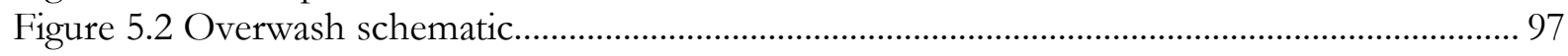

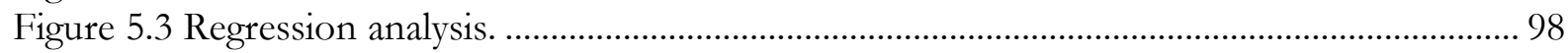

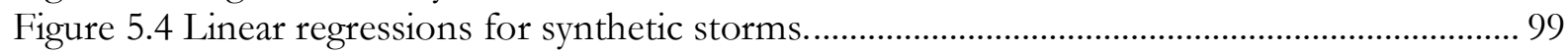

Figure 5.5 Comparison of original to updated inverse modeling techniques.................................. 100

Figure 5.6 Updated inverse modeling results................................................................................... 101

Figure 5.7 Comparison of modeled and observed/estimated values .............................................. 102

Figure 5.8 Other potential sediment sources in the systems............................................................. 103

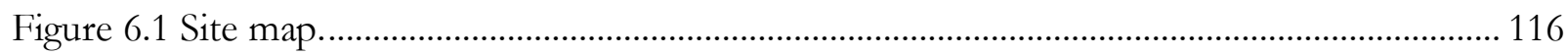

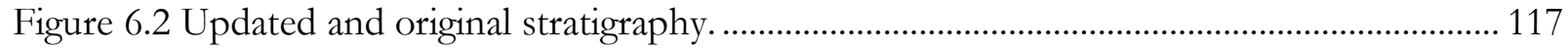

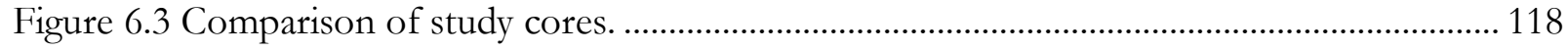

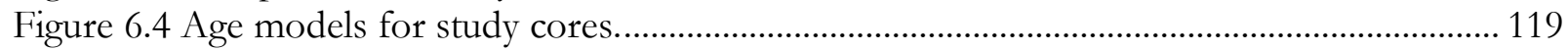

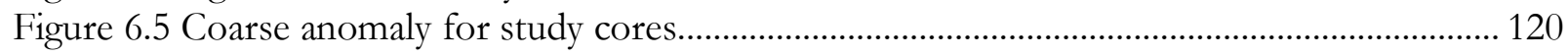

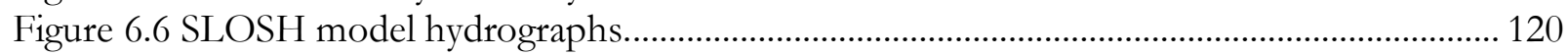

Figure 6.7 Proposed mechanisms for erosion sequence ............................................................... 121 


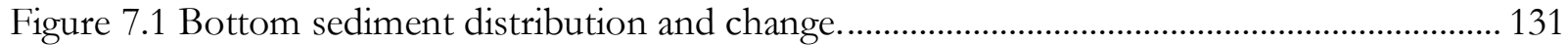

Figure 7.2 Sediment budget related to study parameters................................................................... 132

Figure 7.3 Sediment budget related to magnitude and duration of study parameter..................... 133

Figure 7.4 Sediment budget by grain size related to maximum storm surge................................... 134

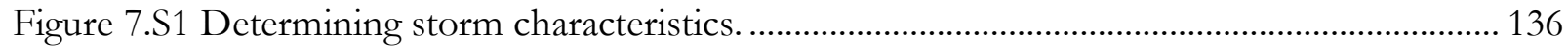

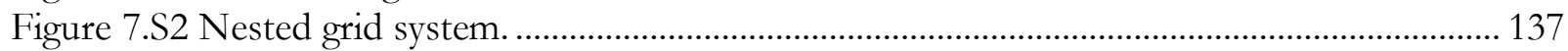

Figure 7.S3 Comparison between modeled and measured water levels........................................ 138

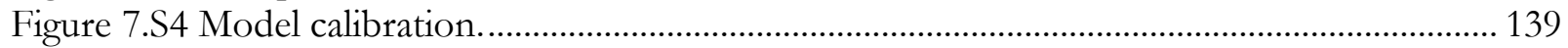

Figure 7.S5 Comparison between modeled and measured SSCs. ................................................... 140 


\section{List of Tables}

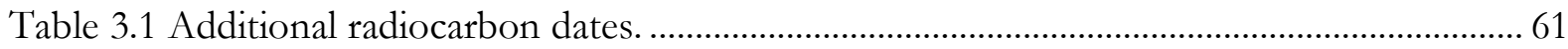

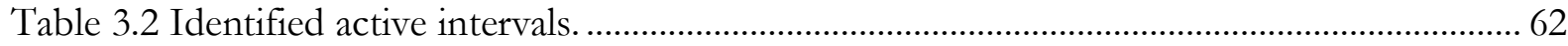

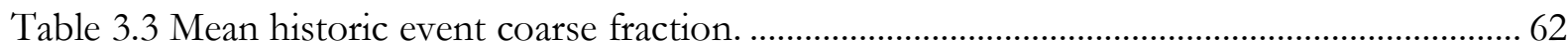

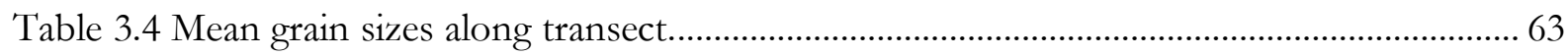

Table 4.1 Grain size and bed thickness for study cores............................................................... 81

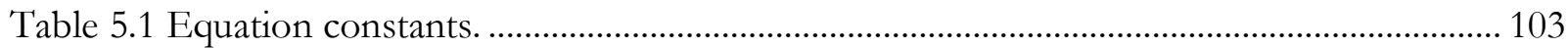

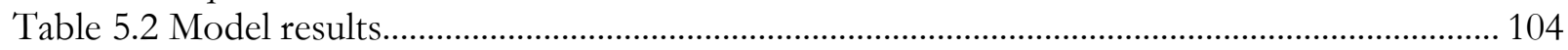

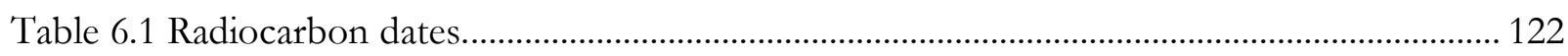

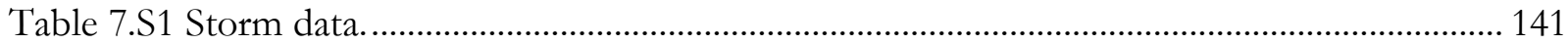

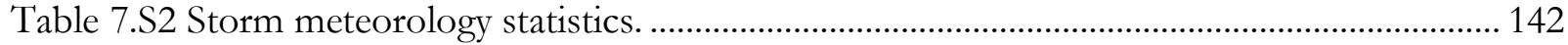

Table 7.S3 Grain-size distribution and storm surge statistics. .......................................................... 142 


\section{Introduction}

Tropical storms and hurricanes pose a growing threat to coastal populations, especially as both populations and economic resources are increasingly concentrated along the eastern coast of the United States. With tropical cyclones responsible for approximately $\$ 20$ billion in annual damage in the United States (ICAT Damage Estimator, 2019; averaged over 119 years from 1900 C.E. to 2019 C.E. and normalized for inflation in 2019 USD), research into past tropical cyclone frequency and intensity is imperative to making informed decisions for these vulnerable areas.

The tropical cyclone dataset for the Atlantic basin extends quantitatively to the 1850s (Jarvinen et al., 1988) and qualitatively as far as 1492 C.E. through historic ship logs and personal accounts (Boose et al., 2001). Proxy records also can be used to reconstruct tropical cyclone activity, extending our understanding of tropical cyclone frequency and intensity millennia past historical records. Storminduced overwash deposits in coastal ponds and salt marshes, the primary signature explored in this thesis, are a reliable proxy for hurricane strikes along the eastern coast of the United States (Boldt et al., 2010; Donnelly et al., 2001; Donnelly et al., 2015; Woodruff et al., 2008).

This thesis seeks to characterize the signatures of past tropical cyclones in coastal ponds and marshes along the eastern coast of the United States. A process-based interpretation of proxy records is imperative to understanding past climate trends and informing decisions for the future. This thesis uses a variety of methods in several different locations to:

1) quantify the spatiotemporal signatures of tropical cyclone events in these locations,

2) explore the potential for determining intensity from the grain sizes of these events,

3) investigate potential erosional signatures associated with hurricane events, and

4) model the accumulation and erosion of sediments during storm events.

Chapter 2, in press for Marshes: Function, Dynamics and Stresses (Cambridge University Press, edited by Duncan Fitzgerald and Zoe Hughes), is a detailed literature review of the impacts of storms on salt marshes. It is driven by the research questions:

1. How have hurricanes and other major storms impacted salt marshes on both modern and prehistoric timescales?

2. Are salt marshes an effective tool for coastal protection from hurricanes?

Chapter 3 explores the spatiotemporal trends of event beds in a coastal kettle pond in Falmouth, MA. Previous work has focused on a 2,000-year, event-frequency record from one sediment core in the basin (Donnelly et al., 2015). This chapter expands and updates the record using 
multiple cores along a $\sim 100 \mathrm{~m}$ transect, as well as determines variations in grain-size distribution for several key events. Research questions guiding this chapter include:

1. Is the hurricane record presented by Donnelly et al. (2015) robust and reproduceable across multiple cores?

2. How do the grain-size distributions of storm events vary spatiotemporally within the basin?

Chapter 4 details grain-size distribution trends in hurricane-induced event beds in a backbarrier marsh in Mattapoisett, MA. Building on previous work chronicling event frequency at this location by Boldt et al. (2010), this chapter analyzes trends in grain-size distribution across a transect of three separate cores from the same marsh. Research questions guiding this chapter include:

1. Do events from the study location follow expected trends?

2. What are the factors influencing the observed trends?

Chapter 5 assesses the potential to inversely model storm intensity from the maximum grain size present in a deposit. The chapter presents an updated inverse modeling technique from those proposed by Woodruff et al. (2008) and Brandon et al. (2014), incorporating synthetic storm data for calibration. Data from the study sites of chapters 3 and 4 are used to explore both the utility and caveats of this approach. Research questions for this chapter include:

1. How can we quantify the intensity of prehistoric storms leaving overwash deposits?

2. Is the inverse modeling technique appropriate for reconstructing storm intensity?

Chapter 6 expands on and tests the hypothesis proposed by van de Plassche et al. (2006) that an observed $\sim 600$-year sedimentary hiatus in a Niantic, CT, salt marsh was caused by erosion from the Great Colonial Hurricane of 1635. This chapter confirms the hiatus and erosional sequence identified by van de Plassche et al. (2006), while qualifying the proposed erosional mechanism. The guiding research questions for this chapter include:

1. What mechanisms are responsible for the unique, pervasive erosional sequence seen in the marsh?

2. Why is this unique sequence not seen elsewhere in the historic record or in other New England marshes?

Chapter 7, originally published in Geophysical Research Letters (Castagno et al., 2018), uses highresolution numerical simulations of real storm data to quantify the sediment budget of a system of coastal bays in Virginia. It is driven by the research questions:

1. Do storms cause erosion or deposition on coastal bays and marshes?

2. How does the intensity of the storm change the system's sediment budget? 
Together, the chapters of this thesis explore the impacts of tropical cyclones on coastal ponds and salt marshes along the eastern coast of the United States using both field and modeling approaches, expanding our understanding of the processes behind the sedimentological signatures of these natural hazards. 


\section{Storm Processes and Salt Marsh Dynamics}

This chapter is currently in press as: Castagno, K. A., J. P. Donnelly and J. D. Woodruff, In press: Chapter 9: Storm Processes and Salt Marsh Dynamics. In: Marshes: Function, Dynamics and Stresses [Fitzgerald, D. and Z. Hughes (eds.)]. Cambridge University Press, Cambridge. Used with permission as granted in the original copyright agreement.

\subsection{Introduction}

Marshes have long been considered useful for their ecosystem service of coastal protection. Their roles in protection from storms and floods are seen as necessary and important to many coastal communities (Barbier et al., 2011; Butchart et al., 2005; Costanza et al., 1997; Morgan et al., 2009). Understanding the impacts that storms have on coastal ecosystems and adjacent coastal communities is imperative to increasing coastal resilience in the face of future increases in coastal flooding and associated damage (Pielke et al., 2008; Mendelsohn et al., 2012). Salt marshes have been lauded as buffers to storm surges, wind-generated waves, and elevated water levels (French, 2006; Möller, 2012). The ecological restoration economy, which includes salt marsh restoration, in the United States alone generates $\$ 9.5$ billion in annual economic output and employs an estimated 126,000 workers (BenDor et al., 2015). After Hurricane Sandy, the United States Fish and Wildlife Service spent more than $\$ 40$ million on salt marsh restoration projects in response to this single event, including $\$ 11$ million toward restoring a series of salt marshes along Long Island (US F\&WS, 2017).

Recent research reviewed in this chapter explores the impacts of storms on salt marsh erosion and accumulation, with an eye toward the utility of salt marshes for coastal protection in the face of rising sea levels and increasing storminess. Our review is primarily focused to the East and Gulf Coast of the United States as well as Europe. This is in part due to the concentration of researchers and the prevalence of marsh systems in these regions, compared to mangrove wetlands that tend to dominate the tropics (Fig. 2.1). Our review highlights the processes that occur in marshes resulting from storms (Fig. 2.2), and provides insight into the future response of marshes to changes in storminess. The variability in storm impacts to marshes is largely based on both intensity and circumstance, with the

potential for a spectrum of effects to be seen at a single marsh (Fig. 2.3; Cahoon, 2006; Morton \& Barras, 2011). Though marshes may be generally resilient to coastal flooding on larger spatial and temporal scales, storms may have more subtle impacts, causing cascading effects on a variety of smaller scales. A single storm may result in overwash that provides sediment to build the marsh in some 
sections, while wave activity and higher channel velocities increases marsh-edge erosion/retreat in other sections due to scarping, undercutting, and slumping (Fig. 2.3). Given the prevalence of marshes worldwide and the likelihood of changes in storminess as climate changes (Walsh et al., 2016), it is important to understand the effectiveness of marshes in flood mitigation, as well as the role of storms in controlling marsh morphology. Our review begins with a discussion on the depositional record of storms in marshes, followed by an overview of modern storm impacts on marshes, and marsh attenuation of waves and storm surge.

\subsection{Stratigraphic evidence of storms in marshes}

Marsh stratigraphy and sediments provide both accretional and erosional evidence of paleostorms. With respect to accretion, storm-induced overwash deposits in salt marshes have been used to augment our understanding of hurricane strikes (e.g., Boldt et al., 2010; Donnelly et al., 2001a, 2001b). Elevated water levels from storm surge and waves can be significant enough to overtop sandy barriers, transporting and depositing coarse sediment on top of salt marsh peat. During the years following the storm, organic material accumulates/grows over the associated overwash layer, thus preserving the storm event as a stratigraphically-distinct allochthonous layer. Donnelly et al. (2001b) described this sedimentary pattern in a salt marsh in southern Rhode Island (Fig. 2.4a). At this salt marsh, aerial photos after major hurricanes in 1938 and 1954 confirm overwash fans deposited by the events. These overwash fans, along with four older deposits, were confirmed in a series of 14 sediment cores, suggesting that several intense hurricanes had impacted the area since 1635. Other studies have also identified storm-induced deposits in marsh, including in the Gulf of Mexico (Williams, 2012), South Carolina (Hippensteel, 2008; Hippensteel \& Martin, 1999), and Georgia (Kiage et al., 2011). For a complete database of paleo-storm reconstructions from marshes and other back-barrier environments please see recent reviews by Oliva et al. (2018) and Muller et al. (2017).

van de Plassche et al. $(1999,2004,2006)$ proposed that intense storms (under a specific, yet unknown, combination of conditions) may be the cause of preserved stratigraphic evidence of widespread erosional events in a Connecticut salt marsh. At Pattagansett River Marsh, two distinct erosional events were discovered (van de Plassche et al., 2006), where the portion of the marsh that had been eroded appeared to have been quickly infilled with tidal mud, which then transitioned to low and then high marsh peat. This was interpreted to represent a small-scale complete transition from marsh to tidal creek/mudflat system then back to a low-to-high marsh again. Though storms have been shown to cause smaller, localized erosional events, the large-scale unconformities observed by 
van de Plassche et al. (on the order of $>100 \mathrm{~m}^{2}$ ) were surprising. Erosion of this scale has not been documented in modern salt marshes, and did not appear to have deposited large blocks of excavated peat elsewhere. van de Plassche et al. (2006) found that the dates of their two identified erosional events corresponded with the age ranges of known hurricane deposits found at another salt marsh approximately 60 kilometers away (Donnelly et al., 2001a), including a hurricane in 1635, which is considered by many to be the most intense hurricane in the historical record to impact southern New England (Boose et al., 2001; Ludlum, 1963).

Nikitina et al. (2014) expanded on the van de Plassche et al. (2006) research with sedimentary evidence of potential storm erosion from more than 200 gouge cores along seven transects in a salt marsh in New Jersey. The authors documented similar depositional sequences as those seen by van de Plassche et al. (2006) across great swathes of marsh: in at least seven sequences, there were abrupt contacts between salt marsh peat and overlying intertidal mud, suggesting that the underlying peat was eroded and then rapidly infilled by tidal mud (Fig. 2.5f). Though the authors suggested several different processes that may produce these sequences, they developed a chronology that suggested that these events may have correlated with historic and prehistoric tropical cyclone events observed previously in the northeast (Donnelly et al., 2001b). The authors proposed that the most recent episodes of marsh erosion may correlate with tropical cyclones in 1903 AD, 1821/1788 AD, and 1635 $\mathrm{AD}$.

Erosional features in marsh stratigraphy are attributed to storms largely through the discrediting of other potential mechanisms (Nikitina et al., 2014). Alternative explanations for the intertidal mud deposits overlying high marsh peat include an increase in tidal range (Long et al., 2006), gradual migration of tidal channels (Stumpf, 1983), background rates of marsh-cliff retreat (McLoughlin et al., 2015), marsh pond formation (Wilson et al., 2009), and changes in sea level (Schwimmer \& Pizzuto, 2000). Migration of tidal channels was ruled out in the Nikitina et al (2014) study since tidal creeks are generally considered stable over long timescales (Redfield, 1972), and the process of tidal creek migration in the case of stabilizing vegetation loss is a slow time-transgressive process that would not result in the observed sharp contacts (Stumpf, 1983). Though many marshes have been extensively ditched for mosquito control since the 1800 s and the erosive contacts may represent infilling of ditches, the authors suggest that would limit those contacts to post-1800, which is not observed in the record. Such erosive sequences would then also be common across many marshes-an observation also not seen as yet. Salt pans, which form either from marsh growing around a tidal depression or after significant vegetation disturbance (Wilson et al., 2009), have a similar 
stratigraphic signature to that seen by Nikitina et al. (2014) and van de Plassche et al. (2006). The authors assert, however, that the stratigraphic sequences seen in their study site appear to be laterally continuous across large areas of the marsh. This observation is more consistent with a major erosional event than a localized salt pan. Additionally, while most of these ruled-out processes occur over longer timescales, higher-energy events could also be responsible for more rapid changes in tidal range, channel geometry, or cliff erosion, among others.

It is important to consider why the Nikitina et al. (2014) and van de Plassche et al. (2006) studies observed evidence of wide-spread marsh erosion that they attribute to hurricanes when other marshes in the vicinity do not (e.g. Donnelly et al., 2001a; Donnelly, 2004; Miller et al., 2009). A variety of factors-including sampling biases, marsh geomorphology, marsh composition, storm track, and storm intensity-may play roles in observing eroding or depositing sediment in different locations or at different times. Indeed, sediment cores from marshes in New England suggest that a given location can experience both depositional and erosional events (Fig. 2.6). While the extensive erosion of marsh platforms by intense hurricanes remains an explanation for the features mapped in these marshes, the physical processes of erosion and the character and magnitude of the storms potentially responsible remains elusive. Smaller scale erosional processes have been observed historically and therefore the mechanisms responsible for them are better understood.

Analysis of paleorecords shows that salt marshes and intense storm events have coexisted for thousands of years. Boldt et al. (2010) identified 30 distinct storm events (including seven historical severe landfalling hurricanes) over the past 2,000 years in a sediment core collected from a salt marsh in Mattapoisett, MA (Fig. 2.7). Though there have been periods of increased hurricane activity and quiescence in the last two millennia (Donnelly et al., 2015), cores from Mattapoisett suggest continuous marsh development. Despite significant variability in both storminess and storm impact over the past millennia (Fig. 8a and 8c), sea levels have remained relatively stable (Fig. 2.8b and 2.8d), with the most notable increase in global sea levels occurring in the last 150 years (Donnelly et al., 2015; Kemp et al., 2014, 2015; Kopp et al., 2016; Lane et al., 2011; Fig. 2.8e). Tandem increases in sea levels and storminess may serve to multiply marsh vulnerability. The paleorecord shows that patterns of and mechanisms for erosion or deposition from intense storms are complex. These patterns and mechanisms will be explored in more detail in the following section on modern processes. 


\subsection{Modern storm impacts on marshes}

To determine the modern impacts of storm events on marshes, one must first consider the factors that contribute to marsh stability (Fig. 2.9). Here, we provide an abbreviated review on the topic specific to storm impacts. A series of biological and physical feedbacks allow marshes to vertically keep pace with sea-level rise. Following Redfield's bi-directional model of salt marsh evolution (Redfield, 1965), as sea level rises and organic material and clastic sediment accumulates on the marsh, the marsh accretes vertically over basement material or mudflats (Fig. 2.2). Following the model described by Stumpf (1983), deposition of sediment on the marsh occurs predominantly with tidal flooding. As water from tidal currents floods the marsh surface, marsh vegetation slows the currents, trapping suspended sediment (Postma, 1961). In addition to regular tidal flooding, storms can be a major source of sediment for the marsh (Donnelly, 2004; Donnelly et al., 2001a; Turner et al., 2006; Walters et al., 2014; Walters \& Kirwan, 2016; Fig. 2.4). Large storms can produce storm surge and wave heights significant enough to overtop sandy barriers, transporting and depositing coarse sediment on top of salt marsh peat. Highly turbid water from storms can also be carried into the marsh via creek networks along the back side of the marsh (Schuerch et al., 2013). Kolker et al. (2009) found a strong correlation between short-term sea-level change (e.g., storms) and increased accretion in marshes in Long Island, NY. Stumpf (1983) proposed that total sedimentation is from a combination of tidal and storm sources, with storms controlling sediment supply and movement on smaller time scales than daily tidal flooding, when considered over decades or centuries.

Though flooding during storms has documented impacts on marshes, in some cases very high storm surges over a marsh may actually help protect its surface from both erosion and accumulation of sediment. Elsey-Quirk (2016) measured the impacts of Hurricane Sandy (2012) on salt marshes in New Jersey, finding only localized and temporary marsh elevation changes and disturbances, despite Sandy making direct landfall. Similar conditions were seen after Hurricane Hugo (1989) in a salt marsh in South Carolina (Gardner et al., 1992). In both cases, the perpendicular coastal approach by both storms resulted in significant storm surges. The surge completely inundated the marsh, such that sediment associated with the surge was deposited more inland, being transported over and bypassing

much of the marsh surface. Storm waves on top of the deep surge caused minimal erosion along the marsh surface or edge.

The marsh edge is subjected to constant stress from wind, waves, and currents. Field and model observations confirm that how a marsh edge erodes depends largely on the type of waves to which it is exposed. Leonardi and Fagherazzi (2014) found that, on small spatial scales, high storm 
wave energy conditions erode marsh boundaries uniformly, whereas low wave energy conditions result in a jagged erosion pattern-largely due to the influence of local marsh resistance. On larger, wholemarsh scales, boundaries of rapidly-eroding marshes are significantly smoother than those of sheltered or slowly-eroding marshes, though marshes experiencing low-wave energy conditions may be more susceptible to increased large, isolated failures (Leonardi et al., 2016; Priestas et al., 2015). There does not appear to be a threshold of wave power over which marsh erosion accelerates drastically. For example, Leonardi et al. (2016) identified a linear relationship between salt marsh erosion and wave power and determined that wind speeds associated with moderate storms (1.6-10.7 m/s) are associated with the greatest amounts of marsh deterioration due to their higher frequency of occurrence. In contrast, extreme wind speeds associated with rarer and more violent storms and hurricanes $(>28.5$ $\mathrm{m} / \mathrm{s}$ ) contribute less than 1\% of long-term marsh deterioration along the lateral plane. Due to short observational periods, however, studies such as Leonardi et al. (2016) may miss more intense (e.g., > $50 \mathrm{~m} / \mathrm{s}$ ), relatively rare events.

Morton and Barras (2011) explored patterns of wetland erosion and deposition following major hurricanes in southern Louisiana. The authors determined-through analysis of aerial photography, satellite imagery, and on the ground mapping-several depositional features associated with major storms, including wrack zones, interior-marsh deposits, and shoreline deposits. If a storm does not deposit an extremely thick wrack or sediment layer, which would kill supportive vegetation, depositional events generally favor marsh resilience. Overwash fans associated with Hurricanes Audrey (1957), Andrew (1992), Lili (2002), Rita (2005), Gustav (2008), and Ike (2008) often exceeded 50 meters in width, with overwash terraces from Gustav as wide as 150 meters. These overwash deposits, however, were coupled with massive erosional signatures throughout the marshes, suggesting a more complicated relationship between marsh resilience and major storms. Following Hurricanes Audrey (1957), Hilda (1964), Andrew (1992), Katrina (2005), and Rita (2005), erosional features (including pond formation or expansion, marginal incised damage, braided channels, plucked or denuded marsh, floating-marsh redistribution, and shoreline erosion) were substantial. Hurricanes Katrina and Rita, for example, increased the water area in coastal Louisiana by $230 \mathrm{~km}^{2}$ and $295 \mathrm{~km}^{2}$, respectively (Barras, 2007). Most substantially, ponds expanded or created by hurricane erosion tended to become permanent features - increasing the open water area substantially across southern Louisiana. Contrary to the previously mentioned findings of Leonardi et al. (2016), Barras (2007) asserts that storm-related erosion is the primary natural process by which marshes in southern Louisiana degrade, especially since the self-healing capabilities of marsh systems using sediment and 
nutrients from the Mississippi delta system have been hindered since land development in the late $19^{\text {th }}$ century. Barras (2007) suggests that increased wetland loss will increase overall vulnerability of southern Louisiana marshes to extreme storms, particularly in seasons with multiple storms, but the difficulty in predicting where and when extreme landfalls will occur makes it challenging to predict loss in specific areas at specific rates. Many of these marshes experiencing losses were fresh to brackish marshes, also emphasizing the importance of salinity for storm resilience (Howes et al., 2010).

Howes et al. (2010) determined that 2005 Hurricanes Katrina and Rita eroded more than 500 $\mathrm{km}^{2}$ of wetlands within coastal Louisiana. Higher-salinity marshes were found to be more resilient to erosion than lower-salinity marshes, with lower-salinity marshes preferentially failing. Using field and lab measurements of soil strength, lower-salinity marshes were found to have a weak zone approximately $30 \mathrm{~cm}$ below the marsh surface (with shear strengths between 500 and $1450 \mathrm{~Pa}$ ). Higher-salinity marshes had no documented weak zones, with shear strengths greater than $4500 \mathrm{~Pa}$ throughout the entire soil profile. Though controlled by a variety of factors, the difference is likely due to vegetation-S. alterniflora marshes are more tolerant to increased salinities, with more substantial, deeper root systems than less-saline marshes dominated by $S$. patens. The authors suggest that this research may have broader implications for current freshwater diversion plans. For example, the introduction of freshwater to marsh systems may decrease their resilience to large storms by creating weak zones within the marsh soil more susceptible to erosion.

As seen in the Howes (2010) study, variations in vegetation assemblage influence both sediment capture and platform stabilization, and such differences in vegetation are controlled by several factors that include salinity, tidal range, wave energy, and climatic setting (Frey and Basan, 1978). In addition to the findings of Howes et al. (2010), Snedden et al. (2014) found a negative relationship between the duration of flood inundation during an experimental mesocosm study of above- and below-ground Spartina biomass in the Mississippi deltaic plain, as did Watson et al. (2017) in southern New England marshes. Möller (2012) explored how individual plants can act as erosional agents, discovering that a stand of Salicornia spp. within a Spartina marsh may be responsible for largescale bank failure in Tillingham, Essex, UK (Fig. 2.5b). These individual plants can interact with waves, causing small scale erosion at the plant scale, which, when extended to each individual plant within a stand, can lead to erosion on massive scales. Goodbred and Hine (1995) explored the impacts of the March 1993 "Storm of the Century" in a J. roemerianus-dominated marsh in west-central Florida, where despite storm surges nearing $3 \mathrm{~m}$ and deposition of up to $2 \mathrm{~cm}$ of sediment on the marsh, there was minimal marsh shoreline erosion. The authors attribute this to increased sediment stabilization 
from dense $J$. roemeranius root mats, as well as decreased surface erosion from a reduction in near-bed flow velocities by its canopy (L. A. Leonard et al., 1995). Tate and Battaglia (2013), however, found J. roemaranius to be vulnerable to storm surge and wrack deposition in an experimental set up in a marsh on the Florida panhandle.

Using a three-dimensional hydrodynamic and sediment transport model for a salt marsh in the Netherlands, Temmerman et al. (2005) found that vegetative impacts on flow velocity may influence marsh erosion. Erosion of sediment occurs as flow velocity increases over unvegetated portions of the marsh. Accumulation of sediment occurs as flow velocity decreases at the vegetation edge and sediment is trapped. The water level of the flow in relation to the height of the vegetation is also important-when the water level exceeds the vegetation height, flow shifts from a more regional deposition-erosion pattern to larger-scale, homogenous sheet flow. A certain threshold, however, may exist above which stabilizing vegetation cannot recover from destruction by wave action, as explored by a numerical model of salt marsh development by van de Koppel et al. (2005). Storm-induced disturbances, therefore, may trigger cascading vegetation loss and marsh collapse.

The positive feedback between vegetation growth and sediment accumulation, such as that described by Temmerman et al. (2005) among others, continues until the marsh reaches a critical state where marsh edge grows so steep that it is particularly vulnerable to erosion by storm waves. As the marsh collapses, it forms a scarp, which can retreat inland even in the absence of storm stress. The composition of the marsh sediment also plays a role in scarp retreat. Allen (1989) explored how sandy and muddy marsh scarp systems in west-coast British estuaries responded to wave attack. They found that muddy marsh systems in the Severn Estuary were more resilient to storm waves due to increased cohesion, often reach 5-10m in height, and only experience small cantilever failures after strong storms. Sandier marsh systems in Solway Firth and Morecambe Bay more frequently experience toppling and cantilever failures, with much of the soil strength limited to the first $10-20 \mathrm{~cm}$ of rootdominated sediment.

Baustian and Mendelssohn (2015) analyzed the recovery rate of plant cover in coastal Louisiana salt marshes following Hurricanes Gustav and Ike (2008). To determine marsh resilience in the absence of stabilizing vegetation, the study followed control and experimentally-disturbed plots (treated with herbicide), and quarterly monitored rate of recovery-both prior to and after the impact of the 2008 hurricanes. The authors found that hurricane-induced sedimentation was highly correlated with above ground primary vegetative production and increased recovery rates after the disturbance. The sedimentation from Hurricanes Gustav and Ike was found to increase the vigor of the vegetation 
in the experimental plots and, overall, increase marsh resilience. Though the authors acknowledge marsh destruction from the two hurricanes studied, they suggest that increased sedimentation may be beneficial in locally increasing marsh resilience to long-term sea-level rise and future storms.

A marsh requires sediment to accrete fast enough to ensure resilience to rising sea level. Walters and Kirwan (2016) suggest that overwash from hurricane waves actually may be responsible for increasing marsh resilience, citing an optimal thickness of deposit to maximize vegetation productivity, above which vegetation death begins to occur. Using a series of mesocosms to simulate a range of burial scenarios of Spartina alterniflora in a marsh in the Virginia Coast Reserve, the authors found that, though major overwash events $(>10 \mathrm{~cm})$ may cause marsh loss, smaller, more regular storm events (between 5-10 cm of overwash) contribute to the continued resilience of these marshes.

Turner et al. (2006) investigated the accumulation of inorganic sediment on coastal wetlands of Louisiana from Hurricanes Katrina and Rita and found that accumulation exceeded $131 \times 10^{6}$ metric tons over more than $38,500 \mathrm{~km}^{2}$, with an average thickness of $5.18 \mathrm{~cm}$. Sediment was not equally distributed throughout the marshes, with almost $5 \mathrm{~m}$ of storm surge depositing $>10 \mathrm{~cm}$ of inorganic mud in some regions. Analyzing the spatial distribution and amount of sediment, the authors determine that major storm action is the dominant pathway by which offshore inorganic sediment moves inshore onto the coastal marshes of Louisiana. Burkett et al. (2007), however, suggest that this study fails to take into consideration the significant erosion that also occurred during these major storms, and did not adequately discern the true fluvial source of sediment sampled. Regardless, sedimentation from large storms in Louisiana (McKee \& Cherry, 2009; Tweel \& Turner, 2012) and elsewhere (Allison \& Kepple, 2001; Hu et al., 2018) remains well documented and modeled, and attempts at developing a sediment budget of a marsh system over the course of a storm are necessary to understand the dynamics and impacts of major storms on these systems (Ganju et al., 2015).

Storm sediment dynamics play a large role in the elevation of a marsh, which ultimately determines its resilience. Marsh elevation is a controlling factor in several ecogeomorphic feedbacks, including vegetation establishment, growth, and survival (Cahoon, 2006). Cahoon (2006) reviewed major storm impacts on marsh elevations from Louisiana, Florida, North Carolina, Maryland, California, and the Honduras. Storm impacts on elevation vary based on both storm and marsh properties. Storms impacted marsh elevation positively in a variety of ways, including sediment deposition, root growth, soil swelling, and lateral folding of the root mat. Storms impacted marsh elevation negatively through sediment erosion, sediment compaction, soil shrinkage, and root decomposition. 


\subsection{Marsh attenuation of storm waves and surge}

Salt marshes have recently been considered a critical resource in coastal protection (e.g. Gedan et al., 2011; Temmerman et al., 2013). Hurricanes Katrina and Rita both devastated southern Louisiana in 2005, but despite being of similar size and intensity, Hurricane Rita traveled over 30 to $50 \mathrm{~km}$ of wetland before reaching a main population center. In contrast, Hurricane Katrina traveled over a series of large lagoons, artificial channels, and highly-degraded wetlands before reaching a main population center. In the case of the Rita event, marshes were able to accommodate extra surge, reducing the impact when the storm reached populated areas, while the surge for Katrina was far less attenuated (Day et al., 2007). Though the marshes in both storm paths experienced significant destruction (Day et al., 2007; Tweel \& Turner, 2012), the large extent of marshes in Hurricane Rita's path provided substantial protection. Wamsley et al. (2009) modeled the effects of Katrina and Rita on southern Louisiana marshes, finding similar results_increased restoration of marshes results in decreased storm surge and wave heights, though the amount of attenuation was highly variable among different marshes. Modeling results by Barbier et al. (2013) indicate that sea-to-land storm surge in Louisiana decreased as wetland continuity (i.e., presence of wetlands) and vegetation roughness (i.e., presence of vegetation in these wetlands) increased, and that a 10\% increase in wetland continuity along a $6 \mathrm{~km}$ transect could save 3-5 homes/properties per storm. Some research has indicated that increased water depth associated with marsh erosion and conversion to a mudflat or open-water system may reduce storm surge levels (Loder et al., 2009). Decreased marsh continuity, however, is also associated with wetland loss increases storm surge levels and helps to highlight potential benefits of marsh restoration for coastal protection in many cases.

Stark et al. (2015) studied tidal and storm surge attenuation in a marsh along the Western Scheldt estuary, the Netherlands. The study site was a 4-km intertidal channel with a surrounding marsh platform of varying width. The authors found that maximum attenuation occurred along channels with wider marsh platforms. Interestingly, channels amplified smaller neap tides and attenuated larger spring tides. Optimal storm surge attenuation occurred when inundation heights were between $0.5-1 \mathrm{~m}$. Inundation heights outside of this range were not attenuated as greatly, perhaps due to reduced bottom or vegetation friction. The authors propose that storm surge attenuation is both location- and event-specific, with storm surge reductions in the literature ranging from as much as $25 \mathrm{~cm} / \mathrm{km}$ length of marsh, down to $-2 \mathrm{~cm} / \mathrm{km}$ where this negative value denotes actual amplification. This suggests that coastal management plans should consider the height and geometry 
of an individual marsh and the storm intensity threshold of interest on a case-by-case basis when considering their utility in mitigating storm surge.

Orton et al. (2015) ran hydrodynamic models for Jamaica Bay, New York City, to determine the utility of the site's marsh system for coastal protection. The Jamaica Bay marsh, though undergoing restoration beginning in 2006, has deep dredged channels throughout. Orton et al. (2015) found that the presence of these deep channels effectively short circuited the ability of the marsh to reduce storm surge, and that channel infilling would be far more beneficial for storm surge attenuation than the restoration of surrounding marshes, particularly for fast-moving events. Marsooli et al. (2016), however, showed that the Jamaica Bay marsh system did substantially reduce flow velocity of waves simulated for a tropical storm impacting the region in 2011 (Irene). Numerical modeling of morphological change caused by Hurricane Sandy (2012) found that the presence of marsh vegetation reduced erosion during coastal storms as well (Hu et al., 2018). Thus, though marshes may not be effective in all cases to mitigate storm surge, they may still prove to be highly effective as a means to attenuate storm waves.

Experimentally, lab-based research into the utility of marshes for attenuation of storm waves has involved the use of flume tanks or other in-lab procedures with natural or simulated marsh. Möller et al. (2014) used a 300-m flume tank to simulate a series of storm surge conditions on a transplanted natural marsh from the German Wadden Sea. The authors found that up to $60 \%$ of observed wave reduction in the marsh was due to the presence of vegetation. As the waves grew in intensity (heights up to $0.9 \mathrm{~m}$ in $2 \mathrm{~m}$ of water), the marsh continued to resist surface erosion, even as the waves began to flatten and break down vegetation. This suggests that wave attenuation by marsh vegetation is particularly important to continued resilience of marshes - especially since many field studies focus primarily on relatively low energy conditions. Möller et al. (2014) built on the meta-analysis of Shepard et al. (2011), which found that smaller, more frequent waves are easily attenuated by marsh vegetation. Across all 30 studies considered by Shepard et al. (2011), marsh vegetation was observed to play a significant role in shoreline stabilization. Although many studies focus on the utility of vegetation to attenuate high wave energy, a study by Feagin et al. (2009) suggests that soil type may be more influential than vegetation cover, with humic soils richer in fine-grained organics more resistant to erosion than soils rich in coarse-grained organics like roots or other plant debris. This is also consistent with the earlier mentioned study by Allen (1989), which showed a higher degree of stability for mud-dominated when compared to sand-dominated marshes. Vegetation, however, does play a major role in these soil parameters, so it is important to consider how marsh ecosystem maintenance, 
restoration, and creation can continue to develop sustainable and ecologically-sound coastal protection (Temmerman et al., 2013).

\subsection{Regional setting}

Storms are a natural component of most ecological systems. Though paleorecords show significant variability in both storminess and storm impact, coastal salt marshes have thrived since their development over the Holocene (Engelhart et al., 2009; Shennan \& Horton, 2002). Intense storms have the capacity to dynamically impact marshes-particularly at meso- and microscales-but marshes also have the capacity to adapt and adjust to storm-induced changes, provided they have room to migrate. These dynamic impacts may be erosion of the marsh, accumulation of sediment on the marsh, or, more likely, a combination of both. Through the last several millennia, storm climate has varied considerably (Brandon et al., 2013; Donnelly et al., 2015), sea level has remained relatively stable (Kemp et al., 2014, 2015), and marshes have persisted (Figs. 2.7 and 2.8). Only in the last 150 years has sea-level risen at a significant rate (Fig. 2.8e), potentially leading marshes to become more vulnerable to storm impacts. Even so, a recent preliminary assessment of aerial photography before and after Hurricanes Michael (2018; category 4 landfall in Florida) and Florence (2018; category 1 landfall in North Carolina) shows only limited accumulation and erosion effects. This speaks to the ongoing resilience of salt marshes in the face of intense storms.

It is important to consider that marshes vary widely in terms of their geologic, geomorphic, geographic and climatic setting. J. roemeranius marshes, primarily located in the southeastern United States, are often more directly in the path of tropical cyclones. South-facing Spartina-dominated marshes in the northeastern United States may be more susceptible to tropical cyclones tracking up the east coast, whereas north-facing New England marshes may be more susceptible to damage from nor'easters. More protected marshes (e.g., those located up drowned river valleys) may be less susceptible to wave attack and surge associated with less intense storms, whereas coastal marshes are exposed to wave attack both daily and from storms of varying intensities. Storm impacts also are often highly variable on smaller scales, dependent on both storm characteristics (proximity to marsh, angle of approach, tide levels, rainfall levels, wind speeds, etc.; Resio \& Westerink, 2008) and marsh properties (marsh health, soil strength, local bathymetry, groundwater levels, etc.; Cahoon, 2006). The interplay among all of these properties dictate the impact of a particular storm on a given marsh, and different impacts from the same storm may be seen at the same marsh or proximal marshes. 


\subsection{Summary}

The appreciation of marshes for their storm protection and erosion control services continues to grow and is largely responsible for over an order of magnitude increase in the appraised value of tidal marshes in recent decades (e.g. from $\$ 14 \mathrm{k}$ to $\$ 194 \mathrm{k} / \mathrm{ha} / \mathrm{yr}$ between 1997 and 2014; Costanza et al., 2014). Critical to this increase in value is the perceived effectiveness of marshes in storm protection. Marsh sediments preserve evidence of storm-induced erosion and deposition that has and should continue to be utilized to gain more insight on both early historic and pre-historic storm events. This sedimentological evidence of past storm events also exhibits a high degree of spatial variability, both in terms of deposition and erosion. Studies of modern marsh processes confirm the spatial temporal variance in marsh response to storms. When depositional conditions occur, recent research indicates that storms can be a valuable mechanism for marsh resilience to sea-level rise. However, erosion primarily on the marsh edge causes systems in open water to be in a continued state of flux. Minor and moderate storms have been found to largely be responsible for most marsh edge erosion, although catastrophic loss from more intense events has the potential to significantly modify a marsh system. The diversity of responses and rates of erosion and accretion of different marshes during storms also highlight the importance that vegetative species and sediment composition play.

The effectiveness of marshes as a form of flood mitigation is an area of active research. It is clear that marshes provide an effective means of wave attenuation; however, the capacity of these systems to reduce storm surge varies significantly from site to site. As investments in ecosystemdefenses continue to grow, so should research on marsh-storm relationships. Of particular importance are the spatial and temporal factors that determine a marsh's effectiveness in storm flood mitigation, as it is likely that costs and benefits will vary widely depending on the specific setting. 


\subsection{Figures}

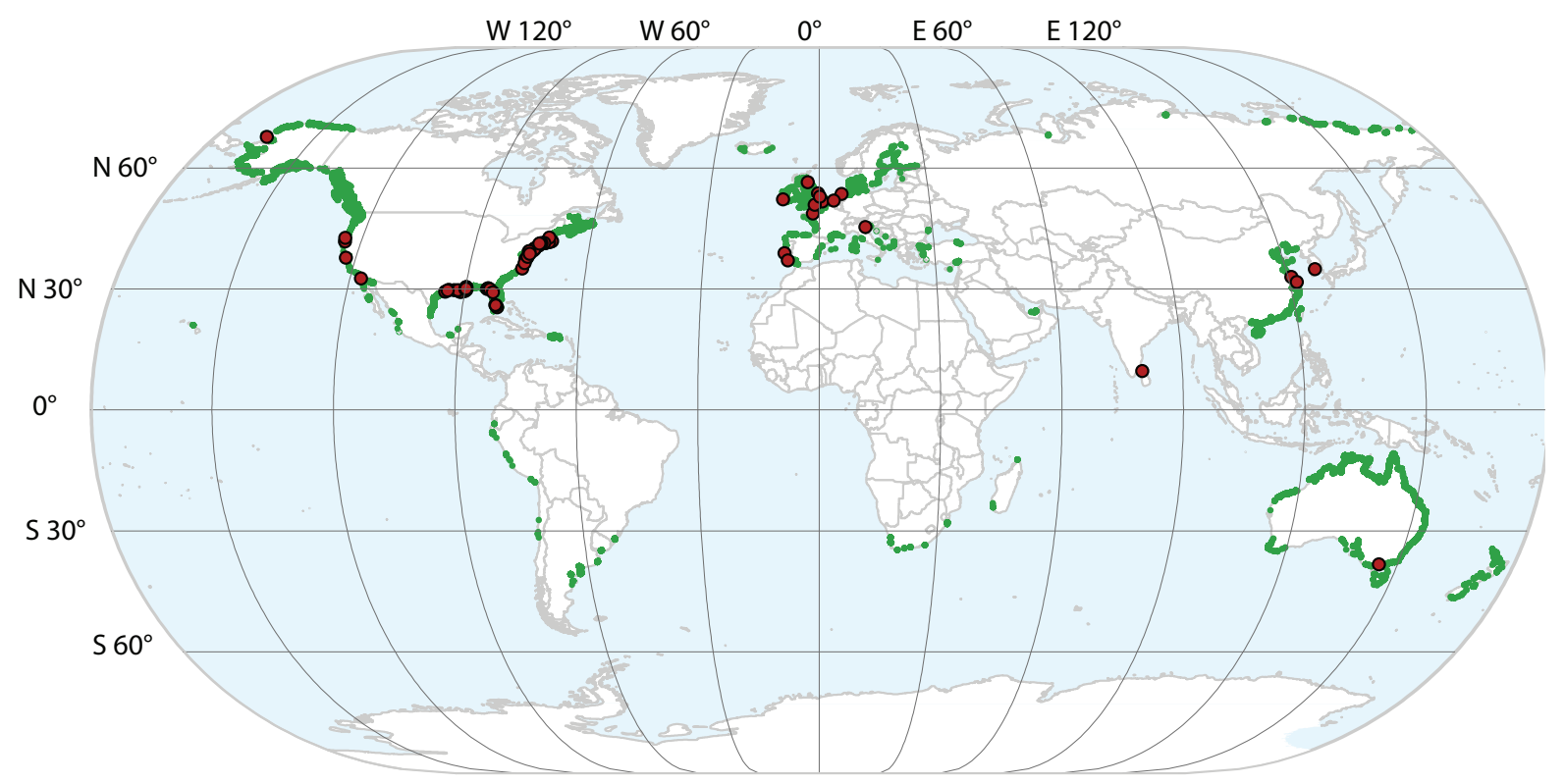

Figure 2.1 Locations of major research (red circles) on the effects of storms on salt marshes. Global marsh extent is indicated in green (Mcowen et al., 2017). For a full list of research locations, please see http://arcg.is/1CCuXj. 


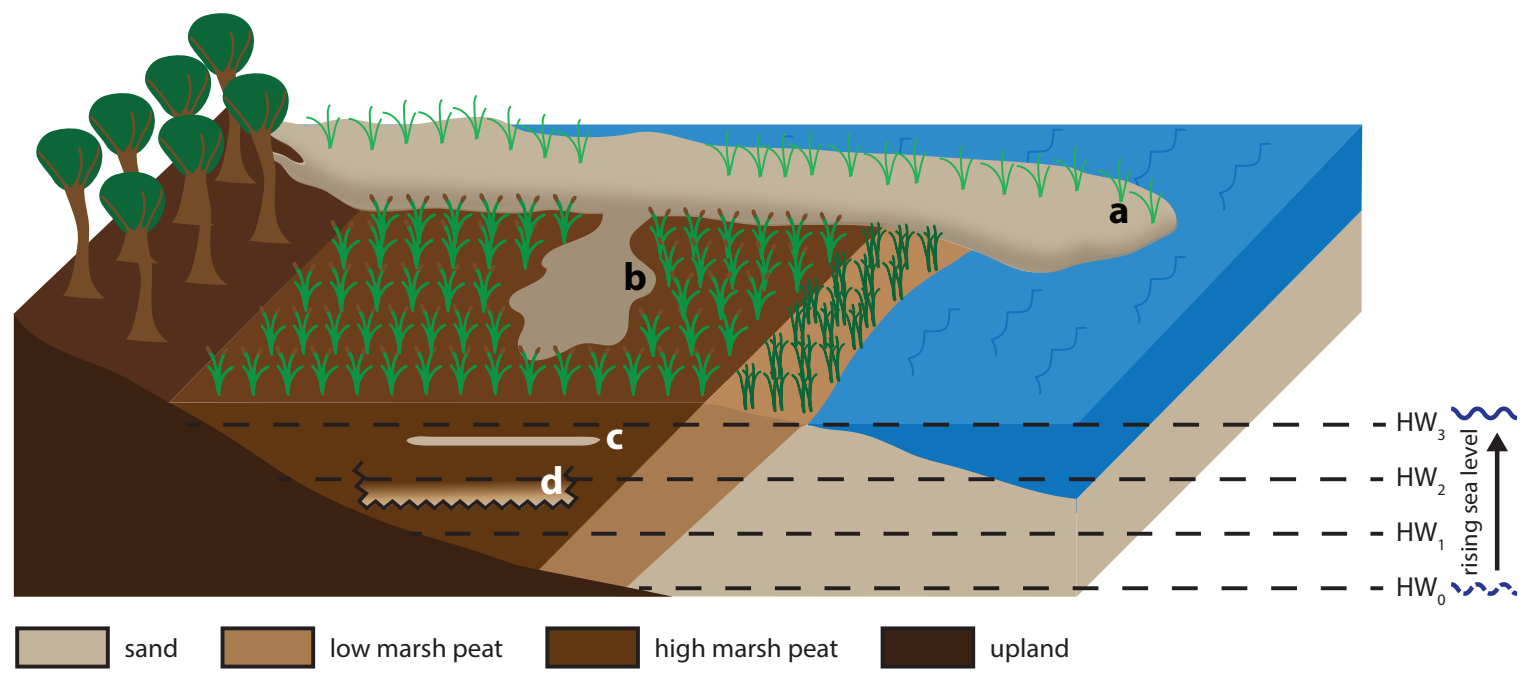

Figure 2.2 Theoretical structure of a salt marsh based on Redfield's bi-directional model of salt marsh evolution (Redfield, 1972), including a coastal barrier (a). As sea level rises, the salt marsh spreads over both sand and upland through accumulation of sediment. Storm waves can overtop the barrier, leaving both present (b) and past (c) sandy overwash deposits in the marsh. Evidence of erosion (d) may also be seen.

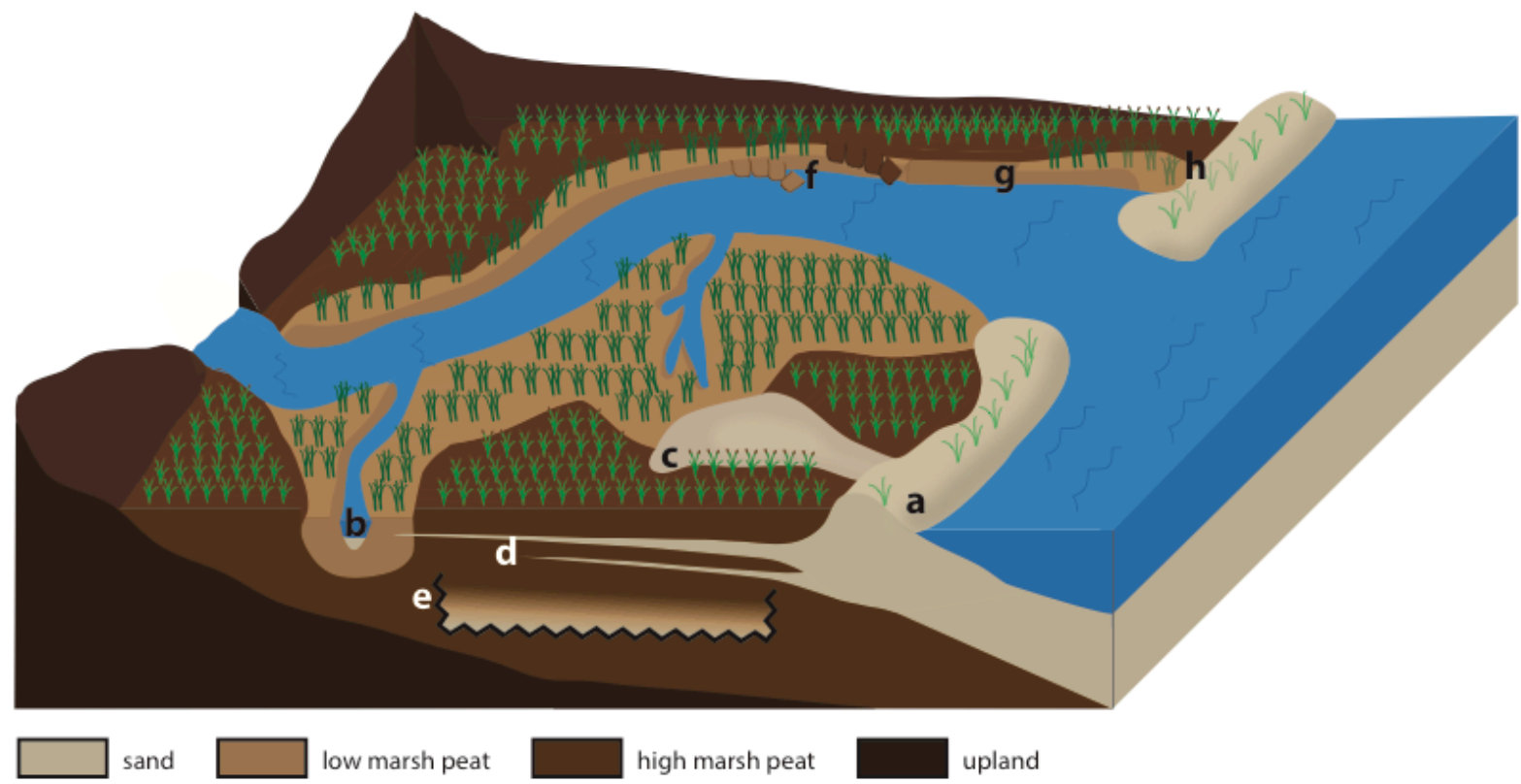

Figure 2.3 Theoretical structure of a salt marsh, including a coastal barrier (a) and channels (b). Impacts of storms on marshes exist along a spectrum based on a variety of factors, including intensity, circumstance, storm track, and marsh structure. Depositional features, such as present (c) and past (d) sandy overwash deposits, can occur concurrently with erosional features, such as stratigraphic evidence (e), edge erosion (f), slumping (g), and vegetation plucking (h). 


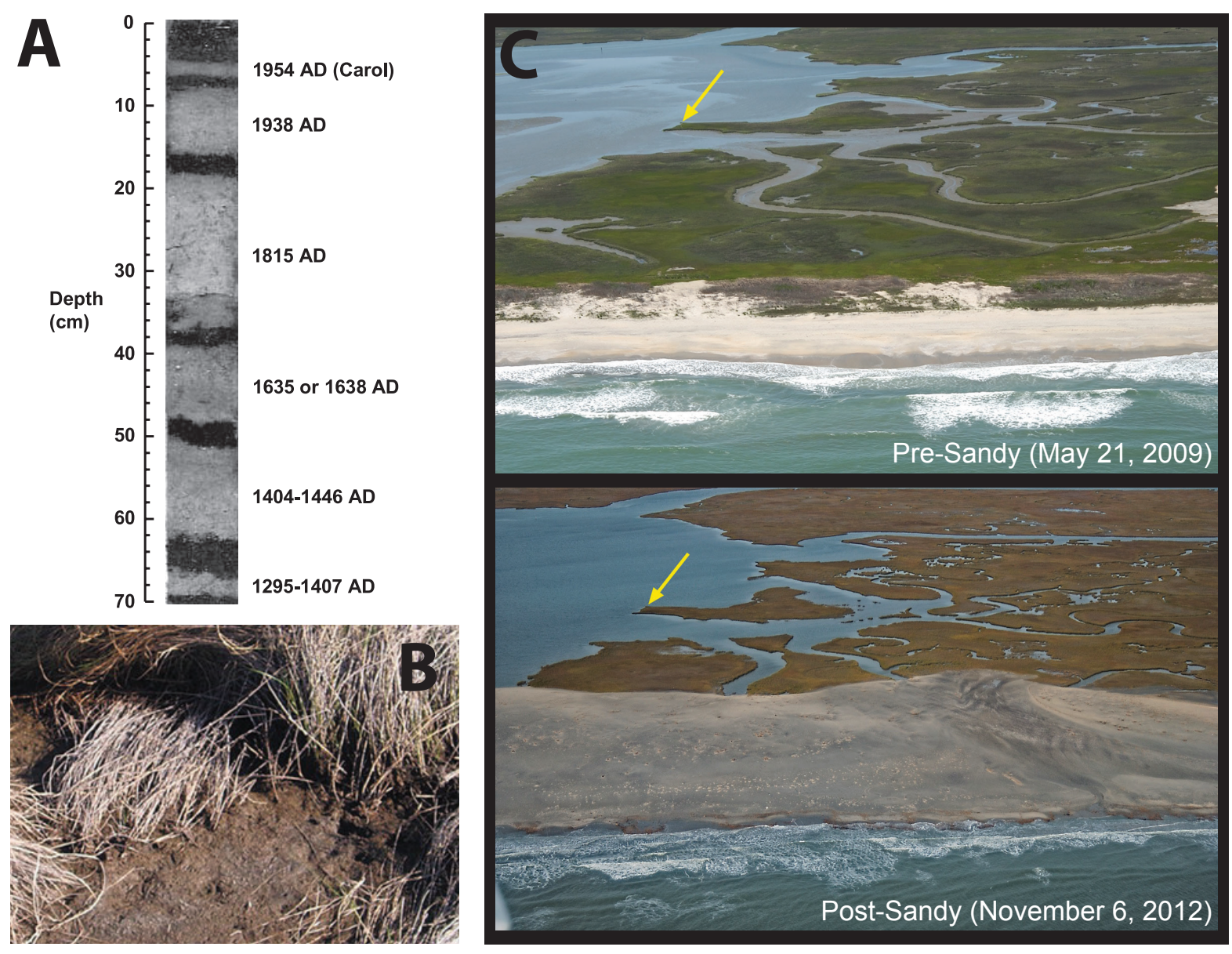

Figure 2.4 Field photos of various depositional impacts of storms on marshes. A) Storm-induced overwash deposits from Succotash Marsh, East Matunuck, RI (Cheung et al., 2007; Donnelly et al., 2001a). B) Example of sediment deposited on the marsh after Hurricanes Katrina and Rita (Turner et al., 2006). C) Aerial photos of overwash deposits left by Hurricane Sandy in Assateague Island, VA (Sopkin et al., 2014). 

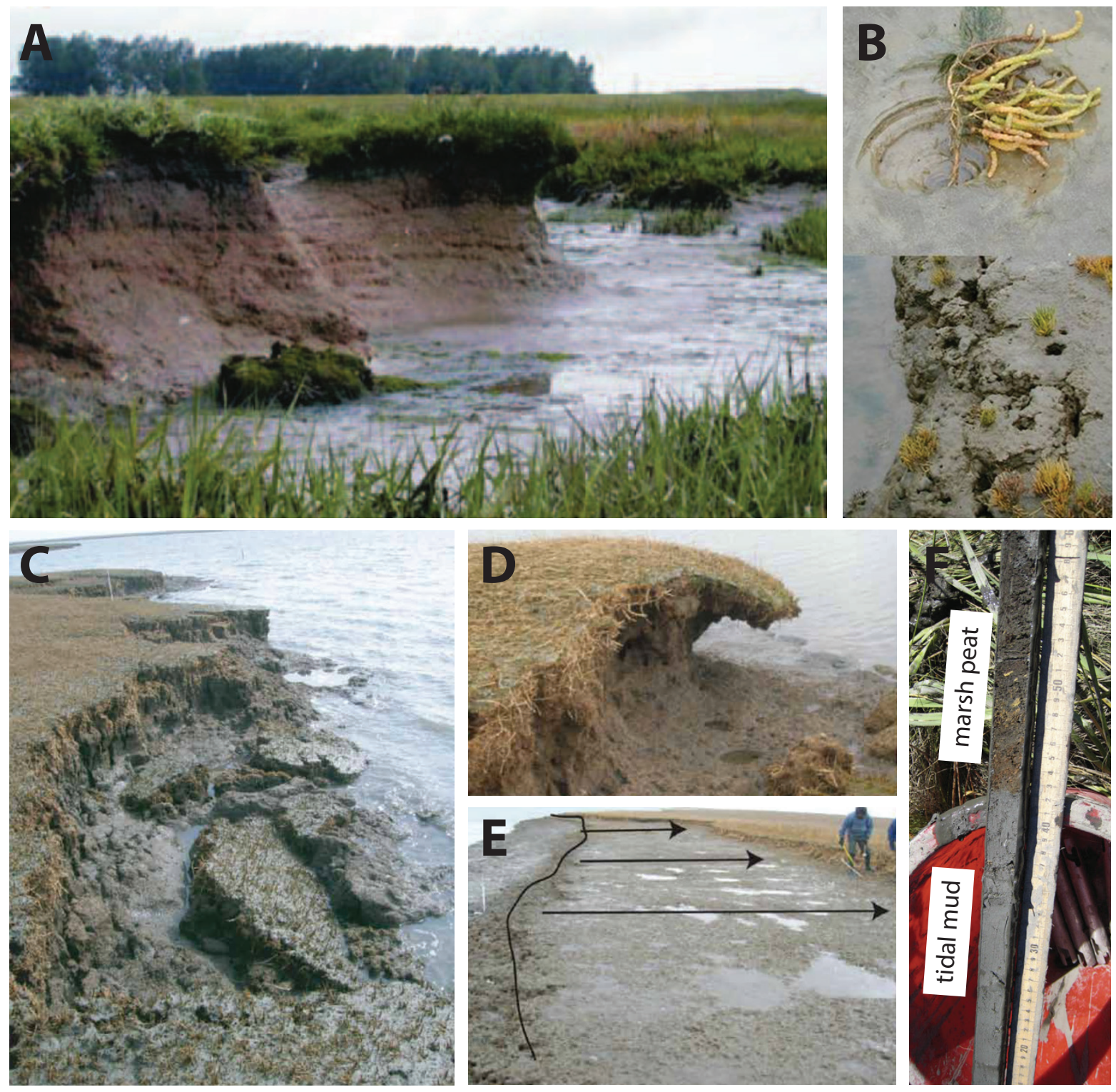

Figure 2.5 Field photos of various erosional impacts of storms on marshes. A) Eroding cliffs in the Westerschelde, the Netherlands (van de Koppel et al., 2005). B) Example of Salicornia spp. causing massive bank erosion in Tillingham, Essex, UK (Möller, 2012). C-E) Different kinds of marsh erosion (slumping, undercutting, and root scalping, respectively) in the Virginia Coast Reserve (Fagherazzi et al., 2014). F) Stratigraphic evidence of salt marsh peat overlain by tidal mud after a proposed erosional event in Sea Breeze Marsh, New Jersey (Nikitina et al., 2014). 

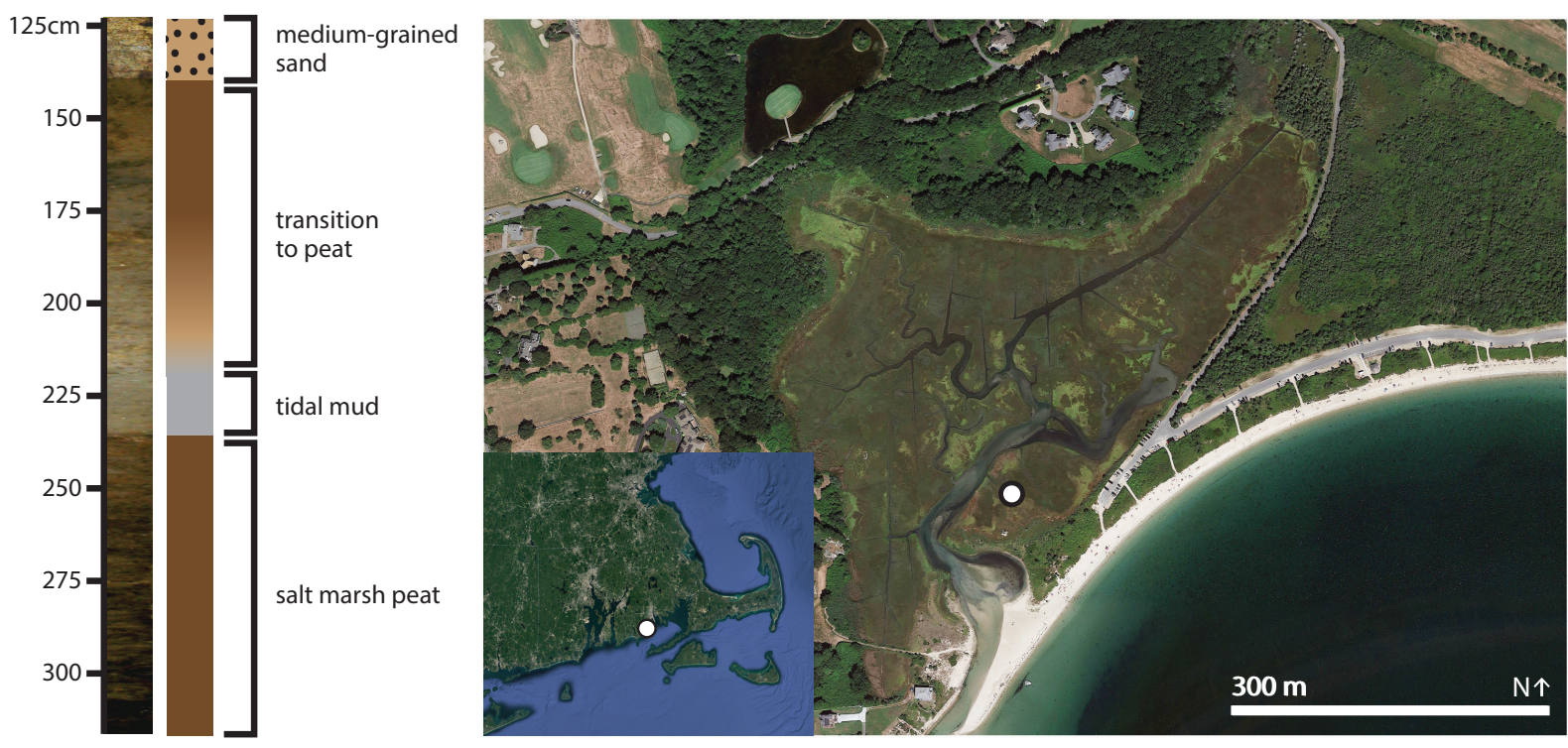

Figure 2.6 Evidence of erosional (sharp contact with tidal mud and transition back to peat) and depositional (medium-grained sand overwash) features in the same core from Round Hill Beach, Dartmouth, MA.

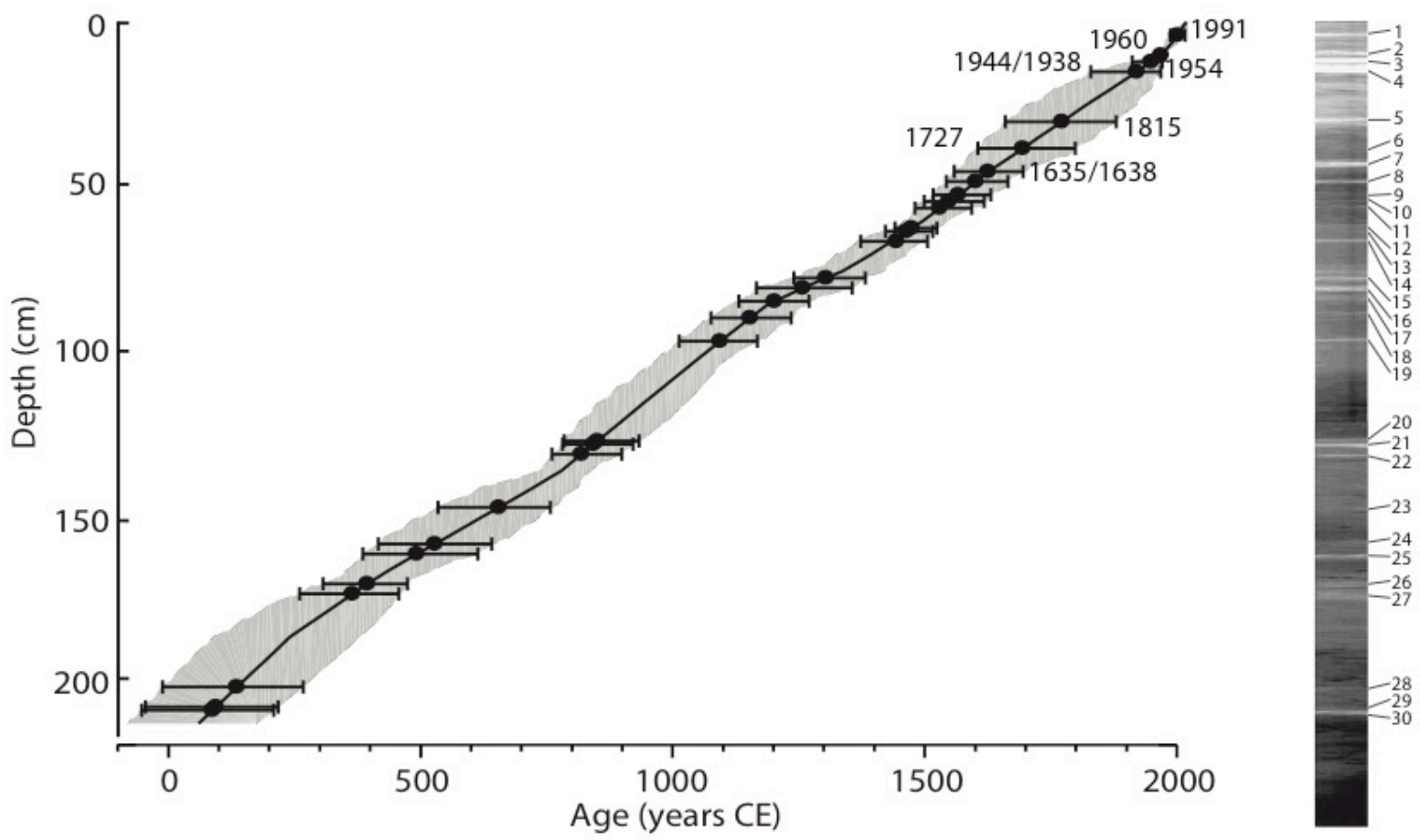

Figure 2.7 Evidence of continued storm activity and marsh persistence over the past 2,000 years from a salt marsh in Mattapoisett, MA (modified from Boldt et al., 2010). Left, radiocarbon-derived age model (gray) for 30 identified storm-induced overwash events (black circles, with uncertainties). Right, radiograph imagery identifying storm-induced overwash events. 

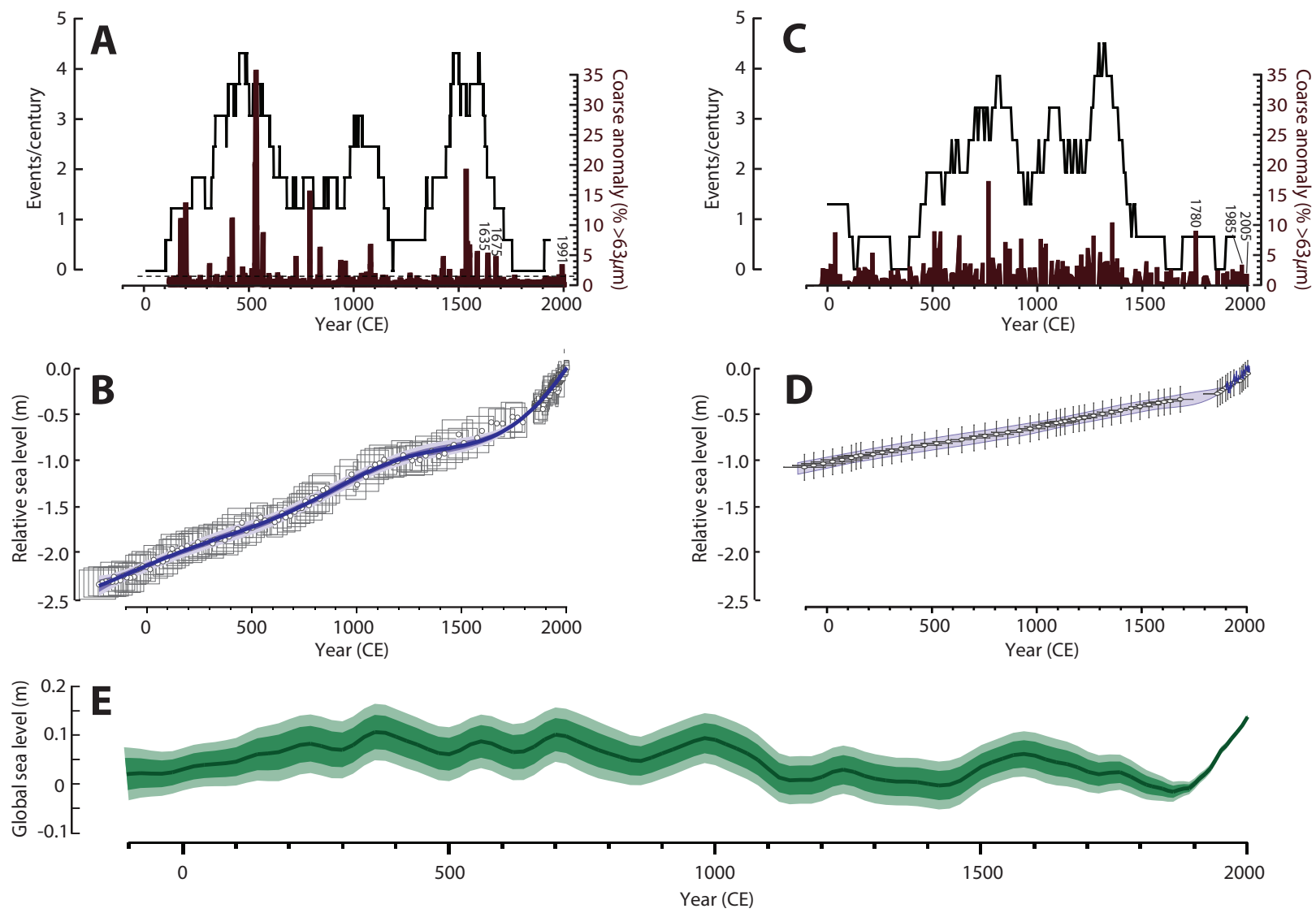

Figure 2.8 Though storminess has fluctuated over the past 2,000 years, sea level has remained relatively stable prior to the Industrial Revolution. A) Storm record for Salt Pond, Falmouth, MA, where peaks in coarse anomaly indicate a storm deposit (Donnelly et al., 2015). B) Relative sea-level reconstruction from East River Marsh, Guilford, CT, from salt marsh sediment dates and tide-gauge records (Kemp et al., 2015). C) Storm record for Mullet Pond, Apalachee Bay, FL (Lane et al., 2011). D) Relative sea-level reconstruction from Nassau Landing, FL, from salt marsh sediment dates and tide-gauge records (Kemp et al., 2014). E) Global sea-level curve for the past 2,000 years from statistical meta-analysis of proxy relative sea-level reconstructions and tide-gauge data (Kopp et al., 2016). 


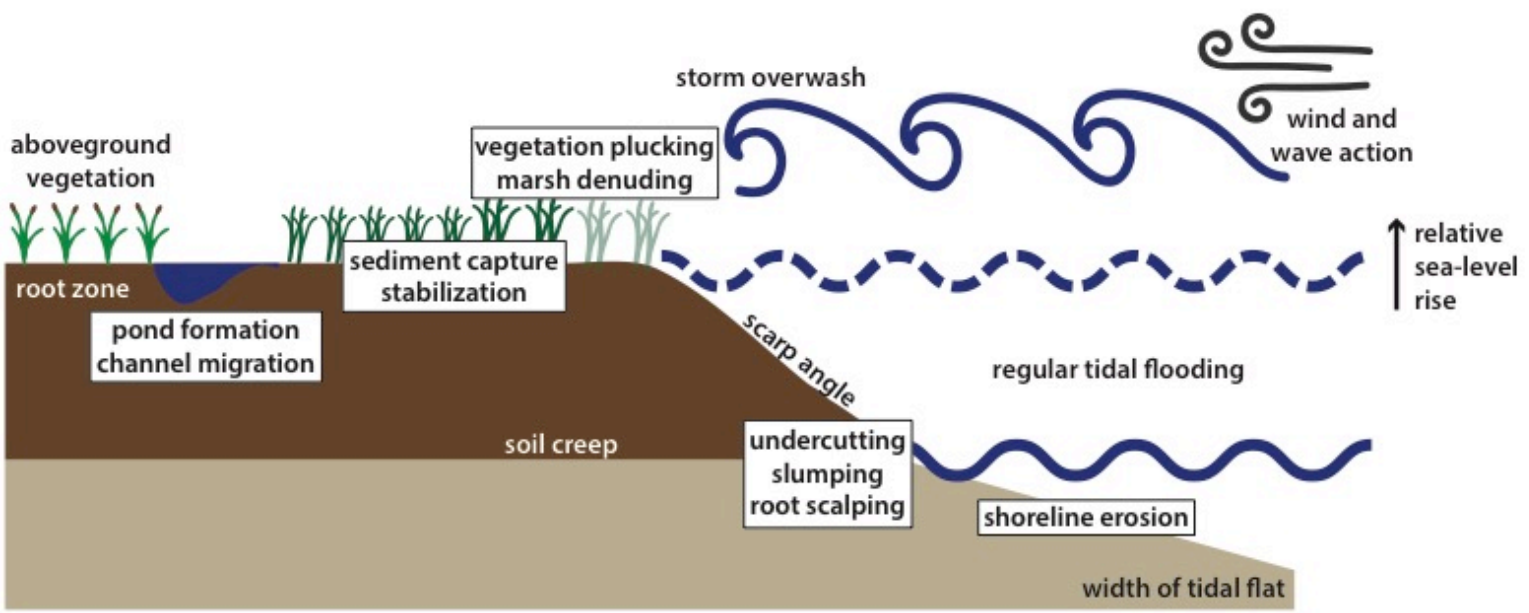

Figure 2.9 Diagram of different processes discussed in text related to storms that impact marsh stability. 


\title{
3. Spatial and temporal stratigraphic analysis of hurricane activity in a coastal New England pond
}

\begin{abstract}
As coastal populations grow in size and infrastructure, they also grow increasingly susceptible to the impacts of tropical cyclone events. Tropical cyclones are expected to change in both frequency and intensity over the next century, posing a greater threat of property damage and loss of life. This study analyzes the grain-size distribution of major historic and prehistoric storm event beds along a transect of sediment cores from a kettle pond in Falmouth, MA. Reconstructions of intense-hurricane landfalls from this location identify a series of event beds spanning the past 2,000 years. The grain-size trends of these event beds vary both spatially and temporally, emphasizing the importance of site-specific deposition dynamics. This study expands on previous work in the same location by confirming two active intervals of increased tropical cyclone activity ( 250 to 1200 C.E. and 1400 to 1800 C.E.), as well as identifying the last 150 years to present as an active interval. Though the dynamism of the relationship between future global hurricane frequency and intensity remains difficult to quantify, hurricane frequency and (perhaps equally important) duration can have as equally devastating effects on coastal communities as hurricane intensity. Research into prehistoric intervals of increased storm activity provides important insight into the current and future hurricane risks facing coastal communities in the northeastern United States.
\end{abstract}




\subsection{Introduction}

As coastal populations continue to grow in both size and wealth, hurricanes pose a growing threat. In the United States, where both population and economic resources are concentrated along the coast, tropical cyclones caused average annual damage of approximately $\$ 20$ billion for the 119 years that spanned from 1900 C.E. to 2019 C.E. (ICAT Damage Estimator, 2019; data normalized for inflation in 2019 dollars). Though tropical cyclone landfalls in the continental United States have not changed significantly in frequency or intensity since 1900, increasing coastal wealth has potentially led to an increase in hurricane-related damage (Klotzbach et al., 2018). Damage associated with the 2017 Atlantic hurricane season exceeded \$125 billion and is considered one of the costliest on record-whether damage is computed nominally, inflation-adjusted, or normalized (Podlaha et al., 2017). Atlantic tropical cyclones are responsible for, on average, 50 US deaths per year, though that number varies widely by year and storm-Hurricane Sandy was responsible for 72 deaths, whereas Hurricane Katrina was responsible for more than 1,100 deaths (Rappaport, 2014).

The most comprehensive tropical cyclone dataset exists for the Atlantic basin, with quantitative records dating to the 1850s (Jarvinen et al., 1988) and historic records from ship logs and personal accounts dating back as far as 1492 C.E. (Ludlum, 1963). In New England, historic accounts of tropical cyclone landfalls extend as far as 1620 C.E. (Boose et al., 2001). To better understand tropical cyclone frequency and intensity before historic records, however, we must turn to proxy records. Proxy records can be used to reconstruct millennia of tropical cyclone activity and are imperative for understanding the climate drivers that result in changes in tropical cyclone activity.

Storm-induced overwash deposits in coastal ponds and salt marshes have been used as a proxy for hurricane strikes in southeastern New England (Boldt et al., 2010; Donnelly et al., 2001a; Donnelly et al., 2015; Woodruff et al., 2008). Large storms produce wave heights, storm surge, and run up significant enough to overtop sandy barriers. Coarse sediment is transported and deposited in relatively deep coastal basins or on top of salt marsh peat as an overwash layer. This layer is then preserved as a stratigraphically-distinct allochthonous layer after it is covered by finer-grained organic material or peat as part of background accumulation. Other studies have also identified storm-induced overwash sequences in the geologic record, including deposits in Florida (Davis et al., 1989) and Alabama (Liu \& Fearn, 1993), as well as in southern New England (Emery, 1969; Boothroyd et al., 1985; Donnelly et al., 2001).

Recent research has identified a series of active intervals in southeastern New England over the past 2,000 years, with the last few centuries among the most quiescent intervals (Donnelly et al., 
2015). Using high-resolution sedimentary proxy records from Salt Pond in Falmouth, MA, Donnelly et al. (2015) identified 35 separate storm events in a record extending back more than two millennia. From these 35 events, two main active intervals-periods of heightened event bed deposition frequency ( $>0.9$ events per century) —were identified: one spanning 150 to 1150 C.E. and one spanning 1400 to 1675 C.E. (Donnelly et al., 2015). These events and active intervals were determined through the analysis in one location in the basin. Here, we develop a process-based understanding of how event beds are deposited in the basin and test the reproducibility of the Donnelly et al. (2015) event bed chronology with a transect of cores across the Salt Pond basin. To do this, we:

1) verify events identified by Donnelly et al. (2015) across six study cores,

2) refine the Donnelly et al. (2015) chronology and active intervals,

3) examine the sorting characteristics to test the assumption that coarse sediment is sourced from the beach and nearshore environment during an intense hurricane strike in a coastal pond setting, and

4) test whether there is a relationship between local storm intensity and grain size distribution in event beds.

Understanding grain-size and sorting characteristics and trends is necessary to characterize hurricaneinduced deposition at the study site. Exploring historic and prehistoric intervals of increased hurricane frequency and the grain-size dynamics associated with their events illuminates a process-based understanding of how these event beds were deposited, which in turn enables more robust interpretations of paleo-hurricane records.

\subsection{Data and methods}

\subsubsection{Study area and field methods}

Salt Pond is a 26-ha brackish kettle pond in Falmouth, MA (Fig. 3.1). The pond is connected to Vineyard Sound by a 1-2m high coastal barrier and a tidal inlet. There are no significant overland flow or sediment inputs into the pond, and most of the freshwater flux is through groundwater infiltration. Since the mean tidal range on the open coast is approximately $0.5 \mathrm{~m}$, the influence of astronomical tide stage on the barrier's susceptibility to storm overwash is limited. Sediment core collection has been described previously by Donnelly et al. (2015). A series of cores from six locations (including the original study core), located along a transect across the deepest section of the pond, were collected from 2009-2017 (Fig. 3.1B). 


\subsubsection{Lab methods}

Donnelly et al. (2015) previously identified 35 hurricane-induced event beds in vibracores from SAP2 ( $>375 \mathrm{~m}$ from shore). Correlation of peaks in coarse $(>63 \mu \mathrm{m})$ fraction of sediment, visual comparison, and radiograph comparison were used to identify correlative events (Fig. 3.2). In-depth grain-size analysis was performed on storm events identified in each of three vibracores, SAP1, SAP8, and SAP9 (375 m, $430 \mathrm{~m}$, and $465 \mathrm{~m}$ from shore, respectively). Fifteen events were identified and sampled-events 1-12, 25, and 26 identified in Donnelly et al. (2015), as well as an event identified as the 1938 New England Hurricane found in all three cores.

The samples were combusted at $550^{\circ} \mathrm{C}$ for 1.5 hours to remove organic material and then sieved at $32 \mu \mathrm{m}$ to isolate grains coarse silt-sized and larger. Coarse fraction of each sample was determined by comparing the sieved weight of the sample to its original dry weight. Sieved samples were analyzed using a Horiba Camsizer digital image processing particle, size, and shape analyzer at the University of Massachusetts, Amherst. Since there is potential for variability in each run, each sample was run 3-5 times and averaged after removing inconsistent runs. $\mathrm{D}_{90}$, the size for which 90\% of the particles in the size distribution are smaller, is used as a metric for the maximum grain size. As discussed by Brandon et al. (2010), the unadjusted distribution (which does not consider the fine grains removed by the sieving process) is best suited for use in sediment transport calculations, since the unadjusted $\mathrm{D}_{90}$ value is more representative of the largest grains transported during a major flood event.

A study to determine the sensitivity of maximum grain size to coarse fraction was performed on the event bed associated with the Great Colonial Hurricane of 1635. This event bed was substantially thicker than most other deposits $(>2 \mathrm{~cm})$, and therefore was sampled at $1 \mathrm{~cm}$ resolution to determine if a peak in coarse fraction aligns with a peak in $\mathrm{D}_{90}$.

\subsection{Results}

\subsubsection{Correlation across transect and application to study cores}

At least 26 of the events identified by Donnelly et al. (2015) were identified in and correlated across a transect of six study cores (Fig. 3.2). Since some of the study cores did not extend through the end of the chronology of the core used in Donnelly et al. (2015; SAP2), the remaining nine events were not captured. There were also events not identified by Donnelly et al. (2015) that could be correlated. These events were typically below the event identification threshold used by Donnelly et al. (2015), but they were traceable throughout several study cores, including the original Donnelly et 
al. (2015) core. Through the expanded correlation, additional radiocarbon dates were used to bolster the original age model presented in Donnelly et al. (2015). An additional 20 dates from SAP5 and SAP6 (proximal to SAP2) agreed well with the current age model, further confirming the correlations across cores in the transect (Table 3.2, Fig. 3.3). These additional dates were combined with original data from Donnelly et al. (2015) to create a chronology based on the master stratigraphy, which can now be applied across all study cores.

Using this updated age model and following the methods identified in Donnelly et al. (2015), event frequencies for three study cores (SAP5, SAP8, and SAP9) were determined using coarse $(>63$ $\mu \mathrm{m})$ fraction data. An updated event chronology and frequency analysis was also developed for SAP2, the core analyzed in Donnelly et al. (2015). From these event frequencies, a series of individual active intervals were determined for each core, when event frequency is greater than 1.2 events per century (Fig. 3.4; Table 3.3).

Four historic events $(1991,1938,1675$, and 1635) were identified across all cores (Fig. 3.5). Of the historic events, 1991, 1675, and 1635 were originally identified in Donnelly et al. (2015). After lowering the event threshold for the Donnelly et al. (2015) study core, the 1938 event was identified and could be correlated across all cores. For each of these historic events, there was no significant spatial trend with distance from shore in coarse $(>63 \mu \mathrm{m})$ fraction. Mean coarse fraction for each event varied from $\sim 3 \%$ (1675) to $\sim 11 \%$ (1635). Mean coarse fraction in the 1635 event was significantly higher $(\mathrm{p}<0.05)$ than any other historic event (Table 3.3).

\subsubsection{Grain-size analysis}

Fifteen events from cores SAP1, SAP8, and SAP9 were identified from the updated stratigraphy and chronology for detailed grain-size analysis. These fifteen events were chosen as representative samples because they were easily identifiable and covered portions of both active intervals identified by Donnelly et al. (2015). Grain size was analyzed for particles $>32 \mu \mathrm{m}$, with focus on three levels: $\mathrm{D}_{10}, \mathrm{D}_{50}$, and $\mathrm{D}_{90}$ (Table 3.4). $\mathrm{D}_{10}$, the size for which $10 \%$ of the particles in the size distribution are smaller, was set through experimental design at $>32 \mu \mathrm{m}$ by removing fines through sieving. Values for $\mathrm{D}_{50}$, the median grain size, and $\mathrm{D}_{90}$ were not adjusted for the removal of the finegrained ash. Since only $26 \%$ of the total variance in $\mathrm{D}_{90}$ is explained by the coarse $(\geq 32 \mu \mathrm{m})$ fraction

of the sample (Fig. 3.6D, $\mathrm{R}^{2}=0.26$ ), the unadjusted $\mathrm{D}_{90}$ value will give a more accurate estimate of the intensity of a given storm event than the coarse $(\geq 32 \mu \mathrm{m})$ fraction. $\mathrm{D}_{90}$ values for SAP1, the core closest to the barrier, averaged $546 \mu \mathrm{m}$, with a range from $220 \mu \mathrm{m}$ to $919 \mu \mathrm{m}$ for the 15 events sampled 
(Fig. 3.6A). $\mathrm{D}_{90}$ values for SAP8 averaged $460 \mu \mathrm{m}$, with a range from $182 \mu \mathrm{m}$ to $729 \mu \mathrm{m}$ for the 15 events sampled (Fig. 3.6B). D90 values for SAP9, the core farthest from the barrier, averaged $577 \mu \mathrm{m}$, with a range from $375 \mu \mathrm{m}$ to $894 \mu \mathrm{m}$ for the 15 events sampled (Fig. 3.6C). The variability in $\mathrm{D}_{90}$ among different runs of the same sample was also considered. SAP8 had the least variability between individual runs (average standard deviation $71 \mu \mathrm{m}$ ), whereas SAP9 had the most (average standard deviation $121 \mu \mathrm{m})$.

\subsubsection{Trends in deposition}

\subsubsection{Spatial trends in deposition}

The three cores in the event bed grain-size analyses are along a transect, with SAP1 closest to the barrier and SAP9 farthest from the barrier. As such, deposition of the events will vary spatially for both size of the deposit and maximum grain size deposited. There was no significant difference in means at any level $\left(\mathrm{D}_{10}, \mathrm{D}_{50}, \mathrm{D}_{90}\right)$ between SAP1 and SAP8. The mean $\mathrm{D}_{90}$ value of SAP9 was significantly higher than the mean $\mathrm{D}_{90}$ value of SAP8 $(\mathrm{p}<0.05)$. The mean $\mathrm{D}_{10}$ value of SAP9 was also significantly higher than the mean $\mathrm{D}_{10}$ value of SAP1 and SAP8 $(\mathrm{p}<0.05)$. Of the 15 storm event deposits that were identified SAP1, SAP8, and SAP9, 7 events (47\%) followed a landward-fining trend, 4 events $(27 \%)$ followed a landward-coarsening trend, 2 events $(13 \%)$ followed a marginally landwardfining trend (slope of the regression line negative but not within uncertainty), and 2 events (13\%) followed a marginally landward-coarsening trend (slope of the regression line positive but not within uncertainty).

\subsubsection{Temporal trends in deposition}

There was no statistically significant difference in means at the $\mathrm{D}_{50}$ and $\mathrm{D}_{90}$ level between historic events (1991-1635) and prehistoric events ( 1600-1400 CE and 600-500 CE), though the mean $\mathrm{D}_{10}$ of the historic interval is significantly higher than that of the prehistoric interval.

\subsubsection{Spatiotemporal trends in deposition}

Of the 15 events sampled across SAP1, SAP8, and SAP9, nine followed a landward- or marginally landward-fining trend in $\mathrm{D}_{90}$ values, and six followed a landward- or marginally landwardcoarsening trend (Fig. 3.7). Of the four historic events (1991-1635), two events followed a landwardfining trend, one followed a landward coarsening trend, and one followed a marginally landward-fining trend. Of the 11 prehistoric events ( 1600-1400 CE and 600-500 CE), seven events followed a 
landward-fining or marginally landward-fining trend, and four followed a landward-coarsening or marginally landward-coarsening trend. With regard to the active intervals established by Donnelly et al. (2015), seven of the events occurring during active intervals (1400-1675 CE and 150-1150 CE) followed landward-fining or marginally landward-fining trends 64\%), compared to only one event $(10 \%)$ during the inactive intervals.

\subsubsection{Relationship between coarse fraction and grain size}

Though only $26 \%$ of the total variance in $\mathrm{D}_{90}$ is explained by the coarse $(\geq 32 \mu \mathrm{m})$ fraction of the sample (Fig. 3.6D, $\mathrm{R}^{2}=0.26$ ), values vary considerably for core in the transect. There is a positive, statistically-significant relationship between coarse fraction and maximum grain size for SAP1 and SAP8 $\left(\mathrm{R}^{2}=0.61\right.$ and $0.69, \mathrm{p}<0.05$, respectively, Fig. $3.8 \mathrm{~B}$ and $\left.\mathrm{C}\right)$, but there is a very weak, nonsignificant negative relationship between the two values for SAP9 $\left(R^{2}=0.09\right.$, Fig. 3.8D).

By comparing the ratio of coarse fraction to $\mathrm{D}_{90}$ value for each event, it is possible to determine which events were anomalously long in duration. Events with a ratio larger than one half standard deviation from the historic mean were considered relatively longer in duration (Fig 3.8A). Those events included the Great Colonial Hurricane of 1635, as well as events 7, 11, 12, 25, and 26.

Analysis of event beds associated with the Great Colonial Hurricane of 1635, a substantially thicker deposit than most other deposits $(>2 \mathrm{~cm})$, revealed that peaks in coarse fraction do not always correspond with peaks in $\mathrm{D}_{90}$ value (Fig. 3.9). For SAP1, the peak in coarse fraction occurred at 55.5 $\mathrm{cm}$ depth, whereas the peak in $\mathrm{D}_{90}$ value occurred at $53.5 \mathrm{~cm}$. For SAP8, both the peak in coarse fraction and the peak in $\mathrm{D}_{90}$ value occurred at $25.5 \mathrm{~cm}$.

\subsection{Discussion}

\subsubsection{Updated Salt Pond chronology}

This work presents an updated and expanded exploration of storm events impacting Salt Pond. Additional radiocarbon dates from correlative cores bolster and strengthen the chronology presented by Donnelly et al. (2015; Fig. 3.3). While the updated age model is consistent in the historic period, prehistoric events shift up to 50 years (within the age uncertainty for the chronology). The updated chronology also results in different active intervals (per methodology described in Donnelly et al., 2015). Where the original record for SAP2 identified two main periods of increased activity (150 to 1150 C.E. and 1400 to 1675 C.E), the updated and consolidated records identify three: $\sim 250$ to 1200 C.E., 1400 to 1800 C.E., and 1850 to present. Though the older active intervals generally 
align within age uncertainly with those identified by Donnelly et al. (2015), further analysis of the historic period reveals an additional active interval (Fig. 3.4).

For the Donnelly et al. (2015) study core, events were determined using a cumulative distribution function (CDF) of coarse fraction that exceeded $99 \%$ of the data over the historic interval. This threshold identified three events in the historic period (1991, 1675, and 1635), while avoiding peaks in coarse fraction during the last century that were not attributable to known storm events. The same technique and threshold were used to create an event frequency for SAP5. The events from two other cores in this study (SAP5, SAP8, and SAP9) were determined using a cumulative distribution function (CDF) of coarse fraction that exceeded 98\%,97\%, and 97\% of the data (respectively) over the historic interval. At this threshold, the same three events were identified, as well as several more historic events (Fig. 3.9), including Hurricane Donna (1960) and Hurricane Carol (1954).

From the identification of these events, it becomes clear that the last few centuries of the historic record indeed represents an interval more active than that proposed by Donnelly et al. (2015). The cores along the study transect are in the deepest part of the basin, whereas SAP2 is approximately $30 \mathrm{~m}$ east of the transect, in a slightly shallower location. SAP2 is also at least $60 \mathrm{~m}$ southeast of SAP8 and SAP9 but only $30 \mathrm{~m}$ southeast of SAP5. The difference in location may play a role in the different events recorded, further emphasizing the need for a broader, whole-site view for storm reconstruction.

Several additional events, below the event threshold for the Donnelly et al. (2015) core, were identified and traced across several study cores. These events often had lower coarse-fraction values and were not associated with known historic tropical cyclones. As such, they are likely the result of a different source. Nor'easters and other winter storms typically cause storm surges on northeast-facing shorelines (Donnelly et al., 2001a), and they produce deposits on south-facing shores largely through wave-interaction within the basin-not surge overtopping a sandy barrier. In the case of a colder past climate, where Salt Pond would be frozen for much of the winter (as opposed to days to weeks in today's climate), it is possible that a thin layer of sediment could accumulate on top of the ice through aeolian transport of sand throughout the winter. As the pond warmed, the layer of sediment could settle to the bottom and be relatively indistinguishable from a short-term event. It is important to consider, however, that we do not have historical analogs for this kind of deposition in Salt Pond, and our limited historic record suggests that overwash from tropical cyclone surge is a more likely source of the sediment in the event deposits.

Ultimately, the events identified by Donnelly et al. (2015) are consistently replicated across six cores at least $20 \mathrm{~m}$ apart (Fig. 3.2). This suggests that the storm signal at Salt Pond is robust across 
both large spatial and temporal scales, with only minor refinements to the prehistoric chronology, well within age uncertainty. The additional historic events identified in the study cores suggest that the historic period from 1850 C.E. to present is also an active interval. The additional events identified at the deepest points of study cores SAP5, SAP8, and SAP9 also warrant further investigation to properly constrain the deepest time recorded at this location.

\subsubsection{Assessment of deposition trends}

Previous research into tropical cyclone event deposits has identified a fining-landward trend, consistent with an inundation/run-up overwash regime (Brandon et al., 2014; C. Donnelly et al., 2006; Woodruff et al., 2008). The fall velocity of a given grain determines the sorting trends seen in deposition. Fall velocity is dependent on several factors. Stokes' Law applies to small particles, where the settling is impeded by the drag associated with the laminar flow surrounding the grain (Ferguson \& Church, 2004). Settling of small particles is slow, and fall velocity increases with the square of the diameter of the particle. Larger particles settle far more rapidly, since their settling is impeded by the drag associated with the wake behind each particle. As such, their fall velocity increases with the square root of the diameter (Ferguson \& Church, 2004). Within distributions of both small $(>32 \mu \mathrm{m})$ and large particles $(>32 \mu \mathrm{m})$, larger particles settle sooner, resulting in a landward-fining overwash deposit. This trend, however, is present (six events; 40\%) or marginally present (four events; $26.7 \%$ ) in 10 of the 15 events identified, suggesting a more complicated sediment transport and deposition relationship for the five remaining storm events. Of the five landward-coarsening or marginally landwardcoarsening events, two are confirmed historic hurricanes (1991 and 1938), and three occurred between $\sim 1500$ and $1550 \mathrm{CE}$, during the first active interval defined by Donnelly et al. (2015). Several possible mechanisms could be responsible for landward-coarsening deposition (Fig. 3.10).

Surface waves caused by winds have been shown to be a player in increased bottom stress and resulting sediment resuspension (Booth et al., 2000; Carper \& Bachmann, 1984; Luettich et al., 1990). Luettich et al. (1990) describe the influence of strong winds on surface waves in Lake Balaton, an inland lake in Hungary. The authors found that surface waves related to episodic wind events were the dominant cause of sediment resuspension in the system. Since Salt Pond is adjacent to a coastal barrier, surface-wave resuspension of sediment across the pond is likely not the most influential factor in storm deposits, but it may still play a role in explaining landward-coarsening events. Increased interaction of surface waves with the shallowing, far edge of the pond may result in increased sediment input from the pond edge and increased resuspension of deposited sediment during high-energy 
events. These interactions may have resulted in increased grain-size values for SAP9, the core farthest from the barrier in the transect. Though most storms to impact Salt Pond have large surge components, wave energy is required to transport sediment from the sandy barrier into the basin. As such, the same wind conditions that cause both surface and offshore waves are necessary for deposition of sediment and responsible for an element of resuspension.

Inundation and overwash regimes in a back-barrier coastal pond setting generally assume that the majority of the sediment deposited during storm events is sourced directly from the adjacent barrier. A variable sediment source, however, also may explain landward-coarsening deposits. Rodriguez et al. (2013) found that aeolian sand contributed substantially to the sedimentation of the first $20 \mathrm{~m}$ of back-barrier marsh. The authors suggest that aeolian transport may also be a potential mechanism for emplacement of sand beds. Since aeolian deposits are often finer than overwash deposits (Rodriguez et al., 2013), storms with longer-duration or stronger wind components may deposit fine grains closer to the barrier, causing a landward-coarsening trend. It is also important to consider that deposition at Salt Pond is subaqueous, so grains transported by aeolian means will also be subject to influences of settling and resuspension in the pond prior to their deposition.

The lower maximum grain-size values in the oldest events analyzed (25 and 26; 500-600 CE) may be due to migration of the barrier linked to sea-level rise. Nearby reconstructions indicate a linear increase in mean sea level of approximately $1.0 \pm 0.2 \mathrm{~mm} /$ year from $\sim 1300$ C.E. to $\sim 1850$ C.E., with that rate increasing almost more than twofold in the mid-19 $9^{\text {th }}$ century (Donnelly, 2004). Over the past eight decades, there has been an increase in sea level in Woods Hole, MA (NOAA tide gauge 8447930), of approximately $2.81 \pm 0.18 \mathrm{~mm} /$ year. In accordance with the Bruun Rule, barriers tend to migrate landward as sea-level rises (Bruun, 1988). Research indicates that barriers less than $200 \mathrm{~m}$ in width migrate landward primarily through overwash (Bruun, 1988; Hennessy \& Zarillo, 1987; Leatherman, 1983; Lorenzo-Trueba \& Ashton, 2010). Barrier migration is controlled largely by sea level change and sediment budget (Curray, 1964), and overwash in particular contributes to migration by removing sediment at the front of the barrier and depositing it landward (C. Donnelly et al., 2006). The Massachusetts Shoreline Change Browser indicates that shoreline retreat rates in front of Salt Pond average $0.1 \mathrm{~m} /$ year (ranging from 0.03-0.2 m/year). Though shoreline data has only been collected since 1844, the position of the barrier has changed over time, likely migrating landward during the past 2,000 years. Extrapolating the average rate of shoreline retreat from the last 75 years back 2,000 years the barrier could have migrated more than $220 \mathrm{~m}$ landward in that time. While the barrier may have shifted, the position of the cores, taken from 2014-2017, remains static. This suggests that deeper 
events, if sourced from barrier overwash, may actually have been deposited further from the barrier than they would be today.

\subsubsection{Relationship between grain size and coarse fraction}

The 1635 test case explored the relationship between coarse $(>32 \mu \mathrm{m})$ fraction and maximum grain size in a thick $(>2 \mathrm{~cm}$ ) event (Fig. 3.9). Maximum grain size does not always correspond with maximum coarse fraction of a sample, providing insight into changes in storm intensity. A peak in maximum grain size is likely indicative of the most intense part of the storm, provided that coincides with onshore winds. The overwash event and associated deposition may last several hours, including the time the flood water recedes after an inundation event. This emphasizes the importance of continuous sampling of thick deposits for use in inverse modeling.

The maximum grain size of an event provides insight into the intensity of the storm, whereas the amount of sand deposited in an event may indicate a qualitative measure of the duration of the storm (e.g., an event bed with a large coarse fraction and relatively small $\mathrm{D}_{90}$ value may be the result of a longer duration, less intense storm, whereas an event bed with a relatively small coarse fraction and larger $\mathrm{D}_{90}$ value may be the result of a shorter duration, more intense storm). The ratio of coarse fraction to $\mathrm{D}_{90}$ value for each event provides insight into longer duration, less intense storms with larger coarse fractions and smaller $\mathrm{D}_{90}$ values. Similar to the Great Colonial Hurricane of 1635, these events $(7,11,12,25$, and 26) may have been deposited by similarly destructive storms, which had potentially longer durations, despite lower intensities (Fig. 3.8). Though the oldest events (25 and 26) may be influenced by barrier migration, there is a substantial peak in coarse fraction for event 26 in SAP1. Even considering the dampening effect of migration on maximum grain size, the sheer amount of sand deposited suggests that the storm may have also been longer in duration.

\subsection{Conclusions}

Salt Pond presents a unique environment to study trends in hurricane-induced storm deposits. Given the reproducibility of the events identified by Donnelly et al. (2015) across a >100 m transect, Salt Pond accurately captures a robust storm frequency signal. Our study expands the findings through the identification of three active intervals, from 250 to 1200 C.E., 1400 to 1800 C.E., and 1850 to present. The most recent active interval, beginning 1850 C.E., suggests that the last $\sim 150$ years represent a record of increased intense-storm frequency. 
In-depth grain-size and coarse-fraction analysis of 15 event beds in three study cores reveals the importance of expanding reconstructions beyond one study core. Grain-size analysis of the pond on a larger scale reveals significant variation both spatially and temporally, suggesting that event bed sediment sources are not uniform. Future sediment-based reconstructions must consider the impacts these differences in sediment source may have, including challenging the traditional assumptions that hurricane-induced event beds in these locations are largely directly from sandy-barrier overwash. Coarse-fraction values do not always align with grain-size values, emphasizing the importance of approaching event sedimentation from both angles, especially when events may vary significantly in duration. A broader, whole-site approach to tropical-cyclone reconstruction in coastal ponds will both bolster and illuminate trends in event deposition, which is imperative to painting more accurate portraits of past tropical cyclone activity. 


\subsection{Figures and tables}

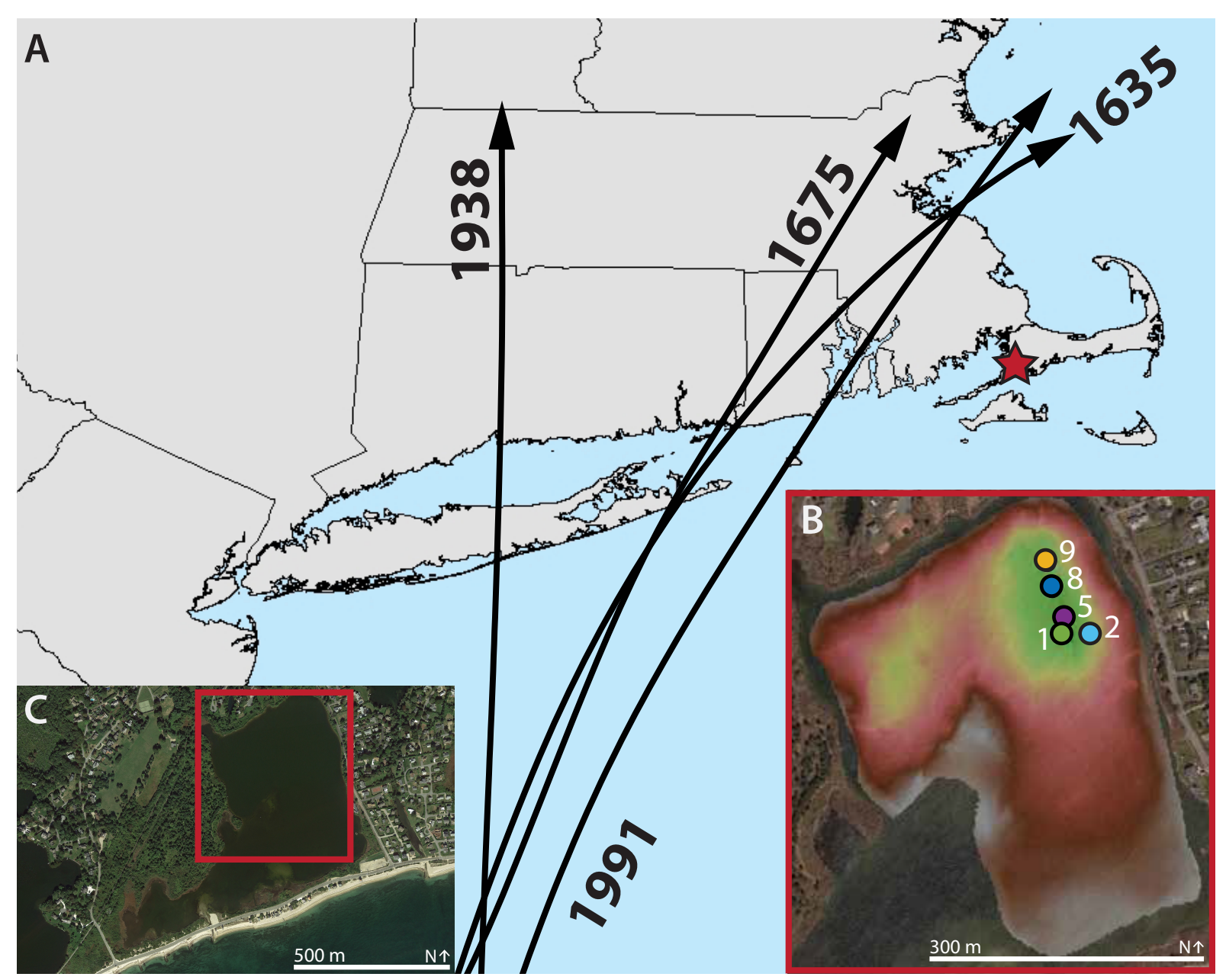

Figure 3.1 A) Map of site location, including tracks of historic storms identified and analyzed in the study cores. B) Core locations along a transect in Salt Pond, Falmouth, MA. C) Location of transect within Salt Pond. 


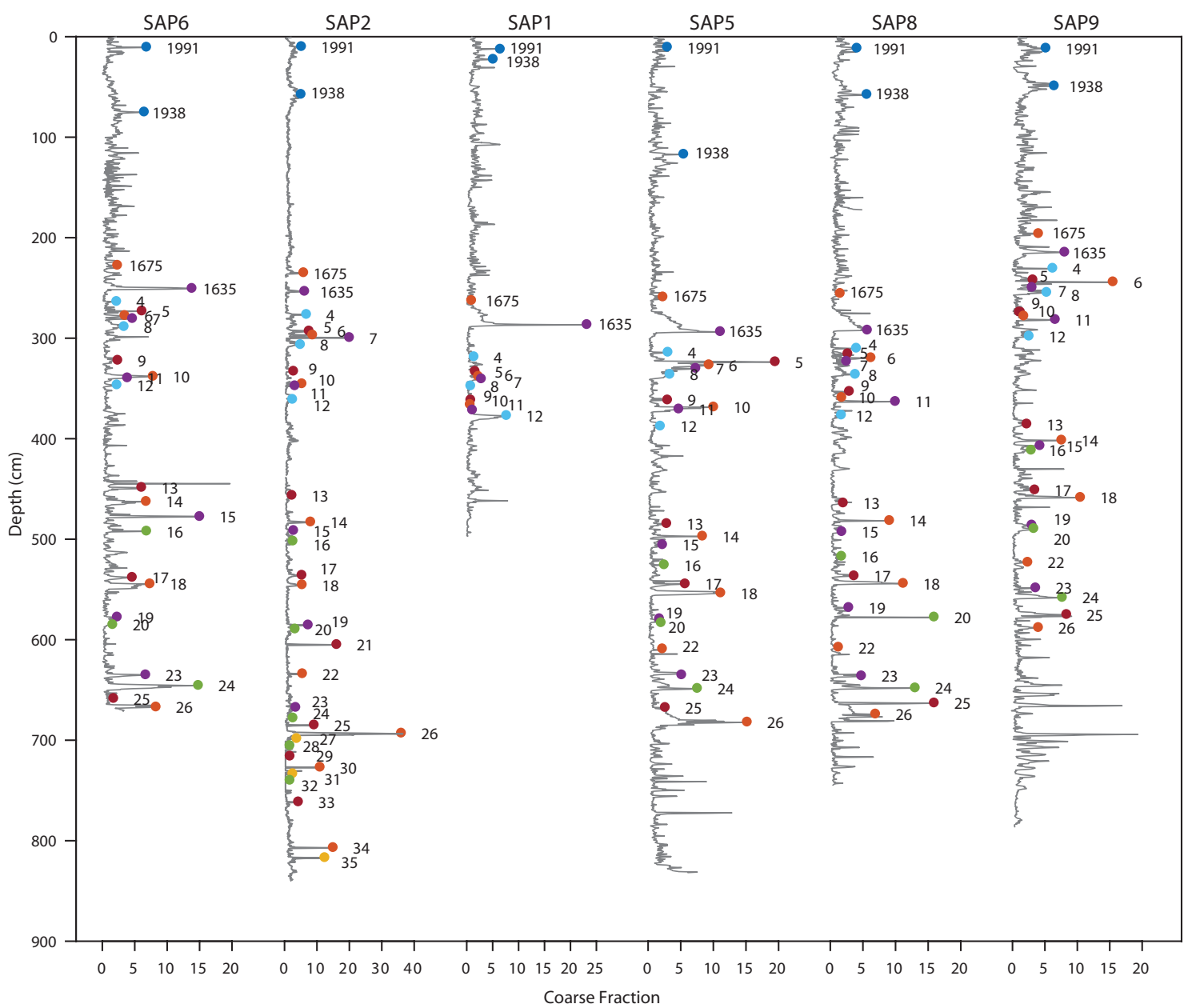

Figure 3.2 Stratigraphic correlation across several different study cores. Events are labeled per Donnelly et al. (2015). 


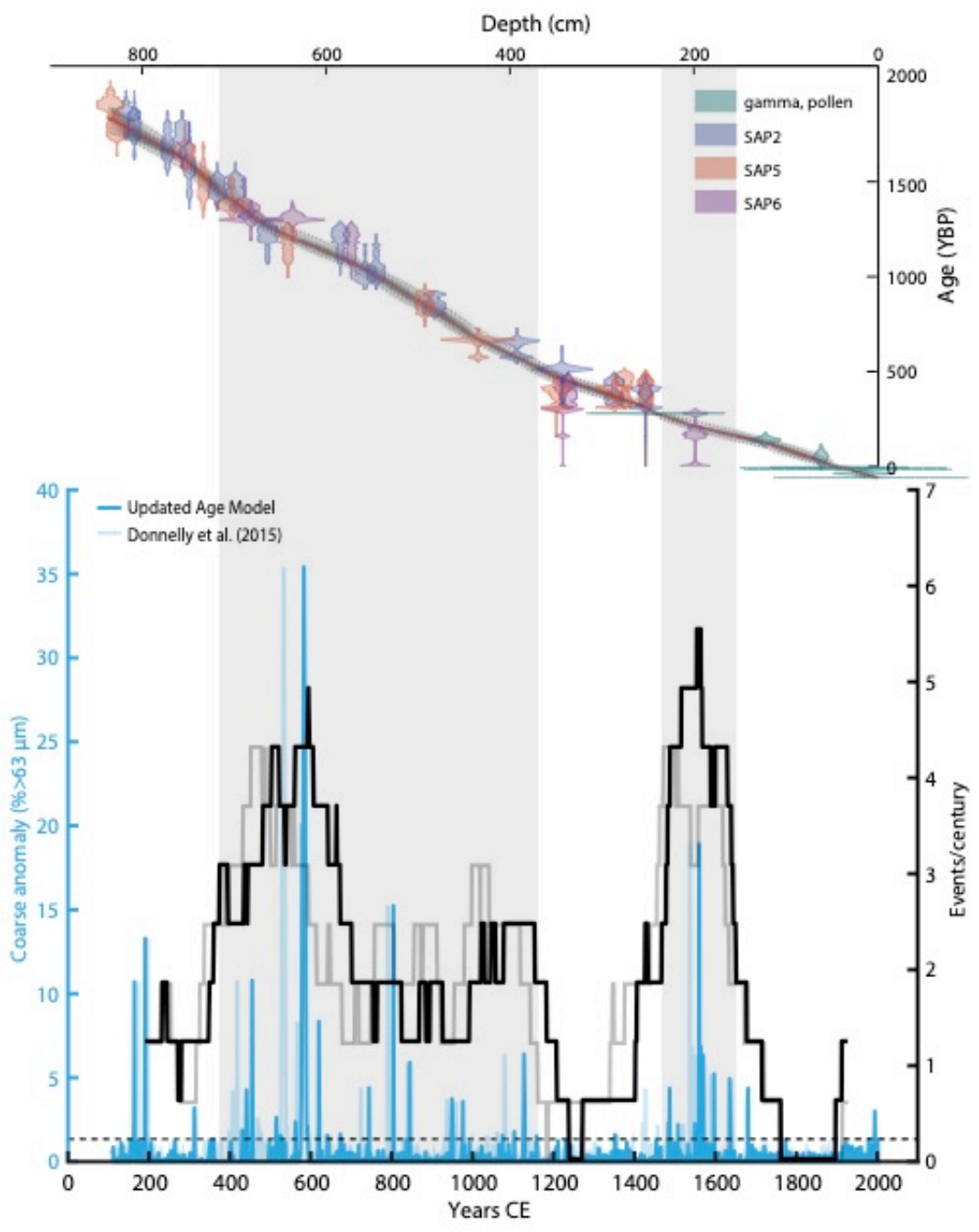

Figure 3.3 Updated age model from Donnelly et al. (2015), after incorporating additional radiocarbon dates from correlative cores. 

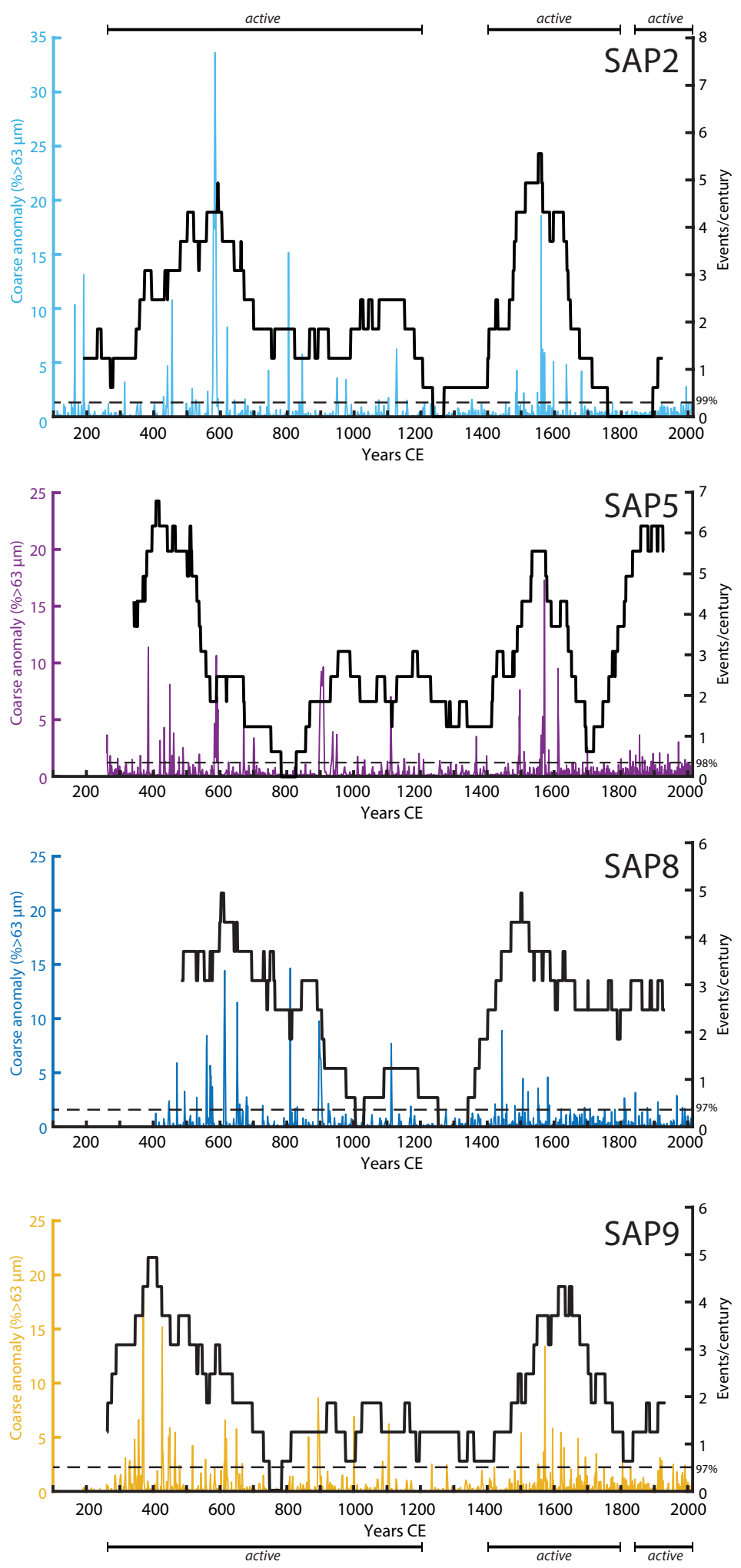

Figure 3.4 Age models and event frequencies of SAP2, SAP5, SAP8, and SAP9. Updated active intervals are indicated by black bars. 


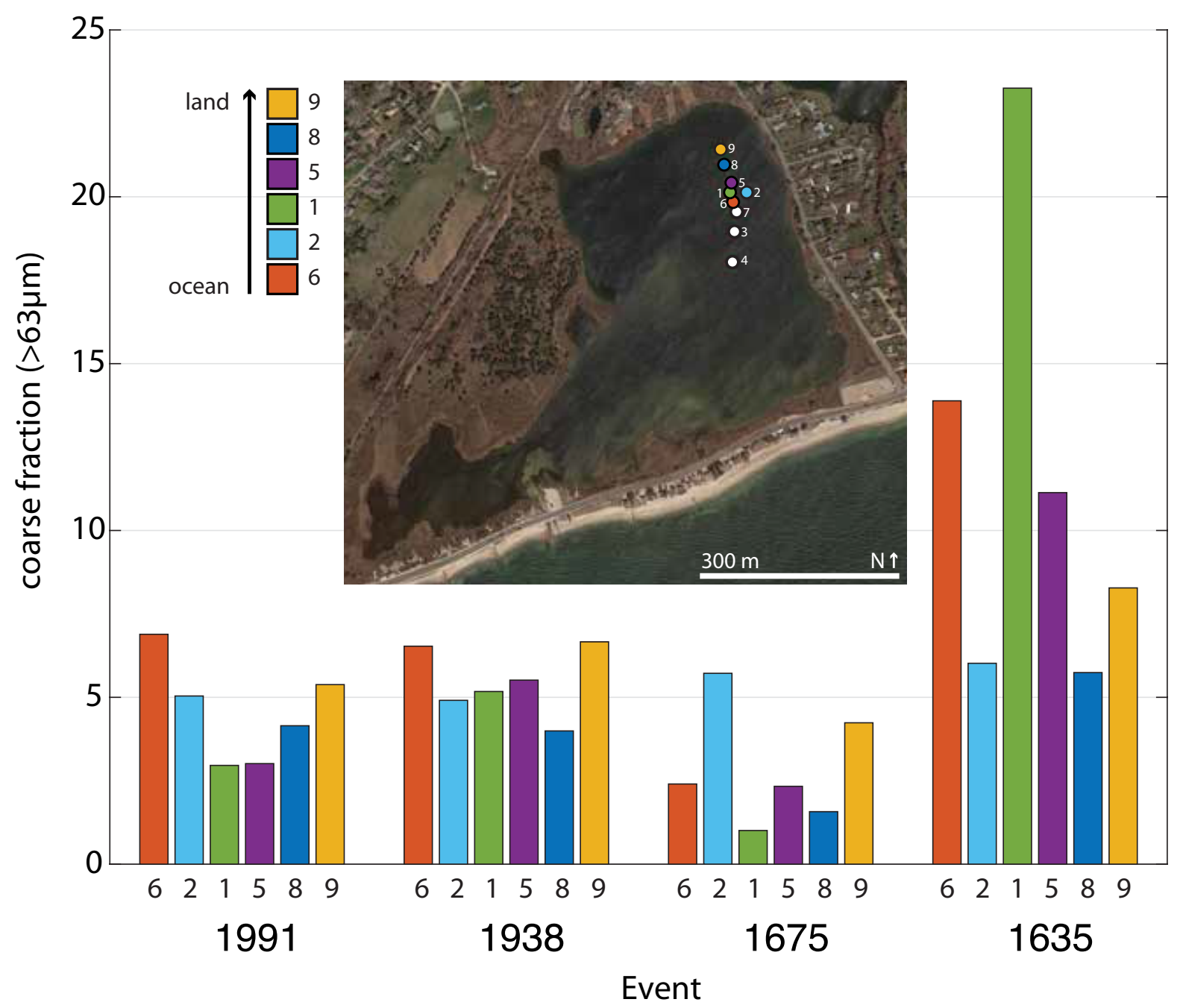

Figure 3.5 Differences in coarse $(>63 \mu \mathrm{m})$ fraction across all study cores for four historic events. Inset, a map of the locations of the various cores. Cores are listed in order from closest to the ocean to closest to the land. 

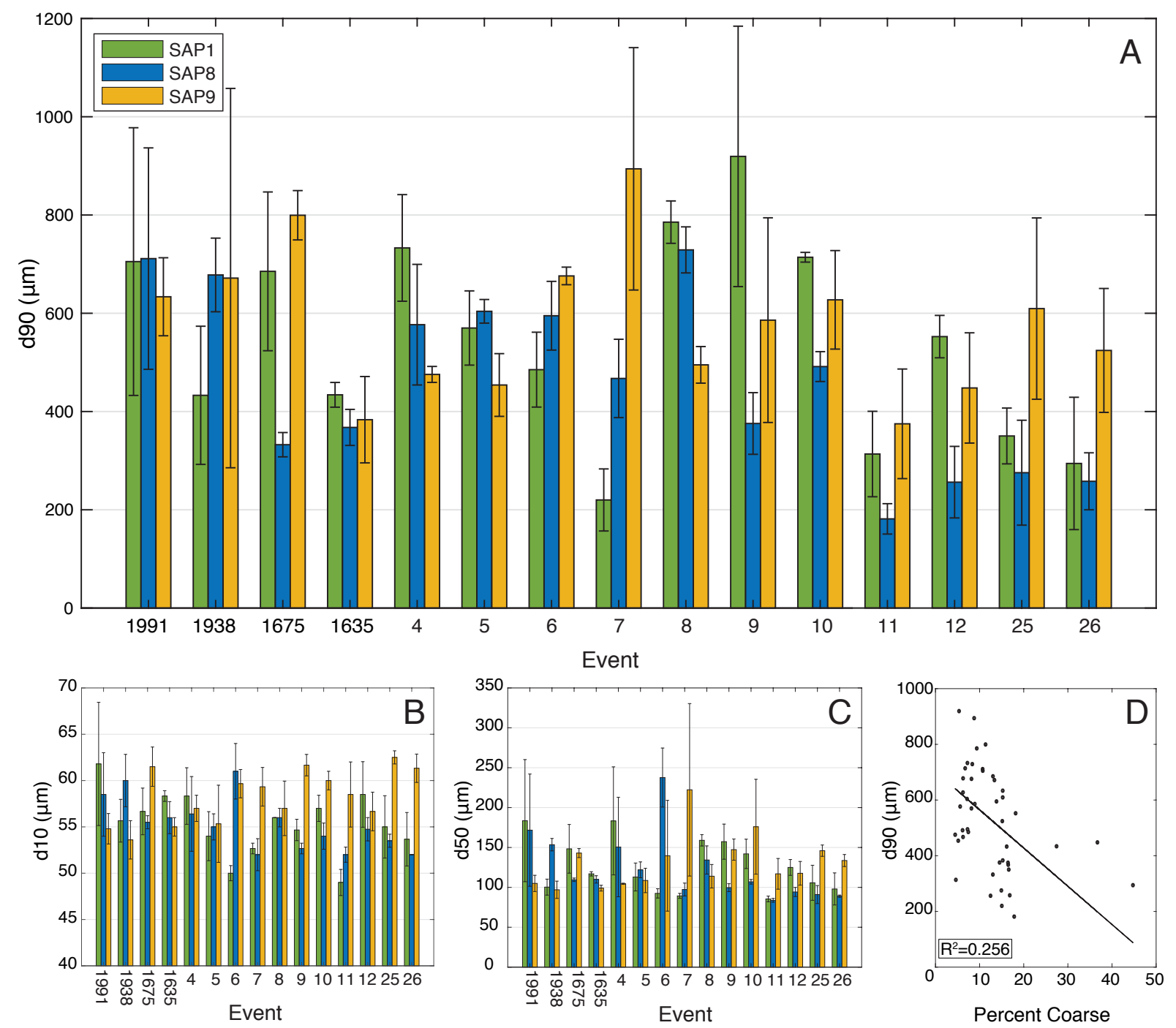

Figure 3.6 Grain-size analysis for the three study cores, SAP1, SAP8, and SAP9. A) Average $\mathrm{D}_{90}$ values. B) Average $\mathrm{D}_{10}$ values. C) Average $\mathrm{D}_{50}$ values. D) Relationship (negative) between average $\mathrm{D}_{90}$ values and coarse $(>32 \mu \mathrm{m})$ fraction values. $\mathrm{R}^{2}=0.256, \mathrm{p}<0.05$. 


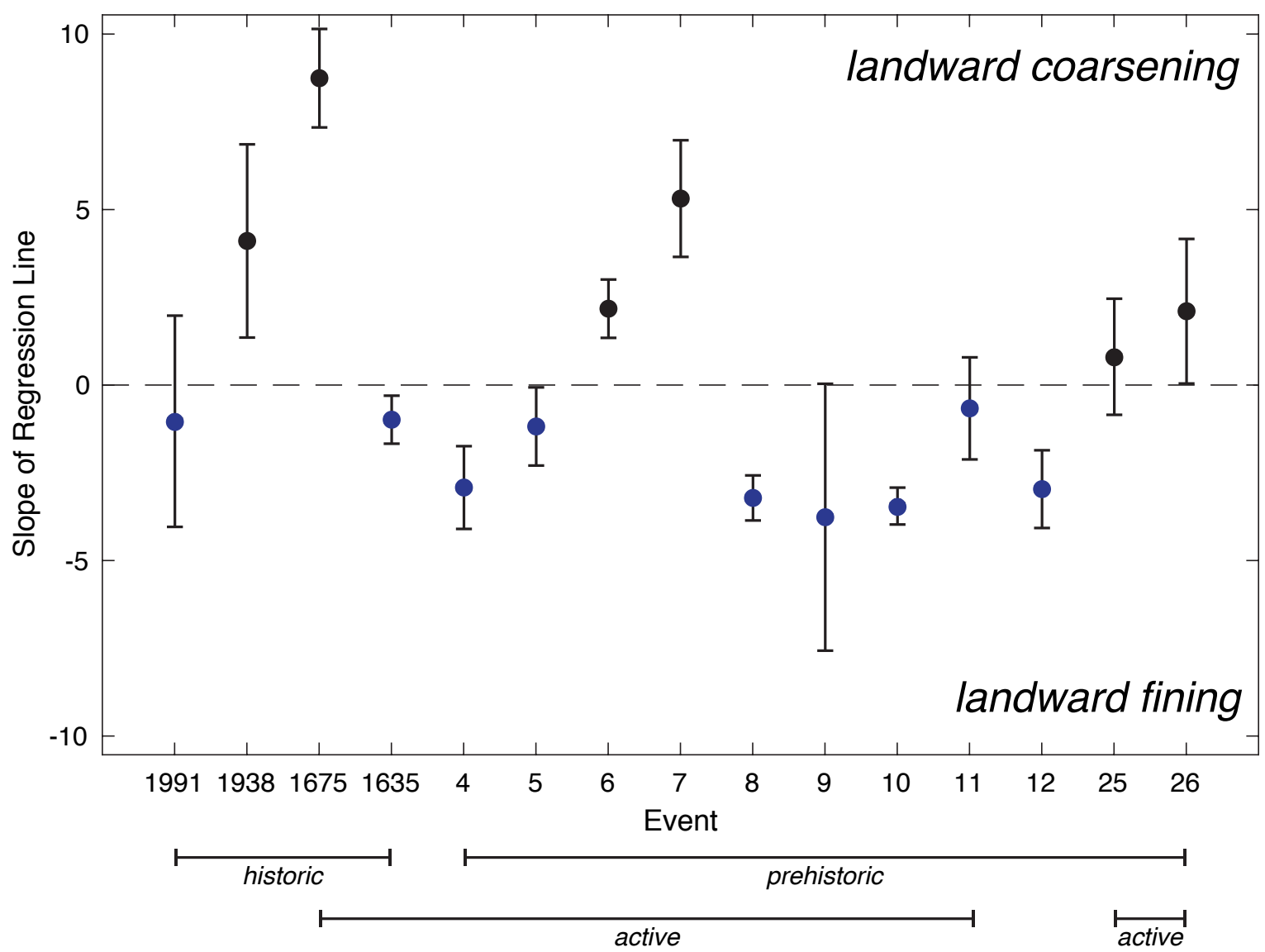

Figure 3.7 Regression analysis. Blue stars indicate landward fining trends, consistent with our expectations for an overwash event. Active intervals as determined by Donnelly et al. (2015). 


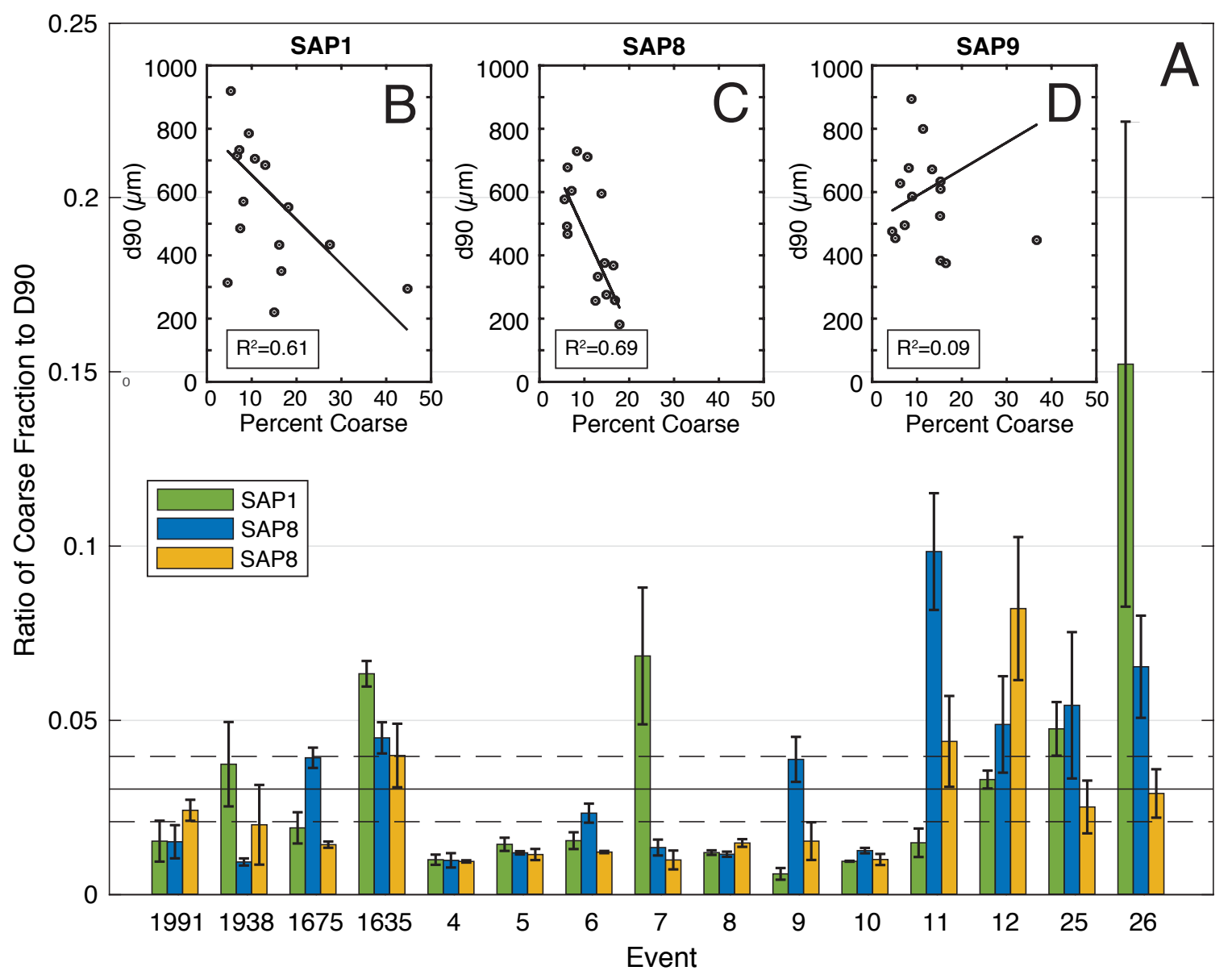

Figure 3.8 A) The ratio of coarse fraction (fine sand $>63 \mu \mathrm{m}$ ) to maximum grain size for each event. Inset, trends between coarse fraction and maximum grain size for B) SAP1 ( $<<0.05)$, C) SAP8 $(\mathrm{p}<0.05)$, and $\mathbf{D})$ SAP9 (not significant). 


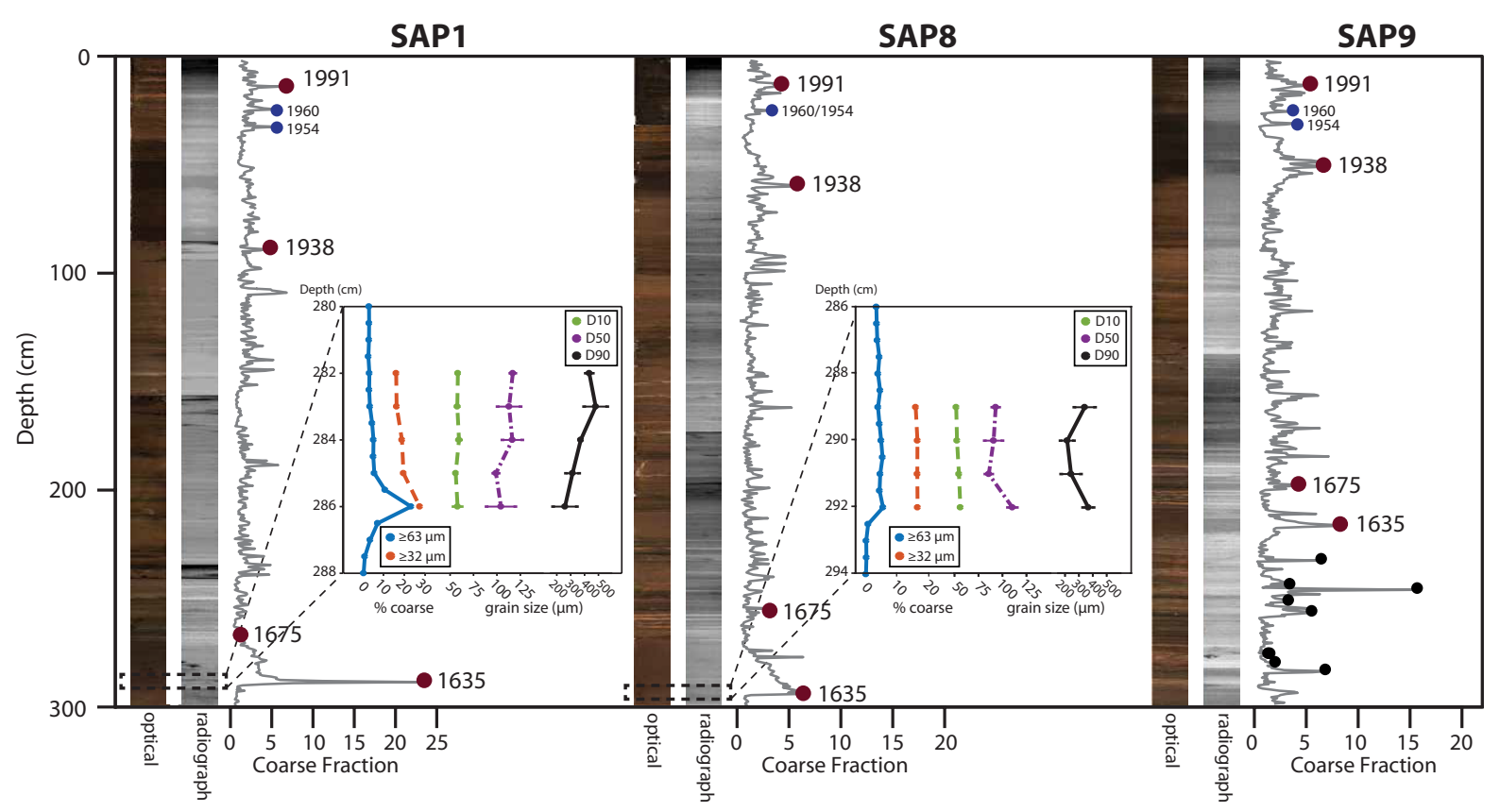

Figure 3.9 Relationship of coarse fraction to maximum grain size; red circles indicate historic study events. Blue circles indicate additional events identified from coarse fraction and correlative age models. Black circles indicate additional events identified and correlated with hurricane events identified in SAP2 by Donnelly et al. (2015). 


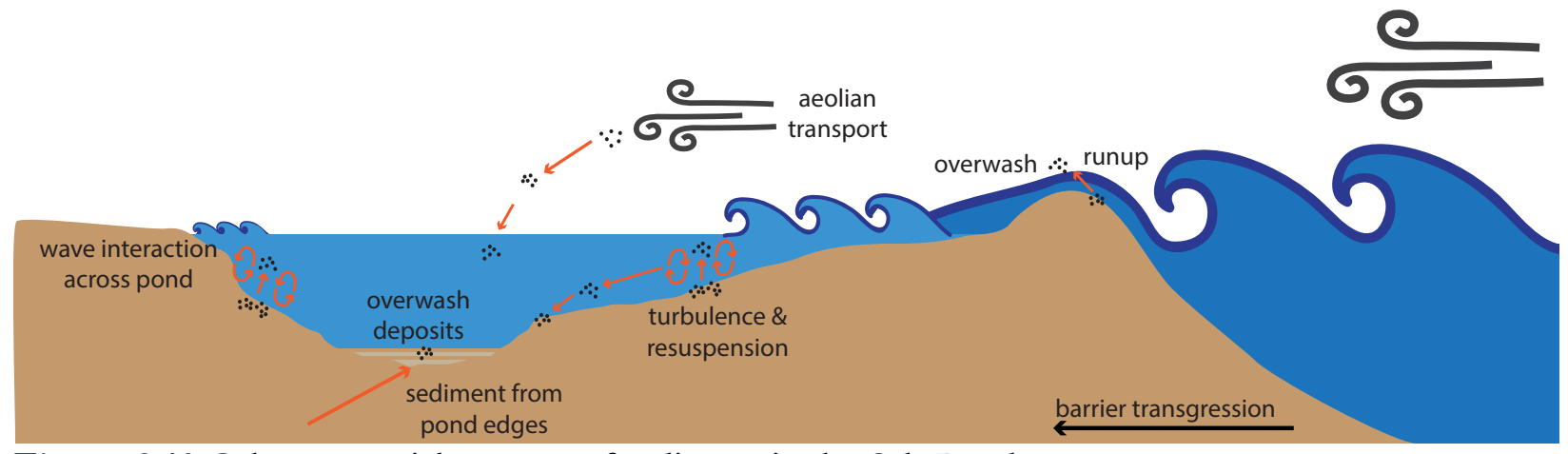

Figure 3.10 Other potential sources of sediment in the Salt Pond system. 
Table 3.1 Additional radiocarbon dates (uncalibrated) included in new age models.

\begin{tabular}{|c|c|c|c|c|c|}
\hline Sample ID & Core & Age & Error & Type & d13C \\
\hline SAP5 D2_3:5_16.5 & SAP5 & 370 & 30 & Plant/Wood & -24.31 \\
\hline SAP5 D2_4:5_79.5 & SAP5 & 950 & 30 & Plant/Wood & -27.75 \\
\hline SAP5 D2_5:5_43.5 & SAP5 & 1240 & 25 & Plant/Wood & -29.88 \\
\hline SAP5_D2_3:5_27 & SAP5 & 735 & 90 & Mollusk & \\
\hline SAP5_D2_3:5_16.5 & SAP5 & 770 & 95 & Mollusk & \\
\hline SAP5_D2_4:5_11cm & SAP5 & 705 & 25 & Plant/Wood & -27.59 \\
\hline SAP5 D2 2:5 111-112 cm & SAP5 & 290 & 20 & Plant/Wood & -20.5 \\
\hline SAP5 D2 2:5 $113 \mathrm{~cm}$ & SAP5 & 340 & 20 & Plant/Wood & -23.6 \\
\hline SAP5 D2 3:5 79-80 cm & SAP5 & 295 & 20 & Plant/Wood & -26.57 \\
\hline SAP5_D2_2:5_69cm & SAP5 & 395 & 15 & Plant/Wood & -10.98 \\
\hline SAP5_D2_3:5_49cm & SAP5 & 300 & 15 & Plant/Wood & \\
\hline SAP5_D2_3:5_126.5cm & SAP5 & 760 & 20 & Plant/Wood & -13.89 \\
\hline SAP5A D4_5:7_32 & SAP5A & 1340 & 25 & Plant/Wood & -29.93 \\
\hline SAP5A D4_6:7_20 & SAP5A & 1600 & 55 & Plant/Wood & -26.52 \\
\hline SAP5A D4_7:7_52 & SAP5A & 1690 & 25 & Plant/Wood & -27.09 \\
\hline SAP5A D4_7:7_54 & SAP5A & 1960 & 25 & Plant/Wood & -28.01 \\
\hline SAP5A_D4_6:7_133 & SAP5A & 2120 & 95 & Mollusk & \\
\hline SAP5A_D4_7:7_30 & SAP5A & 2320 & 95 & Mollusk & \\
\hline SAP5A_D4_5:7_77.5 & SAP5A & 1780 & 20 & Plant/Wood & -12.31 \\
\hline SAP5A D4 5:7 105-106 cm & SAP5A & 1770 & 45 & Plant/Wood & -13.86 \\
\hline SAP5A D4 5:7 $113 \mathrm{~cm}$ & SAP5A & 1500 & 20 & Plant/Wood & -24.67 \\
\hline SAP5A D4 6:7 87-88 cm & SAP5A & 1740 & 20 & Plant/Wood & -14.04 \\
\hline SAP5A D4 6:7 138-139 cm & SAP5A & 2170 & 20 & Plant/Wood & -18.35 \\
\hline SAP5A D4 7:7 7-8 cm I & SAP5A & 2120 & 20 & Plant/Wood & -15.73 \\
\hline SAP5A D4 7:7 7-8 cm II & SAP5A & 1860 & 20 & Plant/Wood & -27.92 \\
\hline SAP5A D4 7:7 7-8 cm III & SAP5A & 1840 & 20 & Plant/Wood & -24.94 \\
\hline SAP6D2_3:5_97.5-98cm, seed & SAP6 & 725 & 30 & Other & -12.85 \\
\hline SAP6D2_4:5_70cm & SAP6 & 1300 & 20 & Plant/Wood & -9.69 \\
\hline SAP6D2_5:5_21-22cm & SAP6 & 1240 & 35 & Plant/Wood & -27.09 \\
\hline SAP6D2 3:5_73-74cm & SAP6 & 265 & 25 & Plant/Wood & -25.21 \\
\hline SAP6D2_2:5_115cm, seed & SAP6 & 410 & 35 & Plant/Wood & -11.31 \\
\hline SAP6D2_5:5_116GB & SAP6 & 1930 & 130 & Mollusk & \\
\hline SAP6D2_5:5_116 & SAP6 & 1480 & 25 & Plant/Wood & -25.85 \\
\hline SAP6_D2_5:5_107.5 & SAP6 & 1390 & 25 & Plant/Wood & -26.1 \\
\hline SAP6 D2 2:5 64-65 cm & SAP6 & 195 & 20 & Plant/Wood & -11.86 \\
\hline SAP6 D2 3:5 6-7 cm I & SAP6 & 695 & 20 & Plant/Wood & -8.56 \\
\hline SAP6 D2 3:5 6-7 cm II & SAP6 & 695 & 20 & Plant/Wood & -12.06 \\
\hline
\end{tabular}




\begin{tabular}{|l|l|l|l|l|l|}
\hline SAP6 D2 3:5 66-67 cm & SAP6 & 330 & 20 & Plant/Wood & -12.44 \\
\hline SAP6 D2 4:5 66-67 cm & SAP6 & 1280 & 20 & Plant/Wood & -11.11 \\
\hline SAP6 D2 4:5 109-110 cm & SAP6 & 1140 & 20 & Plant/Wood & -13.05 \\
\hline $\begin{array}{l}\text { SAP8_D1_2of2_cookie_101- } \\
\text { 104cm }\end{array}$ & SAP8 & 380 & 20 & Plant/Wood & -13.68 \\
\hline $\begin{array}{l}\text { SAP8_D3_5of5_Base_118- } \\
\text { 120cm }\end{array}$ & SAP8 & 1690 & 20 & Plant/Wood & -28.36 \\
\hline SAP8_D2_1of3_104-105cm & SAP8 & 425 & 15 & Plant/Wood & -12.61 \\
\hline SAP8_D2_2of3_73-74cm & SAP8 & 410 & 15 & Plant/Wood & -10.57 \\
\hline SAP8_D2_2of3_75cm & SAP8 & 140 & 15 & Plant/Wood & -11.63 \\
\hline SAP8_D2_2of3_108-109cm & SAP8 & 645 & 15 & Plant/Wood & -12.05 \\
\hline SAP8_D3_4of5_60cm & SAP8 & 1210 & 15 & Plant/Wood & -27.69 \\
\hline SAP8_D3_4of5_109.5 & SAP8 & 1230 & 15 & Plant/Wood & -28.8 \\
\hline SAP8_D3_3:5_23.5cm & SAP8 & 360 & 20 & Plant/Wood & -24.46 \\
\hline SAP8_D3_5:5_101cm & SAP8 & 2510 & 130 & Plant/Wood & -18.5 \\
\hline
\end{tabular}

Table 3.2 Table of active intervals. Active intervals are determined as periods of time when the number of events per century is greater than 1.2 and the distance between active intervals is less than 50 years. Asterisk indicates that the active interval extends to the end of the record. All years are in C.E.

\begin{tabular}{|l|l|l|l|l|l|l|l|}
\hline \multicolumn{2}{|l|}{ SAP2 } & \multicolumn{2}{l}{ SAP5 } & \multicolumn{2}{l|}{ SAP8 } & \multicolumn{2}{l|}{ SAP9 } \\
\hline start & end & start & end & start & start & start & end \\
\hline present & 1913 & present & 1746 & present & present & present & 1841 \\
\hline 1716 & 1407 & 1696 & 868 & 1806 & 1806 & 1806 & 1427 \\
\hline 1201 & 287 & 752 & $262^{*}$ & 1356 & 1356 & 1356 & 1342 \\
\hline 248 & $190^{*}$ & & & 1308 & 1308 & 1308 & 1007 \\
\hline & & & & 967 & 967 & 967 & 812 \\
\hline & & & & 724 & 724 & 724 & $262^{*}$ \\
\hline
\end{tabular}

Table 3.3 Mean coarse $(>63 \mu \mathrm{m})$ fraction for historic events.

\begin{tabular}{|l|l|l|l|l|}
\hline & $\mathbf{1 9 9 1}$ & $\mathbf{1 9 3 8}$ & $\mathbf{1 6 7 5}$ & $\mathbf{1 6 3 5}$ \\
\hline Mean (\%) & 4.57 & 5.46 & 2.88 & 11.39 \\
\hline Standard Deviation (\%) & 1.5 & 1.0 & 1.8 & 6.6 \\
\hline
\end{tabular}


Table 3.4 Analysis of mean grain sizes along the transect.

\begin{tabular}{|l|l|l|l|}
\hline & SAP1 & SAP8 & SAP9 \\
\hline D90 $(\mu \mathrm{m})$ & 546 & 460 & 577 \\
\hline Standard Deviation $(\mu \mathrm{m})$ & 104 & 71 & 122 \\
\hline D50 $(\mu \mathrm{m})$ & 127 & 123 & 131 \\
\hline Standard Deviation $(\mu \mathrm{m})$ & 21 & 17 & 24 \\
\hline D10 $(\mu \mathrm{m})$ & 55 & 55 & 58 \\
\hline Standard Deviation $(\mathrm{cm})$ & 2 & 2 & 2 \\
\hline
\end{tabular}




\title{
4. Grain-size analysis of hurricane-induced event beds in a New England salt marsh
}

\begin{abstract}
This study explored trends in maximum grain size of storm event deposits along a transect of three sediment cores from a salt marsh in Mattapoisett, MA. A new approach was used to determine the grain size distribution of the cores in the transect. Though maximum grain size values are expected to decrease as distance from the barrier increases, not all study events followed this trend within uncertainty. Analysis of the storm event beds revealed a significant difference between historic and prehistoric deposits, suggesting that complex sedimentation or geomorphic dynamics may be at play in this area. This in-depth, whole-site approach has implications for improving future storm reconstructions.
\end{abstract}




\subsection{Introduction}

As coastal population continues to grow in both size and wealth, hurricanes pose a growing threat to livelihood and infrastructure along the coast. Recent research has explored the influence of a changing climate on hurricane frequency, intensity, genesis location, and track. While most assessments agree that an increase in sea surface temperatures should indicate an increase in the intensity of tropical cyclones (Emanuel, 2008; Holland \& Webster, 2007; Sobel et al., 2016; Walsh et al., 2016), natural variability and confounding factors complicate the hurricane-climate connection. Sobel et al. (2016) suggest that, historically, aerosol cooling may have dampened the intensifying effect of greenhouse gas forcing, but increased greenhouse gas emissions may eventually overtake that dampening, further increasing future hurricane intensity. Research into both the historic and prehistoric North Atlantic hurricane record is imperative to understanding future impacts of climate change on these destructive events.

Quantitative tropical cyclone records for the entire Atlantic basin date back to the 1850s (Jarvinen et al., 1988), making it the most comprehensive tropical cyclone dataset. Historical records for the Atlantic extend as far back as 1492 C.E. (Ludlum, 1963). In New England, the historical record extends as far back as 1620 C.E. (Boose et al., 2001). Since our instrumental and historical records are too short to understand interactions between tropical cyclones and climate on a longer (multidecadal to centennial to millennial) scale, proxy records are imperative for reconstructing millennia of tropical cyclone impacts.

Storm-induced overwash deposits in coastal ponds and salt marshes have been used to augment our understanding of hurricane strikes in southeastern New England (Boldt et al., 2010; Donnelly et al., 2001a; Donnelly et al., 2015; Woodruff et al., 2008). Large storms can produce storm surge and wave heights significant enough to overtop sandy barriers, transporting and depositing coarse sediment in deep coastal basins or on top of salt marsh peat. This overwash layer is then covered by finer-grained organic material or peat, preserving the storm event as a stratigraphicallydistinct allochthonous layer. Donnelly et al. (2001a) first described this sedimentary pattern in a salt marsh in southern Rhode Island. At this salt marsh, aerial photos after major hurricanes in 1938 and 1954 confirm overwash fans. These overwash fans, along with four others, were confirmed in a series of 14 sediment cores, suggesting that several intense hurricanes had impacted the area since 1635 . Other studies have also identified sequences in the geologic record as due to large storms, including deposits in Florida (Davis et al., 1989) and Alabama (Liu \& Fearn, 1993), as well as in southern New England (Boothroyd et al., 1985). 
Boldt et al. (2010) identified 30 distinct storm events in a sediment core collected from a salt marsh in Mattapoisett, MA, approximately $18 \mathrm{~km}$ northwest from the high-resolution site explored by Donnelly et al. (2015). These storm event layers were then correlated with layers in several other sediment cores along the same transect (Boldt et al., 2010). Of the 30 distinct storm events, seven historical severe landfalling hurricanes were identified-1991 (Bob), 1960 (Donna), 1954 (Edna and Carol), 1944/1938, 1815, and 1638/1635. Boldt et al. (2010) analyzed the grain size distribution of these events by contiguously sampling the sediment core, combusting the organic material, and running the resultant ash through a particle size analyzer. As a result, the particle size analysis included ash from combusted peat as well as siliciclastic sand grains, which influenced the distribution, making this kind of analysis inappropriate for accurately characterizing the transport of sand grains from storm events. This study analyzes 30 major storm event beds along the transect identified by Boldt et al. (2010), to

1) determine the grain size characteristics of individual event beds,

2) examine lateral sorting trends, and

3) compare the grain size characteristics of historic event beds with prehistoric event beds.

Understanding these characteristics and trends is imperative to further exploring the complexities inherent in hurricane-induced sediment deposition.

\subsection{Data and methods}

\subsubsection{Study area}

Mattapoisett Marsh (4139'8” N, 7047’12” W) is an 8-acre marsh system located on Buzzards Bay between New Bedford and Wareham (Fig. 4.1). The marsh is separated from western Buzzards Bay by a $\sim 50 \mathrm{~m}$ wide sand/gravel/cobble barrier. Lidar analysis indicates that the topography of the barrier varies from 1-2.5 m (elevation based on the NAVD88 vertical datum). The most prominent feature of the marsh system is a small tidal creek, which empties at the western edge of the barrier. The inlet is approximately $5 \mathrm{~m}$, and the creek itself spans $5-10 \mathrm{~m}$ in width and more than $350 \mathrm{~m}$ in length. Previous research has indicated that location of both the barrier and the inlet have remained stable throughout the past century, with USGS topographic maps showing no changes in position of either in the past 130 years (Boldt et al., 2010). Simulations of Hurricane Bob on Buzzards Bay provide insight into how Mattapoisett Marsh is vulnerable during hurricane strikes to the west of the site: though there was substantial sheltering and dispersion of wave energy that resulted in reduced wave height along the coast, there was also a focusing effect on the storm surge associated with the hurricane 
(Cheung et al., 2007). The geomorphology of Buzzards Bay leaves Mattapoisett Marsh particularly vulnerable to storm surge effects (Boldt et al., 2010).

\subsubsection{Field and lab methods}

A series of eight vibracores were collected in 2007. The eight cores represent two transectsbeach parallel and beach perpendicular. The cores (Matt1-Matt8) were composed primarily of organic-rich high-marsh peat, punctuated by coarser-grained, denser sand layers (Boldt et al., 2010). For each core, sand layers were identified using high-resolution $(200 \mu \mathrm{m})$ digital radiographs, where a sharp contrast in sediment density indicated the presence of a sand layer (Boldt et al., 2010). The thickness of each event layer was determined using the pixel count of the high-resolution radiographs. Previous research focused extensively on grain-size analysis of Matt2, a core in the beachperpendicular transect, taken $83 \mathrm{~m}$ from the beach. Peaks in Matt2 $\mathrm{D}_{90}$ grain size were identified using a Beckman-Coulter LS13320 laser diffraction particle size analyzer, after combusting the organic material of each contiguous centimeter at $550^{\circ} \mathrm{C}$ for one hour (Boldt et al., 2010). Following the inferred correlation lines previously published by Boldt and colleagues (2010), 30 correlative events were identified in Matt7a, the longest core recovered at $\sim 250 \mathrm{~cm}$ of sediment, and 20 correlative events were identified in both Matt6 and Matt8 (Fig. 4.2). The chronology of these events was constrained in Matt2 and then inferred across cores using a variety of techniques, including C-14 radiocarbon dating and gamma analysis of cesium isotopes. These dates and their uncertainties were used in conjunction with a Bayesian age-depth modeling program (Bacon) to produce age models and associated 95\% uncertainties (Blaauw \& Christen, 2011), an update from the chronology presented by Boldt et al. (2010). The first seven identified storm events have been correlated with known historical storms, from 1991 (Hurricane Bob) to 1635 (The Great Colonial Hurricane) (Fig. 4.3).

In the current work, a new approach was used to determine the grain size distribution of other cores in the beach-perpendicular transect. Using the event correlations established by Boldt and colleagues (2010), identified storm events were sampled in three vibracores, Matt6, Matt7a, and Matt8 (50 m, $100 \mathrm{~m}$, and $115 \mathrm{~m}$ from shore, respectively). The samples were combusted at $550^{\circ} \mathrm{C}$ for 1.5 hours to remove organic material and then sieved at $32 \mu \mathrm{m}$ to isolate grains coarse silt-sized and larger. Coarse fraction of each sample was determined by comparing the sieved weight of the sample to its original dry weight. This represents a departure from the 2010 procedure, where the samples were not sieved prior to grain size analysis - the sieving removes the fine-grained ash and the larger sample sizes provide more material for quantifying grain size distributions. Sieved samples were analyzed 
using a Horiba Camsizer digital image processing particle, size, and shape analyzer at the University of Massachusetts, Amherst. Since there is potential for variability in each run, each sample was run three times and averaged. $\mathrm{D}_{90}$, the size for which $90 \%$ of the particles in the size distribution are smaller, is used as a metric for the maximum grain size. For Matt8 and Matt7a, all correlative events were analyzed for particle size distribution. For Matt6, only events with a coarse fraction $(\geq 32 \mu \mathrm{m})$ above a threshold value of 5\% were analyzed. As discussed by Brandon et al. (2010), the unadjusted distribution (which does not consider the fine grains removed by the sieving process) is best suited for use in sediment transport calculations, since the unadjusted $D_{90}$ value is more representative of the largest grains transported during a major flood event.

Following the advective-settling model described by Woodruff et al. (2008), storm deposits from tropical cyclones often exhibit landward-fining trends, such that coarser grains are found deposited closer to the barrier and finer grains are found further from the barrier. As waves overwash the barrier during large-scale inundation events, observational and experimental data (C. Donnelly et al., 2006) suggest that flow behind the barrier becomes supercritical - the flow velocity is larger than the wave velocity. During extreme inundation conditions, the sediment transport may also be dominated by suspended load (C. Donnelly et al., 2006). Given a sizable reduction in turbulence between the barrier and the area behind it, it is thought that settling of the sediment plays a larger role in the ultimate transport of the sediment grains than turbulent resuspension (Woodruff et al., 2008). Larger particles in a fluid experience more drag, and, as a result, settle out of suspension faster. The maximum grain sizes in each event along the transect were analyzed to determine if they followed a landward-fining trend. To accomplish this, a simple regression analysis was performed for each event - a negative correlation among points indicated that the results followed the expected trend.

\subsection{Results}

\subsubsection{Grain-size analysis}

Grain size was analyzed across the entire spectrum, with focus on three levels: $\mathrm{D}_{10}, \mathrm{D}_{50}$, and $\mathrm{D}_{90} . \mathrm{D}_{10}$, the size for which $10 \%$ of the particles in the size distribution are smaller, was set through experimental design at $>32 \mu \mathrm{m}$ by removing fines through sieving. Values for $\mathrm{D}_{50}$, the median grain size, and $\mathrm{D}_{90}$ were not adjusted for the removal of the fine-grained ash. Since only $11 \%$ of the variance in $\mathrm{D}_{90}$ is explained by the coarse $(\geq 32 \mu \mathrm{m})$ fraction of the sample (Fig. 4.4, top, $\mathrm{R}^{2}=0.11, \mathrm{p}<0.05$ ), the unadjusted $\mathrm{D}_{90}$ value will give a more accurate estimate of the intensity of a given storm event than the coarse $(\geq 32 \mu \mathrm{m})$ fraction alone. The summed particle distribution number (PDN, a count of the 
grains sampled) explains more of the variance in coarse fraction, whereas has no significant correlation with $\mathrm{D}_{90}$ values (Fig. 4.4, middle, $\mathrm{R}^{2}=0.38, \mathrm{p}<0.05$; Fig. 4.4, bottom, no significant correlation). $\mathrm{D}_{90}$ values for Matt6, the core closest to the barrier, averaged $450 \mu \mathrm{m}$, with a range from $175 \mu \mathrm{m}$ to 699 $\mu \mathrm{m}$ for the 14 event samples (Fig. 4.5, top). $\mathrm{D}_{90}$ values for Matt7a averaged $580 \mu \mathrm{m}$, with a range from $193 \mu \mathrm{m}$ to $1601 \mu \mathrm{m}$ for the 30 event samples (Fig. 4.5, middle). D 90 values for Matt8, the core farthest from the barrier, averaged $514 \mu \mathrm{m}$, with a range from $194 \mu \mathrm{m}$ to $832 \mu \mathrm{m}$ for the 20 event samples (Fig. 4.5, bottom). The variability in $\mathrm{D}_{90}$ among different runs of the same sample was also considered. Matt6 had the least variability between individual runs (average standard deviation 140 $\mu \mathrm{m})$, whereas Matt7a had the most (average standard deviation $338 \mu \mathrm{m}$ ).

\subsubsection{Spatial trends in deposition}

The three cores in this study are along a transect, with Matt6 closest to the barrier and Matt8 farthest from the barrier. As such, deposition of the events will vary spatially for both size of the deposit and maximum grain size deposited. Particularly for the historical storm events (events 1-7), deposits appear to thin as the distance from the barrier increases (Fig. 4.6). Though there is no statistically significant trend in event bed thickness, the average bed thickness of Matt6 is greater than the average bed thickness of both Matt7a and Matt8 (Table 4.1). Of the $\sim 22$ event beds identified in the cores, Matt6 has an average event bed thickness of $1.06 \mathrm{~cm}$, with values ranging from $0.36 \mathrm{~cm}$ to $3.26 \mathrm{~cm}$. Matt $7 \mathrm{a}$ has an average event bed thickness of $0.7 \mathrm{~cm}$, with values ranging from $0.2 \mathrm{~cm}$ to $4.18 \mathrm{~cm}$. Matt 8 has an average event bed thickness of $0.77 \mathrm{~cm}$, with values ranging from $0.32 \mathrm{~cm}$ to $3.26 \mathrm{~cm}$.

Though there was no significant difference in mean $\mathrm{D}_{90}$ value across each core, the mean $\mathrm{D}_{50}$ value for Matt6 was significantly higher than that of Matt7a and Matt8 ( $p<0.001$; Table 4.1). Though $\mathrm{D}_{90}$ values are expected to decrease as distance from the barrier increases, not all study events followed this trend within uncertainty (Fig. 4.7). Of the 22 storm event deposits that were identified in at least two of the three transect cores, 8 events $(36 \%)$ followed a landward-fining trend, 8 events $(36 \%)$ followed a landward-coarsening trend, and 6 events (27\%) did not follow either trend within uncertainty (Fig. 4.7).

\subsubsection{Temporal trends in deposition}

To understand how historic events compared to prehistoric events, the two groups were analyzed. The mean maximum grain size of the historic events (events 1-7) is significantly higher 
$(\mathrm{p}<0.01)$ than the mean maximum grain size of the prehistoric events (events $8-22)$. This trend is observed when averaging events across all three cores in the transect. Individual cores show no statistically significant difference in mean maximum grain size between the two temporal frames of reference. There was also no statistically significant difference in mean maximum grain size between events in active and inactive intervals, as identified by Donnelly et al. (2015).

\subsubsection{Spatiotemporal trends in deposition}

Spatial trends in grain size were also analyzed temporally (Fig. 4.7). Of the 11 events with data from all three cores, there is a statistically significant difference $(\mathrm{p}<0.05)$ between historic and prehistoric events. Historic events (1-6) follow a landward-fining trend, whereas prehistoric events (8-19) follow a landward-coarsening trend. Event 7, which corresponds to the 1635/1638 hurricane, does not follow either trend, suggesting a temporal transition. There were no significant differences in trends between active intervals and inactive intervals.

\subsection{Discussion}

This work represents a reanalysis of the grain-size distributions in event beds documented by Boldt and colleagues (2010), using a new technique to better estimate the maximum grain size of storm event deposits. Previous research into tropical cyclone event deposits has identified a fining-landward trend, consistent with an inundation/run-up overwash regime (Brandon et al., 2014; C. Donnelly et al., 2006; Woodruff, 2008). The fall velocity of a given grain determines the sorting trends seen in deposition. Fall velocity is dependent on several factors. Stokes' Law applies to small particles, where the settling is impeded by the drag associated with the laminar flow surrounding the grain (Ferguson \& Church, 2004). Settling of small particles is slow, and fall velocity increases with the square of the diameter of the particle. Larger particles settle far more rapidly, since the drag associated with the wake behind each particle accelerates their settling. As such, their fall velocity increases with the square root of the diameter (Ferguson \& Church, 2004). In both cases, larger particles have larger fall velocities and settle sooner, resulting in a landward-fining overwash deposit. This trend, however, is present in only $36 \%$ of the 22 events identified, suggesting a more complicated sediment transport and deposition relationship.

Of particular interest is the difference between historic and prehistoric deposits. The first seven events identified in the study sediment cores are correlated to hurricanes dating from the Great Colonial Hurricane of 1635 to present. Of those events, all seven follow a landward-fining trend, 
where, at the very least, the maximum grain size of the event bed closest to the barrier is larger than the maximum grain size of the event bed furthest from the barrier. The mean maximum grain size of the historic events is also significantly higher than the mean maximum grain size of the prehistoric events. The prehistoric events, however, display a landward-coarsening trend, which is seemingly at odds with our understanding of particle fall velocities.

The simplest way to explain this difference between historic and prehistoric events is a migration of the barrier separating the marsh from the ocean. Barrier migration is inherently linked to sea-level rise. A sea-level reconstruction from Barn Island, Connecticut, indicates a linear increase in mean sea level of approximately $1.0 \pm 0.2 \mathrm{~mm} /$ year from $\sim 1300$ C.E. to $\sim 1850$ C.E., with that rate increasing almost threefold in the mid-19 $9^{\text {th }}$ century (Donnelly, 2004). Tide gauge data from Woods Hole, Massachusetts (NOAA tide gauge 8447930), indicates an increase in sea level of approximately $2.81 \pm 0.18 \mathrm{~mm} /$ year over the past 83 years. As sea level rises, barriers tend to migrate landward in accordance with the Bruun Rule, with research indicating that barriers less than $200 \mathrm{~m}$ in width migrate landward primarily through overwash (Bruun, 1988; Hennessy \& Zarillo, 1987; Leatherman, 1983; Lorenzo-Trueba \& Ashton, 2010). Barrier migration is controlled largely by two primary factors: sea level change and sediment budget (Curray, 1964), though more recent studies have expanded the list of players (McBride et al., 2013). Overwash in particular contributes to migration by removing sediment at the front of the barrier and depositing it landward (C. Donnelly et al., 2006). Given our record of at least 30 overwashing storm events over the past 2,000 years, it is highly probable that these events — often several within the same century—played a role in barrier migration.

Though analysis of USGS topographic maps indicated no change in the location of the barrier at Mattapoisett for the last 125 years (Boldt et al., 2010), the Massachusetts Shoreline Change Browser indicates that shoreline retreat rates in front of Mattapoisett Marsh average $0.06 \mathrm{~m} /$ year (ranging from 0.04-0.2 m/year). While the barrier may have moved, the position of the cores, taken in 2007, remains static. This suggests that deeper events may actually have been deposited further from the barrier than they would today. As such, it is not surprising that the mean maximum grain size for the historic events is significantly higher than the mean maximum grain size for the prehistoric events.

The transition from landward-coarsening to landward-fining deposition occurs by 1750 C.E., when the town of Mattapoisett was settled. This suggests that anthropogenic changes in sediment supply and coastal stabilization may be influential. The transition also occurs not long after the Great Colonial Hurricane of 1635, which devastated southeastern New England with category 3 winds 
(Jarvinen, 2006). It is possible that surge and winds associated with this massive storm substantially changed the geomorphic layout of the area.

\subsection{Conclusions}

Mattapoisett Marsh presents a unique environment to study grain-size trends in hurricaneinduced storm deposits. Previous reconstructions of storm frequency have assumed relatively straight-forward overwash and deposition dynamics, but a deeper look into the intricacies of both spatial and temporal grain-size trends requires a more nuanced technique. While many reconstructions focus on one core from one location, a whole-site approach is necessary to properly constrain the sediment dynamics. While the incongruity between historic and prehistoric deposits may be unique to Mattapoisett Marsh, the breadth of variation in grain-size trends likely apply to back-barrier marshes throughout New England. Back-barrier marshes provide a valuable location for preserving storminduced overwash events, but the complexity of deposition dynamics must be considered in future reconstructions. 


\subsection{Figures and tables}

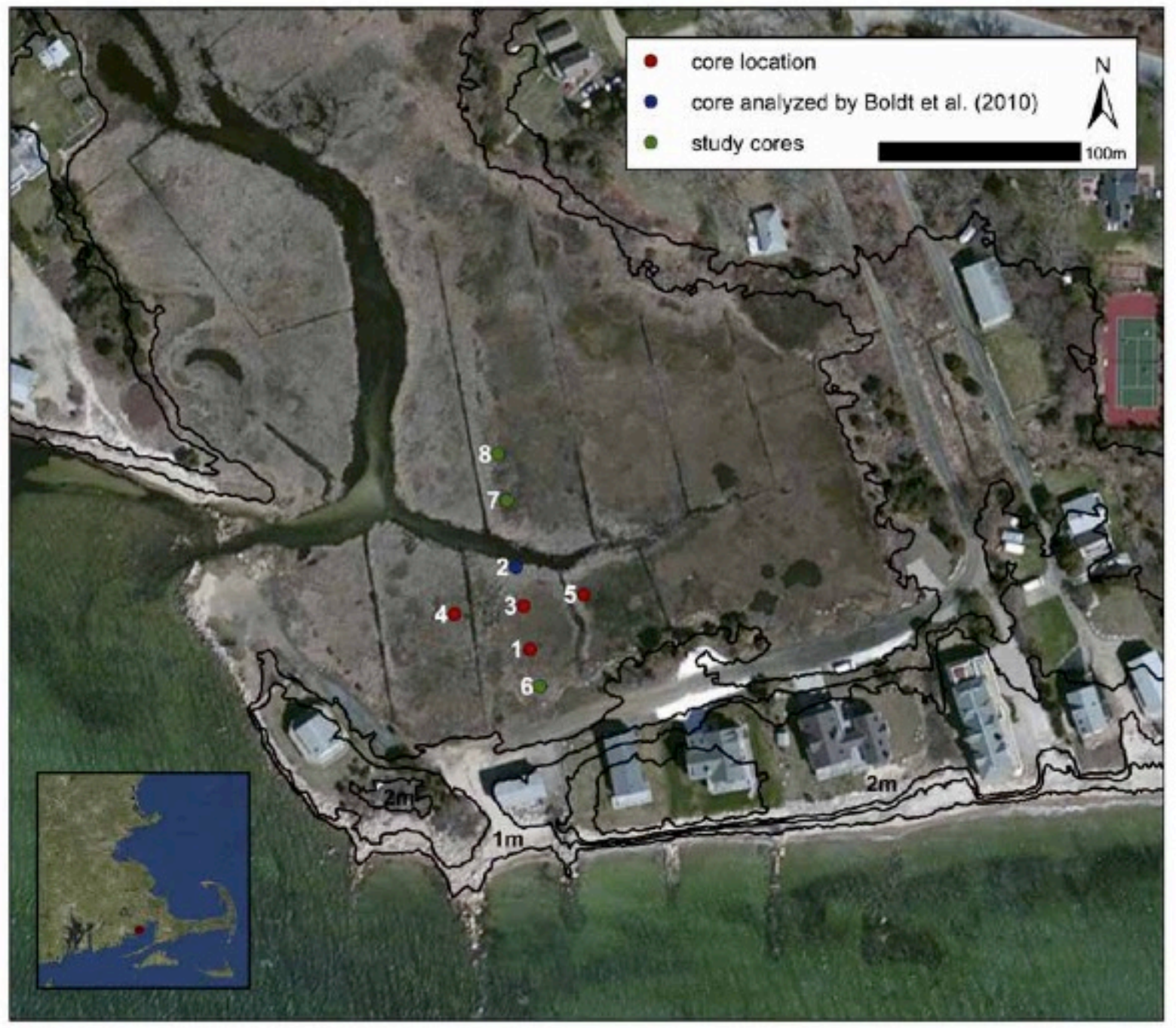

Figure 4.1 Aerial photo of the study area. Blue core was analyzed by Boldt and colleagues (2010). Green cores are analyzed in this study. Lidar topography indicated by black lines. The barrier is approximately $1-2.5 \mathrm{~m}$ in elevation. 


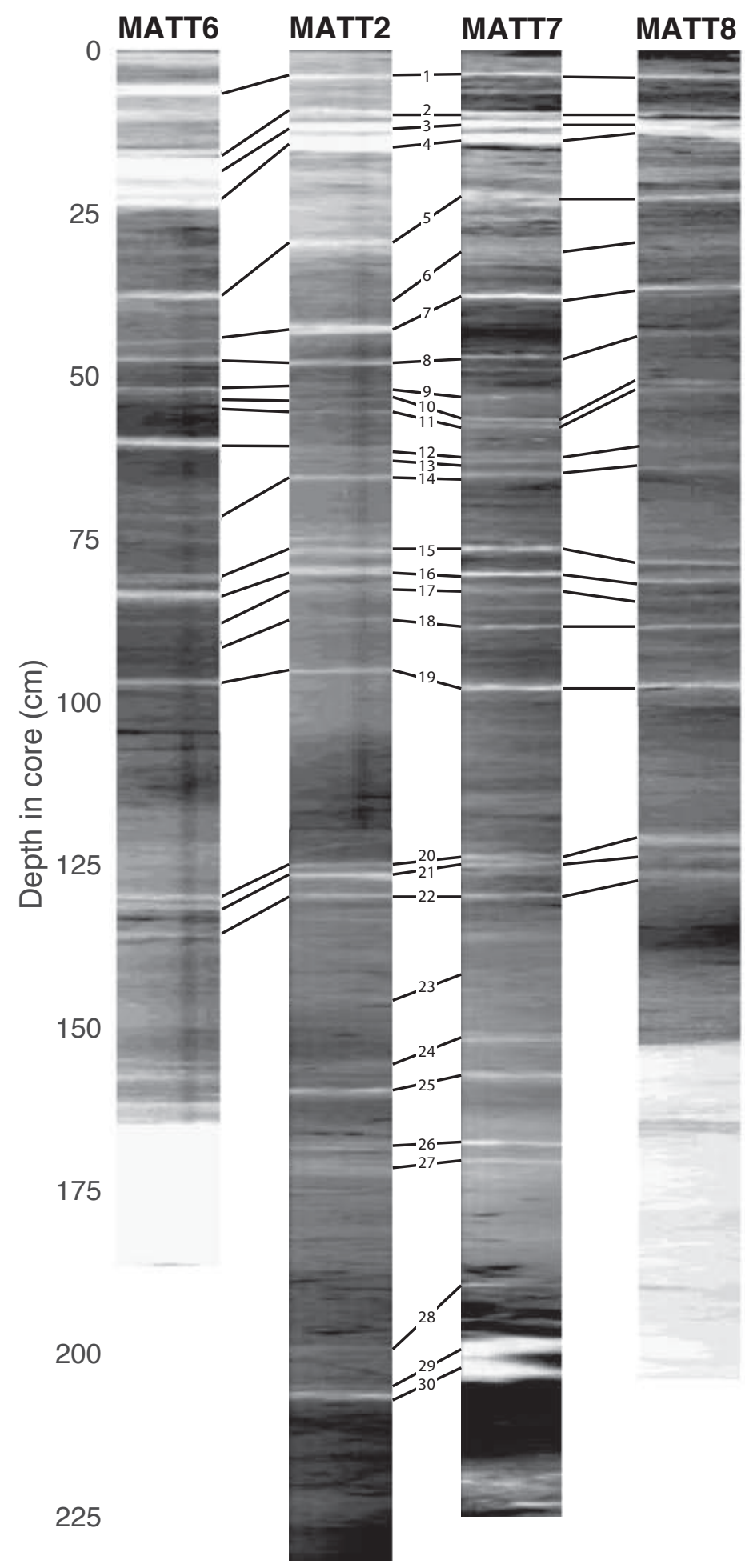

Figure 4.2 Radiographic images of the cores and event beds analyzed in this study, with inferred correlation lines connecting storm event beds. Lighter layers indicate areas of decreased density; a potential storm event layer. 

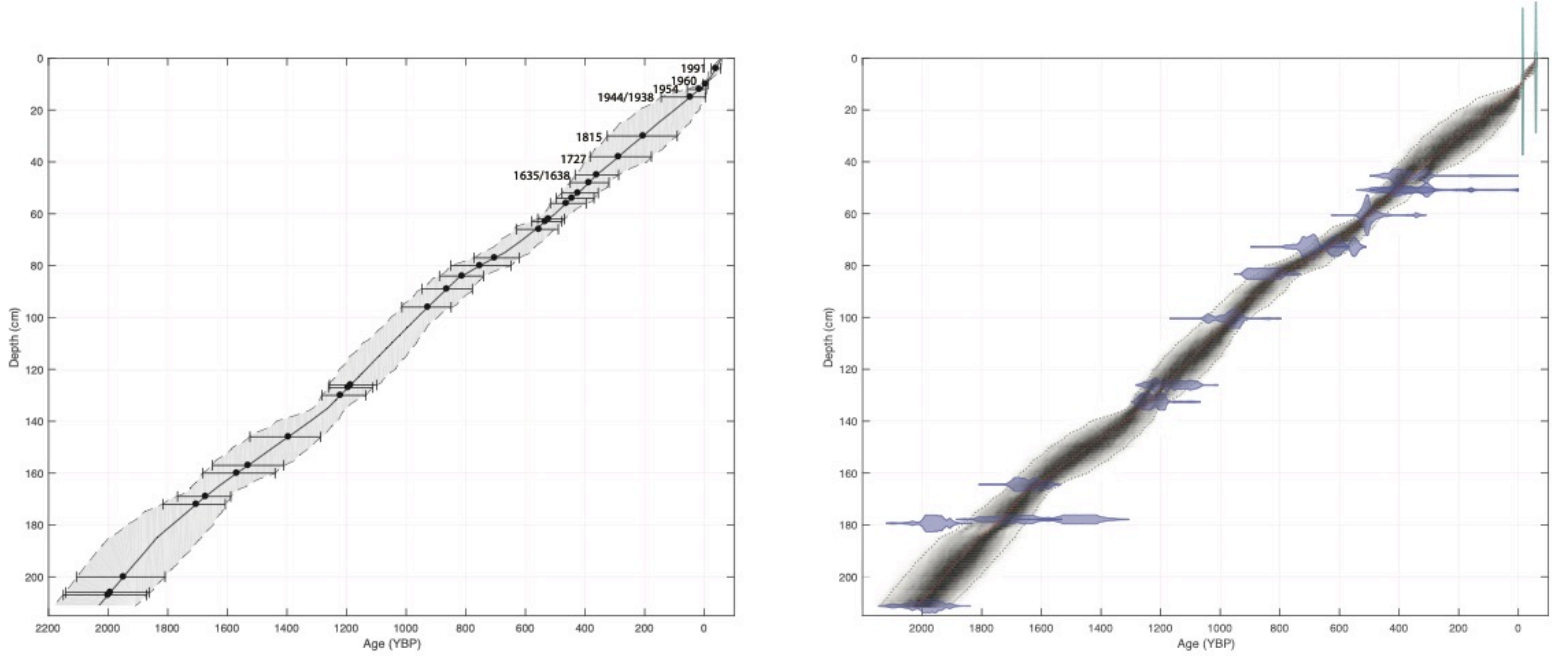

Figure 4.3 Left, age estimates and 95\% confidence intervals of the different event beds identified in Fig. 4.2 by depth. Age estimates are determined using Bayesian age-depth modeling program Bacon. The first seven events are identified and correlated with historic storms. Right, output from the Bacon program indicating C-14, cesium-137, and surface dates used to create the age model. 

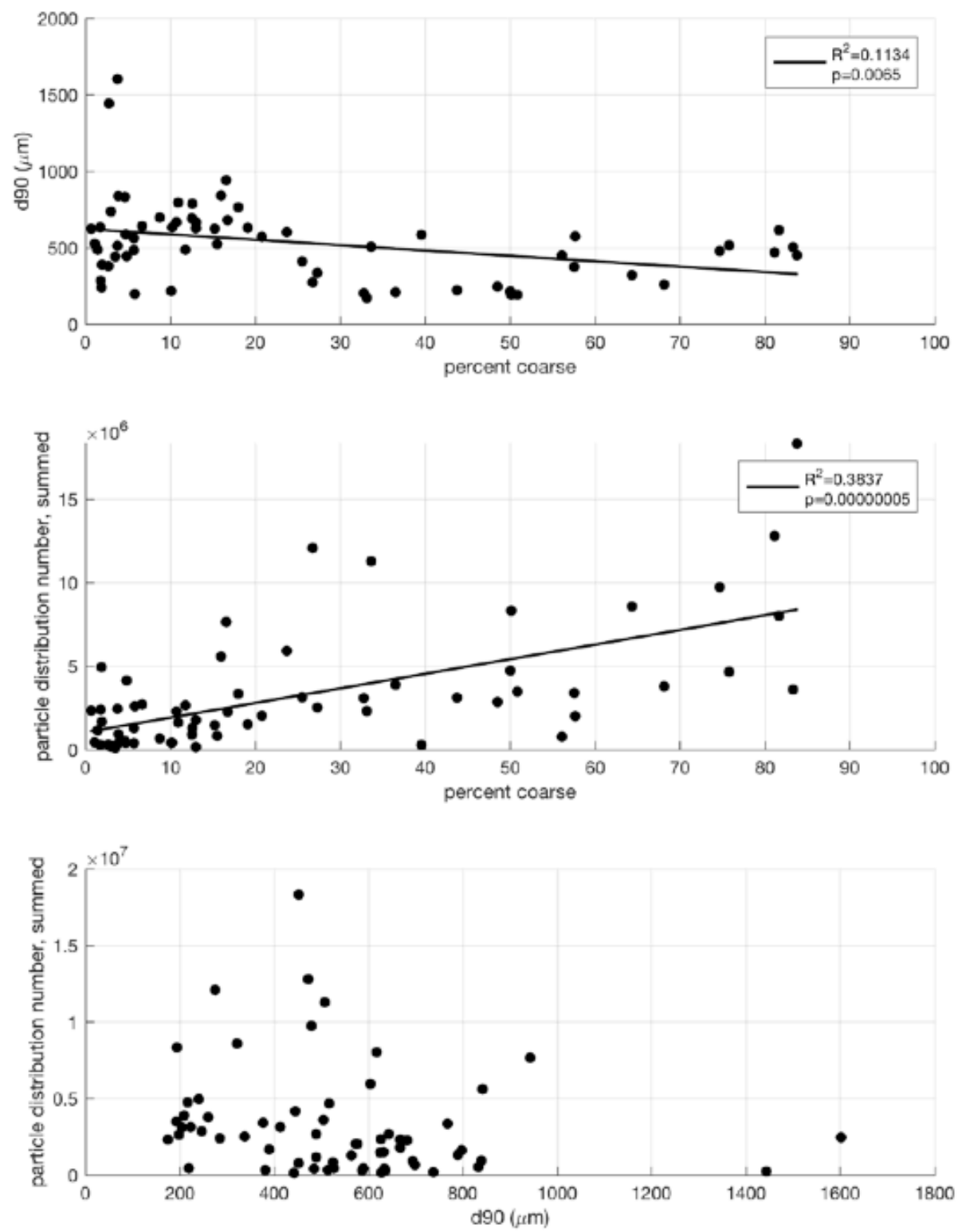

Figure 4.4 Top, the relationship between sample $\mathrm{D}_{90}$ and coarse $(\geq 32 \mu \mathrm{m})$ fraction suggests that the unadjusted $\mathrm{D}_{90}$ value will give a more accurate estimate of the intensity of a given storm event than the coarse $(\geq 32 \mu \mathrm{m})$ fraction alone (coarse fraction explains only $11 \%$ of the variance in $\left.\mathrm{D}_{90}, \mathrm{p}<0.001\right)$. Middle, the relationship between the number of particles measured in a given sample and coarse $(\geq 32$ $\mu \mathrm{m})$ fraction suggests that coarser samples tend to have more particles to measure $(\mathrm{p}<0.001)$. Bottom, there is no significant relationship between the number of particles measured in a given sample and the sample $\mathrm{D}_{90}$. 

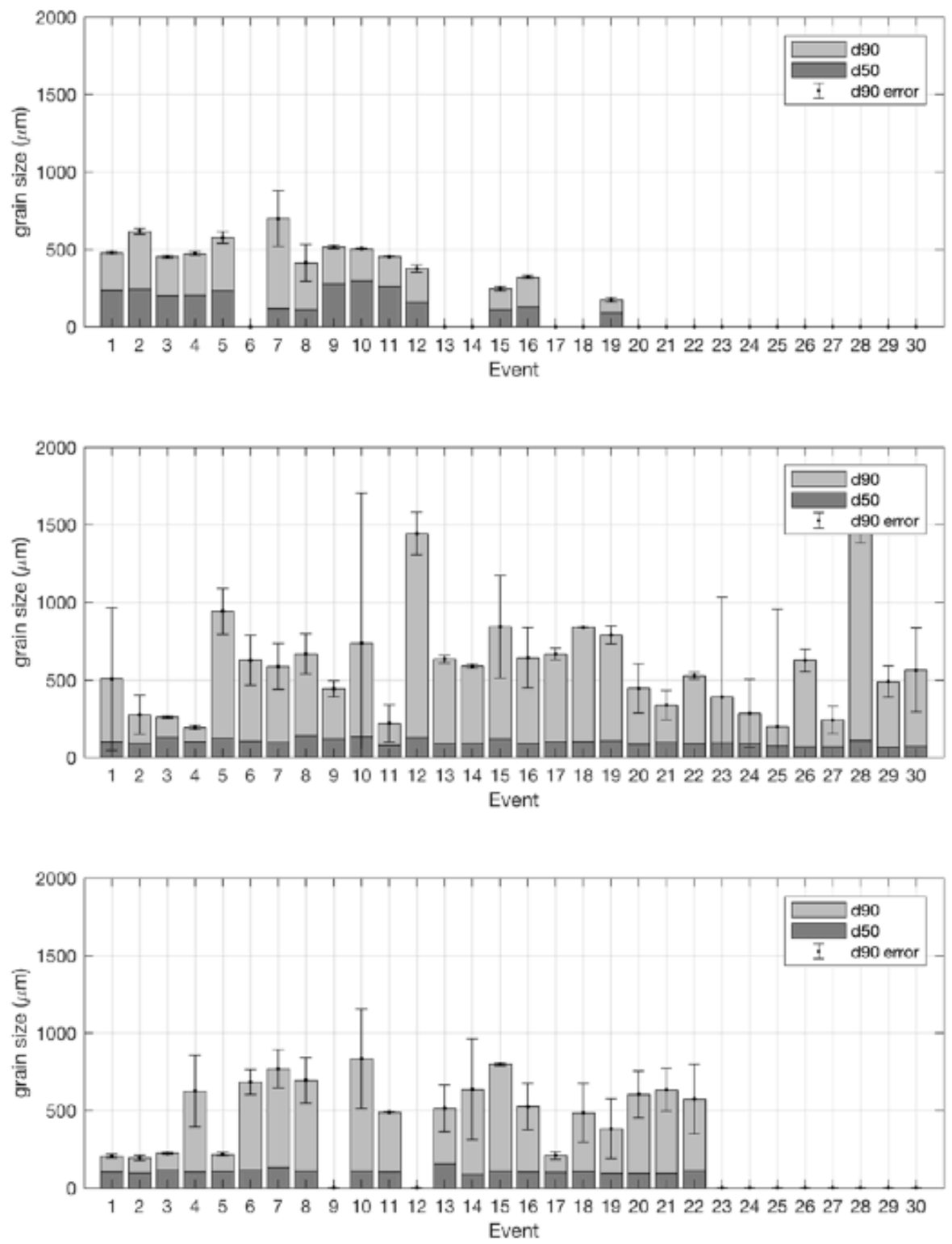

Figure 4.5 Top, $\mathrm{D}_{50}$ and $\mathrm{D}_{90}$ values and associated $\mathrm{D}_{90}$ error for Matt6. Middle, $\mathrm{D}_{50}$ and $\mathrm{D}_{90}$ values and associated $\mathrm{D}_{90}$ error for Matt7a. Bottom, $\mathrm{D}_{50}$ and $\mathrm{D}_{90}$ values and associated $\mathrm{D}_{90}$ error for Matt8. 

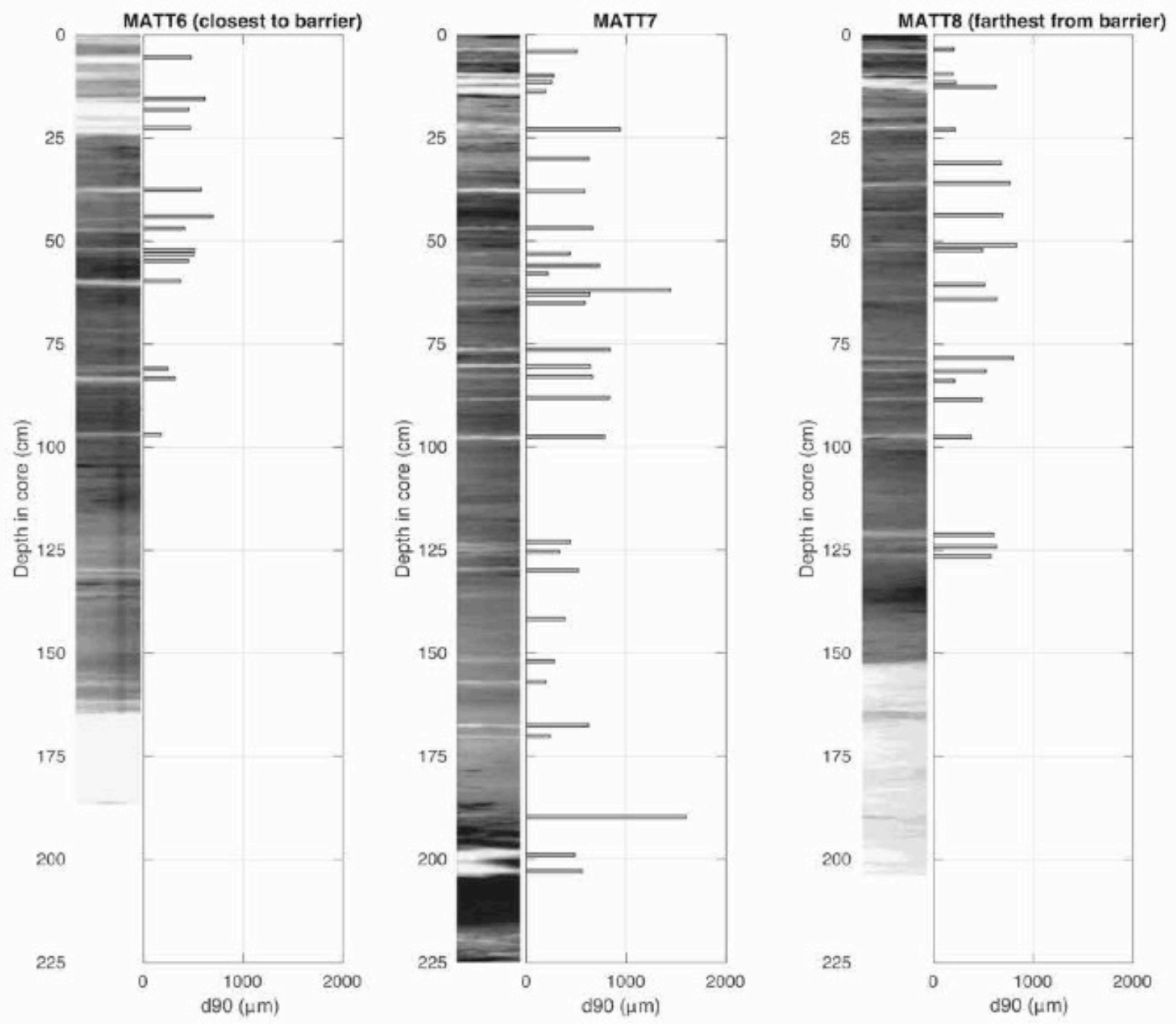

Figure 4.6 Radiographic images of the study cores, with storm event beds and their $\mathrm{D}_{90}$ values indicated by depth in core. 


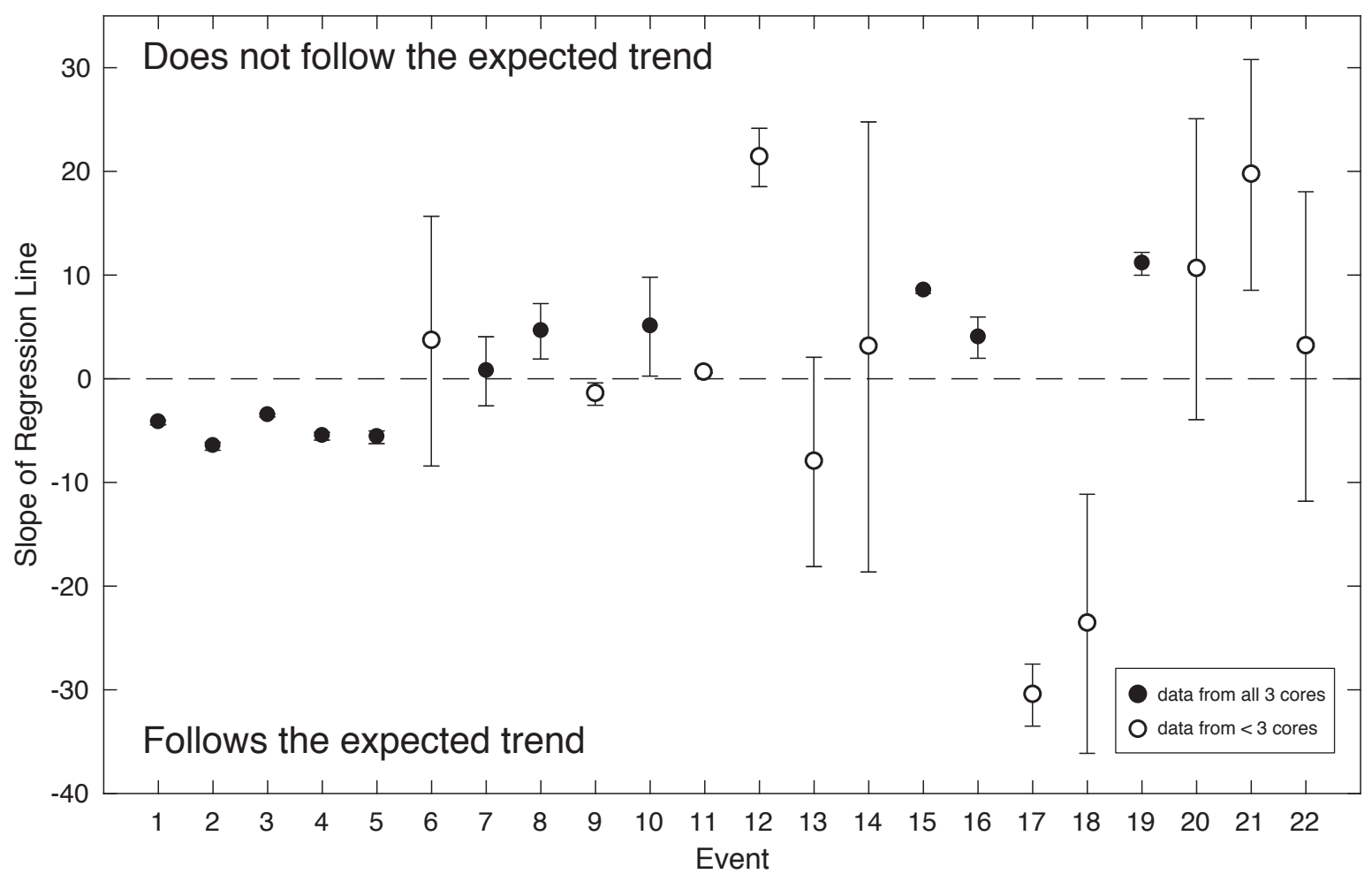

Figure 4.7 Plot of the slope of the regression line of $\mathrm{D}_{90}$ values of the same event across the transect of cores. A negative slope indicates a landward-fining trend, whereas a positive slope indicates a landward-coarsening trend. Filled points have a regression with all three cores in the transect. Empty points have data from $<3$ cores. Of the filled points, historical values (events 1-7) are statistically different $(\mathrm{p}<0.05)$ from prehistoric values (events 8-19). 
Table 4.1 Analysis of event bed thickness, maximum, and median grain size along the transect.

\begin{tabular}{|l|l|l|l|}
\hline & Matt6 & Matt7a & Matt8 \\
\hline D90 $(\mu \mathrm{m})$ & 450 & 580 & 514 \\
\hline Standard Deviation $(\mu \mathrm{m})$ & 140 & 338 & 211 \\
\hline D50 $(\mu \mathrm{m})$ & 191 & 98 & 108 \\
\hline Standard Deviation $(\mu \mathrm{m})$ & 70 & 20 & 14 \\
\hline Event Thickness $(\mathrm{cm})$ & 1.06 & 0.70 & 0.77 \\
\hline Standard Deviation $(\mathrm{cm})$ & 0.80 & 0.83 & 0.66 \\
\hline
\end{tabular}




\title{
5. Applications and caveats of inverse modeling to reconstruct tropical cyclones
}

\begin{abstract}
Recent research has attempted to use grain-size distributions of overwash deposits and hurricaneinduced event beds to estimate the intensity of past tropical cyclones. Here, we present an updated inverse modeling technique applied to overwash deposits in two different environments in coastal New England. This inverse modeling technique, when appropriately calibrated with synthetic storm records to determine offshore wind and wave properties, produces mean wind speed values consistent with observational and estimated values for historic storms. Further investigation suggests that grainsize and deposition trends in these environments are more complex and nuanced than originally assumed. Application of the inverse modeling technique, therefore, must be assessed and validated at each particular setting before application in paleo-storm reconstructions.
\end{abstract}




\subsection{Introduction}

Records of hurricane-induced overwash deposits have long constrained tropical cyclone frequency (e.g. Boldt et al., 2010; Donnelly et al., 2001, 2015; van Hengstum et al., 2014; Liu \& Fearn, 1993), revealing varying trends in hurricane activity both regionally and historically. More recent research has attempted to estimate the intensity of the storms responsible for these deposits (Brandon et al., 2013, 2014; Woodruff et al., 2008). The inverse hurricane modeling techniques developed by Woodruff et al. (2008) and updated by Brandon et al. (2013, 2014) have been used to reconstruct flooding and wind speed intensities associated with tropical-cyclone-induced overwash deposits around the globe and in several depositional environments (Bregy et al., 2017; Hong et al., 2018; Wallace \& Anderson, 2010).

Following the advective-settling model described by Woodruff et al. (2008), a relationship exists among the maximum grain size of a storm deposit, the distance the grain traveled inland from the barrier, and the wind and resulting wave conditions necessary to cause that travel. As waves overwash the barrier during large-scale inundation events, observational and experimental data (C. Donnelly et al., 2006) suggest that flow on the backside of a barrier can becomes supercritical— the flow velocity is larger than the wave velocity. During extreme inundation conditions, the sediment transport may also be dominated by suspended load (C. Donnelly et al., 2006). Given a sizable reduction in turbulence between the barrier and the area behind it, it is thought that advective settling of the sediment plays a larger role in the ultimate transport of the sediment grains than turbulent resuspension at a critical distance landward (Woodruff et al., 2008). Through a series of settlingvelocity equations and empirically derived relationships between wave-runup and off-shore winds, it is possible to tentatively reconstruct the offshore wind and wave characteristics of a given storm.

The Woodruff et al. (2008) study used these settling velocity equations to reconstruct storm intensities relative to known historic deposits in a back-barrier lagoon system in Laguna Playa Grande, Vieques, Puerto Rico. During hurricanes, the environment is largely runup- and wave-dominated. Relationships to offshore wave conditions were drawn from known historic storm values. Brandon et al. (2014) applied the Woodruff et al. (2008) model to two storm events from a back-barrier pond on Staten Island, New York. Brandon et al. (2014) expanded on the model by applying known relationships between offshore wave conditions and wind speeds. Though there is storm surge amplification in the area from the New York Bight, the greatest sediment transport during storms is similar to that of the study site of Woodruff et al. (2008). Transport occurs from breaching and inundation of the barrier by low-frequency infra-gravity waves, which flood the pond as tidal bores. 
These inverse modeling techniques make several assumptions in their various applications. The advective-settling model proposed by Woodruff et al. (2008) assumes that transport occurs as inflow from a tidal bore travelling over a sandy barrier and into an adjacent pond or lagoon, at which point there is a significant reduction in both velocity and turbulence. For this reason, settling of siliciclastic sediment is considered more important than turbulent resuspension in the system. There still remains, however, a distance from the barrier before which the influence of settling overtakes the influence of turbulence. This does not account for changes or differences in sediment supply or source, such as deposition from aeolian transport or sediment sourced from marsh channels or pond edges. The model also does not account for the influence of a surge-dominated wave regime during storms (such as if the surge completely inundates the barrier) and assumes that majority of the sediment transport occurs during wave-dominated regimes.

Here, we test the applicability of this inverse modeling approach applied to overwash deposits in two different environments in coastal New England. An updated inverse modeling technique from Woodruff et al. (2008) and Brandon et al. (2014) is appropriately calibrated with synthetic storm records to determine offshore wind and wave properties, since the original systems of equations overestimated results at the study sites by an order of magnitude. The resulting model produces wind speed values consistent with observational and estimated values for historic storms, albeit with large

uncertainties. Further investigation suggests that grain-size and deposition trends in these environments are more complex and nuanced than originally assumed. Application of the inverse modeling technique, therefore, needs to be assessed on a site-by-site base and potentially for a variety of storm conditions. The inverse modeling technique, even in its updated form presented here, has several caveats that must be considered before extending its use beyond the sites considered.

\subsection{Study sites and methods}

\subsubsection{Study sites}

Salt Pond, in Falmouth, MA, is a 26-ha brackish kettle pond (Fig. 5.1C). A 1-2m high coastal barrier and a tidal inlet connect the pond to the Atlantic Ocean via Vineyard Sound (Fig. 5.1B), a broad $5 \mathrm{~km}$ wide channel that separates the island of Martha's Vineyard and the Cape Cod mainland. Most of the freshwater flux in the system is through groundwater infiltration, and there are no significant overland water or sediment inputs into the pond. The mean semidiurnal tidal range on the open coast is approximately $0.5 \mathrm{~m}$, limiting the influence of astronomical tide stage on the barrier's susceptibility to storm overwash. Sediment core collection has been described previously by Donnelly 
et al. (2015). A series of cores from three locations, located along a transect across the deepest section of the pond, were used for analysis (Fig. 5.1D).

Mattapoisett Marsh is an 8-acre marsh system separated from western Buzzards Bay by a $\sim 50$ $\mathrm{m}$ wide and 1-2.5 $\mathrm{m}$ high coastal barrier (Fig. 5.1C). A small tidal creek empties at the western edge of the barrier. The inlet is approximately $5 \mathrm{~m}$ wide, and the creek itself spans $5-10 \mathrm{~m}$ in width and $\sim 350 \mathrm{~m}$ in length. The mean tidal range is approximately $1.2 \mathrm{~m}$, and the marsh elevation is approximately at mean high water. Sediment core collection has been described previously by Boldt et al. (2010). A series of cores from three locations, located both in front of and behind the inlet, were used for analysis.

\subsubsection{Lab Methods}

Event deposits were identified using techniques identified in Chapters 3 and 4 (see also Boldt et al., 2010; Donnelly et al., 2015). Sampled event deposits were combusted at $550^{\circ} \mathrm{C}$ for 1.5 hours to remove organic material. The samples were then sieved at $32 \mu \mathrm{m}$ to isolate grains larger than coarse silt. Sieved samples were analyzed using a Horiba Camsizer digital image processing particle size, and shape analyzer. Each sample was run 3-5 times and averaged after removing inconsistent runs to account for run variability. $\mathrm{D}_{90}$, the size for which $90 \%$ of the particles in the size distribution are smaller, is used as a metric for the maximum grain size. Per Brandon et al. (2010), an unadjusted distribution, which does not consider fine grains removed by the sieving, is best suited for use in sediment transport calculations, since the unadjusted $\mathrm{D}_{90}$ value is more representative of the largest grains transported during a major event.

\subsubsection{Determining appropriate trends}

As seen in Woodruff et al. (2008), storm deposits from tropical cyclones often exhibit landward-fining trends, such that coarser grains are found deposited closer to the barrier and finer grains are found further from the barrier (Fig. 5.2). Settling velocity typically increases monotonically with grain size (e.g. Ferguson and Church, 2004). As such, the maximum grain sizes in each event along the transect were analyzed to determine if they followed a landward-fining trend. To accomplish this, a regression analysis was performed for each selected event. A linear regression, taking into consideration the individual variation of each event in each core, was performed for each event. A negative trend among points indicated that the results followed the expected landward-fining trend (Fig. 5.3), and indicates a predictable sediment pattern and utility for inverse modeling techniques. 


\subsubsection{The updated model}

An updated model based on systems of equations in Woodruff et al. (2008) and Brandon et al. (2014) is presented here. Monte Carlo simulations (100,000 runs) were used to determine intensity values and propagate error. The maximum grain size, $\mathrm{D}_{90}$, is first related to fall velocity based on diameter, $w_{s,}$ a relationship explored by Ferguson and Church (2004):

$$
w_{s}=\frac{R g D^{2}}{C_{1} v+\left(0.75 C_{2} R g D^{3}\right)^{0.5}}
$$

where $R$ is the submerged specific gravity (a constant, 1.65, for quartz in water), $g$ is gravity, $D$ is the diameter of the particle (in this case, the $\mathrm{D}_{90}$ value for a given event), $v$ is the kinematic viscosity of fluid (a constant, $1.0 \times 10^{-6} \mathrm{~kg} / \mathrm{ms}$ for water at $20^{\circ} \mathrm{C}$ ), and $C_{1}$ and $C_{2}$ are equation constants (18 and 1 , respectively). The diameter-based fall velocity can then be used to determine the maximum waveinduced run-up over the barrier, $R_{\max }$, as defined by Woodruff et al. (2008):

$$
R_{\max }=\left(\frac{x_{L}^{2} w_{s}^{2}}{g}\right)^{\frac{1}{3}}+h_{b}
$$

where $x_{L}$ is the distance of the particle from the barrier and $b_{b}$ is the height of the barrier. Assuming dissipative breaking conditions from offshore wave steepness, Stockdon et al. (2006) defined an empirical relationship between maximum wave-induced run-up over the barrier and offshore wave properties:

$$
R_{\max }=0.73 \beta_{f}\left(H_{0} L_{0}\right)^{\frac{1}{2}}
$$

where $\beta_{f}$ is the beach slope, $H_{0}$ is the significant offshore wave height, and $\mathrm{L}_{0}$ is the offshore wavelength. $L_{0}$ is determined using the known relationship between wavelength and wave period, $T$ :

$$
L_{0}=\frac{g T^{2}}{2 \pi}
$$

where the relationship between local average offshore wave period $(T)$ and storm wind speed $\left(U_{\text {wind }}\right)$ was derived using SWAN (Simulating WAves Nearshore; Booij et al., 1999) wave model downscaling output for a suite of synthetic storms using techniques adapted from Lin et al. (2012) and Emanuel et al. (2006). This site-specific wave-modeling element represents a significant addition to the advectivesettling model presented initially by Woodruff et al. (2008). Only storms with a significant offshore wave height exceeding $3 \mathrm{~m}$ for Salt Pond and $1 \mathrm{~m}$ for Mattapoisett Marsh, respectively, at the peak wave period were considered. These threshold values were similar to offshore wave heights at the respective study areas during 1991's Hurricane Bob (Cheung et al., 2007). The average peak wave 
period and its standard deviation were used to produce a representative estimate of offshore wavelength for large storm events, which was then combined with maximum wave-induced run-up over the barrier, and then combined in equation (3) to obtain a value for significant offshore wave height, $H_{0}$. Wind speed $\left(U_{\text {wind }}\right)$, was determined based on its relationship with offshore wave height at the study site using SWAN model results for a suite of more than 300 synthetic storms, identified as producing $0.5 \mathrm{~m}$ of storm surge or more across New England. Similar to work by Ochi (2005), an empirical relationship between wind speed and SWAN-derived significant offshore wave height was determined for each site through linear regression (Fig. 5.4). For Salt Pond:

$$
U_{\text {wind }}=10.321 H_{0}
$$

For Mattapoisett Marsh:

$$
U_{\text {wind }}=13.907 H_{0}
$$

For a list of variables and values used in the inverse modeling, please see Table 5.1.

Through the use of Monte Carlo simulations, the model is able to consider the impacts of variability in a natural system. For example, inclusion of a $0.25-0.5 \mathrm{~m}$ error in the height of barrier $\left(b_{b}\right)$ takes into consideration the natural variation in barrier height, as well as the potential for the overwash to occur at different locations along the barrier. The same is true for the distance variable $\left(x_{L}\right)$, where variation in overwash location may result in a different distance from barrier to deposition location.

To confirm the model results, a combination of historic observations from the literature and SLOSH (Sea, Lake, and Overland Surges from Hurricanes) storm surge modeling (Jelesnianski et al., 1992) from Boldt et al. (2010) were used. Modeled SLOSH values were based on Best Track Reanalysis Data (Jarvinen et al., 1988) and reconstructions from historical records by Boose et al. (2001).

\subsection{Results}

\subsubsection{Grain-size analysis}

As discussed in Chapter 3, fifteen events were identified across three different cores from Salt Pond and sampled and analyzed for grain-size trends both spatially and temporally. Events from the core furthest from the barrier (SAP9) had consistently larger minimum and maximum grain sizes, a deviation from expected settling rates. This suggests that events recorded in the core further from the barrier may be influenced by other variables (e.g. wave breaking and erosion on back side of pond during event) and, as such, are not appropriate for application of this inverse modeling technique. Due to its high standard deviation and poor sorting, we exclude SAP9 and focus our analysis to events in the remaining two cores, which are further away from the back end of the pond (SAP1 and SAP8). 
Of those 15 events, the $\mathrm{D}_{90}$ values of 10 followed a landward- or marginally landward-fining trend. Five followed a landward- or marginally landward-coarsening trend (Fig 5.3a). Four historic events were identified in the cores (1991, 1938, 1675, and 1635; per Donnelly et al., 2015). Two historic events followed a landward-fining trend, one followed a landward coarsening trend, and one followed a marginally landward-coarsening trend. Of the 11 prehistoric events ( 1600-1400 CE and 600-500 $\mathrm{CE})$, eight events followed a landward-fining or marginally landward-fining trend, and three followed a landward-coarsening or marginally landward-coarsening trend.

As seen in Chapter 4, twelve events identified across three different cores from Mattapoisett were sampled and analyzed for spatial and temporal grain-size trends. Events from the cores furthest from the barrier (MAT'T7 and MATT8) consistently overestimate wind speeds by at least an order of magnitude, suggesting that their position behind the tidal creek may influence their sedimentation. Due to the location of the cores furthest from the barrier, only events from the core closest to the barrier (MATT6) were considered for analysis. Of those 12 events, the $\mathrm{D}_{90}$ values of six followed a landward-fining trend, five followed a landward-coarsening trend, and one event had similar grain sizes throughout the transect. Seven historic events were identified in the cores $(1991,1960,1954$, 1938, 1815, and 1635; per Boldt et al., 2010), of which all but the 1635 event followed a landwardfining trend. The 1635 event did not follow either trend, and the remaining five historic events ( 1600-800 CE) followed a landward-fining trend (Fig. 5.3b).

\subsubsection{Inverse modeling results}

Assessment of the updated inverse modeling technique is important, since using the original set of equations from Brandon et al. (2014) and Woodruff et al. (2008) with our grain-size data overestimate wind speeds by an order of magnitude (Fig. 5.5). For Salt Pond, inverse modeling of wind speeds from $\mathrm{D}_{90}$ values of storm-induced event beds in cores SAP1 and SAP8 produced results consistent with observed and estimated historic data. Storms ranged in intensity from tropical depression $(<17 \mathrm{~m} / \mathrm{s})$ to strong category 1 storm $(\sim 35 \mathrm{~m} / \mathrm{s})$ (Fig. 5.6a). This is consistent with observed wind speeds associated with major historic storms in the study location (Fig. 5.6a; Table 5.2). Results from 100,000-run Monte Carlo simulations propagated error in model inputs, with an average standard deviation of $7.7 \mathrm{~m} / \mathrm{s}$. Standard-deviation values for landward-fining events ranged from tropical depression $(<17 \mathrm{~m} / \mathrm{s})$ to strong category 2 storm $(\sim 49 \mathrm{~m} / \mathrm{s})$.

For Mattapoisett, inverse modeling of wind speeds from $\mathrm{D}_{90}$ values of storm-induced event beds in MATT6 produced results consistent with observed and estimated historic data from Boldt et 
al. (2010) and other sources. Best estimates of storms ranged in intensity from tropical storm ( 25 $\mathrm{m} / \mathrm{s}$ ) to category 3 storm ( $\sim 52 \mathrm{~m} / \mathrm{s}$ ) (Fig. 5.6b). This is also consistent with observed wind speeds associated with major historic storms in the study location (Fig. 5.6b, Table 5.2). Error was higher in this location, with an average standard deviation of $14.9 \mathrm{~m} / \mathrm{s}$. Standard-deviation values for landwardfining events ranged from tropical storm $(\sim 18 \mathrm{~m} / \mathrm{s})$ to a strong category 4 storm $(\sim 69 \mathrm{~m} / \mathrm{s})$.

\subsection{Discussion}

\subsubsection{Comparison to original inverse modeling technique}

The Woodruff et al. (2008) study reconstructed storm intensities relative to known historic deposits in a back-barrier lagoon system in Laguna Playa Grande, Vieques, Puerto Rico. Where Laguna Playa Grande is dominated by wave run-up (surge events largely $<1 \mathrm{~m}$ ), Salt Pond and Mattapoisett are more influenced by storm surge during intense storms (surge events largely $>1 \mathrm{~m}$ and $>2 \mathrm{~m}$, respectively). These differences in setting require site-specific adaptations (equations 3-5) to the advective-settling model. Our study expanded on the inverse modeling procedures of Woodruff et al. (2008) and Brandon et al. (2014) by using a series of synthetic storms to calibrate the model for offshore wave characteristics and wind speeds appropriate for Salt Pond. Since Salt Pond is sheltered from the open Atlantic Ocean by the island of Martha's Vineyard and Vineyard Sound, wave heights and wind speeds tend to be smaller than those recorded in the open ocean. The resulting windspeeds were largely consistent with observations from known historic storms, as will be discussed in the next section (Table 5.2).

Similar to Salt Pond, Mattapoisett Marsh is influenced by the geomorphology of Buzzards Bay (Boldt et al., 2010). Simulations of Hurricane Bob on Buzzards Bay by Cheung et al. (2007) provide insight into how Mattapoisett Marsh is vulnerable during hurricane strikes to the west of the site: though there is substantial sheltering and dispersion of wave energy that results in reduced wave height along the coast, there is also a focusing effect on the storm surge into Buzzards Bay when the front right quadrant of the hurricane impacts the site. Sediment reconstructions of wind speeds based on offshore wave characteristics influenced by these focusing effects result in values consistent with known historic storm intensities in eastern Massachusetts. SLOSH-modeled storm surges at Mattapoisett Marsh are also higher ( $>2 \mathrm{~m}$ ) than those at Salt Pond ( $>1 \mathrm{~m}$; Boldt et al., 2010). Generally, the wind speeds of historic storms were much higher at Mattapoisett Marsh than Salt Pond, potentially a result of the closer proximity of known hurricane impacts to the Mattapoisett site. 


\subsubsection{Comparison to historic storms}

Hurricane Bob made landfall as a category 2 hurricane on August 19, 1991, first on Block Island, and then in Newport, Rhode Island, approximately $60 \mathrm{~km}$ from Salt Pond and $50 \mathrm{~km}$ from Mattapoisett Marsh. NOAA buoy BUZM3, located in Buzzard's Bay approximately $35 \mathrm{~km}$ southwest of Salt Pond and Mattapoisett Marsh, reported maximum wind speeds of $34.5 \mathrm{~m} / \mathrm{s}$. Vallee and Dion (1998) reported windspeeds at Salt Pond between 29 and $34 \mathrm{~m} / \mathrm{s}$. SLOSH modeling returned wind speeds at Salt Pond of $\sim 47 \mathrm{~m} / \mathrm{s}$ Inverse modeling of the storm from the maximum grain size of the deposit in SAP1 returns a value of $30 \pm 13 \mathrm{~m} / \mathrm{s}$. Inverse modeling of the storm from the maximum grain size of the deposit in SAP8 returns a value of $36 \pm 14 \mathrm{~m} / \mathrm{s}$. For Mattapoisett Marsh, Vallee and Dion (1998) reported windspeeds during Hurricane Bob of between 34 and $38 \mathrm{~m} / \mathrm{s}$, and SLOSH modeling for the storm at Mattapoisett indicated a windspeed of $\sim 42 \mathrm{~m} / \mathrm{s}$ (Boldt et al., 2010). Inverse modeling of the storm from the maximum grain size of the deposit in MATT6 returns a value of 44 $\pm 15 \mathrm{~m} / \mathrm{s}$. Therefore, in most test cases observed wind values for Hurricane Bob fall within the reconstructed range derived from the resultant event deposits in the Salt Pond and Mattapoisett sites.

Hurricane Donna made landfall in Florida on September 10, 1960, as a category 4 hurricane. After traveling up the east coast, it made landfall in Long Island, New York, on September 12, 1960, as a category 2 hurricane (Dunn, 1961). SLOSH modeling by Boldt et al. (2010) determined peak windspeeds at Mattapoisett as $\sim 44 \mathrm{~m} / \mathrm{s}$. Inverse modeling of the storm from the maximum grain size of the deposit in MATT6 returns a value of $47 \pm 17 \mathrm{~m} / \mathrm{s}$, well within the modeled values.

In 1954, New England was hit by Hurricanes Carol and Edna. Hurricane Carol made landfall in Long Island, New York, on August 31, 1954, as a strong category 2 hurricane. Valle and Dion (1997) reported winds across eastern Massachusetts from 36-45 m/s. Hurricane Edna made landfall in eastern Massachusetts 11 days later as a weaker category 2 storm, tracking directly over Cape Cod with reported sustained winds from 34-42 m/s (Smith-Johnson, 2014). Given the close timing and proximity of landfall, it is not possible to determine which storm left the deposit in the Mattapoisett Marsh core-if not both. SLOSH modeling for the 1954 hurricanes resulted in peak winds speeds at Mattapoisett of $\sim 42 \mathrm{~m} / \mathrm{s}$. Inverse modeling of the storm from the maximum grain size of the deposit in MATT6 returns a value of $40 \pm 15 \mathrm{~m} / \mathrm{s}$, and is consistent with both observed values and SLOSH derived values for both of the major New England hurricanes of 1954.

The Great New England Hurricane of 1938 made landfall as a category 3 hurricane on September 21, 1938, first on Long Island, and then in Milford, Connecticut, approximately $200 \mathrm{~km}$ east from both Salt Pond and Mattapoisett. Though winds at landfall were $51 \mathrm{~m} / \mathrm{s}$, Myers and Jordan 
(1956) reported windspeeds at the more distal Salt Pond site of between 18 and $22 \mathrm{~m} / \mathrm{s}$. SLOSH modeling at Salt Pond returned wind speed values of $\sim 35 \mathrm{~m} / \mathrm{s}$. Inverse modeling of the storm from the maximum grain size of the deposit in SAP1 returns a value of $18 \pm 8 \mathrm{~m} / \mathrm{s}$, and are in agreement with observed values at Salt Pond during the event. Inverse modeling of the storm from the maximum grain size of the deposit in SAP8 returns a value of $35 \pm 9 \mathrm{~m} / \mathrm{s}$, higher than the observed values for the event but in agreement with modeled SLOSH values. Further to the west at Mattapoisett Marsh, Myers and Jordan (1956) reported windspeeds between 22 and $27 \mathrm{~m} / \mathrm{s}$ for the 1938 event, while SLOSH modeling by Boldt et al. (2010) derived a wind speed of $\sim 41 \mathrm{~m} / \mathrm{s}$ at the same site (Boldt et al., 2010). Inverse modeling of the storm from the maximum grain size of the deposit in MATT6 returns a value of $40.7 \pm 15 \mathrm{~m} / \mathrm{s}$, which is higher than the observed values (but still within the error range) and similar to the modeled values.

The Great September Gale of 1815 made landfall on September 23, 1815, in Long Island, New York, as an estimated category 3 hurricane (Ludlum, 1963). The storm, estimated to be similar to the Great New England Hurricane of 1938, devastated east-central Massachusetts, Weather reporters in New Bedford described a "tremendous gale" (Ludlum, 1963), and storm tides in New Bedford rose 3-4 m higher than usual (Jarvinen, 2006). Boose et al. (2001) assigned a majority of damage reports to Fujita scale 2 and 3-associated with sustained windspeeds from 36-62 m/s. SLOSH modeling results support windspeeds at Mattapoisett Marsh of $\sim 56 \mathrm{~m} / \mathrm{s}$ (Boldt et al., 2010). Inverse modeling of the storm from the maximum grain size of the deposit in MATT6 returns a value of $45 \pm 17 \mathrm{~m} / \mathrm{s}$, and thus consistent with SLOSH derived windspeeds for the 1815 event at the site. This deposit was not seen at Salt Pond, likely due to its more westerly track.

The New England Hurricane of 1675 hit coastal Connecticut, Rhode Island, and Massachusetts on September 7, 1675 (Ludlum, 1963). Similar to the Great Colonial Hurricane of 1635, Boose et al. (2001) identified that damage from the storm likely resulted from wind speeds ranging from 18 to $35 \mathrm{~m} / \mathrm{s}$. Inverse modeling of the storm from the maximum grain size of the deposit in SAP1 returns a value of $29 \pm 10 \mathrm{~m} / \mathrm{s}$. Inverse modeling of the storm from the maximum grain size of the deposit in SAP8 returns a value of $16 \pm 5 \mathrm{~m} / \mathrm{s}$. Both of these value ranges contain the observed values of the 1675 storm. The 1675 storm could not be delineated at Mattapoisett, given its lower resolution deposition rate than that of Salt Pond.

The Great Colonial Hurricane of 1635 devastated southeastern New England on August 26, 1635 (Jarvinen, 2006). The intensity of the storm is considered to be similar to the Great New England Hurricane of 1938, and modeled simulations of the storm were calibrated using known storm surge 
accounts in Providence, Rhode Island, and at the head of Buzzards Bay. The storm surge associated with the 1635 event at Salt Pond ranged between 2.4 and 3.0 m above mean sea level (Jarvinen, 2006). For comparison, the storm surge associated with the 1938 event at Salt Pond ranged between 2.6 and $3.5 \mathrm{~m}$ above mean sea level (Grossi et al., 2008), suggesting that the 1635 and 1938 storms had similar effects in the study region (i.e. from wind speeds $18-22 \mathrm{~m} / \mathrm{s}$ ). SLOSH modeling using best estimates for the 1635 storm indicated wind speeds at Salt Pond of $\sim 56 \mathrm{~m} / \mathrm{s}$. Inverse modeling of the 1635 storm from the maximum grain size of the resulting event deposit in SAP1 returns a value of $18 \pm 5$ $\mathrm{m} / \mathrm{s}$. Inverse modeling of the storm from the maximum grain size of the deposit in SAP8 returns a value of $18 \pm 6 \mathrm{~m} / \mathrm{s}$. Both of these value ranges are lower than SLOSH results, but still consistent with estimations in the literature. It is important to note that, despite the smaller wind speeds associated with the 1635 storm (as compared to other historic storms), the deposit associated with the storm was significantly larger than any other historic storm. This suggests that the storm deposited sand for a longer duration and, therefore, may have been more destructive overall. For the Mattapoisett Marsh location, modeled wind speeds from SLOSH were similar to the 1815 storm, at $\sim 56 \mathrm{~m} / \mathrm{s}$. Inverse modeling of the storm from the maximum grain size of the deposit in MATT6 returns a value of $50 \pm 20 \mathrm{~m} / \mathrm{s}$, also within the estimated wind speeds values for the storm in that location.

\subsubsection{Caveats and considerations}

The inclusion of site-specific modeling of offshore wave characteristics during a suite of synthetic storms provides an important way to account for differences in geologic settling. This improvement on the original technique has produced inverse-modeling results similar to historic observations/estimations, admittedly with large uncertainties (accounting for natural variation in the system, which contributes to uncertainties). Despite these uncertainties, mean wind speed values are remarkably similar to independently-obtained observations and numerical simulations of the same events. This suggests that the updated, site-specific model has tentative utility across a variety of different locations_-from runup-dominated back barrier lagoons (Woodruff et al., 2008) to surgedominated coastal ponds and marshes (this study). Despite this, the model still represents an oversimplification of the sediment sources and transport regimes present in the study areas such that derived storm intensities should always be viewed as an approximation, and whenever possible should be complimented/supported with additional information (e.g. historical records, numerical simulations, hydrodynamic models). 
The addition of location-specific values in this technique does aid in returning reasonable estimates of storm wind intensities from known storms, but it does not account for differences in shore geometry, which may produce anomalously large storm surges from lower wind speeds. It also does not take wind direction into consideration - a storm blowing in an offshore wind direction at its peak wind speed will not leave the same deposit as a storm blowing directly onshore at its peak wind speed. This is a potential explanation for the discrepancies between model results and model output from SLOSH simulations in the same location (Fig. 5.7).

Our study illuminates the importance of core location in reconstruction (Fig. 5.8). Though the Woodruff et al. (2008) model considers the settling of siliciclastic sediment more important than turbulent resuspension, there is a critical distance from the barrier at which this transition occurs, as well as a critical distance at which settling and deposition no longer occurs. Cores taken too close to the barrier may not display expected settling trends due to enhanced turbulence. Cores taken too far from the barrier may be more influenced by other factors, such as an increase in turbulence again via wave breaking on the back side of the pond and resultant resuspension. Basins with steep backside bathymetry are also vulnerable to gravity flows and turbidity currents not considered in the model, and cores taken from these areas may misrepresent storm intensity as such. For this reason, careful consideration of grain-size trends and local geomorphology is necessary to ensure that the cores used for analysis are indeed in an appropriate location for reconstruction.

For Salt Pond, events from the core furthest from the barrier consistently deviated from expected settling rates, with larger minimum and maximum grain sizes than the two cores closer to the barrier. Given this discrepancy and the close proximity of the core to the far side of the pond $(>100 \mathrm{~m})$, it is likely that deposition at this core location was influenced by sediment sourced from the pond edge and resuspension from waves propagating across the pond. Inverse modeling techniques for this location consistently overestimated wind speeds and, as such, this core location was not included in our analysis.

At Mattapoisett Marsh, three cores were taken along a transect that intersected a 2-5m tidal channel. Modeling of samples from the two cores located behind the tidal channel also consistently overestimated wind speeds. The geomorphology of the marsh suggests that these two cores, located both further from the barrier and bordered on the south and west by an established tidal channel, may be influenced more by the channel than direct overwash and deposition from the barrier. In both cases, a critical look at the grain-size settling trends and geomorphology of the surrounding area were necessary to choose core locations appropriate for the inverse modeling procedure. 
Though our model of inundation and overwash regimes in these settings assumes that the majority of the sediment deposited during surge/runup events is sourced directly from the adjacent barrier, landward-coarsening deposits at both Salt Pond and Mattapoisett Marsh deviate from expected landward-fining sediment-transport trends. This suggests a change in sediment source, whether that be aeolian transport of sand during a storm (Rodriguez et al., 2013), sediment sourced from pond or channel edges, or turbulence and resuspension during deposition (Booth et al., 2000; Carper \& Bachmann, 1984; Luettich et al., 1990).

There are characteristics of sediment deposition in a salt marsh in particular that may not be accurately reflected in the original model. The model is based on settling velocity equations appropriate to deposition in a coastal pond or lagoon, where sediment transported over the barrier would be deposited into a body of water. From there, the sediment can settle to the bottom of the basin in accordance with standard grain-size settling velocity relationships (e.g. Ferguson and Church, 2004). The ability of salt marsh vegetation to trap sediment, however, is well-documented (Fagherazzi et al., 2012; Gleason et al., 1979). Overwash may cause sediment to be deposited directly onto the marsh surface, where friction and increased drag from the marsh vegetation may trap sediment earlier than anticipated by the model (Christiansen et al., 2000; Fagherazzi et al., 2012; Leonard \& Luther, 1995; Nepf, 2012; Yang et al., 2015).

Given the surge-dominated environments of the study sites, it is also important to consider how a complete inundation of the barrier may influence sediment transport dynamics. Modeling of the effects of Hurricane Bob on southern New England suggests that Mattapoisett, along with other areas in Buzzards Bay, may have experienced an inundation regime during Hurricane Bob (Cheung et al., 2007), where the storm surge alone is greater than the height of the barrier (C. Donnelly et al., 2006). Modeled storm surge estimates for Mattapoisett during Hurricane Bob exceeded 2.5-3 m (Boldt et al., 2010; Cheung et al., 2007), which is above the Lidar-recorded barrier height of 1-2.5 m. Extreme inundation effectively negates the influence of the barrier, since a sheet of water and sediment can flow unimpeded over the barrier, depositing sediment through porosity and friction losses (C. Donnelly et al., 2006). The advective-settling model is built around the assumption that the majority of the sediment is transported during a wave-dominated regime and as such does not consider surgea major shortcoming for modeling intensity in these surge-dominated study locations.

The model also does not take into consideration potential changes in the barrier over timewhether changes in width or distance from the core site. Barrier migration is controlled largely by two primary factors: sea level change and sediment budget (Curray, 1964), and overwash in particular 
contributes to migration by removing sediment at the front of the barrier and depositing it landward (C. Donnelly et al., 2006). Barrier transgression would typically result in an artificial increase in derived storm intensities over time, as the advective distance (equation 2) decreases. Migration is common in almost all barrier-dominated systems, increasingly complicating the interpretation of model results particularly for paleo-deposits where barrier morphology is not known.

Many of the processes mentioned, if in play in these study sites, would produce lower-thanactual intensities from our updated inverse modeling technique. Resuspension, turbulence, and aeolian transport would likely result in lower mean $\mathrm{D}_{90}$ values through introducing or reworking smaller grains into the deposits. Vegetation influence would result in larger grains deposited closer to the barrier, also producing smaller intensities when considered in our model. In all of these cases, event grain size characteristics are likely limited by the grain sizes available to transport, which may vary both seasonally and over time. As such, if no coarse sediment exists to transport or resuspend, then the inverse modeling technique will return anomalously low intensities. This has particularly interesting implications for use in risk assessments, since these estimates may in fact represent a lower bound of storm intensity in the area.

\subsection{Conclusions}

The improved inverse modeling technique presented here produces results consistent with historic values and estimates for both coastal pond and back-barrier marsh settings. Sensitivity of the model to natural variations in the system, including height of and distance from the barrier result in sizeable error bars; however, in general median derived storm intensities from resultant storm deposits are similar to independent values obtained via observations and numerical simulations for historical events. Understanding trends in storm event deposition is imperative to developing an accurate and effective approach for inversely modeling the intensity of the storm from the maximum grain size of its deposit. An expansive, whole-site approach aids in choosing suitable cores for analysis. It also aids in considering what may be left out of a more traditional analysis of one event from one core in one location. The addition of location-specific modeling of offshore wave characteristics better accounts for local variation in storm properties. While the uncertainties in the model are still large, calibration of the model to known storms in known locations allows for a sense of relative, if not absolute, storm intensity from prehistoric deposits. This has implications for the technique's utility in policy-based applications, which are also largely location-specific. 


\subsection{Figures and tables}

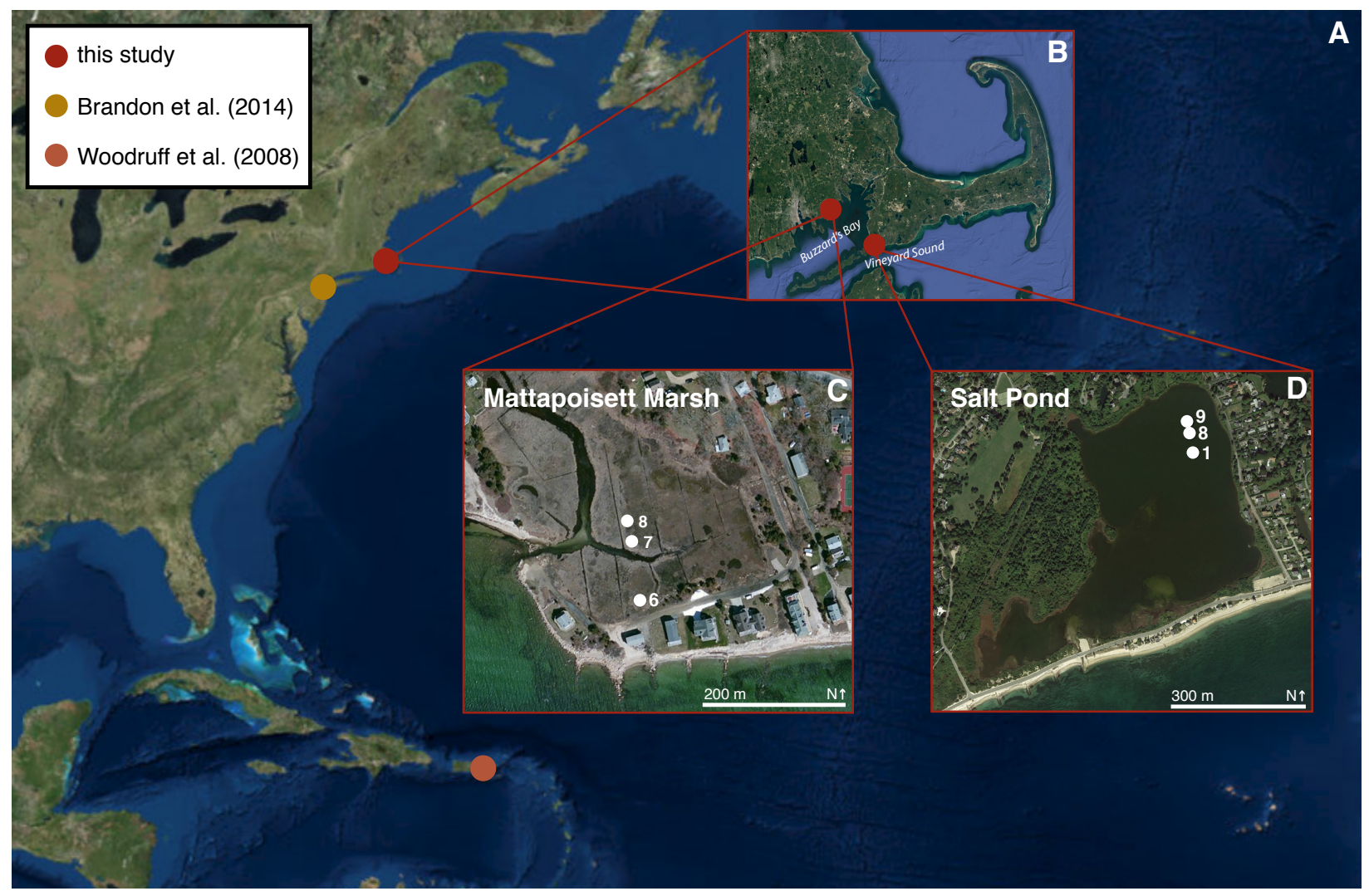

Figure 5.1 Maps of locations analyzed in this study, in addition to sites used for previous inversemodeling work.

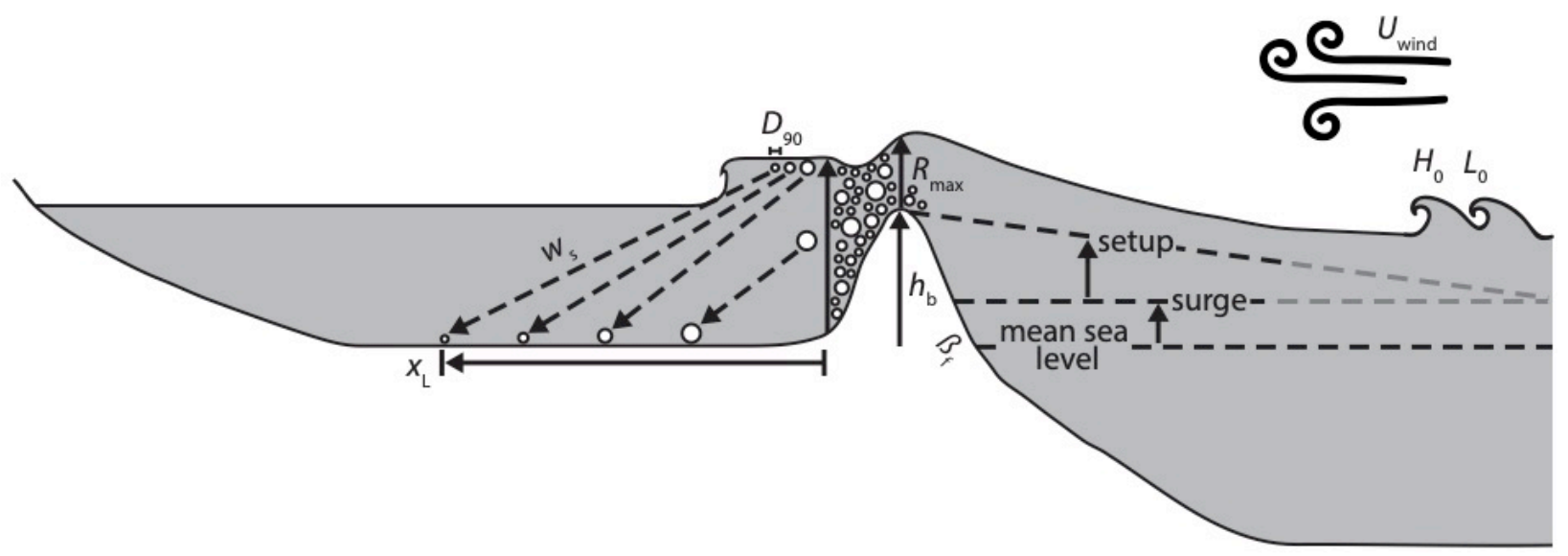

Figure 5.2 Updated inverse-modeling schematic with variables indicated (modified from Woodruff et al., 2008). 

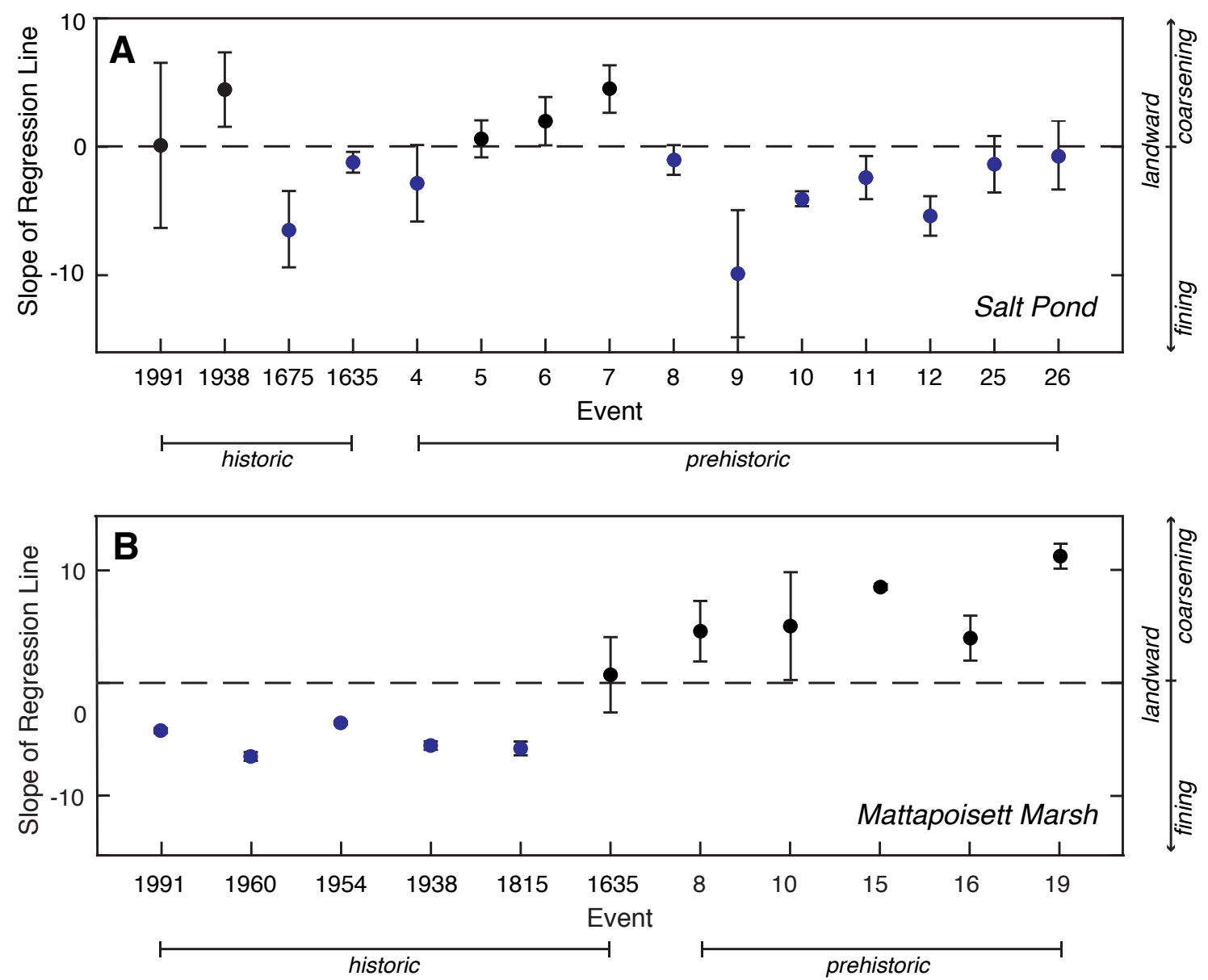

Figure 5.3 Regression analysis for A) Salt Pond, and B) Mattapoisett Marsh. Blue circles indicate a landward-fining trend, consistent with the assumptions of the inverse modeling equations. 

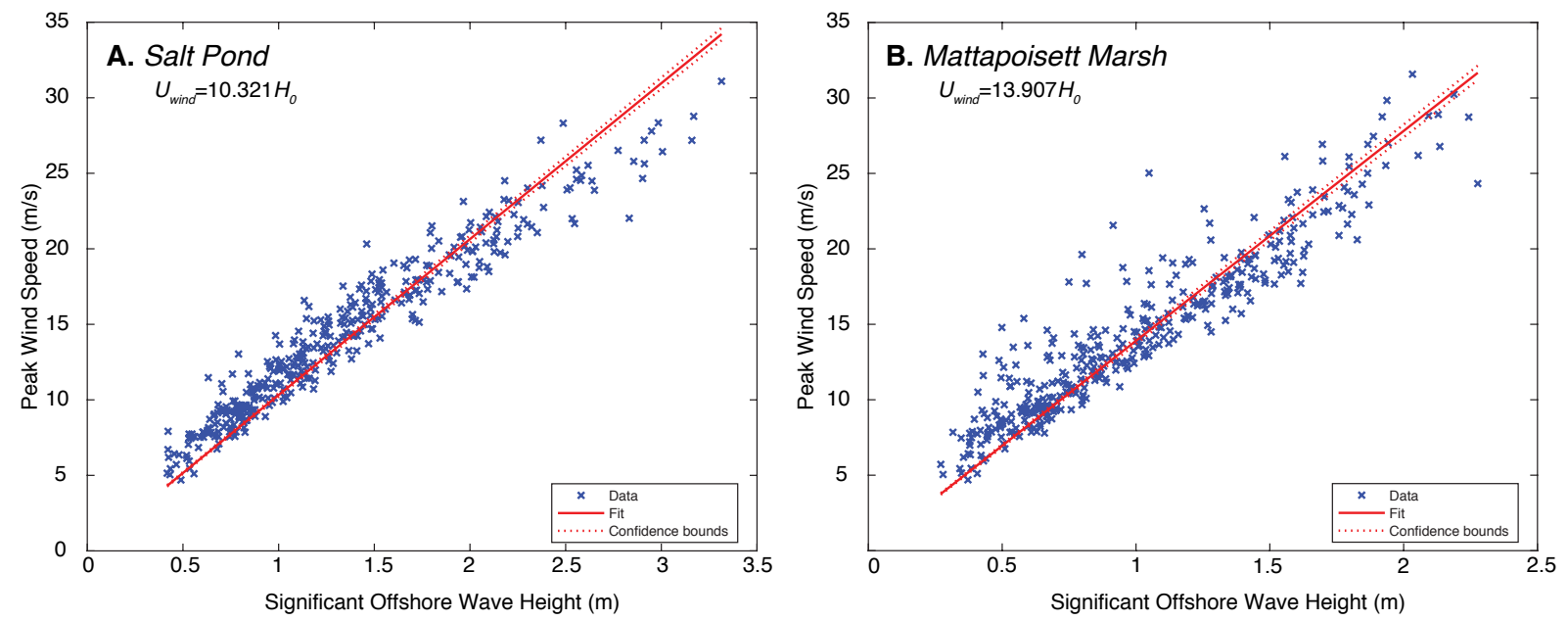

Figure 5.4 Linear regressions between peak wind speed and significant offshore wave height for synthetic storms. These regressions were used to determine the location-specific relationship between offshore wave height and windspeed for each storm. 

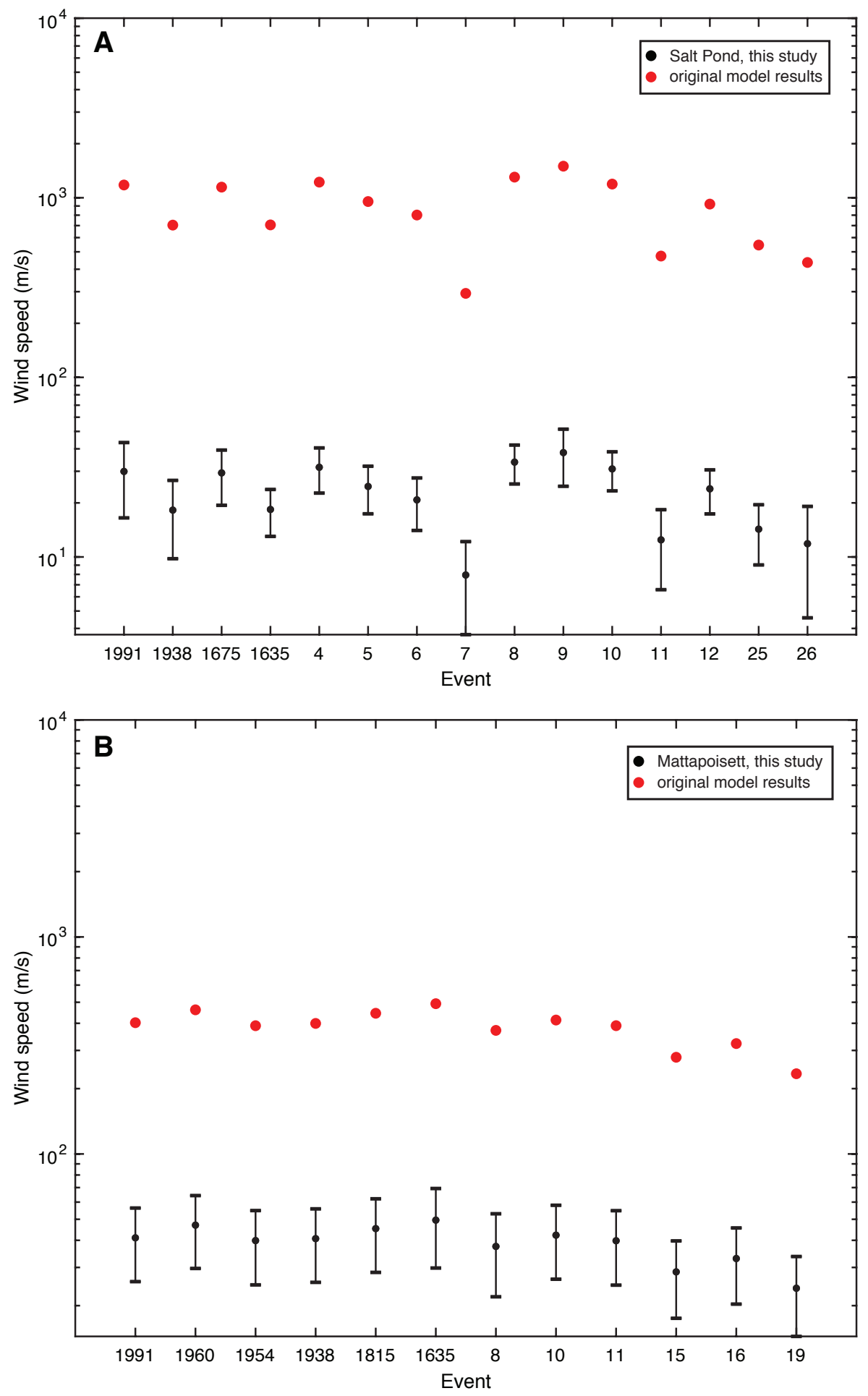

Figure 5.5 Comparison of the inverse modeling technique proposed by Brandon et al. (2014) and Woodruff et al. (2008) with the updated inverse modeling technique from this study. As seen, the original technique overestimates wind speeds by an order of magnitude. A) Results for Salt Pond core, SAP1. B) Results for Mattapoisett Marsh core, MATT6. 

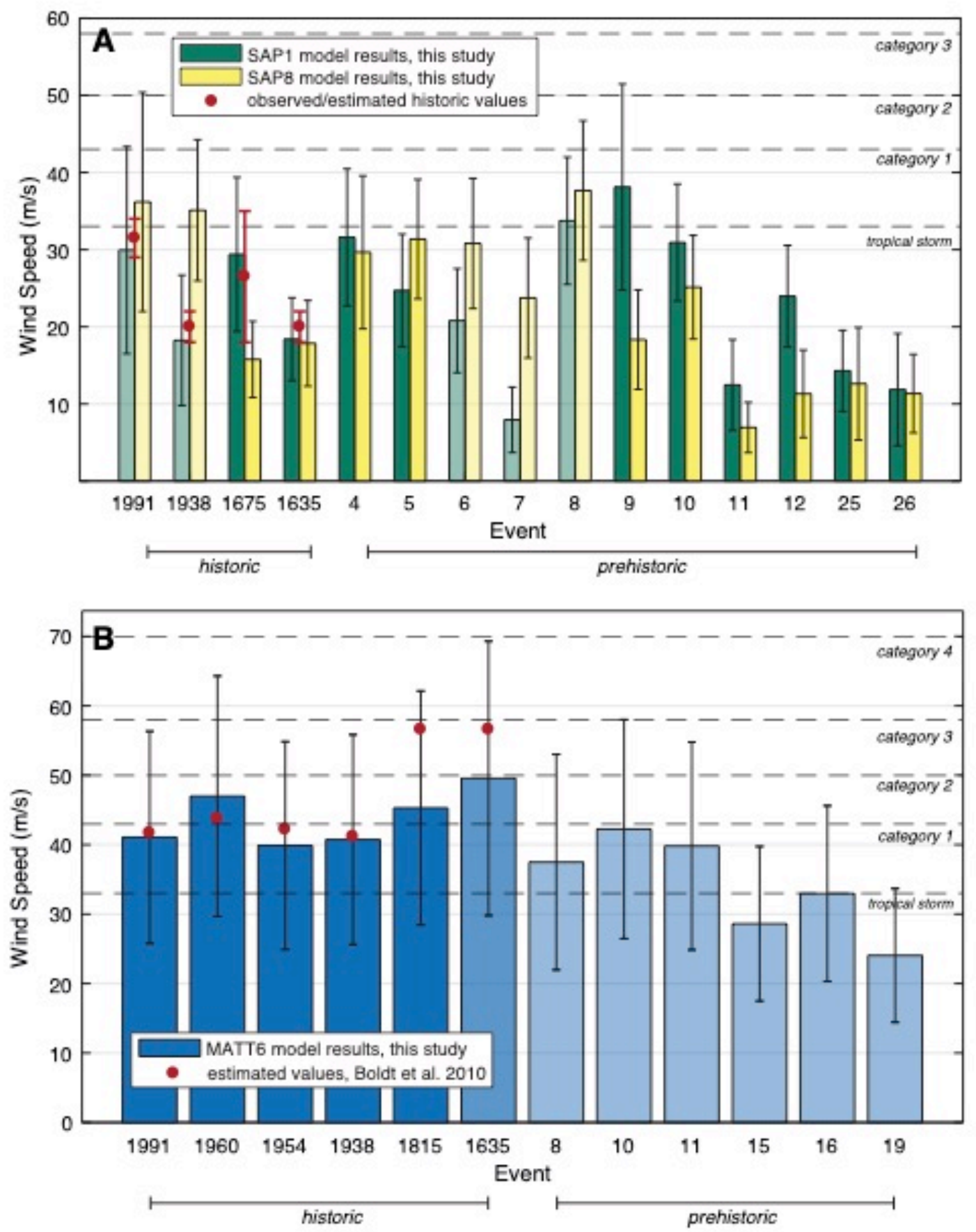

Figure 5.6 Modeled storm wind speeds for events from A) Salt Pond and B) Mattapoisett Marsh. Observed/estimated historic wind speeds for each location indicated in red. Darker bars indicate event deposits that fine landward. 


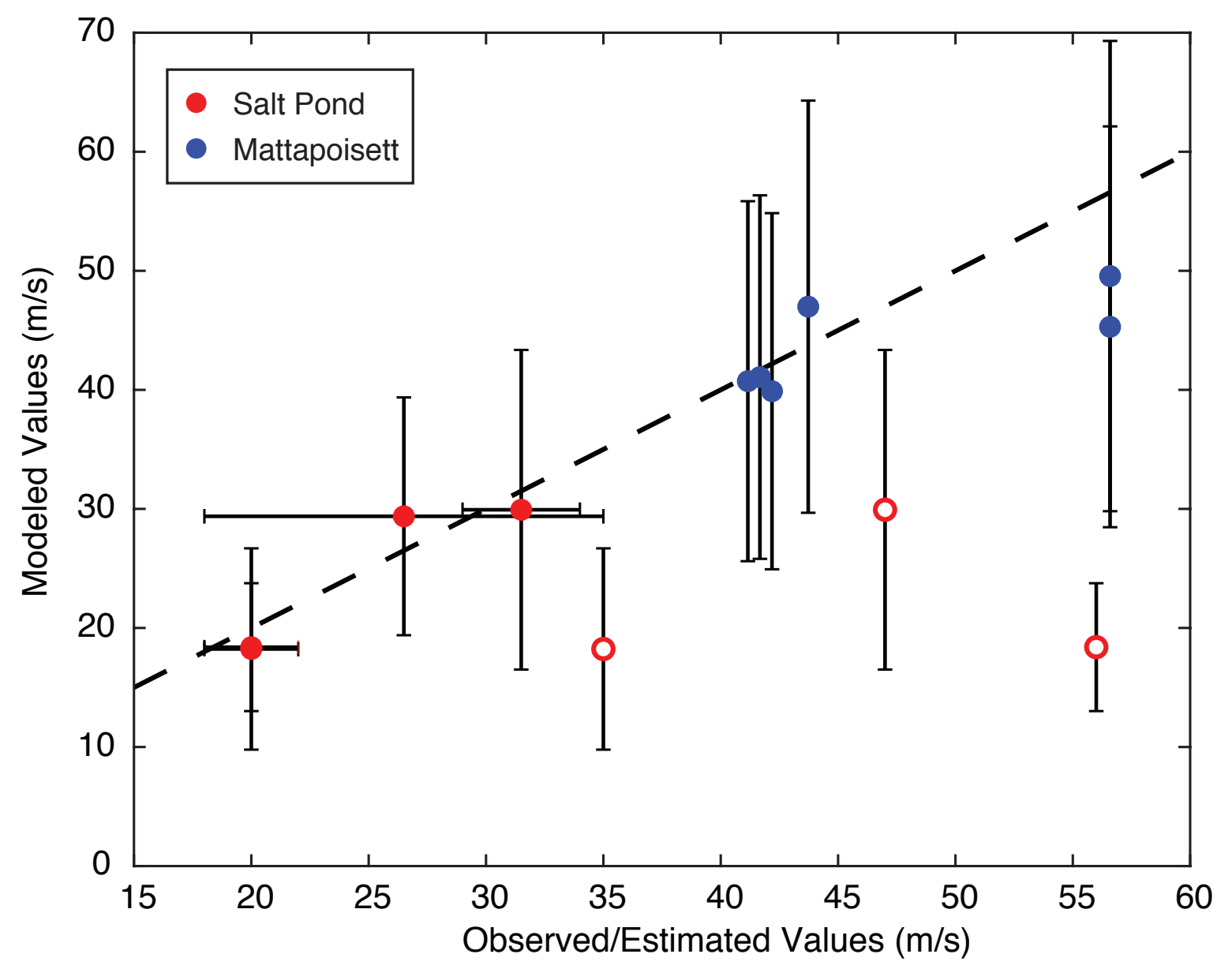

Figure 5.7 Comparison of modeled and observed/estimated values for historic storms from Salt Pond (SAP1, red) and Mattapoisett (Matt6, blue). Open red circles plot inverse model values with SLOSH model output for Salt Pond. Results are plotted against each other; the 1:1 relationship is indicated by the dashed line. 


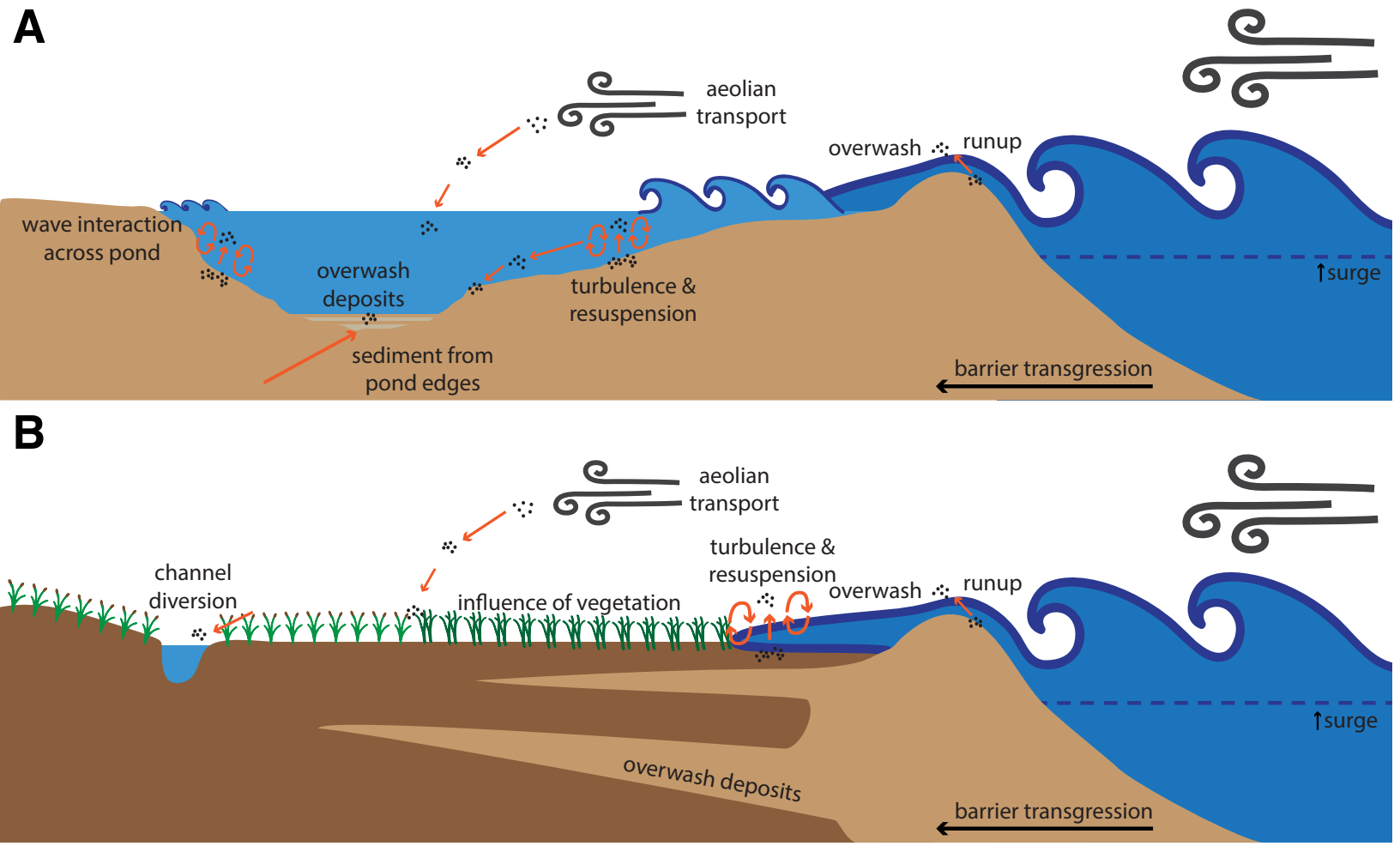

Figure 5.8 Potential other sources of deposition and concerns for the inverse modeling technique as applied at A) Salt Pond and B) Mattapoisett Marsh.

Table 5.1 Constants in inverse modeling equations.

\begin{tabular}{|l|l|l|l|}
\hline \multicolumn{5}{|l|}{ Salt Pond } & Mean & Standard Deviation & Units \\
\hline Variable & 0.75 & 0.5 & $\mathrm{~m}$ \\
\hline height of barrier & 360 & 10 & $\mathrm{~m}$ \\
\hline distance from barrier, SAP1 & 420 & 10 & $\mathrm{~m}$ \\
\hline distance from barrier, SAP8 & 6.413 & 0.457 & $\mathrm{~s}$ \\
\hline offshore period (wave height $>3 \mathrm{~m}$ ) & 30 & 1 & degrees \\
\hline beach slope & \multicolumn{5}{|l|}{} \\
\hline Mattapoisett Marsh & Mean & Standard Deviation & Units \\
\hline Variable & 1.5 & 0.25 & $\mathrm{~m}$ \\
\hline height of barrier & 50 & 10 & $\mathrm{~m}$ \\
\hline distance from barrier, MATT6 & 4.896 & 0.596 & $\mathrm{~s}$ \\
\hline offshore period (wave height $>1 \mathrm{~m})$ & 19 & 1 & degrees \\
\hline beach slope &
\end{tabular}


Table 5.2 Model results.

Salt Pond

\begin{tabular}{|c|c|c|c|c|c|c|}
\hline Event & $\begin{array}{l}\text { SAP1 Wind } \\
\text { Speed }(\mathrm{m} / \mathrm{s})\end{array}$ & $\begin{array}{l}\text { SAP1 Standard } \\
\text { Deviation }(\mathrm{m} / \mathrm{s})\end{array}$ & $\begin{array}{l}\text { SAPS Wind } \\
\text { Speed }(\mathrm{m} / \mathrm{s})\end{array}$ & $\begin{array}{l}\text { SAP8 Standard } \\
\text { Deviation }(\mathrm{m} / \mathrm{s})\end{array}$ & Historic Storm & $\begin{array}{c}\text { Observed/Estimated Wind } \\
\text { Speed }(\mathrm{m} / \mathrm{s})\end{array}$ \\
\hline 1 & 29.9 & 13 & 36.2 & 14 & 1991 & $\begin{array}{c}29-34 \\
\text { Valle and Dion (1998) }\end{array}$ \\
\hline 1938 & 18.2 & 8 & 35.1 & 9 & 1938 & $\begin{array}{c}18-22 \\
\text { Meyers and Jordan (1956) }\end{array}$ \\
\hline 2 & 29.4 & 10 & 15.8 & 5 & 1675 & $\begin{array}{c}18-35 \\
\text { Boose et al. (2001) }\end{array}$ \\
\hline 3 & 18.4 & 5 & 17.9 & 6 & 1635 & $\begin{array}{c}18-22 \\
\text { Jarvinen (2006) }\end{array}$ \\
\hline 4 & 31.6 & 9 & 29.6 & 10 & & \\
\hline 5 & 24.7 & 7 & 31.4 & 8 & & \\
\hline 6 & 20.8 & 7 & 30.8 & 8 & & \\
\hline 7 & 7.9 & 4 & 23.7 & 8 & & \\
\hline 8 & 33.7 & 8 & 37.7 & 9 & & \\
\hline 9 & 38.1 & 13 & 18.3 & 6 & & \\
\hline 10 & 30.9 & 8 & 25.1 & 7 & & \\
\hline 11 & 12.5 & 6 & 6.9 & 3 & & \\
\hline 12 & 24.0 & 7 & 11.3 & 6 & & \\
\hline 25 & 14.3 & 5 & 12.6 & 7 & & \\
\hline 26 & 11.9 & 7 & 11.3 & 5 & & \\
\hline
\end{tabular}

Mattapoisett Marsh

\begin{tabular}{|c|c|c|c|c|}
\hline Event & $\begin{array}{l}\text { Wind Speed } \\
(\mathrm{m} / \mathrm{s})\end{array}$ & $\begin{array}{c}\text { Standard } \\
\text { Deviation }(\mathrm{m} / \mathrm{s})\end{array}$ & Historic Storm & $\begin{array}{l}\text { Estimated Wind Speed } \\
\qquad(\mathrm{m} / \mathrm{s}) \\
\text { from Boldt et al. }(2010)\end{array}$ \\
\hline 1 & 41.1 & 15 & 1991 & 42 \\
\hline 2 & 47.0 & 17 & 1960 & 44 \\
\hline 3 & 39.9 & 15 & 1954 & 42 \\
\hline 4 & 40.7 & 15 & 1938 & 41 \\
\hline 5 & 45.3 & 17 & 1815 & 57 \\
\hline 7 & 49.6 & 20 & 1635 & 57 \\
\hline 8 & 37.5 & 16 & & \\
\hline 10 & 42.2 & 16 & & \\
\hline 11 & 39.8 & 15 & & \\
\hline 15 & 28.6 & 11 & & \\
\hline 16 & 33.0 & 13 & & \\
\hline 19 & 24.1 & 10 & & \\
\hline
\end{tabular}




\title{
6. Impacts of hurricane events on form and function of a Connecticut salt marsh
}

\begin{abstract}
Salt marshes have long been considered sources of coastal protection, acting as buffers to storm surges, wind-generated waves, and elevated water levels. In the northeastern United States, salt marshes have kept pace with moderate sea-level rise, and augmented sedimentation from mild-tomoderate storms contributes to their resilience. Recent geological evidence, however, suggests that periods of extreme storm frequency or intensity may cause significant marsh platform erosion in some locations. This has major implications for coastal inundation risk to lives and property, as well as the resilience of these coastal wetlands to a changing climate. This study investigates a stratigraphic sequence in a salt marsh in Niantic, CT, associated with an erosional unconformity and a 600-year sedimentary hiatus, followed by a period of recovery and a change in vegetation. van de Plassche et al. [Geology, 34(10), 829-832 (2006)] originally hypothesized that this widespread, expansive erosional sequence was a result of the 1635 Great Colonial Hurricane. This study tests this hypothesis through in-depth sedimentologic and chronologic methods. Extensive radiocarbon dating and stratigraphic exploration confirms the presence of the hiatus, which is associated with a significant coarse-lag deposit. This is likely the result of one or several intense hurricanes impacting the area between 1400 C.E. and 1675 C.E., since a continuous core from the same transect records several hurricane deposits during the same period as the hiatus. Sediment cores in this location also document mud and sand deposits associated with historic hurricanes, including 1954 and 1938, among others. The pervasive erosion seen at this site may mark a departure from our current understanding of salt marsh evolution, form, and function. This is of particular importance as intense hurricanes, augmented by rising sea levels, are expected to pose a greater threat of property damage and loss of life over the next century.
\end{abstract}




\subsection{Introduction}

In 2006, van de Plassche et al. posited that intense storms may be responsible for a curious stratigraphic sequence found in Pattagansett Marsh, Niantic, CT. Through extensive coring of the marsh, the authors identify an approximately 900 -year hiatus associated with a widespread portion of the marsh that appears to be quickly infilled with tidal mud, which then transitions to low and high marsh peat - a small-scale complete transition from original marsh system to mud flat to marsh system. The authors dated the hiatus along one transect to the mid-seventeenth century, consistent with the timing of the 1635 Great Colonial Hurricane. Despite limited replication in other New England salt marshes (van de Plassche et al., 2004) and lack of a modern analog, the authors ruled out the influence of a variety of factors known to cause erosion in salt marshes, including an increase in tidal range (Long et al., 2006), gradual migration of tidal channels (Stumpf, 1983), background rates of marsh-cliff retreat (McLoughlin et al., 2015), marsh pond formation (Wilson et al., 2009), and changes in sea level (Schwimmer \& Pizzuto, 2000).

Here, we test the hypothesis presented by van de Plassche et al. (2006) that erosion and subsequent recovery from the Great Colonial Hurricane of 1635 were responsible for the unique, widespread hiatus and stratigraphic sequence in Pattagansett River Marsh. If the van de Plassche et al. hypothesis is valid, we would expect other evidence of high-energy events, such as coarse-lag deposits associated with the hiatus or depositional evidence (e.g., sand layers) in uneroded portions of the marsh. Stratigraphic, radiocarbon, and coarse-fraction analysis of new sediment cores taken along the same primary transect as van de Plassche et al. (2006) suggest that this expansive hiatus is indeed replicable and correlated with a high-energy event between 1400 C.E. and 1675 C.E., though the stratigraphic sequence we recovered differs in some ways from van de Plassche et al.'s interpretations. Given the storm-buffering capacity of salt marshes and their tendency to accumulate sediment during storms (Castagno et al., 2018), the pervasive erosion seen at this site may mark a departure from our current understanding of Redfield (1972)'s model of salt marsh evolution, form, and function. This is of particular importance as intense hurricanes, augmented by rising sea levels, are expected to pose a greater threat of property damage and loss of life over the next century (Sobel et al., 2016; Walsh et al., 2016; Woodruff et al., 2013). 


\subsection{Data and methods}

\subsubsection{Study area and field methods}

The study area is located in the inland portion of the Pattagansett River Marsh, in Niantic, CT $\left(41.31618^{\circ} \mathrm{N}, 72.21503^{\circ} \mathrm{W}\right)$. The 64 -acre marsh is connected to Long Island Sound via the Pattagansett River (Fig. 6.1). Located too far upstream ( $2 \mathrm{~km})$ for storm waves to leave overwash deposits directly by overtopping a sandy barrier (Boldt et al., 2010; Donnelly et al., 2001a), deposition from storms largely occurs from storm surge flooding and overtopping the tidal creek banks. Marsh vegetation is largely high-marsh Spartina patens and Distichlis spicata, with some areas of tall- and shortform Spartina alterniflora. The area is separated from a residential area by a thick stand of Phragmites. The marsh has several shallow ponds and was anthropogenically ditched prior to the mid-twentieth century, likely for mosquito control or salt marsh haying (Griswold et al., 1975).

Following the extensive mapping by van de Plassche et al. (2006), this study replicated the transect suggested to have the most pervasive erosional sequence (Transect C). This $\sim 150-\mathrm{m}$ transect extends from the Pattagansett River channel on the southeast to the Phragmites stand separating the marsh from the residential area on the northwest. In this transect, van de Plassche et al. (2006) identified an erosional contact $\sim 75 \mathrm{~cm}$ deep, which dated from 1640-1670 C.E. This erosional contact was marked by a single layer of tidal mud ( 10-15 cm thick) at its base, topped by a low-marsh peat layer ( $\sim 50 \mathrm{~cm}$ thick), and then a transition to high-marsh peat (Fig. 6.1). After a series of reconnaissance cores using a 1-m-long core auger and a 0.5-cm-long Russian corer, five locations along the transect were chosen for vibracores (Fig. 6.1). The vibracores ranged from $1.75 \mathrm{~m}$ to $>3 \mathrm{~m}$ with $<20 \mathrm{~cm}$ of compression.

\subsubsection{Lab methods}

Cores were split, photographed, and described in the lab. Distinctions between high and low marsh were determined through visual analysis of plant assemblages within the core (Niering \& Warren, 2006; Richard A. Orson et al., 1987; Warren \& Niering, 1993). To further test the hypothesis of van de Plassche et al. (2006), two cores were chosen for additional organic and coarse fraction analysis, one with the hiatus sequence (C15, $\sim 50 \mathrm{~m}$ from the channel), and one with continuous deposition (C20; 15m from the channel). The amount of organic content throughout the cores can be used to further distinguish among high marsh, low marsh, and event layers, with lower organic percentages indicating more minerogenic input from tidal inundation (Donnelly \& Bertness, 2001). Both cores were sampled at $1-\mathrm{cm}$ resolution, after which samples were combusted at $550^{\circ} \mathrm{C}$ for 1.5 
hours to determine organic loss on ignition (LOI; Dean, 1974) The remaining ash was then sieved at $63 \mu \mathrm{m}$, the distinction between very fine sand and silt. Coarse fraction of each sample was determined by comparing the sieved weight of the sample to its original dry weight.

Two different methods were used to determine ages of storm event deposits and the hiatus. Peaks in ${ }^{137} \mathrm{Cs}$ activity within the cores are the result of global fall-out from nuclear weapons testing, which began in 1954 and peaked at 1959 and 1963 C.E. (Dunphy \& Dibb, 1994). The first $50 \mathrm{~cm}$ of both cores were sampled using a high-resolution Canberra gamma detector to determine ${ }^{137} \mathrm{Cs}$ activity. Thirteen radiocarbon dates were obtained from vegetation preserved within the cores. These dates were obtained using accelerator mass spectrometry (AMS) radiocarbon techniques at the National Ocean Sciences Accelerator Mass Spectrometer (NOSAMS) facility at Woods Hole Oceanographic Institution (WHOI). Age models and 95\% uncertainties were developed using Bacon (Bayesian accumulation histories for deposits) software (Blaauw \& Christen, 2011). Sea, Lake, and Overland Surges from Hurricanes (SLOSH), a regional-scale surge model, was used to determine storm surge levels at the mouth of the Pattagansett River for several known historic storms (Jelesnianski et al., 1992), using the same storm tracks as those used in Boldt et al. (2010).

\subsection{Results}

\subsubsection{Event stratigraphy and chronology}

The study transect revealed three distinct components of the marsh: visible historical sand layers within S. patens-rich high marsh at the top of the core, a section of S. alterniflora-rich low marsh atop two distinct sandy mud layers in the middle, and transition from high marsh through low marsh to sandy tidal mud at the base (Fig. 6.2). These components are replicated throughout the four study cores furthest from the channel to the southeast. The core closest to the channel (C20) lacks the lowmarsh and mud sequence and instead has a series of four distinct sandy mud layers.

The upper $\sim 20 \mathrm{~cm}$ of the marsh contain a visible layer of sandy organic-rich peat $(15-20 \mathrm{~cm}$ in depth in both C15 and C20). This layer corresponds to two peaks in coarse fraction in both C15 and C20 (Fig. 6.3). ${ }^{137}$ Cs dating (Fig. 6.3) and the Bacon age model (Fig. 6.4) indicate that these peaks are date with 95\% confidence between 1952-1959 C.E. (mean 1955 C.E.) and 1922-1947 C.E. (mean 1931 C.E.), respectively. These visible coarse layers were not indicated in the original stratigraphy presented by van de Plassche et al. (2006). Similar to Donnelly et al. (2015), coarse anomaly of the samples was also determined to filter out multiyear variability. This was accomplished by subtracting an 11-year moving average from the coarse fraction dating, excluding values greater than $5 \%$. This technique 
revealed at least three more anomalous peaks in coarse fraction in both cores. These peaks were dated at 95\% confidence between 1967-2014 C.E. (median 1994 C.E.), 1736-1889 C.E. (mean 1821 C.E.), and 1615-1780 C.E. (median 1644 C.E.).

The distinct sandy-mud layers in the middle of the marsh range from $\sim 70 \mathrm{~cm}$ to $\sim 135 \mathrm{~cm}$ in depth across all cores (Fig. 6.2). In cores with the hiatus present, there are two distinct layers associated with peaks in coarse fraction and troughs in organic percentage (Fig. 6.3), These layers date from $~ 900$ C.E. to 1200 C.E. The core furthest from the channel has only one mud layer, suggesting a pinchingout of these event deposits. The continuous core, C20, has four distinct mud layers, also associated with peaks in coarse fraction and troughs in organic percentage. These layers date from $\sim 900$ C.E. to $\sim 1400$ C.E.

Three major peaks in coarse anomaly in the lower core (after the sandy mud layers) are found in and correlated across both study cores. These peaks date to roughly 700 C.E. to $\sim 900$ C.E. The transition to tidal mud in the continuous core closer to the channel (C20) occurs by $190 \mathrm{~cm}$, which dates to $\sim 500$ C.E. The transition to tidal mud in the core with the hiatus (C15) occurs by $165 \mathrm{~cm}$, which dates to $\sim 350$ C.E.

\subsubsection{Hiatus stratigraphy and chronology}

Extensive radiocarbon dating of plant material above and below the sandy-mud layers in three separate cores along the transect confirm the presence of an erosional unconformity and a 600-year sedimentary hiatus throughout the marsh (Fig. 6.2). This erosional unconformity occurs $\sim 78 \mathrm{~cm}$ deep in $\mathrm{C} 15$, and is topped by $\sim 10 \mathrm{~cm}$ of $S$. alterniflora-rich sediment. We constrain the date of the erosional unconformity by dating the first recolonization of marsh flora ( $S$. alterniflora), assuming that recolonization of the sediment occurred quickly after erosion. The erosional unconformity thus dates between the mid-sixteenth and mid-seventeenth centuries (based on radiocarbon calibration curves, between 1523 C.E. to 1571 C.E. or between 1630 C.E. to 1653 C.E.). Interestingly, the hiatus is not associated with the sandy-mud layers visible in the core, as suggested by van de Plassche et al. (2006), as the sandy-mud layers consistently date prior to 1200 C.E. The hiatus is, however, associated with a significant peak in coarse fraction in C15, thought to be a coarse-lag deposit from a high-energy event. During the $\sim 10 \mathrm{~cm}$ recovery period in C15, there are no peaks in coarse fraction or anomaly other than the peak at $\sim 78 \mathrm{~cm}$. Given correlations in the age model, it is thought that the hiatus encompasses $\sim 600$ years, during which at least nine separate hurricane-induced peaks in coarse fraction anomaly are found in the continuous core (Fig. 6.5). 


\subsection{Discussion}

\subsubsection{Attribution of event layers}

Given their temporal proximity to many known storms and similarity to other deposits in the area (Boldt et al., 2010; Donnelly et al., 2001a), we suggest that the peaks in sand content throughout the core represent periods of overwash and flooding from the adjacent channel due to increased storm surge during a hurricane. The first peak in coarse fraction is at $5.5 \mathrm{~cm}$ in $\mathrm{C} 15$, dated at $95 \%$ confidence as between 1967-2014 C.E., with a mean value of 1994 C.E. Because this peak is relatively small in coarse-fraction (Fig. 6.3) but significant in its anomaly (Fig. 6.5), we attribute it to Hurricane Bob (1991). Hurricane Bob made landfall in 1991 as a category 2 storm $\sim 55 \mathrm{~km}$ to the east in Rhode Island. SLOSH modeling of the storm indicates that Hurricane Bob generated the smallest surge of the modeled storms, with a surge of $1.4 \mathrm{~m}$ at the mouth of the Pattagansett River, associated with a $2 \mathrm{~m}$ difference between maximum and minimum surge (Fig. 6.6).

The two visible sand layers (between $15-20 \mathrm{~cm}$ in C15 and C20) date with 95\% confidence between 1952-1959 C.E. (mean 1955 C.E.) and 1922-1947 C.E. (mean 1931 C.E.), respectively. In 1954, Hurricane Carol made landfall as a strong category 2 hurricane in Long Island, New York, 60 $\mathrm{km}$ southwest of Pattagansett Marsh. SLOSH modeling of the storm returns a storm surge of $2.8 \mathrm{~m}$ at the mouth of the Pattagansett River ( $4 \mathrm{~m}$ total change in surge), substantially higher than that of Hurricane Bob. In 1938, the Great New England Hurricane made landfall as a category 3 hurricane,

first on Long Island, and then in Milford, Connecticut, $\sim 70 \mathrm{~km}$ west of the study area. SLOSH modeling returns a storm surge of $3.2 \mathrm{~m}$ (4.2m total change in surge). Given these substantial surges and their temporal proximity to peaks in both coarse fraction and coarse-fraction anomaly, we attribute these two events to hurricanes in 1954 and 1938.

The Great September Gale of 1815 made landfall on in Long Island, New York, as an estimated category 3 hurricane. SLOSH modeling returns the highest surge of all modeled storms of $3.4 \mathrm{~m}$ at the mouth of the Pattagansett River (4.9m total change in surge). Given the $95 \%$ confidence intervals and mean age of the peak at $30.5 \mathrm{~cm}$ in C15 (1736-1889 C.E., mean 1821 C.E.), it is likely this peak in coarse fraction and anomaly was due to the 1815 storm.

The Great Colonial Hurricane of 1635 made landfall in Long Island, devastating southeastern New England with an estimated intensity similar to that of the Great New England Hurricane of 1938. SLOSH modeling returns surges of $2.3 \mathrm{~m}$ at the mouth of the Pattagansett River $(3.6 \mathrm{~m}$ total change in surge), making the peak in both coarse fraction and anomaly at $59.5 \mathrm{~cm}$ in C15 likely due to this event. 
This is consistent with the age model at this depth, returning 95\% confidence values of 1615-1780 C.E. (median 1644 C.E.).

\subsubsection{Testing the van de Plassche et al. (2006) hypothesis}

Our study tests the hypothesis presented by van de Plassche et al. (2006) that the Great Colonial Hurricane of 1635 caused pervasive erosion in Pattagansett River Marsh. Stratigraphic investigation of new cores along the same transect, however, reveal substantial differences from the original stratigraphy (Fig. 6.2). Several visible sandy-mud layers, consistent with hurricane deposits, exist throughout the marsh. van de Plassche et al. (2006) indicated only one of these visible layers in the stratigraphy (Fig. 6.2) and interpreted it as a gray, siliciclastic tidal deposit composed of silty clay. Our analysis reveals two distinct, gray, sandy-mud layers where van de Plassche et al. (2006) only identified one, finer-grained layer. In addition to the visible layers, analysis of both study cores reveals several additional peaks in coarse fraction, also consistent with hurricane-induced deposition. Because the van de Plassche et al. (2006) stratigraphy did not consider sand content, it does not distinguish between these different sand layers, which when viewed as a whole do not appear to be tidal mud from complete erosion of the marsh. Instead, these sandy mud layers represent periods of overwash and flooding from the adjacent channel, likely due to increased storm surge during a hurricane. The 600-year sedimentary hiatus discovered by van de Plassche et al. (2006) is indeed replicable, and our analysis reveals that it is associated with a peak in coarse fraction. This suggests a coarse-lag deposit, indicative of a high-energy event. Given that the visible sandy-mud layers exclusively prior to 1200 C.E., however, the hiatus is not associated with the gray visible layer, as originally posited.

\subsubsection{Mechanisms for erosion}

Our tests of van de Plassche et al. (2006)'s marsh erosion hypothesis corroborate the theory that a high-energy event was the likely culprit of a $\sim 600$-year sedimentary hiatus. Given the site's propensity to record overwash events for major historic hurricanes, it is likely that similar peaks in coarse fraction are the result of hurricane activity. Therefore, we interpret the peak in coarse fraction at the base of the hiatus as a coarse-lag deposit from a high-energy erosional event. Since the coarselag deposit dates between the mid-sixteenth and mid-seventeenth centuries, it is possible that a storm or multiple storms during or prior to that time period caused the erosion.

Given a similar radiocarbon date, van de Plassche et al. (2006) suggested that the Great Colonial Hurricane of 1635-recorded as a deposit $\sim 60 \mathrm{~km}$ away in a salt marsh in Matunuck, Rhode 
Island (Donnelly et al., 2001a) — may have caused the widespread erosion seen in the marsh. SLOSH simulations (tracks from Boldt et al., 2010) of storm surge in the Pattagansett River, however, reveal that the maximum storm surge for the Great Colonial Hurricane of 1635 was likely substantially lower than that of both the Great New England Hurricane (1938) and Hurricane Carol (1954), both of which leave an overwash deposit in the sedimentary record (Fig. 6.6). There was also no substantial difference in return surge between any of the modeled storms. Therefore, the Great Colonial Hurricane of 1635 alone is unlikely to cause such expansive erosion (Fig. 6.7a). The erosional sequence encompasses $\sim 600$ years of activity, during which there were at least nine hurricane deposits in the continuous core (Fig. 6.5). This time period corresponds to roughly 1100 C.E. through 1700 C.E., consistent with other local overwash fans in Rhode Island (Donnelly et al., 2001a) and Massachusetts (Chapters 3 and 4).

If the erosion indeed was the result of multiple storms over a relatively short time period $(>1$ storm/century), it is possible that the additive impact of storm events was enough to weaken the marsh such that it became vulnerable to erosion. Consistent overwash deposits from storm surge and flooding of the Pattagansett River may have been enough to kill vegetation and start a positive feedback loop of destabilization (S. Temmerman et al., 2005). For example, a marsh system $12 \mathrm{~km}$ away in Lyme, CT, experienced so much overwash from the Great New England Hurricane in 1938 that the vegetation began to convert to "brush and reeds" (West, 2008). Howes et al. (2010) also documented that less-saline, $S$. patens-dominated marshes, like our study area, are more likely to have weak zones due to shallower root systems as compared to more saline, S. alterniflora-dominated marshes. Temmerman et al. (2012) found that removal of tidal marsh vegetation increased platform flow velocities by a factor of 2 to 4 . NOAA's National Storm Surge Hazard Maps indicate that the entire study area has the potential to be significantly inundated by at least two meters of water during a category 1 storm. For a category 3 storm, similar to that of the Great Colonial Hurricane of 1635, the inundation could be greater than three meters (NOAA). Combining increased flow due to vegetation loss with significant storm surge may have created an ideal circumstance for erosion. Even without substantial vegetation death, a series of repetitive overwash deposits, regardless of thickness, may have been sufficient to weaken the root structure, leaving the area more susceptible to erosion from a storm that may have otherwise not been powerful enough to cause such destruction (Fig. 6.7b). 


\subsubsection{Other potential mechanisms}

It is important to consider other potential mechanisms for the sequences seen at Pattagansett River Marsh. van de Plassche et al. (2006) and Nikitina et al. (2014) explore different explanations for intertidal mud deposits overlying high marsh peat, including an increase in tidal range (Long et al., 2006), gradual migration of tidal channels (Stumpf, 1983), background rates of marsh-cliff retreat (McLoughlin et al., 2015), marsh pond formation (Wilson et al., 2009), and changes in sea level (Schwimmer \& Pizzuto, 2000). Our in-depth analysis of the stratigraphy, coarse fraction, and chronology of this sequence reveals that the mud layers interpreted by van de Plassche et al. (2006) are in fact sandy storm event layers, deposited $\sim 600$ years prior to the erosional event.

Gradual migration of tidal channels would result in a visible transition from high marsh to low marsh, but tidal creeks are generally stable over long timescales (Redfield, 1972), and the process of migration is a slow, time-transgressive process. Since the sand at the base of the sequence is quartzrich, it indicates a tidal source that is not associated with the precipitate grain signature of the formation of marsh ponds or pans. The ditches present in the marsh have existed since 1934 at the latest (UConn MAGIC) and likely occurred after the hiatus. Though the hiatus and low marsh to high marsh transition may represent infilling of ditches, it is unlikely that the ditches would encompass such a wide swath of marsh. The upper $2 \sigma$ age for the radiocarbon date acting as an upper bound for recovery from the hiatus is 1653 C.E. The town of Lyme, containing Pattagansett Marsh, was first named in 1665. This suggests that the erosion was likely prior to European settlement in the area.

Another proposed mechanism is the influence of ice rafts during particularly cold winters. Argow et al. (2007) determined that ice rafts have the potential to transport sediment loads more than $100 \mathrm{~m}$ from the source and that $97 \%$ of ice rafts carry sizeable sediment loads. Wood et al. (2006) identified several marshes in Maine with sedimentation rates influenced by at least $20 \%$ ice-rafted sediment. Hardwick-Witman (1986) identified a series of ice-rafted peat blocks throughout a New Hampshire salt marsh. While ice rafts presently tend to form further north in New England (Hardwick-Witman, 1986; Wood et al., 2006) than Connecticut, it is possible that cooler climates may have extended their range in the past. The proposed dates of the hiatus roughly encompass parts of the Little Ice Age (1500s through 1800s; Mann, 2003), when there was an estimated drop of $\sim 0.6^{\circ} \mathrm{C}$ across the Northern Hemisphere. Ice rafting has the potential to erode large portions of the marsh or deposit loads of sandy mud from adjacent tidal channels. A sequence of erosion followed quickly by sand/mud deposition from another ice-rafting event or a high-energy event such as a hurricane has the potential to leave a similar signature (Fig. 6.7c). 
Higher-energy events, such as hurricanes, may also contribute to other proposed mechanisms, including rapid changes in tidal range, channel geometry, or cliff erosion. For example, the Great New England Hurricane of 1938 caused a portion of a barrier spit in front of the Barn Island Marsh system (Stonington, CT) to separate, causing a significant change in the geometry of Little Narragansett Bay while still leaving an event deposit in the marsh (Orson et al., 1998). Even if the coarse-lag deposit is a direct result of a rapid change in tidal range, channel geometry, or cliff erosion, it is likely (given the age range and our understanding of the marsh's history) that the cause of that rapid change is a major hurricane.

It is important to consider why the Pattagansett River Marsh shows evidence of pervasive, hurricane-induced erosion when other local marshes do not (e.g. Donnelly, Smth Bryant, et al., 2001; Donnelly, 2004; Miller et al., 2009). This may be due to a variety of factors, including marsh geomorphology, marsh composition, storm track, and storm intensity. Additionally, the erosional sequence in the study marsh is relatively visually subtle at first glance, and the presence of the $\sim 600$ year hiatus is confirmed only through extensive radiocarbon dating throughout the core. It is possible that similar sequences could exist unrecognized in other marshes. It is clear through our study that a single marsh can experience both depositional and erosional events. These erosional events, however, are likely due to a confluence of ideal factors as discussed above.

\subsection{Conclusions}

Our study tested the hypothesis presented by van de Plassche et al. (2006) that a widespread, 600-year hiatus and associated stratigraphic sequence in Pattagansett River Marsh was the result of erosion from the Great Colonial Hurricane of 1635. Though our analysis confirmed that the hiatus in the marsh was indeed present and widespread, the stratigraphy differed from that presented by van de Plassche et al. (2006). Though the hiatus was associated with a potential high-energy coarse-lag deposit, it occurred well after the gray, sandy-mud layers, interpreted by van de Plassche et al. (2006) as tidal deposits and interpreted here as storm event layers, were deposited. Radiocarbon dating indicates that the erosion occurred between 1400 C.E. and 1675 C.E., but SLOSH modeling suggests that the Great Colonial Hurricane of 1635 produced no more surge than other historic hurricanes that left event deposits. As such, the erosional sequence may have been the result of several hurricanes degrading the marsh over a longer period of time, eventually reaching a threshold of vulnerability to erosion at which an intense storm could scour out a large swath of the marsh. 
The widespread erosion at this site may mark a departure from our current understanding of salt marsh evolution, form, and function. This has significant implications for coastal communities and infrastructure relying on the surge-buffering properties of marshes. If a series of intense hurricanes is capable of degrading marshes to the point of massive erosion, then the increasing frequency of intense hurricanes in the coming century (Bhatia et al., 2018; Emanuel, 2013; Korty et al., 2017), augmented by sea-level rise (Woodruff et al., 2013), may pose an even greater threat. This also has implications for marshes that are already degraded, since New England salt marshes have continued to become increasingly vulnerable to both anthropogenic and climate impacts (Gedan et al., 2011). Future work should continue to better understand the erosional potential of New England salt marshes in the face of such increasing storminess. 


\subsection{Figures and tables}

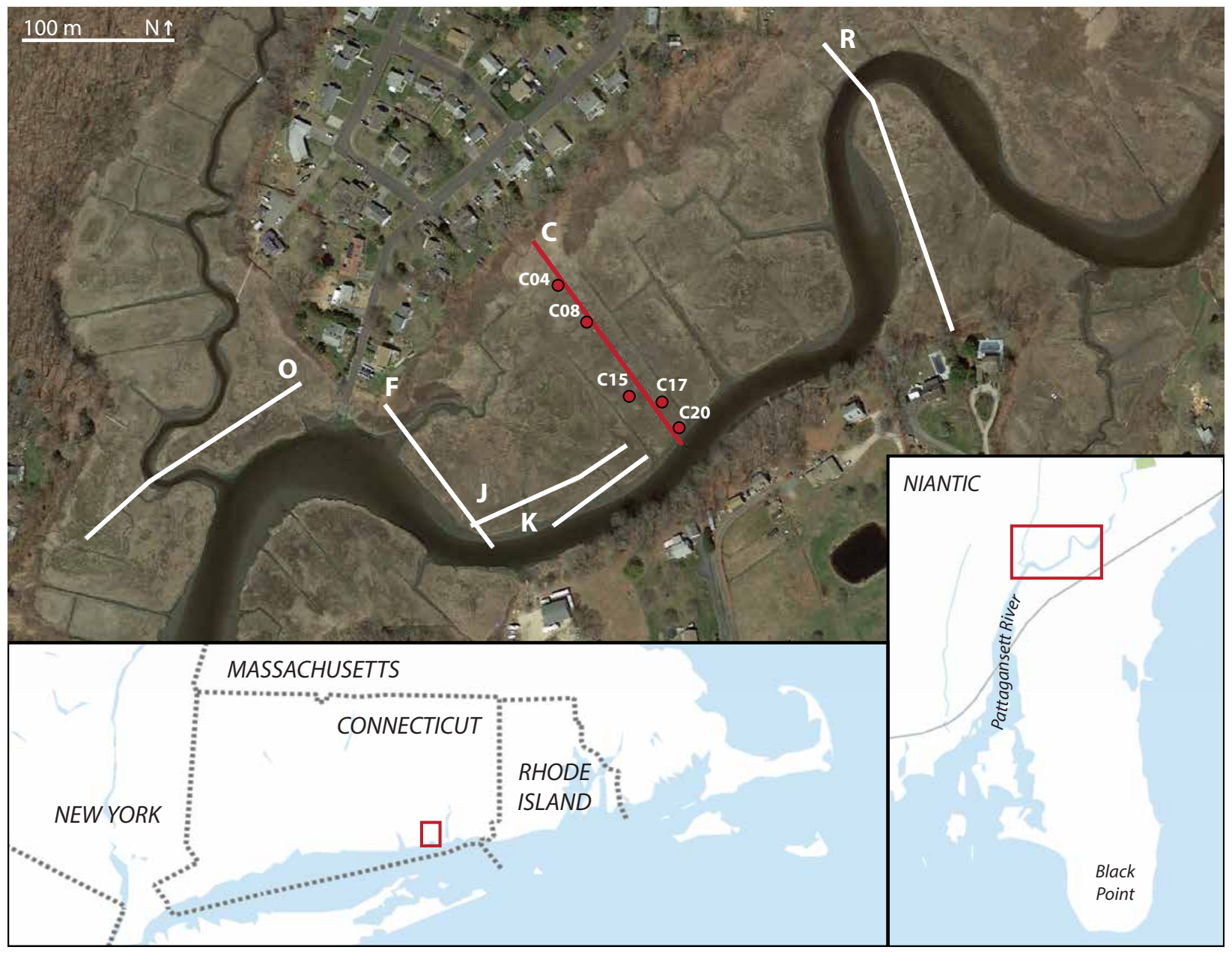

Figure 6.1 Map of study location. White transects indicate those included in the main text of van de Plassche et al. (2006). The red transect is the focus of this study, with core locations indicated. 

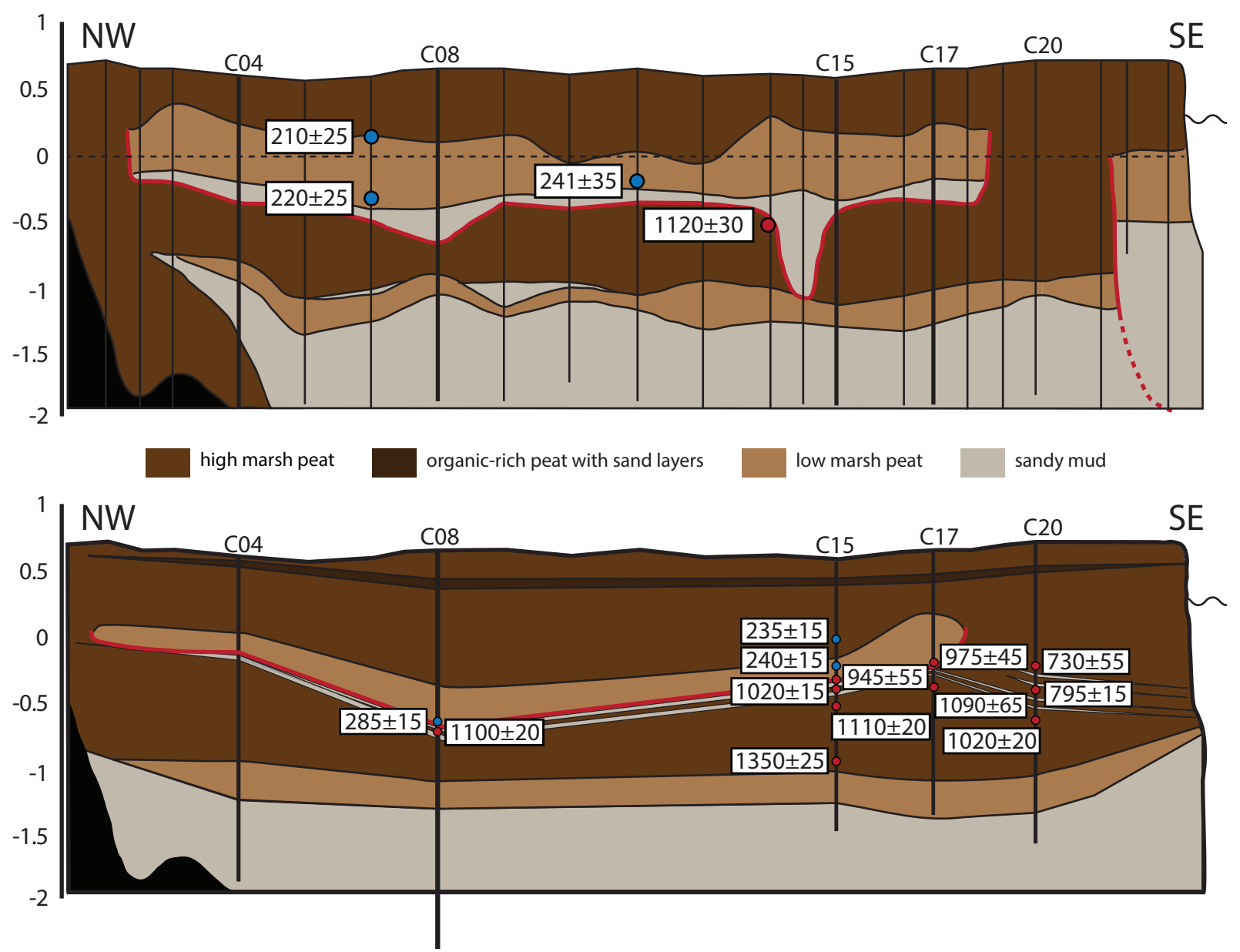

Figure 6.2 Updated stratigraphy from van de Plassche et al. (2006). Top, the original stratigraphy as posited by van de Plassche et al. (2006). Bottom, the updated stratigraphy from this study. Radiocarbon dates are included in the stratigraphy. Blue circles indicate a date above the hiatus. Red circles indicate a date below the hiatus. 

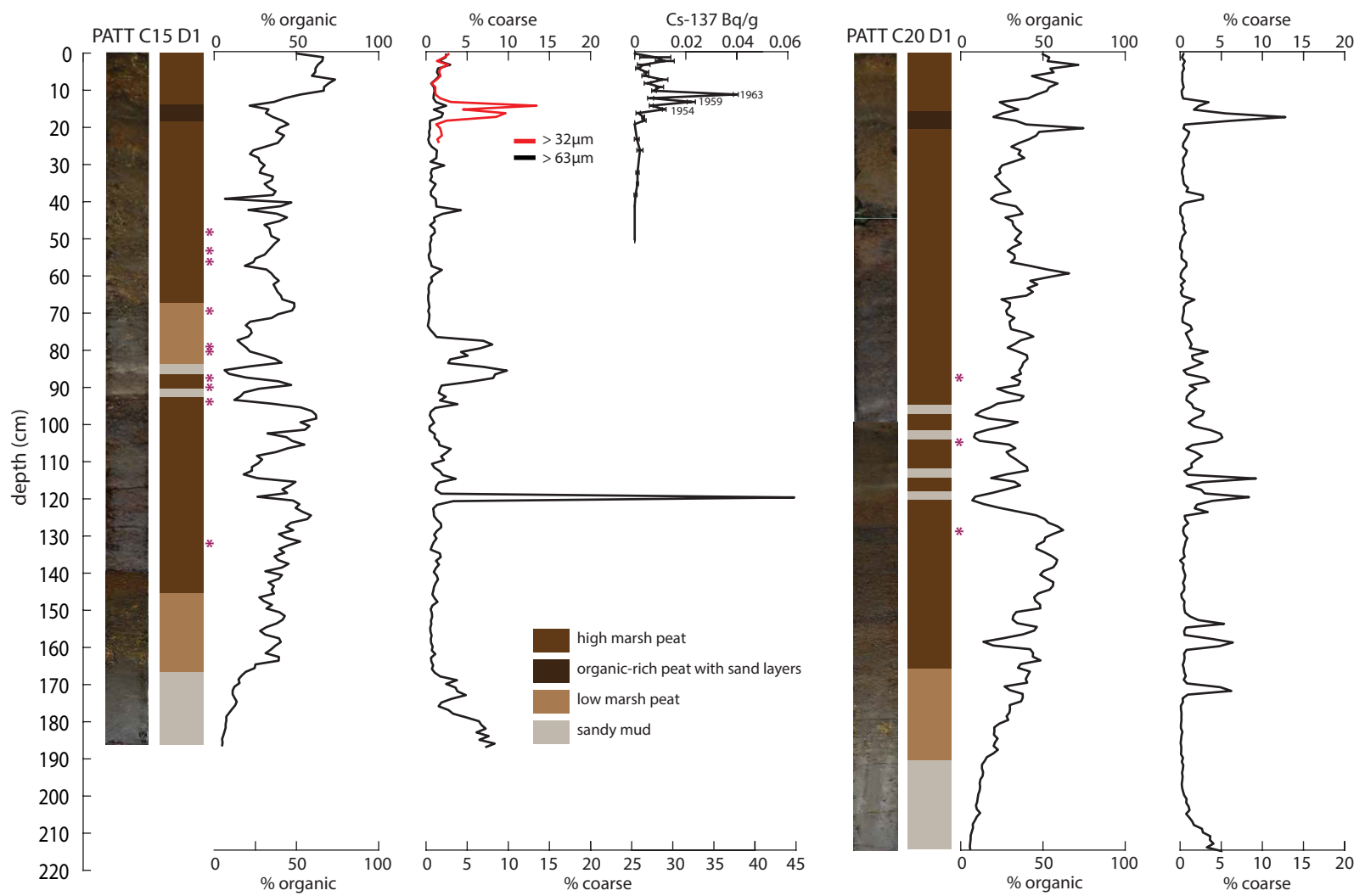

Figure 6.3 Comparison of two study cores. Left, C15 (with hiatus) with visual and stratigraphic representations, percent organic, coarse fraction, and ${ }^{137} \mathrm{Cs}$ values. Right, C20 (continuous) with visual and stratigraphic representations, percent organic, and coarse fraction values. 

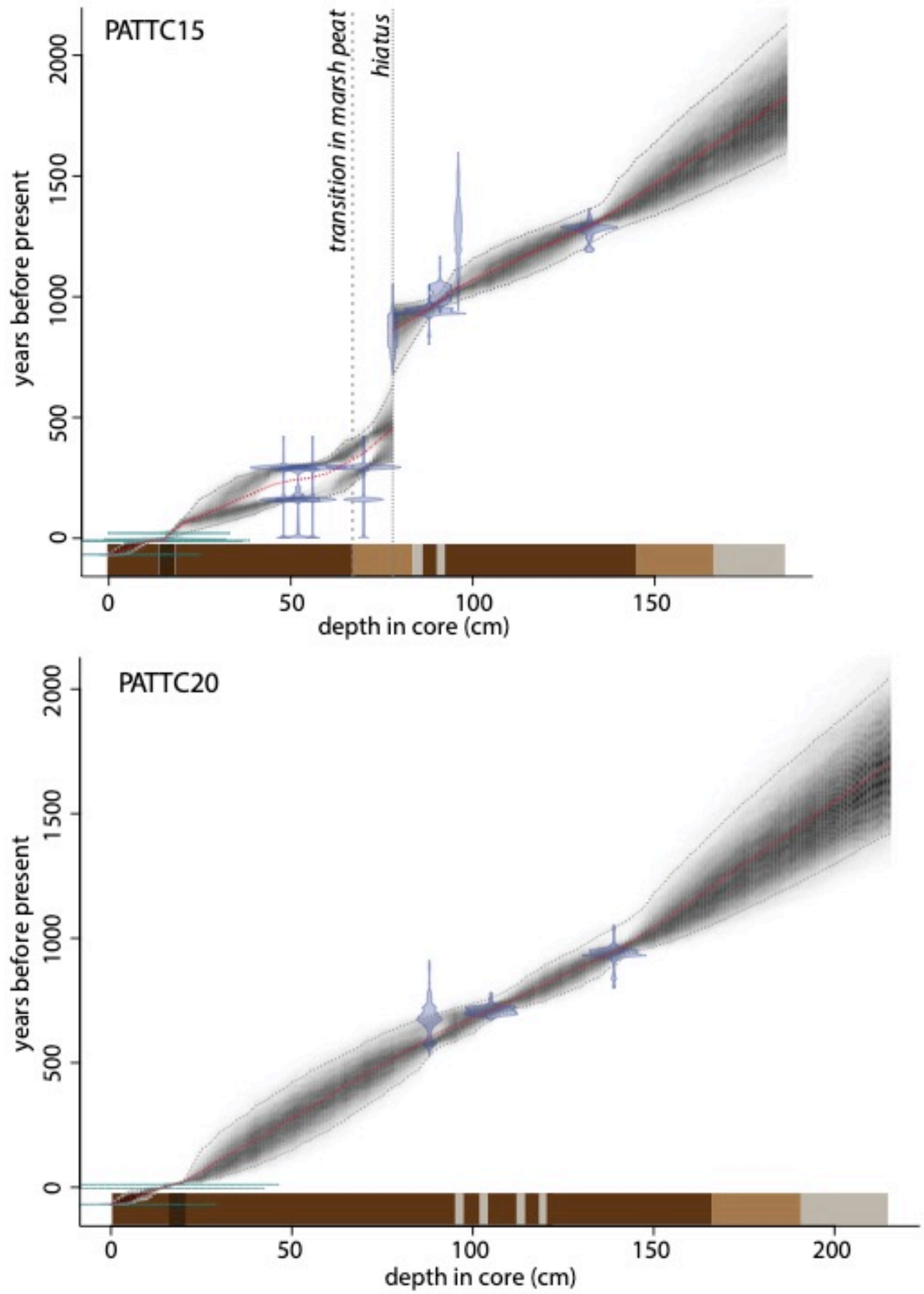

Figure 6.4 Bacon age models for C15 (with hiatus) and C20 (continuous sedimentation). 


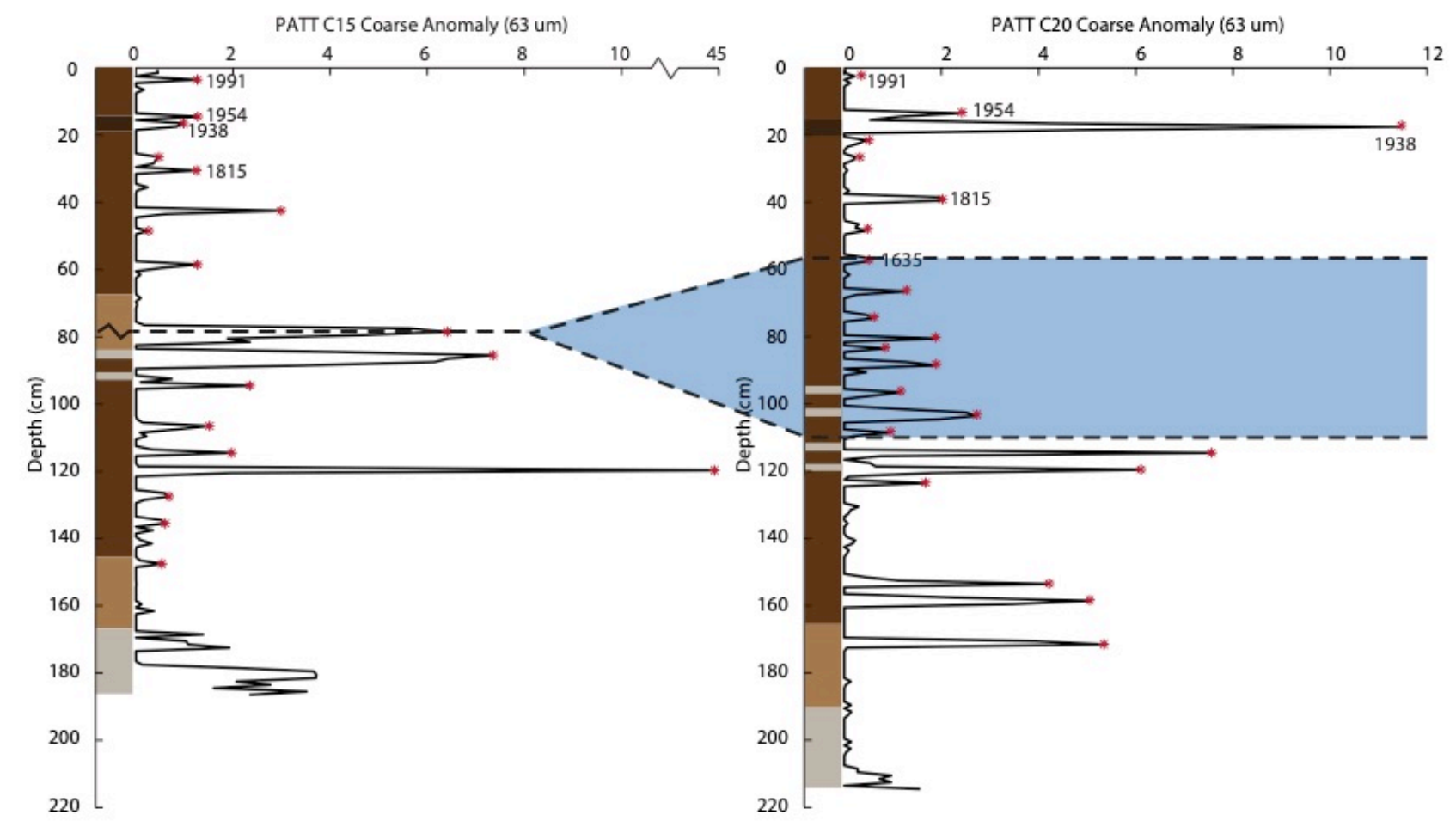

Figure 6.5 Coarse anomaly graphs for C15 (with hiatus) and C20 (continuous). The proposed area of erosion is indicated by the blue box.

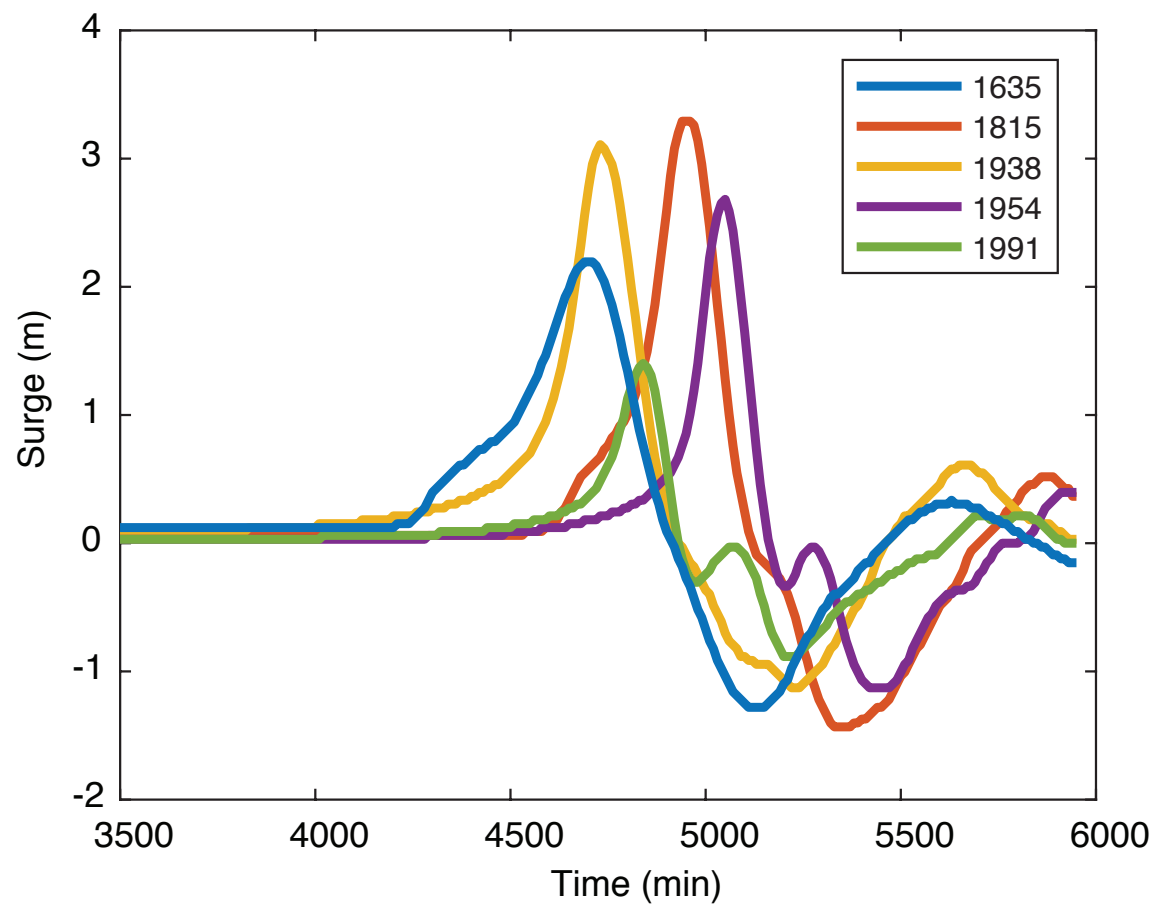

Figure 6.6 SLOSH modeling of storm surge over time at the mouth of the Pattagansett River for several historic storms, data for SLOSH storm tracks from Boldt et al. (2010). 


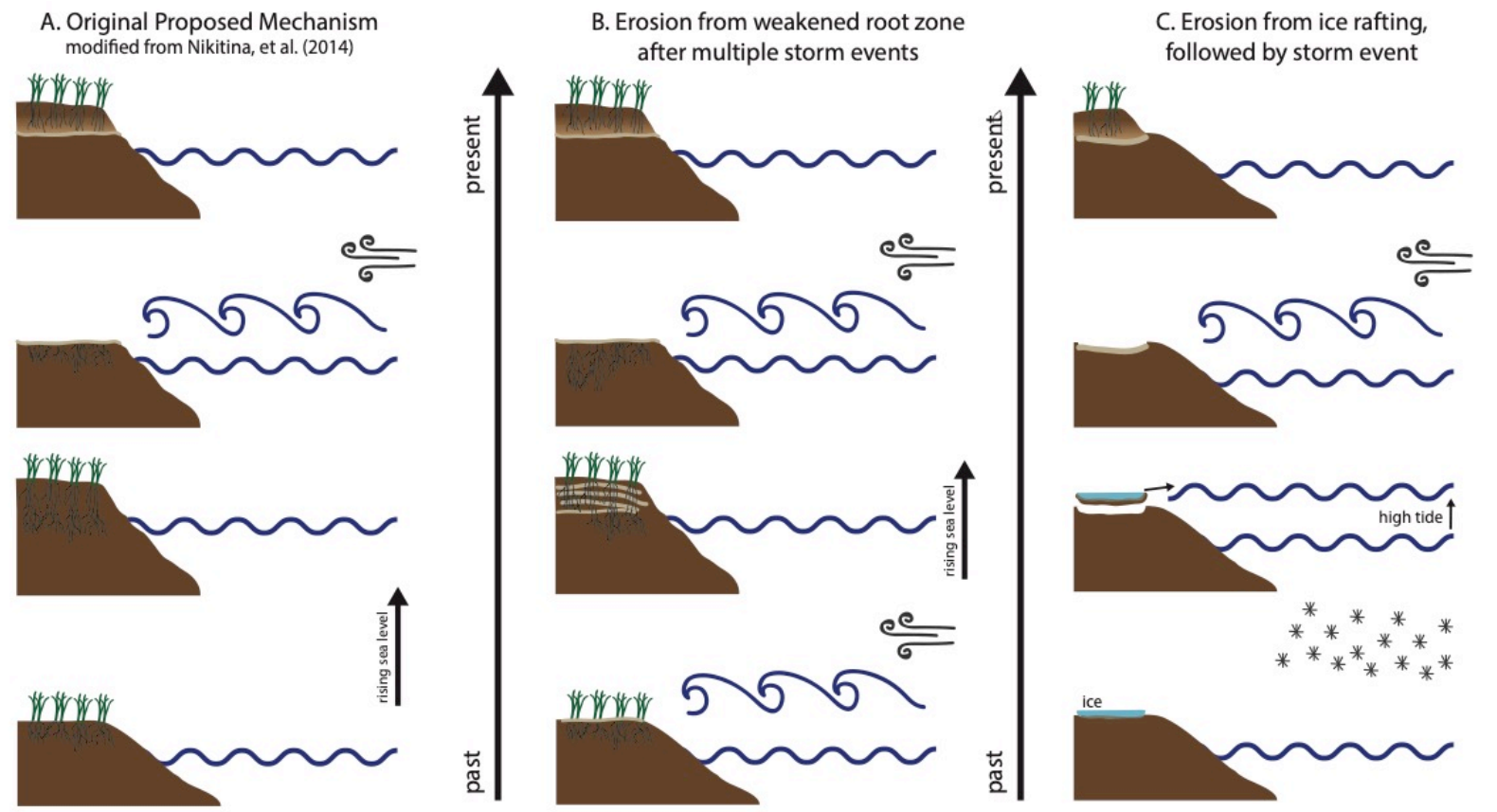

Figure 6.7 Proposed mechanism for the sequence at Pattagansett. A) The originally proposed mechanism, where erosion from one storm creates accommodation space that is rapidly infilled by sandy mud and then recolonized by marsh (modified from Nikitina et al., 2014). B) A proposed mechanism where the root zone of the marsh is weakened by multiple storm events through deposition of sediment; a storm (or storms) can then erode a great deal of the marsh, after which it recovers. C) A proposed mechanism where ice rafting removes a portion of the marsh, then a highenergy storm leaves a sandy deposit, after which the marsh recovers. 
Table 6.1 Radiocarbon dates.

\begin{tabular}{|c|c|c|c|c|}
\hline Sample ID & Age & Error & Type & d13C \\
\hline PATT_C15_D1_1of2_51cm & 235 & 15 & Plant/Wood & -11.48 \\
\hline PATT_C15_D1_1of2_56cm & 210 & 15 & Plant/Wood & -11.94 \\
\hline PATT_C15_D1_1of2_59cm & 235 & 15 & Plant/Wood & -11.85 \\
\hline PATT_C15_D1_1of2_73cm & 240 & 15 & Plant/Wood & -13.87 \\
\hline PATT_C15_D1_1of2_82cm & 945 & 55 & Plant/Wood & -13.81 \\
\hline PATT_C15_D1_1of2_83cm & 210 & 15 & Plant/Wood & -13.15 \\
\hline PATT_C15_D1_1of2_92cm & 1,020 & 15 & Plant/Wood & -14 \\
\hline PATT_C15_D1_1of2_95cm & 1,110 & 20 & Plant/Wood & -13.15 \\
\hline PATT_C15_D1_1of2_99cm & 1,370 & 100 & Plant/Wood & -13.73 \\
\hline PATT_C15_D1_1of2_139.5cm & 1,350 & 25 & Plant/Wood & -13.48 \\
\hline PATT_C08_D3_2of3_64cm & 285 & 15 & Plant/Wood & -12.49 \\
\hline PATTC08_D3_2of3_68.5cm & 1,100 & 20 & Plant/Wood & -13.54 \\
\hline PATTC17_D1_1of2_64cm & 975 & 45 & Plant/Wood & -14.21 \\
\hline PATTC17_D1_1of2_72.5cm & 1,090 & 65 & Plant/Wood & -10.97 \\
\hline PATT_C20_D1_1of2_139cm & 730 & 55 & Plant/Wood & -13.39 \\
\hline PATT_C20_D1_2of2_4cm & 795 & 15 & Plant/Wood & -28.16 \\
\hline PATT_C20_D1_2of2_28cm & 1020 & 20 & Plant/Wood & -28.05 \\
\hline
\end{tabular}




\title{
7. Intense storms increase the stability of tidal bays
}

This chapter was originally published as: Castagno, K. A., Jiménez-Robles, A. M., Donnelly, J. P., Wiberg, P. L., Fenster, M. S., \& Fagherazzi, S. (2018). Intense Storms Increase the Stability of Tidal Bays. Geophysical Research Letters, 45(11), 5491-5500. Used with permission as granted in the original copyright agreement.

\begin{abstract}
Coastal bays and, specifically, back-barrier tidal basins host productive ecosystems, coastal communities, and critical infrastructure. As sea level continues to rise and tropical cyclones increase in intensity, these coastal systems are increasingly at risk. Developing a sediment budget is imperative to understanding how storm events affect the system's resilience, where net import of sediment indicates growth and resilience against sea level rise, and net export of sediment indicates deterioration. Using high-resolution numerical simulations, we show that intense storms import sediment into a system of bays in Virginia, USA. Duration and magnitude of storm surge are among the most important factors in sediment import, suggesting that intense storms increase the stability of tidal bays by providing the sediment necessary to counteract sea level rise. Since climate models project that tropical cyclones will increase in intensity in coming decades, our results have significant implications for the resilience of tidal bays and the future of coastal communities worldwide.
\end{abstract}

\section{Plain-Language Summary}

In order to counteract rising sea levels, a coastal bay needs to increase its bottom elevation by trapping enough sediment in salt marshes and tidal flats. People believe that storms are deleterious to coastal bays, but this is not necessarily true. In many coastal settings, intense storms are the main mechanism providing coastal bays with the sediments necessary to offset sea-level rise. Here, we show that intense storms provide sediments to the bay and marsh systems of the Virginia coastal bays, USA, thereby increasing their long-term stability. 


\subsection{Introduction}

Coastal bays and barrier island systems provide a variety of ecosystem services and play an integral role in protecting coastal communities from flooding and other destruction associated with coastal storms, including hurricanes and extratropical cyclones (Barbier et al., 2011). Communities are growing increasingly vulnerable to flooding from tropical cyclones and other storms due to increases in sea-level rise (Woodruff et al., 2013), and continuing greenhouse gas-forced warming may augment tropical cyclone intensity and frequency (Sobel et al., 2016; Walsh et al., 2016). Coastal bays must trap sediments so that tidal flats and salt marshes can accrete and maintain the same elevation with respect to mean sea level, allowing the system to keep pace with sea-level rise and avoid drowning (Fagherazzi et al., 2014). Though marshes have been shown to be resilient to periods of moderate sea-level rise (Kirwan et al., 2010, 2016), accelerated sea-level rise can cause marsh drowning and destruction (FitzGerald et al., 2008; Kirwan et al., 2010). Wave attack from intense storms has been shown to cause significant erosion (Barras, 2007; Howes et al., 2010; van de Koppel et al., 2005; Morton \& Barras, 2011), but overwash and other deposition from intense storms have also been suggested as a major source of resilience-building sediment (Donnelly et al., 2001a; Morton \& Barras, 2011; Turner et al., 2006; Walters \& Kirwan, 2016). Developing a sediment budget for these coastal bays is imperative to understanding how storm events in a regime of accelerated sea-level rise affect the resilience of the system, where net import of sediment indicates growth and increasing stability of the system and net export of sediment indicates deterioration (Fagherazzi et al., 2014; Ganju et al., 2015).

In this study, we quantify the sediment fluxes into and out of coastal bays during storms to test the hypothesis that more frequent and intense storms will erode and deteriorate these valuable ecosystems. We focus this study on the Virginia Coast Reserve (VCR), a system of salt marshes and shallow back-barrier tidal bays along the Atlantic side of the Delmarva Peninsula (Fig. 7.1a) because this reach is one of the longest expanses of undeveloped mixed-energy barrier islands worldwide (which controls for anthropogenic impacts) and experiences high rates of relative sea-level rise (which provides an upper-bound for expected marsh demise) (Fenster et al., 2016). The VCR is composed of a system of shallow bays fringed by Spartina alterniflora marshes, which cover approximately $30 \%$ of the total surface area of the system (Fagherazzi \& Wiberg, 2009; Oertel, 2001). The system has a mean tidal range of $1.2 \mathrm{~m}$, and storms are a primary cause of short-term disturbance in the area (Fagherazzi \& Wiberg, 2009; McLoughlin et al., 2015). The system lacks a significant riverine sediment source. Previous research in the VCR has included quantifying the main contributors to salt marsh erosion, a major threat to marsh ecosystem services. Though wave action is the main contributor to erosion 
(Fagherazzi \& Wiberg, 2009; Mariotti \& Fagherazzi, 2010; McLoughlin et al., 2015), vegetation changes and invertebrate burrowing also play a large role (Thomas \& Blum, 2010). Previous geomorphic modeling in this location has focused on developing numerical models for marsh evolution (Fagherazzi et al., 2012; Mariotti \& Fagherazzi, 2010; Mariotti \& Carr, 2013), detailing how waves shape marsh form and function (Leonardi \& Fagherazzi, 2014; Leonardi \& Fagherazzi, 2015), and quantifying how barrier islands and marshes interact (Deaton et al., 2016; Walters et al., 2014). Given the robust nature of previous research in the VCR, it is an ideal location to formulate a sediment budget to determine the supply of sediment to the tidal bays and their resilience in the face of sealevel rise and increasing storminess.

\section{2 Methods}

\subsubsection{Model design}

Hydrodynamic and sediment-transport simulations were conducted using the high-resolution, fluid dynamics model Delft3D-FLOW (Lesser et al., 2004) and the Delft3D-WAVE module, which is based on the SWAN (Simulating WAves Nearshore) wind wave generation and propagation model (Booij et al., 1999). This coupled system is suitable for simulating non-steady flows, wave generation and propagation, sediment transport phenomena, and related morphological developments in shallow seas, coastal areas, estuaries, lagoons, rivers and lakes.

The model used a nested grid system to simulate wave generation and propagation. The outer grid - a curvilinear, coarse-grid wave domain with cell sizes that decrease as depth decreases—extends up to the location of NOAA buoy 44014 or, if no data from 44014 is available, up to the location of NOAA buoy 44099 (Fig. 7.S2). The inner grid—a nested quadrangular grid-covers the area of the bays with a $250 \mathrm{~m}$ constant resolution over the whole domain (Fig. 7.S2). Details on the bathymetry and friction coefficients used for the inner grid can be found in Wiberg et al. (2015).

Water levels at the southern, northern and seaward open boundaries of the second grid were set equal to the water level measured at NOAA station 8631044 (Wachapreague, VA), with a phase shift and an amplitude correction to account for tidal propagation and dissipation in the domain (Fig. 7.S3). Wind speeds were simulated in both grids, with the outer grid using data from the offshore buoys (44014 or 44099) and the inner grid using data from Wachapreague.

Wave heights were forced by offshore buoy data to allow the waves to propagate over a large distance before entering the inner grid. The wave heights were then calibrated to maximize agreement between simulated and measured wave height at the inshore NOAA buoy 44096 (Cape Charles VA; 
Fig. 7.S4). For the purpose of analysis, maximum wave heights and wind speeds were determined using data from NOAA buoy 44096, which had no gaps in data during the study period.

\subsubsection{Storm identification}

A total of 52 storm events from 2009-2015 were simulated (Table 7.S1; Fig. 7.S1). Storm events were identified when wind speed at NOAA station 8631044 (Wachapreague, VA) exceeded 11 $\mathrm{m} / \mathrm{s}$. The duration of each simulated storm was determined by the storm surge (difference between measured and predicted water levels) recorded at NOAA station 8638863 (Chesapeake Bay Bridge Tunnel, VA) - the starting and ending points of the storm were determined so that 4 complete tidal cycles during which the storm surge is below a threshold value of $0.2 \mathrm{~m}$ are included in the simulations before and after the peak wind speed (Fig. S1). Threshold values of $11 \mathrm{~m} / \mathrm{s}$ and $0.2 \mathrm{~m}$ were sufficient to identify all named tropical cyclones impacting the VCR in the given time frame. For storms where the wind speed exceeded the $11 \mathrm{~m} / \mathrm{s}$ threshold but did not produce surge above $0.2 \mathrm{~m}$, the storm was defined as 4 complete tidal cycles before and after the peak in wind speed.

\subsubsection{Sediment budget and flux}

A sediment budget was constructed for each storm to determine resilience of the system (Ganju et al., 2015). Using high-resolution maps of bottom sediment size distributions within the bays of the VCR established by Wiberg et al. (2015), sediment resuspension and flux were modeled for each storm over a domain that included the full VCR and adjacent coastal ocean. Sediment size distributions for the adjacent coastal ocean were derived from grain-size distributions characterized by Fenster et al. (2016). The sediment budget into and out of the VCR (total cumulative sediment flux at the end of the model run for the series of basins) was modeled for three different particle sizes $-20 \mu \mathrm{m}, 63 \mu \mathrm{m}$, and $125 \mu \mathrm{m}$ (Fig. 7.1C-E). At the start of each simulation, mud (20 $\mu \mathrm{m})$ was primarily distributed closer to the mainland. Fine sand $(125 \mu \mathrm{m})$ was primarily distributed closer to the inlets and the tidal flats. Very fine sand $(63 \mu \mathrm{m})$ was relatively evenly distributed throughout the system. Suspended sediment concentrations produced by the model were validated by Wiberg et al. (2015) over a three-week period in January 2003 (Figure S5). Though the model produces results in good accordance with measured data, there is the potential for spatial or temporal variation in the natural storm events that it may not capture.

Trends in cumulative sediment flux were analyzed for relationships with a variety of parameters including wind speed, wave height, storm surge, wind direction, as well as the time each 
storm remained above a given threshold of each parameter (Table 7.S1). Wind direction was highly variable throughout each simulated storm and, as such, was not found to significantly influence sediment flux and was not included in the analysis.

\subsection{Results}

Using high-resolution bottom sediment distributions in the VCR (Fenster et al., 2016; Wiberg et al., 2015) in concert with hydrodynamic modeling, a sediment budget was developed to determine how this system responds to storm events. Averaging cumulative sediment flux spatially over all 52 storms, erosion is focused primarily along the ocean-side shorelines of the barrier islands, and sediment largely accumulated on the marshes, in the bays, and along the inlets (Fig. 1b). Using values for bed porosity consistent with Wiberg et al. (2015), net accumulation of sediment within the domain from the modeled storms ranged from $2.0-5.3 \mathrm{~mm} / \mathrm{yr}$.

Wind speed, wave height, and storm surge displayed statistically significant negative relationships with cumulative sediment flux (Fig. 7.2; Table 7.S2). This suggests that there is increased sediment accumulation in the study region as each parameter increases in intensity. Cumulative sediment flux also displayed statistically significant negative relationships (net accumulation of sediment into the system) with the amount of time each parameter remained over the following thresholds: wave height $>2 \mathrm{~m}$ at Station 44096 or 44014 (dependent on data availability; Fig. 7.S2), wind speed $>10 \mathrm{~m} / \mathrm{s}$, and storm surge $>0.5 \mathrm{~m}$. Relationships were determined using the product of the total time over the threshold and the magnitude of the corresponding variable for each storm. The product of magnitude $(>0.5 \mathrm{~m})$ and duration of storm surge alone explains most of the variance in cumulative sediment flux (Fig. 7.3; Table 7.S2). A multiple regression analysis of the three variables indicates that, similarly, the storm surge threshold-time product contributes the most to the relationship $\left(p<0.001, R^{2}=0.66\right)$. As a result, the influence of storm surge, particularly its duration and magnitude, appears to control the sediment budget of the bays.

While the total cumulative flux indicates that more intense storms tend to result in net import of sediment to the study area, this result varies by sediment type. For all three study parameters, mud and very fine sand (20 $\mu \mathrm{m}$ and $63 \mu \mathrm{m}$, respectively) display the same significant negative relationship with cumulative flux, where increased storm intensity results in increased import of sediment to the back-barrier basin (Fig. 7.4; Table 7.S3). Fine sand $(125 \mu \mathrm{m})$, however, tends to be exported from the tidal basin. Almost all storms $(96 \%)$ exhibit net export of fine sand, regardless of intensity. 
The spatial variation in percent changes in bottom sediment grain-size distributions provides insight into storm-induced sediment dynamics (Fig. 7.1). Following a storm, back-barrier marshes accumulate medium-grained silt, herein defined as mud $(20 \mu \mathrm{m})$, from the ocean side of the inlets. Back-barrier marshes experience erosion of mud $(20 \mu \mathrm{m})$ and deposition of sand (63 and $125 \mu \mathrm{m})$ along their edges, enhancing vertical accretion in those locations. The bay side of the inlets accumulate mud $(20 \mu \mathrm{m})$ and erode fine sand $(125 \mu \mathrm{m})$, whereas the ocean side of the inlets generally erode mud $(20 \mu \mathrm{m})$ and accumulate very fine sand $(63 \mu \mathrm{m})$. The barrier islands experience deposition of very fine sand $(63 \mu \mathrm{m})$ and erosion of fine sand $(125 \mu \mathrm{m})$ along their edges and offshore.

\subsection{Discussion and Conclusions}

Storm surge duration and magnitude have the most significant influence on cumulative storm sediment flux. The energy associated with a storm surge provides the shear stresses necessary for remobilization of sediment near the inlets and transport into the bay system. Storm surges have long been known to deposit sediment in marshes and bays during large storm events, on both historic and prehistoric timescales (Boldt et al., 2010; Donnelly et al., 2001a; Hodge \& Williams, 2016; Smith et al., 2015; Tweel \& Turner, 2012).

Here, we show that these storms transport mud and fine-grained sediment through the inlets and deposit them onto tidal flats and marshes proximal to the inlets (Fig. 7.1F-H). Tidal inlets serve as the conduit for funneling sediment from offshore to the bay. Storm-driven sediment transported through the inlets is then available for further remobilization by waves and tides, feeding additional interior flats and salt marshes (Wells, 1995). Without a net input of sediment through the inlets, in the absence of riverine inputs, the system would drown in place, unable to counteract sea-level rise in the long run.

Our study suggests that a storm surge threshold of $0.5 \mathrm{~m}$ or greater is sufficient to cause a net import of mud to the back-barrier system, regardless of the amount of time that the surge is above that threshold, assuming a continued supply of fine-grained material. Furthermore, the fine-grained sediment accumulation rates in the tidal bay system of $2.0-5.3 \mathrm{~mm} / \mathrm{yr}$ have the potential to exceed the current sea-level rise rates of approximately $4 \mathrm{~mm} / \mathrm{yr}$ (Wiberg et al., 2015). Indeed, recent work documenting marsh accumulation rates has suggested that marshes in the VCR may be accreting at rates great enough to avoid the threat of drowning from accelerated sea-level rise (Kirwan et al., 2016; Walters \& Kirwan, 2016). Other studies have supported sedimentation rates for large hurricanes ranging from 3-10 $\mathrm{cm}$ per storm event as sufficient for increased marsh production and growth 
(Baustian \& Mendelssohn, 2015; McKee \& Cherry, 2009). Since sea-level rise rates in the VCR are relatively high and likely increasing (Mariotti et al., 2010; Sallenger et al., 2012), the resilience of these back-barrier tidal basins has significant implications for coastal bays worldwide, many of which have lower sea-level rise rates.

The sediment budget of a given system is often considered a metric of coastal stability. Ganju et al. (2013) suggested that marsh systems with net export of sediment may be more unstable than marsh systems with net import of sediment. Though marsh stability can be influenced by a variety of factors, including net elevation change and suspended sediment source (Ganju et al., 2015), a marsh system's sediment budget has utility in predicting how the marsh will respond to rising sea levels over time, among other stressors. Our results suggest that storm events transport more sediment into tidal bays as they increase in intensity, thereby increasing their resilience in time.

Our results may also have implications for the fate of marshes globally. Lacking major rivers or other volumetrically important inputs of freshwater (Stanhope et al., 2009) or sediment (Morton \& Donaldson, 1973) to the coastal bays, the major driver of sediment input to back-barrier marsh systems is likely storms. Marsh systems that have more sediment input from riverine sources may have an even greater long-term adaptability to sea-level rise, which additional sediment input from storms will continue to augment. Indeed, meta-analysis of vertical accretion in salt marshes in both North America and Europe has shown that the majority of the 179 studied marshes have been accreting (Kirwan et al., 2016). Accumulation of sediment in tidal bay systems from storms, particularly intense storms, has been documented with Hurricanes Katrina, Rita, and Andrew in Louisiana (List et al., 2001; Morton \& Barras, 2011), though documented impacts from storms are varied (Barras, 2007; List et al., 2001; Morton \& Barras, 2011), and sediment budgets may vary between different tidal basins with different morphological characteristics (Pedersen \& Bartholdy, 2006). Though some studies have suggested that erosion along the ocean-side of barrier islands will increase as sea levels increase (Rusty A. Feagin et al., 2005; Leatherman et al., 2000), our study shows that input from storms alone may enable marsh accretion to keep pace with or counteract relatively high current rates of sea-level rise (as previously suggested by Schuerch et al., 2013), provided the barrier islands remain relatively stable. As such, continued or increased storm activity may have positive implications for the resilience of marshes worldwide. This is particularly important as future projections indicate that rates of sea-level rise will only continue to increase (Parris et al., 2012).

Many assessments agree that an increase in sea surface temperatures should result in an increase in the intensity of tropical cyclones (Holland \& Webster, 2007; Sobel et al., 2016; Walsh et 
al., 2016), even with natural variability and confounding factors (Sobel et al., 2016). Our study identifies the mechanism by which increased storminess increases the resilience of coastal bays. In particular, storms provide the material necessary to counteract rising sea levels as storms entrain finegrained material from the nearshore and transport the material into back-barrier tidal basins through the tidal inlets. These findings are particularly of interest for coastal protection schemes, since salt marshes and shallow tidal flats present a unique natural way to protect vulnerable communities from the effects of storm surge and flooding by dissipating energy, the effects of which will only increase as storminess increases. Sea level is rising in the VCR at fast rates (Mariotti et al., 2010), and, as such, our study provides a potential upper-bound example of the resilience of coastal bay systems in the face of increasing storminess. Increased storminess, therefore, may increase the long-term viability of marshes and coastal bays worldwide.

\section{Acknowledgements}

Water level, wave height, and water level data are available from NOAA's National Data Buoy Center. High-resolution maps of bottom sediment size distributions within the bays of the VCR were established by Wiberg et al. (2015), and grain-size distributions were characterized by Fenster et al. (2016). Partial support was provided by the National Science Foundation LTER under grants NSF 1237733 (SF, PW, MF) and NSF 163630 (SF). 


\subsection{Figures}
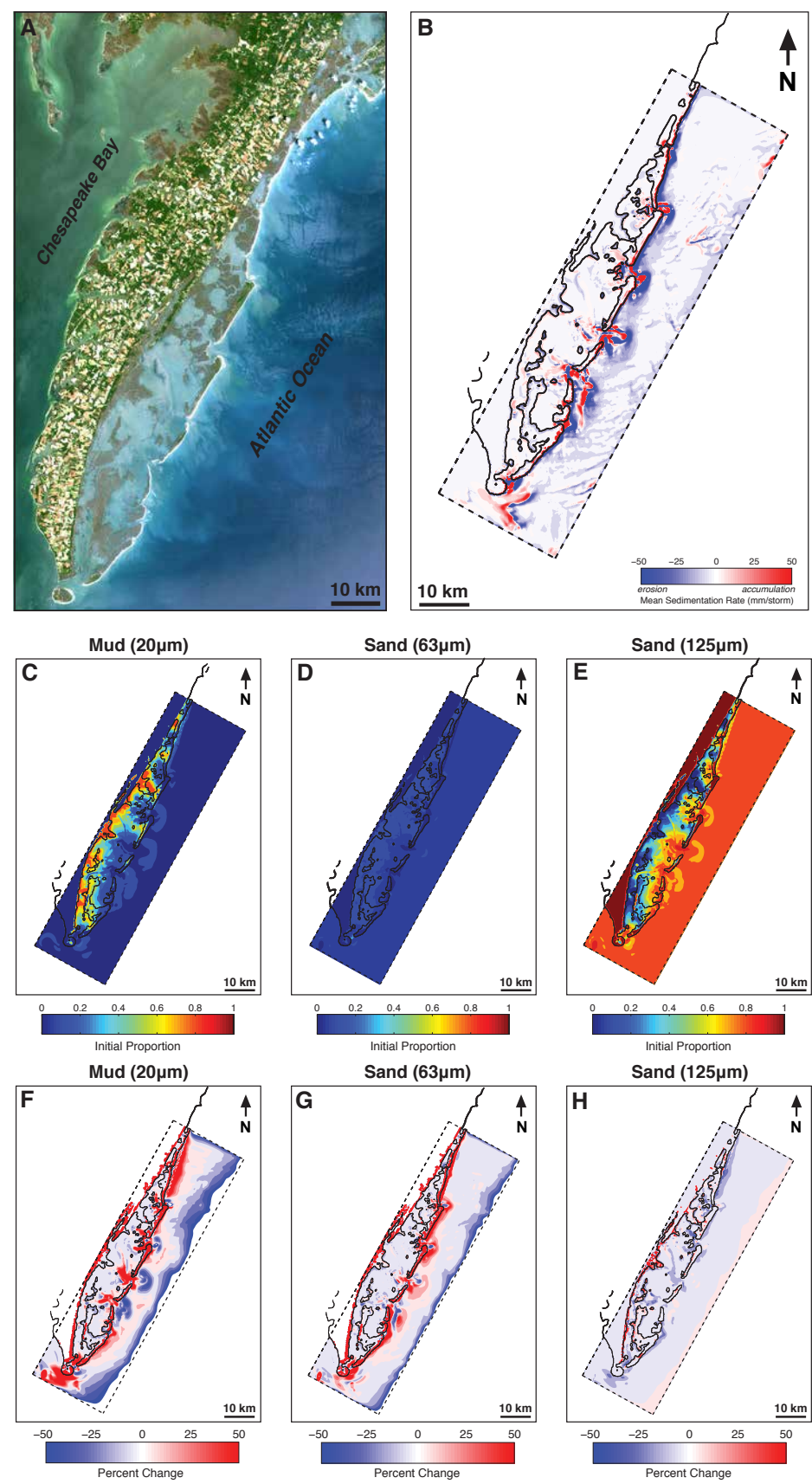

Figure 7.1 Bottom sediment distribution and change. (a) Aerial photograph of the Virginia Coast Reserve. (b) Mean cumulative elevation differences in the system for all 52 study storms. Blue areas indicate net erosion. Red areas indicate net accumulation. (c, d, e) Sediment bottom grain-size distribution. Scale is the proportion of the type of sediment, derived from Wiberg et al. (2015) and Fenster et al. (2016). (f, $\mathbf{g}, \mathbf{h})$ Average change in bottom sediment grain-size distribution after each storm, averaged for each type of sediment. Scale is percent change from initial to final bottom grainsize distribution. 

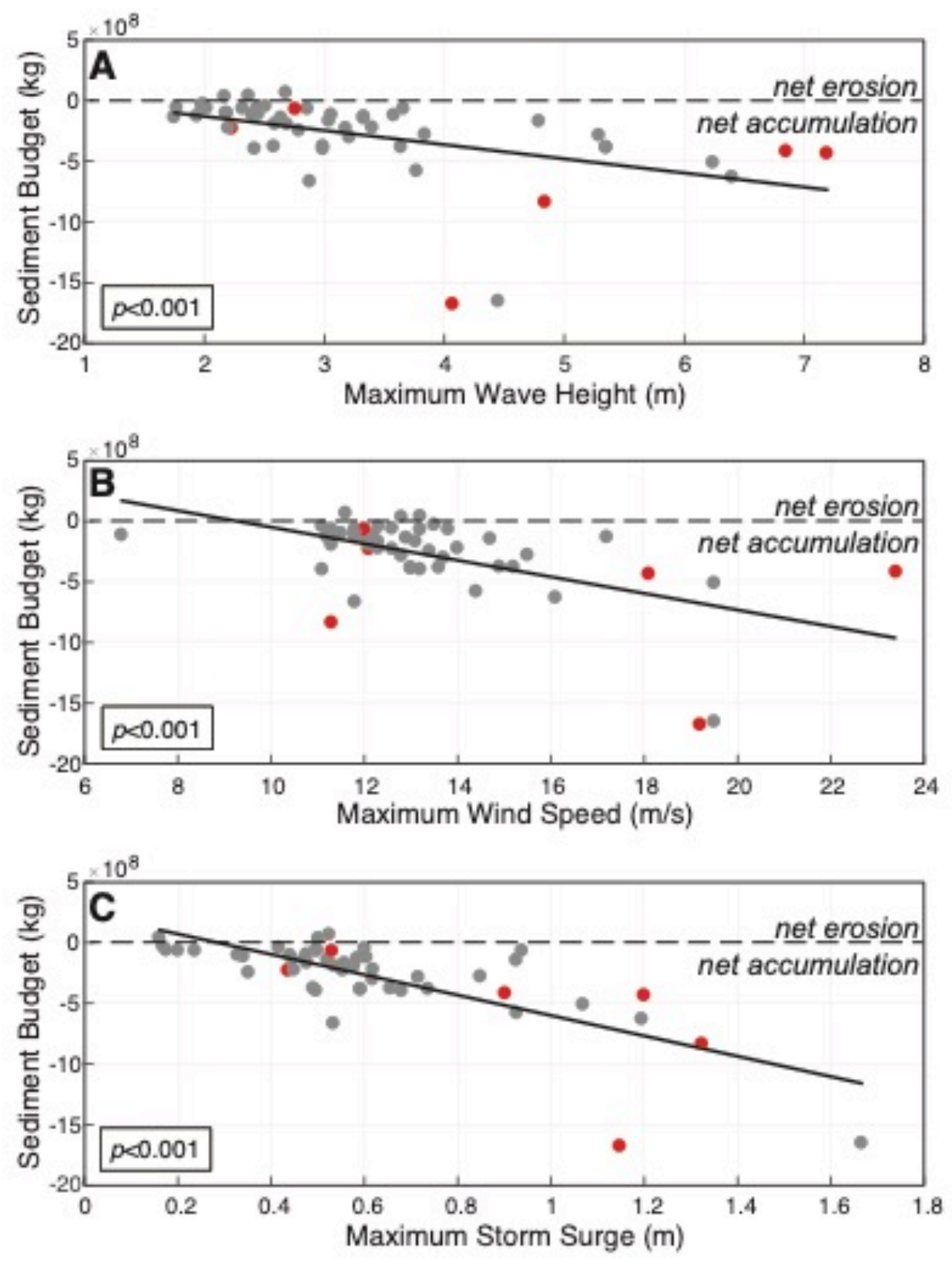

Figure 7.2 Sediment budget related to study parameters. Relationship between sediment budget and the maximum value per event of (a) wave height $\left(R^{2}=0.30 ; p<0.001\right)$ (b) wind speed $\left(R^{2}=0.22\right.$; $p<0.001)$ (c) storm surge $\left(R^{2}=0.57 ; p<0.001\right)$. There is a negative sediment budget (net accumulation of sediment into the system) as all study parameters increase in magnitude and duration. Red circles indicate named tropical cyclones. 

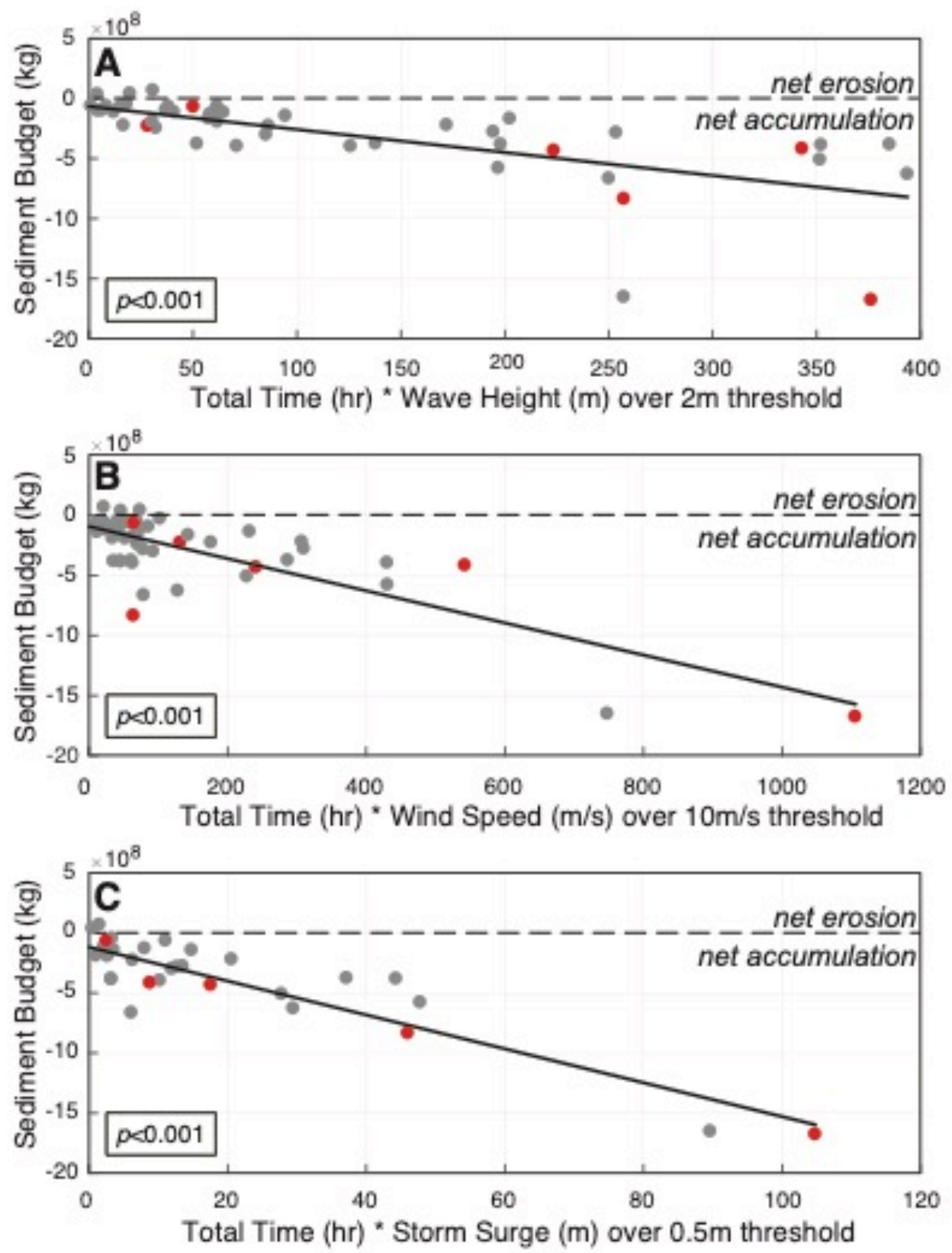

Figure 7.3 Sediment budget related to magnitude and duration of study parameter. Relationship between sediment budget and the product between magnitude and duration of (a) wave height above $2 \mathrm{~m}\left(R^{2}=0.47\right.$; $\left.p<0.001\right)$ (b) wind speed above $10 \mathrm{~m} / \mathrm{s}\left(R^{2}=0.63 ; p<0.001\right)$ and (c) storm surge above $0.5 \mathrm{~m}\left(R^{2}=0.80 ; p<0.001\right)$. There is a negative sediment budget (net accumulation of sediment into the system) as all study parameters increase in magnitude and duration. Red circles indicate named tropical cyclones. 

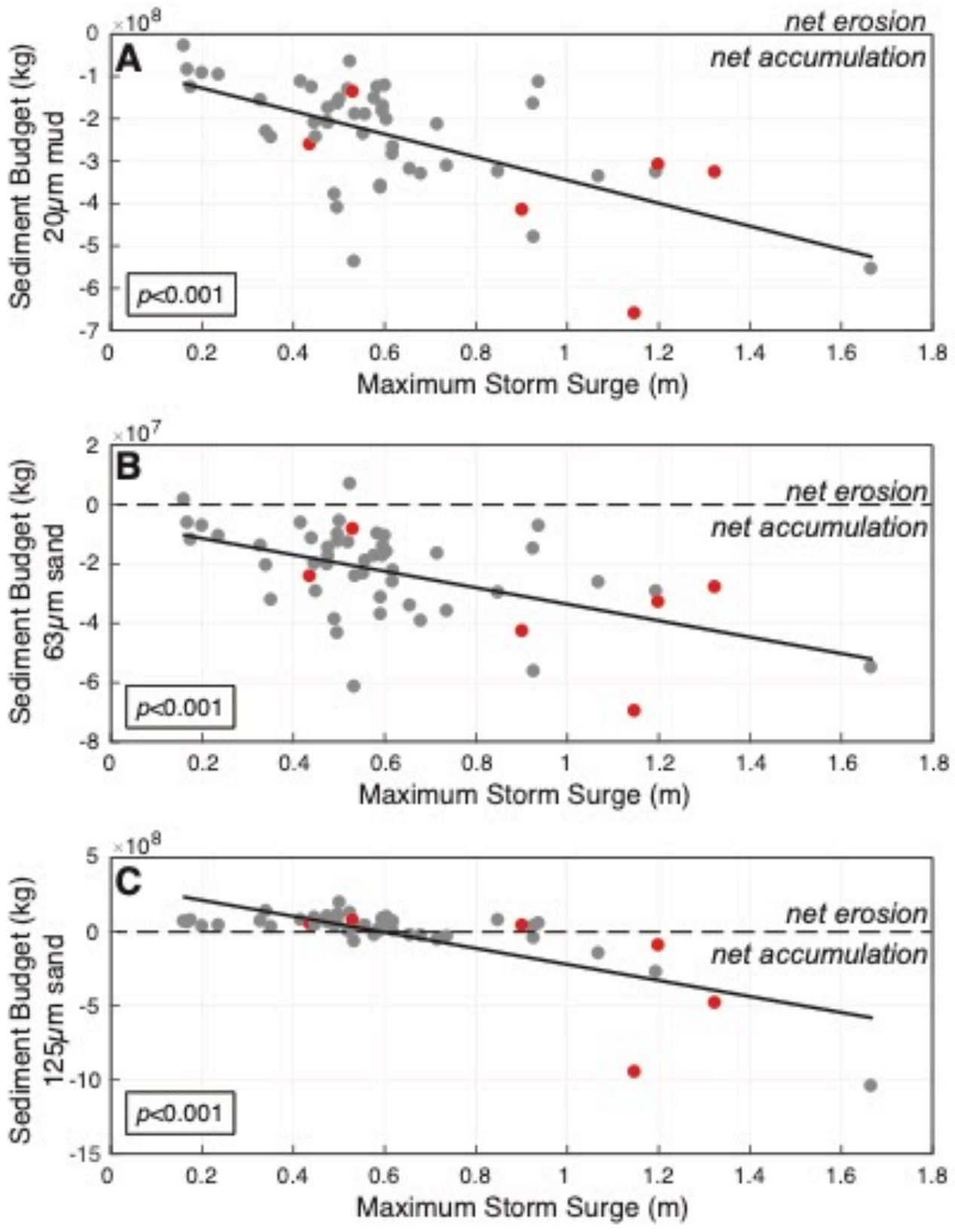

Figure 7.4 Sediment budget by grain size related to maximum storm surge. Relationship between maximum storm surge measured at NOAA stations 8631044 and 8638863 and total cumulative flux of (a) $20 \mu \mathrm{m}$ mud $\left(R^{2}=0.39 ; p<0.001\right)$, (b) $63 \mu \mathrm{m}$ very fine sand $\left(R^{2}=0.28 ; p<0.001\right)$, and (c) $125 \mu \mathrm{m}$ fine sand $\left(R^{2}=0.57 ; p<0.001\right)$. There is a significant negative relationship between total cumulative flux and intensity of storm surge for mud $(20 \mu \mathrm{m})$ and very fine sand $(63 \mu \mathrm{m})$, indicating net accumulation. Though there is a negative relationship between total cumulative flux and storm surge for coarse sand $(125 \mu \mathrm{m})$, total cumulative flux is predominantly greater than zero, indicating net erosion for most study storms. Red circles indicate named tropical cyclones. 


\subsection{Appendices}

\section{Introduction}

The following figures and tables are supporting information for the methods used in the article. Storm events to be simulated on the model domain were determined using a peaks-over-threshold analysis (Fig. S1; Table S1). The model domain consisted of a nested grid system, allowing the use of offshore, deep-water wave and water level measurements for our analysis (Fig. S2). The water level signal was adjusted, finding good agreement in both measured and modeled tidal amplitude and phase (Fig. S3). The model was then calibrated using a March 2014 storm (Fig. S4). Measured and modeled suspended sediment concentration for a three-week span in January 2004 showed good agreement, validating the model. Relationships between sediment budget $(\mathrm{kg})$ and storm meteorology (wave height, wind speed, storm surge, and the time over a given threshold with each) are all statistically significant $(\mathrm{p}<0.001)$, with values associated with storm surge explaining the most of the variance (Table S2). Sediment budget as a function of grain-size distribution was positively related to storm surge values for all three grain sizes $(p<0.001$; Table S3). 

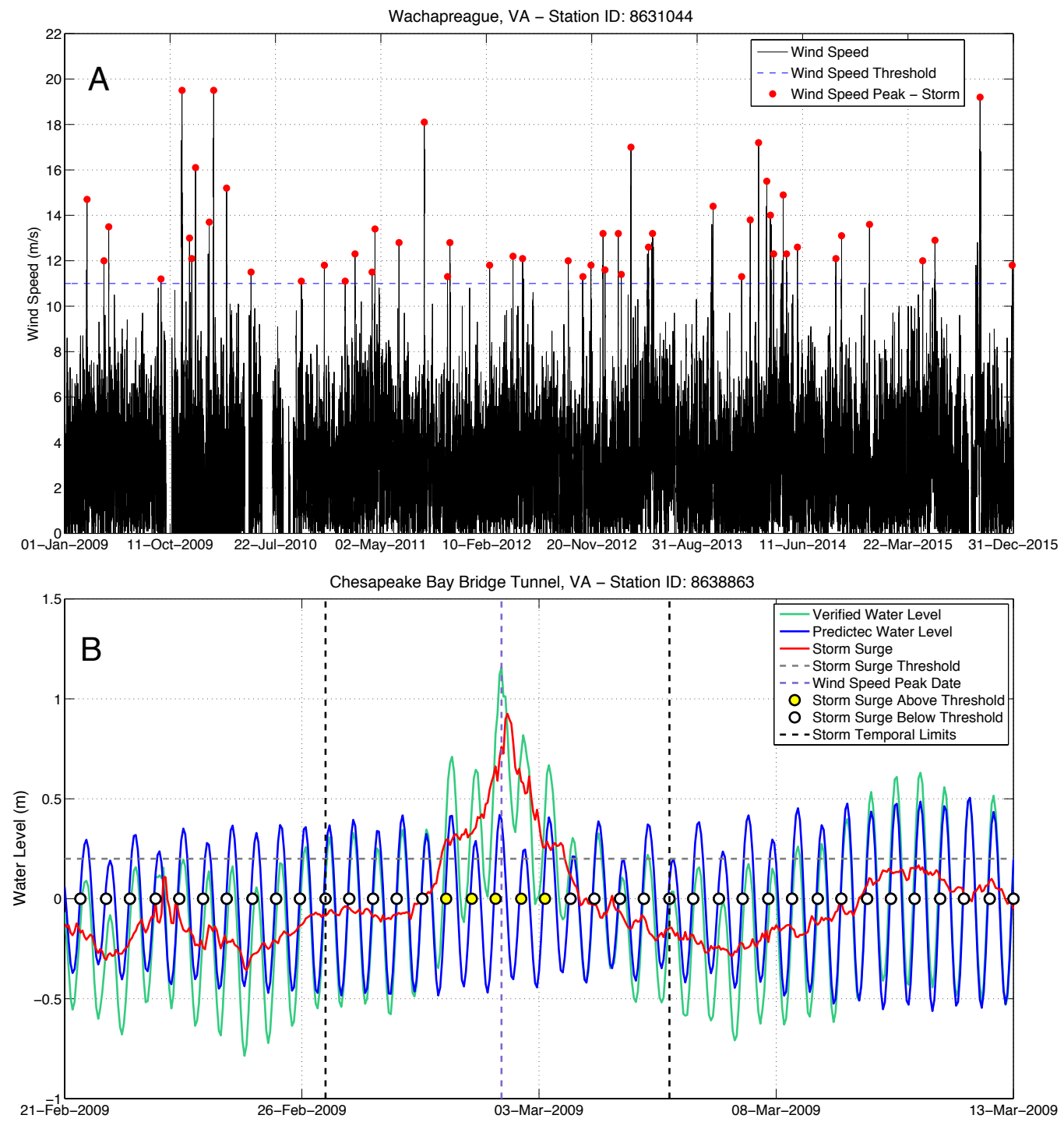

Figure 7.S1 Determining storm characteristics. (a) Peaks Over Threshold analysis for wind speed. Only events with a wind speed above $11 \mathrm{~m} / \mathrm{s}$ were considered as storms (b) Example of identification of a storm period. The storm ends after four full tides having a storm surge below $0.2 \mathrm{~m}$. 


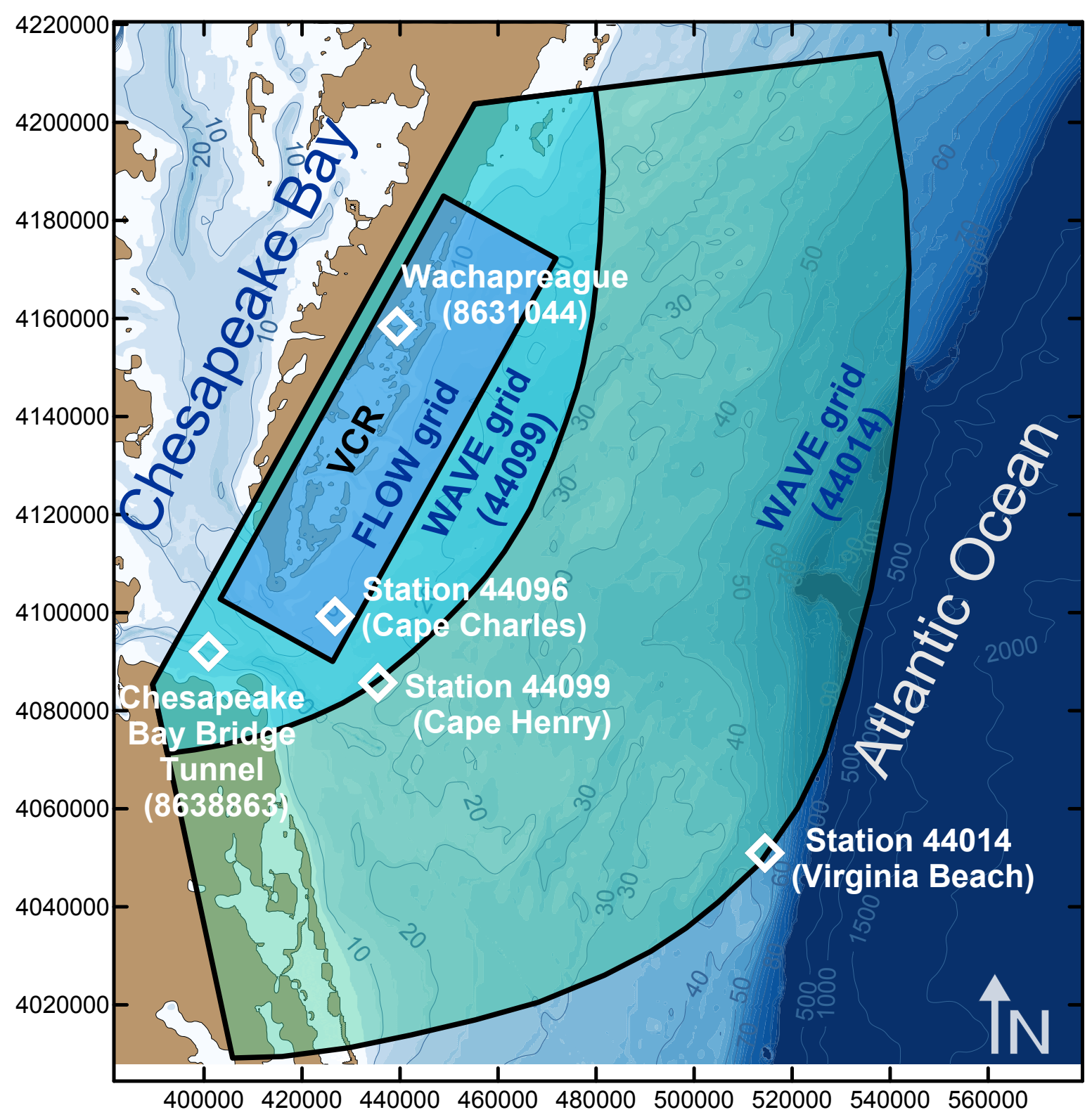

Figure 7.S2 Nested grid system. Numerical grids used for modeling tidal flows and waves. 


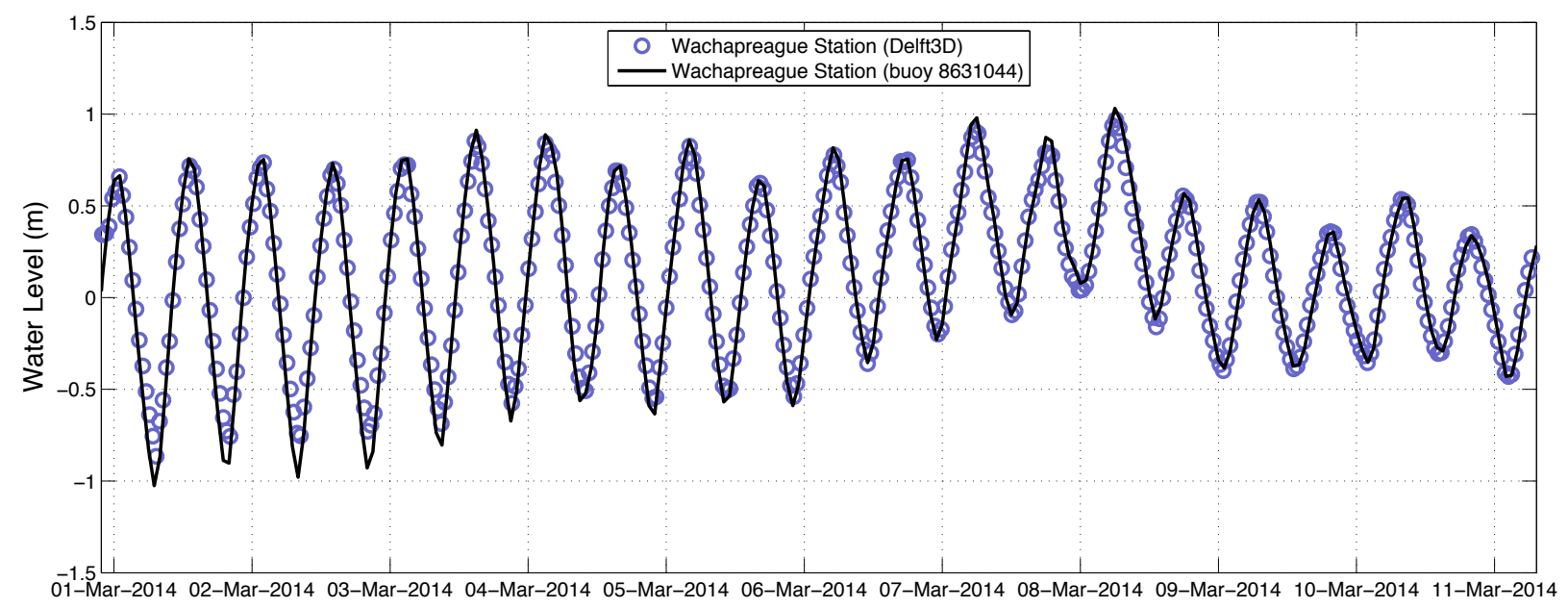

Figure 7.S3 Comparison between modeled and measured water levels. Computed (blue circles) and measured (black line) water levels at NOAA station 8631044 (Wachapreague, VA) during storm number 40 (see Table S1). Model performance was evaluated by adjusting the water level forcing (both phase and amplitude) at the southern, northern and seaward open boundaries in order to obtain the measured water levels at NOAA station 8631044 (Wachapreague, VA). Since the model forces offshore, deep-water wave data through a shallow-water system, it is necessary to adjust the offshore water level signal. A good agreement both in tidal amplitude and tidal phase was obtained $(\mathrm{ME}=$ $0.9814, \mathrm{RMSE}=0.0624 \mathrm{~m}, \mathrm{R}=0.9943, \mathrm{~S}=0.9898$ ) when imposing a water level signal delayed 54 min and dampened by a factor of $88 \%$. Thus, the dynamic inside the shallow water back-barrier tidal basin system is assumed to be properly simulated since its main governing agent is satisfactorily recreated by the numerical model. 

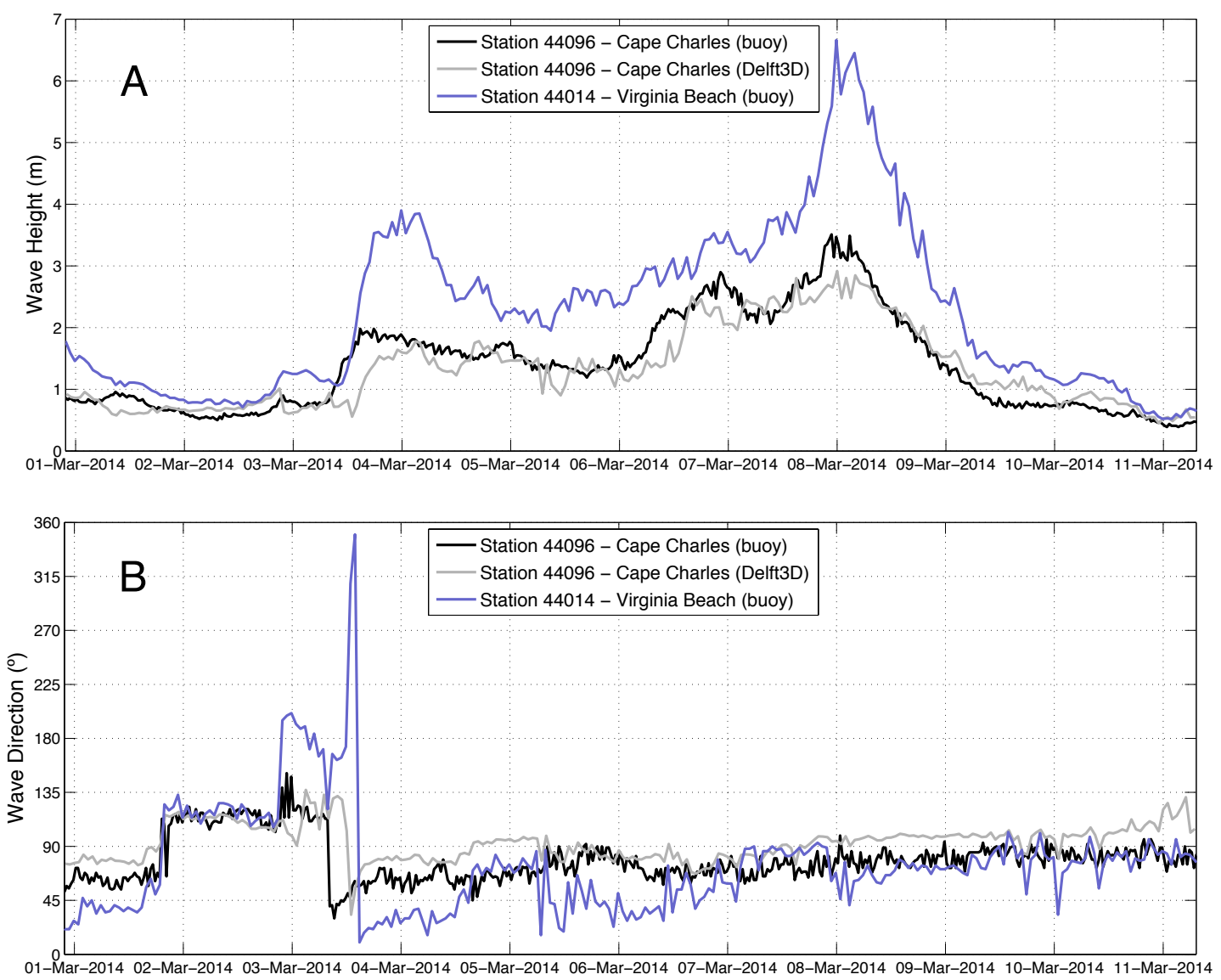

Figure 7.S4 Model calibration. Comparison of computed (grey) and measured (black) (a) wave height and (b) wave direction at the location of the 44096 NOAA buoy during storm number 40 (see Table S1). Blue lines indicate the wave conditions collected by the NOAA 44014 buoy and imposed at the boundary of the domain. For waves: Model Efficiency $\mathrm{ME}=0.8475$, root-mean square error RMSE $=0.3000 \mathrm{~m}$, correlation coefficient $\mathrm{R}=0.9269$, skill $\mathrm{S}=0.9113$. For wave direction: $\mathrm{ME}=$ $0.3359, \mathrm{RMSE}=20.7374, \mathrm{R}=0.5884, \mathrm{~S}=0.4224$. For definition of parameters, see Mariotti et al. (2010) and Olabarrieta et al. 2011). 


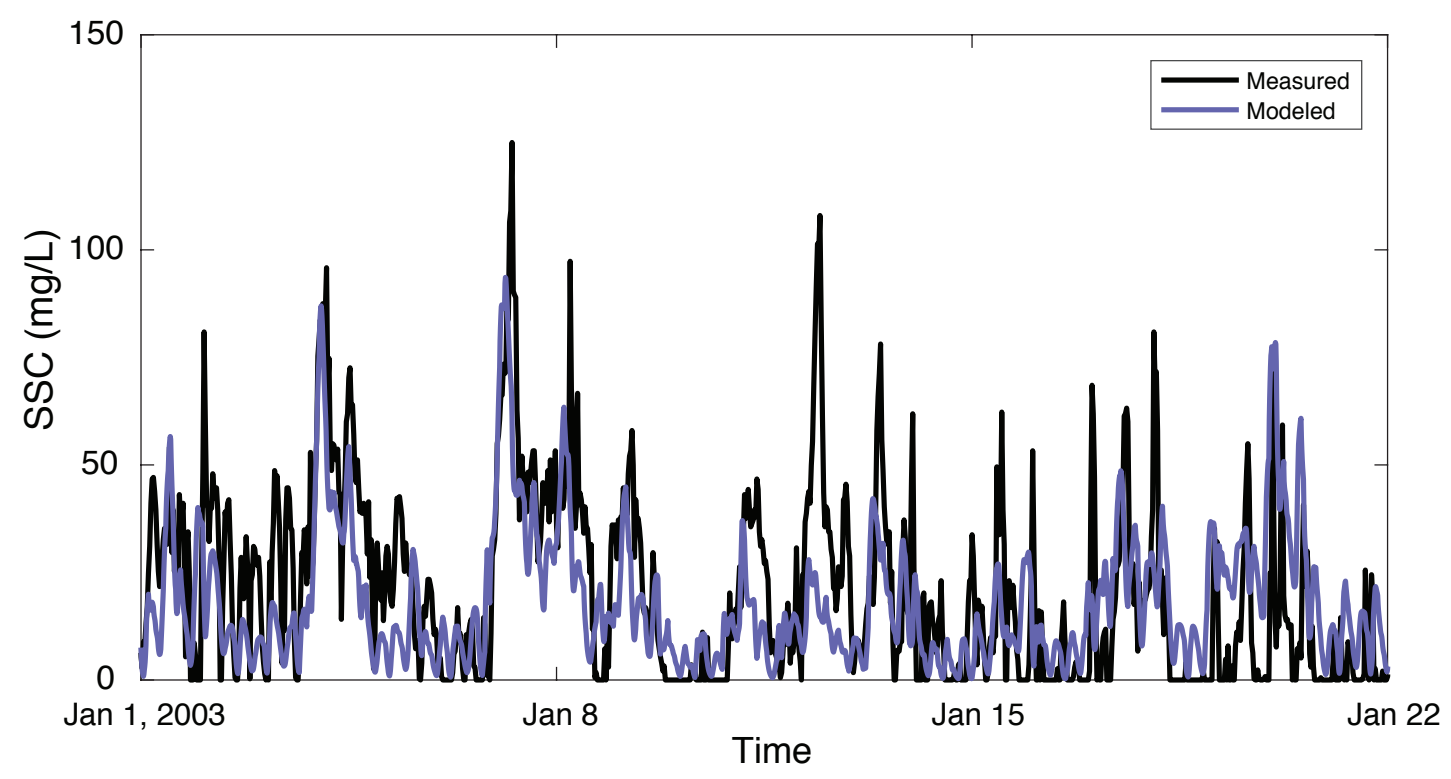

Figure 7.S5 Comparison between modeled and measured suspended sediment

concentrations. Measured and modeled SSC for a three-week span in January 2003. The sediment concentration was computed from the backscatter of an Acoustic Doppler Profiler $37^{\circ} 23^{\prime} 52.78^{\prime \prime} \mathrm{N}$, $75^{\circ} 43^{\prime} 43.83^{\prime \prime W}$ and calibrated with in situ SSC measurements. Model Efficiency ME $=-0.1783$, root-mean square error RMSE $=22.8376 \mathrm{mg} / 1$, correlation coefficient $\mathrm{R}=0.2571$, skill $\mathrm{S}=0.2430$; after Wiberg et al. (2015). 
Table 7.S1 Storm data. Starting and ending dates of simulated storms, including the tide station and wave buoy where the data were acquired.

\begin{tabular}{|c|c|c|c|c|c|c|c|c|}
\hline $\begin{array}{l}\text { Storm } \\
\#\end{array}$ & $\begin{array}{l}\text { Storm Peak } \\
\text { Time }\end{array}$ & $\begin{array}{l}\text { Simulation } \\
\text { Start }\end{array}$ & $\begin{array}{l}\text { Simulation } \\
\text { End }\end{array}$ & NTS & $\begin{array}{l}\text { Wind } \\
\text { Source, } \\
\text { Smaller } \\
\text { Grid }\end{array}$ & $\begin{array}{l}\text { Wind } \\
\text { Source, } \\
\text { Larger } \\
\text { Grid }\end{array}$ & $\begin{array}{l}\text { Wave } \\
\text { Data } \\
\text { Source }\end{array}$ & $\begin{array}{l}\text { Water } \\
\text { Level } \\
\text { Source }\end{array}$ \\
\hline 1 & $3 / 2 / 09$ 5:00 & 26-2-09 12:00 & 5-3-09 18:00 & 175 & WACH & CHLV2 & 44099 & WACH \\
\hline 2 & 4/16/09 19:00 & 13-4-09 13:00 & 19-4-09 6:00 & 138 & WACH & CHLV2 & 44099 & WACH \\
\hline 3 & 4/29/09 17:00 & 27-4-09 12:00 & 2-5-09 4:00 & 113 & WACH & CHLV2 & 44099 & WACH \\
\hline 4 & $9 / 17 / 09$ 13:00 & 12-9-09 15:00 & 21-9-09 0:00 & 202 & WACH & CHLV2 & 44099 & WACH \\
\hline 5 & 11/13/09 1:00 & 10-11-09 4:00 & $22-11-092: 00$ & 287 & WACH & CHLV2 & 44099 & WACH \\
\hline 6 & 12/3/09 7:00 & $30-11-09$ 21:00 & 13-12-09 8:00 & 300 & WACH & 44014 & 44014 & WACH \\
\hline 7 & 12/9/09 10:00 & 2-12-09 23:00 & 13-12-09 8:00 & 250 & WACH & 44014 & 44014 & WACH \\
\hline 8 & $\begin{array}{l}12 / 19 / 0914: 00 \\
\end{array}$ & 13-12-09 8:00 & $24-12-09$ 4:00 & 261 & WACH & 44014 & 44014 & WACH \\
\hline 9 & 1/25/10 14:00 & 15-1-10 11:00 & $27-1-1021: 00$ & 299 & WACH & CHLV2 & 44099 & WACH \\
\hline 10 & 2/6/10 8:00 & 1-2-10 0:00 & 10-2-10 21:00 & 238 & WACH & 44014 & 44014 & WACH \\
\hline 11 & 3/13/10 5:00 & 10-3-10 6:00 & 21-3-10 1:00 & 260 & WACH & CHLV2 & 44099 & WACH \\
\hline 12 & 5/18/10 2:00 & 15-5-10 12:00 & $22-5-10$ 18:00 & 175 & WACH & CHLV2 & 44099 & WACH \\
\hline 13 & 9/30/10 17:00 & 28-9-10 13:00 & 8-10-10 10:00 & 238 & WACH & CHLV2 & 44099 & WACH \\
\hline 14 & $12 / 1 / 1015: 00$ & $29-11-104: 00$ & $3-12-10$ 21:00 & 114 & WACH & CHLV2 & 44099 & \\
\hline 15 & 1/26/11 16:00 & 24-1-11 2:00 & 30-1-11 21:00 & 164 & WACH & CHLV2 & 44099 & $\mathrm{ACH}$ \\
\hline 16 & $2 / 22 / 116: 00$ & 20-2-11 0:00 & $25-2-11$ 17:00 & 138 & WACH & CHLV2 & 44099 & $\mathrm{ACH}$ \\
\hline 17 & 4/9/11 5:00 & 6-4-11 12:00 & $12-4-11 \quad 17: 00$ & 150 & WACH & CHLV2 & 44099 & WACH \\
\hline 18 & $4 / 16 / 1123: 00$ & 11-4-11 16:00 & 20-4-11 12:00 & 213 & WACH & CHLV2 & 44099 & WACH \\
\hline 19 & 6/20/11 16:00 & 11-6-11 6:00 & 23-6-11 4:00 & 287 & WACH & CHLV2 & 44099 & WACH \\
\hline 20 & $8 / 27 / 11$ 19:00 & 24-8-11 18:00 & 30-8-11 11:00 & 128 & WACH & 44014 & 44014 & WACH \\
\hline 21 & 10/29/11 11:00 & $27-10-11$ 10:00 & $31-10-11$ 13:00 & 100 & WACH & CHLV2 & 44099 & WACH \\
\hline 22 & $\begin{array}{l}11 / 4 / 11 \text { 19:00 } \\
\end{array}$ & $3-11-11$ 17:00 & $7-11-1120: 00$ & 100 & WACH & 44014 & 44014 & WACH \\
\hline 23 & $2 / 20 / 12$ 0:00 & $17-2-12$ 7:00 & $23-2-12$ 12:00 & 150 & WACH & CHLV2 & 44099 & WACH \\
\hline 24 & 4/22/12 19:00 & 16-4-12 19:00 & 25-4-12 13:00 & 211 & WACH & CHLV2 & 44099 & WACH \\
\hline 25 & 5/18/12 16:00 & 15-5-12 19:00 & 25-5-12 1:00 & 223 & WACH & CHLV2 & 44099 & WACH \\
\hline 26 & 9/18/12 16:00 & 16-9-12 10:00 & 21-9-12 2:00 & 113 & WACH & CHLV2 & 44099 & WACH \\
\hline 27 & 10/28/12 0:00 & $23-10-12$ 17:00 & 4-11-12 13:00 & 285 & WACH & CHLV2 & 44099 & WACH \\
\hline 28 & 11/18/12 17:00 & 12-11-12 21:00 & $26-11-12$ 22:00 & 338 & WACH & CHLV2 & 44099 & WACH \\
\hline 29 & 12/21/12 8:00 & $14-12-12$ 11:00 & $24-12-12$ 8:00 & 238 & WACH & CHLV2 & 44099 & WACH \\
\hline 30 & 12/26/12 18:00 & 23-12-12 20:00 & 1-1-13 13:00 & 210 & WACH & CHLV2 & 44099 & WACH \\
\hline 31 & 1/31/13 8:00 & $29-1-13$ 0:00 & $2-2-13$ 15:00 & 112 & WACH & CHLV2 & 44099 & WACH \\
\hline 32 & 2/8/13 12:00 & 5-2-13 19:00 & 13-2-13 1:00 & 175 & WACH & CHLV2 & 44099 & WACH \\
\hline 33 & 3/6/13 13:00 & 4-11-13 3:00 & 15-11-13 13:00 & 275 & WACH & CHLV2 & 44099 & WACH \\
\hline 34 & 4/22/13 21:00 & $20-4-13$ 6:00 & $26-4-13$ 23:00 & 162 & WACH & CHLV2 & 44099 & WACH \\
\hline 35 & 5/3/13 15:00 & $28-4-13$ 13:00 & 10-5-13 23:00 & 299 & WACH & CHLV2 & 44099 & WACH \\
\hline 36 & 10/13/13 21:00 & 6-10-13 0:00 & 19-10-13 0:00 & 326 & WACH & CHLV2 & 44099 & WACH \\
\hline 37 & $\begin{array}{l}12 / 29 / 1318: 00 \\
\end{array}$ & $27-12-136: 00$ & $31-12-13$ 22:00 & 113 & WACH & CHLV2 & 44099 & WACH \\
\hline 38 & 1/21/14 20:00 & 19-1-14 1:00 & $26-1-14$ 19:00 & 187 & WACH & CHLV2 & 44099 & WACH \\
\hline 39 & 2/13/14 10:00 & 10-2-14 20:00 & 17-2-14 0:00 & 149 & WACH & CHLV2 & 44099 & WACH \\
\hline 40 & 3/7/14 15:00 & 28-2-14 22:00 & 11-3-14 7:00 & 250 & WACH & CHLV2 & 44099 & WACH \\
\hline 41 & 3/17/14 3:00 & 14-3-14 9:00 & 22-3-14 15:00 & 199 & WACH & CHLV2 & 44099 & WACH \\
\hline 42 & $3 / 25 / 14$ 21:00 & 23-3-14 3:00 & 28-3-14 21:00 & 139 & WACH & 44014 & 44014 & WACH \\
\hline 43 & 4/20/14 16:00 & 14-4-14 22:00 & 25-4-14 19:00 & 262 & WACH & CHLV2 & 44099 & WACH \\
\hline 44 & $4 / 29 / 14$ 12:00 & $24-4-14$ 19:00 & $3-5-14$ 1:00 & 199 & WACH & CHLV2 & 44099 & WACH \\
\hline 45 & 5/29/14 1:00 & $26-5-14$ 21:00 & 4-6-14 15:00 & 211 & WACH & CHLV2 & 44099 & WACH \\
\hline 46 & 9/9/14 12:00 & 7-9-14 8:00 & 12-9-14 0:00 & 113 & WACH & CHLV2 & 44099 & WACH \\
\hline 47 & $9 / 25 / 140: 00$ & 22-9-14 9:00 & 29-9-14 13:00 & 173 & WACH & CHLV2 & 44099 & WACH \\
\hline 48 & $12 / 9 / 14$ 5:00 & 4-12-14 8:00 & $13-12-14$ 15:00 & 224 & WACH & CHLV2 & 44099 & WACH \\
\hline
\end{tabular}




\begin{tabular}{|l|l|l|l|l|l|l|l|l|}
$\mathbf{4 9}$ & $5 / 1 / 1513: 00$ & $28-4-1519: 00$ & $5-5-1512: 00$ & 162 & WACH & CHLV2 & 44099 & WACH \\
\hline $\mathbf{5 0}$ & $6 / 3 / 1514: 00$ & $31-5-159: 00$ & $8-6-1515: 00$ & 199 & WACH & CHLV2 & 44099 & WACH \\
\hline $\mathbf{5 1}$ & $10 / 2 / 1523: 00$ & $29-9-1511: 00$ & $10-10-158: 00$ & 262 & WACH & CHLV2 & 44099 & WACH \\
\hline $\mathbf{5 2}$ & $12 / 28 / 1515: 00$ & $26-12-1511: 00$ & $3-1-1618: 00$ & 200 & WACH & CHLV2 & 44099 & WACH \\
\hline
\end{tabular}

Table 7.S2 Storm meteorology statistics. Coefficients of determination for the relationships between sediment budget $(\mathrm{kg})$ and storm meteorology.

\begin{tabular}{|l|l|l|}
\hline Total Cumulative Sediment Flux $(\mathrm{kg})$ & $\mathrm{R}^{2}$ & $p$ \\
\hline Maximum wave height $(\mathrm{m})$ & 0.30 & $<0.001$ \\
\hline Maximum wind speed $(\mathrm{m} / \mathrm{s})$ & 0.22 & $<0.001$ \\
\hline Maximum storm surge $(\mathrm{m})$ & 0.57 & $<0.001$ \\
\hline Total time $(\mathrm{s}) *$ wave height $(\mathrm{m})$ over $2 \mathrm{~m}$ threshold & 0.47 & $<0.001$ \\
\hline Total time $(\mathrm{s}) *$ wind speed $(\mathrm{m} / \mathrm{s})$ over $10 \mathrm{~m} / \mathrm{s}$ threshold & 0.63 & $<0.001$ \\
\hline Total time $(\mathrm{s}) *$ storm surge $(\mathrm{m})$ over $0.5 \mathrm{~m}$ threshold & 0.80 & $<0.001$ \\
\hline
\end{tabular}

Table 7.S3 Grain-size distribution and storm surge statistics. Coefficients of determination for the relationships between maximum storm surge $(\mathrm{m})$ and the total cumulative flux of the three types of sediment in the model.

\begin{tabular}{|l|l|l|}
\hline Maximum storm surge $(\mathrm{m})$ & $\mathrm{R}^{2}$ & $p$ \\
\hline Sediment budget, $20 \mu \mathrm{m}$ mud $(\mathrm{kg})$ & 0.39 & $<0.001$ \\
\hline Sediment budget, $63 \mu \mathrm{m}$ sand $(\mathrm{kg})$ & 0.28 & $<0.001$ \\
\hline Sediment budget, $125 \mu \mathrm{m}$ sand $(\mathrm{kg})$ & 0.57 & $<0.001$ \\
\hline
\end{tabular}




\section{Conclusions}

This thesis characterizes the varied signatures of past tropical cyclones in coastal ponds and marshes along the eastern coast of the United States. This work deviates from traditional one-core, one-site analysis, instead exploring the benefits of a more expansive, process-based approach in both site selection and grain-size analysis. This extensive literature review of Chapter 2 reveals a high degree of spatial variability, both in terms of deposition and erosion, during both past and modern storm events. Our extensive analysis of storm events along the eastern coast of the United States confirms this finding. Given the spectrum of potential impacts of tropical cyclones on salt marshes (Chapters 2, 4, 5, 6, and 7) and coastal ponds (Chapters 3 and 5), in-depth analysis of complex sedimentary signatures is necessary to build better paleo-reconstructions of storm frequency and intensity. This is of particular importance as the frequency of intense hurricanes, augmented by sea-level rise (Woodruff et al., 2013), is expected to increase in the coming century (Bhatia et al., 2018; Emanuel, 2013; Korty et al., 2017).

Chapter 3, building on work by Donnelly et al. (2015), expands on the idea of whole-site analysis. Extensive analysis of coarse fraction across a transect of cores reveals a robust, replicable storm frequency record in a coastal kettle pond in Falmouth, MA. Analysis of the grain-size distribution of these events, however, suggests that the significant spatial and temporal variation in samples is likely due to nonuniformity in sediment source. Chapter 4 follows the model of Chapter 3, using grain-size distributions to determine trends in storm-induced deposits in a back-barrier marsh in Mattapoisett, MA. Similar to Chapter 3, analysis of grain-size trends in the back-barrier indicates substantial spatial and temporal variation. Previous reconstructions of storm frequency have assumed that event deposits occur from relatively straight-forward overwash dynamics, but a deeper look into the true intricacies of these event trends requires a more nuanced, process-based technique.

Where Chapters 3 and 4 focus on reconstructing storm frequency, Chapter 5 assesses the utility of inverse modeling to reconstruct storm intensity from the maximum grain size of a deposit. Here, we present an approach updated from that proposed by Woodruff et al. (2008), which uses synthetic storm results to generate location-specific storm wave characteristics. Though model results were consistent with historic values, error was sizeable due to the model's sensitivity to natural variations. As with the previous chapter, a whole-site approach, including in-depth analysis of sediment transport trends, aids in smart selection of cores and events for further intensity analysis. 
Though analysis of prehistoric storm intensity remains difficult to quantify (Chapter 5), Chapter 6 explores the potential for salt marshes to be eroded by one or a series of high-intensity storms. Through testing the van de Plassche et al. (2006) hypothesis that a $\sim 600$-year hiatus in a Connecticut salt marsh was associated with erosion from the Great Colonial Hurricane of 1635, we find that, though the hiatus and associated stratigraphic sequence are likely due to a high-energy event such as a hurricane, the intensity of the 1635 storm alone was not enough to cause such pervasive erosion. If the erosion is from degradation by storms over a longer time period, as posited, it suggests that periods of increased storm frequency of intense storms may have detrimental effects on the resilience of marshes. Again, this finding and subsequent interpretation was only possible through extensive analysis of a transect of several sediment cores throughout the marsh to determine how storm signatures vary across spatial and temporal scales.

To geographically expand our analysis of storm impacts to an entire coastal system, we turn to the high-resolution, three-dimensional modeling in Chapter 7. Chapter 7 uses this modeling to determine the impacts of storms on the sediment budget of a system of coastal marshes and bays in Virginia. While the real storm data simulated in the system were largely marked by lower wind speeds $(<24 \mathrm{~m} / \mathrm{s})$, model results show that intense storms import more sediment into the system than less intense storms. This suggests that the resilience of these systems may actually increase as storm intensity increases, but it remains to be seen if a certain threshold of intensity exists at which sediment erosion overpowers accumulation.

Viewed as a whole, this thesis explores the sedimentary signatures of storm events along the eastern coast of the United States through a variety of methods. Deposition and erosion of sediment during a major storm remain both nuanced and complex, emphasizing the importance of contextualizing storm signatures within a broader, process-based view of the study area. Future work in this area should delve deeper into these processes and their impacts on sediment signatures with the aid of both expanded field campaigns and hydrodynamic modeling, with particular focus on the potential for these systems to be severely damaged by intense storms. Improving our understanding of these signatures and the processes behind them strengthens both paleo-reconstructions of storm activity and our ability to make informed decisions regarding coastal management in the face of future changes in storminess. 


\section{Appendices}

A. Salt Pond grain-size distribution data

\begin{tabular}{|c|c|c|c|c|c|c|}
\hline Core & $\begin{array}{c}\text { Event } \\
\text { (per Donnelly } \\
\text { et al., 2015) }\end{array}$ & $\begin{array}{c}\text { Coarse } \\
\text { Fraction (\%) }\end{array}$ & $\mathrm{D} 10(\mu \mathrm{m})$ & $\mathrm{D} 50(\mu \mathrm{m})$ & $\mathrm{D} 90(\mu \mathrm{m})$ & $\begin{array}{l}\text { D90 standard } \\
\text { deviation }(\mu \mathrm{m})\end{array}$ \\
\hline SAP1B & 1 & 10.72 & 61.80 & 183.60 & 705.20 & 272.45 \\
\hline SAP1B & 1938 & 16.14 & 55.67 & 100.33 & 433.00 & 140.63 \\
\hline SAP1B & 2 & 13.03 & 56.67 & 148.33 & 685.33 & 161.58 \\
\hline SAP1B & 3 & 27.44 & 58.33 & 117.00 & 434.00 & 25.16 \\
\hline SAP1B & 4 & 7.24 & 58.33 & 183.33 & 733.00 & 108.50 \\
\hline SAP1B & 5 & 8.14 & 54.00 & 113.00 & 570.00 & 75.54 \\
\hline SAP1B & 6 & 7.44 & 50.00 & 92.50 & 485.25 & 76.20 \\
\hline SAP1B & 7 & 15.03 & 52.67 & 89.33 & 220.00 & 63.17 \\
\hline SAP1B & 8 & 9.35 & 56.00 & 159.00 & 785.50 & 43.13 \\
\hline SAP1B & 9 & 5.34 & 54.67 & 157.33 & 919.33 & 265.01 \\
\hline SAP1B & 10 & 6.73 & 57.00 & 142.00 & 714.00 & 9.90 \\
\hline SAP1B & 11 & 4.62 & 49.00 & 85.50 & 313.50 & 86.97 \\
\hline SAP1B & 12 & 18.16 & 58.50 & 125.00 & 552.50 & 43.13 \\
\hline SAP1B & 25 & 16.61 & 55.00 & 105.75 & 350.25 & 56.81 \\
\hline SAP1B & 26 & 44.75 & 53.67 & 98.00 & 294.33 & 134.69 \\
\hline SAP8A & 1 & 10.68 & 58.50 & 171.75 & 711.25 & 225.36 \\
\hline SAP8A & 1938 & 6.25 & 60.00 & 153.50 & 678.00 & 74.95 \\
\hline SAP8A & 2 & 13.00 & 55.50 & 109.50 & 332.50 & 24.75 \\
\hline SAP8A & 3 & 16.48 & 56.00 & 110.00 & 367.67 & 36.69 \\
\hline SAP8A & 4 & 5.59 & 56.40 & 150.60 & 576.80 & 122.76 \\
\hline SAP8A & 5 & 7.16 & 55.00 & 122.00 & 604.00 & 24.04 \\
\hline SAP8A & 6 & 13.82 & 61.00 & 237.67 & 595.00 & 69.94 \\
\hline SAP8A & 7 & 6.25 & 52.00 & 97.33 & 467.33 & 79.74 \\
\hline SAP8A & 8 & 8.34 & 56.00 & 134.33 & 729.00 & 46.86 \\
\hline SAP8A & 9 & 14.52 & 52.67 & 99.67 & 375.67 & 62.74 \\
\hline SAP8A & 10 & 6.14 & 54.00 & 107.00 & 491.50 & 30.41 \\
\hline SAP8A & 11 & 17.84 & 52.00 & 83.75 & 181.50 & 30.92 \\
\hline SAP8A & 12 & 12.47 & 54.75 & 94.25 & 256.25 & 72.82 \\
\hline SAP8A & 25 & 14.92 & 53.50 & 91.00 & 275.50 & 106.77 \\
\hline SAP8A & 26 & 16.83 & 52.00 & 89.00 & 258.00 & 57.98 \\
\hline SAP9 & 1 & 15.24 & 54.80 & 105.00 & 633.60 & 79.41 \\
\hline SAP9 & 1938 & 13.36 & 53.60 & 97.00 & 671.60 & 386.09 \\
\hline SAP9 & 2 & 11.35 & 61.50 & 143.00 & 799.50 & 50.20 \\
\hline SAP9 & 3 & 15.24 & 55.00 & 99.00 & 383.33 & 87.90 \\
\hline SAP9 & 4 & 4.46 & 57.00 & 104.50 & 475.50 & 16.26 \\
\hline SAP9 & 5 & 5.16 & 55.33 & 108.67 & 454.00 & 63.84 \\
\hline SAP9 & 6 & 8.16 & 59.67 & 139.67 & 676.00 & 17.90 \\
\hline
\end{tabular}




\begin{tabular}{|l|c|c|c|c|c|c|}
\hline SAP9 & 7 & 8.76 & 59.33 & 222.33 & 894.00 & 246.68 \\
\hline SAP9 & 8 & 7.26 & 57.00 & 114.00 & 495.00 & 37.25 \\
\hline SAP9 & 9 & 8.91 & 61.67 & 147.33 & 586.00 & 208.32 \\
\hline SAP9 & 10 & 6.23 & 60.00 & 176.00 & 627.33 & 100.27 \\
\hline SAP9 & 11 & 16.43 & 58.50 & 117.00 & 375.00 & 111.54 \\
\hline SAP9 & 12 & 36.70 & 56.67 & 117.67 & 448.00 & 112.21 \\
\hline SAP9 & 25 & 15.24 & 62.50 & 146.00 & 609.50 & 184.55 \\
\hline SAP9 & 26 & 15.14 & 61.33 & 133.67 & 524.33 & 126.13 \\
\hline
\end{tabular}

\section{B. Mattapoisett grain-size distribution data}

\begin{tabular}{|c|c|c|c|c|c|c|}
\hline Core & $\begin{array}{c}\text { Event } \\
\text { (per Boldt et } \\
\text { al., 2010) }\end{array}$ & $\begin{array}{c}\text { Coarse } \\
\text { Fraction }(\%)\end{array}$ & $\mathrm{D} 10(\mu \mathrm{m})$ & $\mathrm{D} 50(\mu \mathrm{m})$ & $\mathrm{D} 90(\mu \mathrm{m})$ & $\begin{array}{l}\text { D90 standard } \\
\text { deviation }(\mu \mathrm{m})\end{array}$ \\
\hline Matt6 & 1 & 74.67 & 73.00 & 236.33 & 479.00 & 5.57 \\
\hline Matt6 & 2 & 81.67 & 83.00 & 242.67 & 617.00 & 18.25 \\
\hline Matt6 & 3 & 83.76 & 74.33 & 203.33 & 452.00 & 7.94 \\
\hline Matt6 & 4 & 81.14 & 75.33 & 206.67 & 472.33 & 13.20 \\
\hline Matt6 & 5 & 57.67 & 76.33 & 233.33 & 576.00 & 38.43 \\
\hline Matt6 & 7 & 8.73 & 51.00 & 117.67 & 698.67 & 179.49 \\
\hline Matt6 & 8 & 25.55 & 59.33 & 112.33 & 413.33 & 119.92 \\
\hline Matt6 & 9 & 75.78 & 89.33 & 277.33 & 516.00 & 10.54 \\
\hline Matt6 & 10 & 83.35 & 104.33 & 298.00 & 504.33 & 3.06 \\
\hline Matt6 & 11 & 56.12 & 90.00 & 263.00 & 452.33 & 1.15 \\
\hline Matt6 & 12 & 57.59 & 70.33 & 157.00 & 376.33 & 23.46 \\
\hline Matt6 & 15 & 48.51 & 62.00 & 113.50 & 246.50 & 13.44 \\
\hline Matt6 & 16 & 64.33 & 63.50 & 126.50 & 321.50 & 10.61 \\
\hline Matt6 & 19 & 33.14 & 54.33 & 91.67 & 174.67 & 14.05 \\
\hline Matt7a & 1 & 33.64 & 60.00 & 100.00 & 506.50 & 460.33 \\
\hline Matt7a & 2 & 26.76 & 50.00 & 90.00 & 275.00 & 127.28 \\
\hline Matt7a & 3 & 68.16 & 60.00 & 130.00 & 259.67 & 8.08 \\
\hline Matt7a & 4 & 50.85 & 53.00 & 100.00 & 192.50 & 13.44 \\
\hline Matt7a & 5 & 16.57 & 54.75 & 123.25 & 942.17 & 147.50 \\
\hline Matt7a & 6 & 12.99 & 51.25 & 104.25 & 627.08 & 162.07 \\
\hline Matt7a & 7 & 39.57 & 49.00 & 97.00 & 586.50 & 148.36 \\
\hline Matt7a & 8 & 12.96 & 53.67 & 139.00 & 667.67 & 130.66 \\
\hline Matt7a & 9 & 3.50 & 58.00 & 117.00 & 442.00 & 52.78 \\
\hline Matt7a & 10 & 3.00 & 53.33 & 132.33 & 737.00 & 966.83 \\
\hline Matt7a & 11 & 10.08 & 48.33 & 78.67 & 219.33 & 119.93 \\
\hline Matt7a & 12 & 2.75 & 51.67 & 128.33 & 1443.33 & 138.59 \\
\hline Matt7a & 13 & 10.21 & 50.67 & 88.33 & 633.67 & 24.75 \\
\hline Matt7a & 14 & 4.74 & 48.00 & 90.00 & 589.00 & 13.44 \\
\hline Matt7a & 15 & 15.97 & 55.50 & 117.00 & 842.50 & 330.94 \\
\hline Matt7a & 16 & 6.64 & 48.00 & 87.50 & 642.50 & 195.76 \\
\hline Matt7a & 17 & 10.68 & 52.00 & 98.33 & 667.00 & 36.94 \\
\hline
\end{tabular}




\begin{tabular}{|l|c|c|c|c|c|c|}
\hline Matt7a & 18 & 3.89 & 51.33 & 101.00 & 839.00 & 2.83 \\
\hline Matt7a & 19 & 12.57 & 53.67 & 105.67 & 789.67 & 57.28 \\
\hline Matt7a & 20 & 4.86 & 48.00 & 84.00 & 445.00 & 158.50 \\
\hline Matt7a & 21 & 27.29 & 50.75 & 96.58 & 337.08 & 95.11 \\
\hline Matt7a & 22 & 1.11 & 49.00 & 85.67 & 526.00 & 24.04 \\
\hline Matt7a & 23 & 1.96 & 52.00 & 93.67 & 389.67 & 644.05 \\
\hline Matt7a & 24 & 1.82 & 51.50 & 88.00 & 284.50 & 219.73 \\
\hline Matt7a & 25 & 5.79 & 46.00 & 73.00 & 198.00 & 757.31 \\
\hline Matt7a & 26 & 0.66 & 47.67 & 68.67 & 626.33 & 72.51 \\
\hline Matt7a & 27 & 1.90 & 49.00 & 68.67 & 240.33 & 88.69 \\
\hline Matt7a & 28 & 3.76 & 50.50 & 107.50 & 1601.50 & 219.31 \\
\hline Matt7a & 29 & 1.44 & 47.50 & 66.67 & 488.75 & 101.59 \\
\hline Matt7a & 30 & 5.71 & 47.50 & 71.67 & 563.00 & 270.45 \\
\hline Matt8 & 1 & 32.78 & 58.00 & 103.33 & 204.67 & 13.32 \\
\hline Matt8 & 2 & 50.12 & 54.33 & 99.00 & 194.00 & 17.35 \\
\hline Matt8 & 3 & 43.77 & 62.33 & 116.00 & 223.00 & 5.00 \\
\hline Matt8 & 4 & 15.22 & 53.67 & 102.33 & 624.33 & 229.38 \\
\hline Matt8 & 5 & 50.00 & 57.67 & 105.33 & 216.67 & 10.79 \\
\hline Matt8 & 6 & 16.75 & 57.00 & 114.50 & 681.50 & 79.90 \\
\hline Matt8 & 7 & 17.99 & 56.67 & 131.67 & 767.33 & 123.76 \\
\hline Matt8 & 8 & 12.53 & 54.67 & 109.67 & 694.00 & 147.41 \\
\hline Matt8 & 10 & 4.62 & 52.67 & 109.00 & 832.67 & 319.91 \\
\hline Matt8 & 11 & 11.75 & 56.00 & 104.00 & 489.00 & 1.41 \\
\hline Matt8 & 13 & 3.78 & 63.67 & 155.67 & 513.33 & 149.32 \\
\hline Matt8 & 14 & 1.75 & 51.00 & 90.50 & 635.00 & 325.27 \\
\hline Matt8 & 15 & 10.90 & 53.33 & 109.33 & 797.67 & 9.50 \\
\hline Matt8 & 16 & 15.50 & 57.67 & 102.67 & 524.33 & 149.28 \\
\hline Matt8 & 17 & 36.52 & 59.33 & 101.67 & 209.33 & 25.50 \\
\hline Matt8 & 18 & 5.70 & 53.00 & 106.00 & 484.50 & 187.38 \\
\hline Matt8 & 19 & 2.73 & 51.67 & 96.00 & 381.00 & 191.64 \\
\hline Matt8 & 20 & 23.72 & 52.50 & 96.50 & 603.50 & 149.20 \\
\hline Matt8 & 21 & 19.08 & 52.50 & 96.50 & 632.00 & 137.18 \\
\hline Matt8 & 22 & 20.75 & 58.67 & 113.33 & 572.67 & 222.60 \\
\hline
\end{tabular}




\section{Pattagansett coarse-fraction data}

\begin{tabular}{|c|c|c|c|}
\hline Core & Depth in core $(\mathrm{cm})$ & Organic Fraction (\%) & Coarse Fraction $(\%>63 \mu \mathrm{m})$ \\
\hline C15 & 0.5 & 49.67 & 2.38 \\
\hline $\mathrm{C} 15$ & 1.5 & 66.21 & 2.33 \\
\hline C15 & 2.5 & 65.72 & 1.45 \\
\hline C15 & 3.5 & 63.09 & 2.90 \\
\hline C15 & 4.5 & 61.60 & 1.36 \\
\hline C15 & 5.5 & 61.52 & 1.23 \\
\hline $\mathrm{C} 15$ & 6.5 & 59.41 & 1.52 \\
\hline $\mathrm{C} 15$ & 7.5 & 73.50 & 1.05 \\
\hline C15 & 8.5 & 69.68 & 0.51 \\
\hline $\mathrm{C} 15$ & 9.5 & 66.81 & 0.85 \\
\hline C15 & 10.5 & 66.65 & 0.93 \\
\hline C15 & 11.5 & 52.68 & 0.84 \\
\hline $\mathrm{C} 15$ & 12.5 & 43.06 & 0.79 \\
\hline $\mathrm{C} 15$ & 13.5 & 36.49 & 1.11 \\
\hline $\mathrm{C} 15$ & 14.5 & 21.53 & 2.39 \\
\hline C15 & 15.5 & 33.07 & 0.83 \\
\hline C15 & 16.5 & 31.43 & 1.99 \\
\hline C15 & 17.5 & 35.42 & 1.79 \\
\hline C15 & 18.5 & 41.16 & 0.37 \\
\hline C15 & 19.5 & 45.11 & 0.35 \\
\hline C15 & 20.5 & 39.53 & 0.38 \\
\hline C15 & 21.5 & 37.55 & 0.24 \\
\hline C15 & 22.5 & 42.51 & 0.30 \\
\hline C15 & 23.5 & 40.61 & 0.15 \\
\hline C15 & 24.5 & 38.68 & 0.26 \\
\hline C15 & 25.5 & 31.30 & 0.59 \\
\hline C15 & 26.5 & 23.77 & 1.23 \\
\hline C15 & 27.5 & 21.74 & 1.18 \\
\hline $\mathrm{C} 15$ & 28.5 & 26.95 & 1.16 \\
\hline C15 & 29.5 & 27.65 & 0.43 \\
\hline C15 & 30.5 & 30.72 & 2.15 \\
\hline $\mathrm{C} 15$ & 31.5 & 28.54 & 0.62 \\
\hline C15 & 32.5 & 27.67 & 0.46 \\
\hline C15 & 33.5 & 35.71 & 0.61 \\
\hline C15 & 34.5 & 35.15 & 0.37 \\
\hline C15 & 35.5 & 30.67 & 1.08 \\
\hline C15 & 36.5 & 33.20 & 0.77 \\
\hline C15 & 37.5 & 37.35 & 0.46 \\
\hline C15 & 38.5 & 35.81 & 0.49 \\
\hline C15 & 39.5 & 6.52 & 1.08 \\
\hline
\end{tabular}




\begin{tabular}{|c|c|c|c|}
\hline C15 & 40.5 & 46.96 & 1.13 \\
\hline C15 & 41.5 & 40.37 & 1.16 \\
\hline C15 & 42.5 & 20.81 & 4.22 \\
\hline $\mathrm{C} 15$ & 43.5 & 38.00 & 1.88 \\
\hline C15 & 44.5 & 44.28 & 0.87 \\
\hline C15 & 45.5 & 39.72 & 0.96 \\
\hline C15 & 46.5 & 30.55 & 0.37 \\
\hline C15 & 47.5 & 33.60 & 0.91 \\
\hline C15 & 48.5 & 34.04 & 0.98 \\
\hline $\mathrm{C} 15$ & 49.5 & 34.71 & 0.48 \\
\hline $\mathrm{C} 15$ & 50.5 & 39.53 & 0.52 \\
\hline C15 & 51.5 & 36.86 & 0.35 \\
\hline C15 & 52.5 & 34.80 & 0.39 \\
\hline $\mathrm{C} 15$ & 53.5 & 32.72 & 0.41 \\
\hline C15 & 54.5 & 30.70 & 0.20 \\
\hline C15 & 55.5 & 25.13 & 0.26 \\
\hline C15 & 56.5 & 23.88 & 0.46 \\
\hline $\mathrm{C} 15$ & 57.5 & 18.62 & 0.56 \\
\hline C15 & 58.5 & 31.83 & 1.85 \\
\hline $\mathrm{C} 15$ & 59.5 & 34.71 & 1.11 \\
\hline C15 & 60.5 & 36.59 & 0.50 \\
\hline C15 & 61.5 & 39.33 & 0.64 \\
\hline C15 & 62.5 & 36.06 & 0.26 \\
\hline $\mathrm{C} 15$ & 63.5 & 37.32 & 0.18 \\
\hline C15 & 64.5 & 38.55 & 0.22 \\
\hline C15 & 65.5 & 40.59 & 0.13 \\
\hline $\mathrm{C} 15$ & 66.5 & 41.39 & 0.14 \\
\hline $\mathrm{C} 15$ & 67.5 & 48.65 & 0.22 \\
\hline C15 & 68.5 & 48.80 & 0.29 \\
\hline C15 & 69.5 & 47.36 & 0.14 \\
\hline C15 & 70.5 & 38.77 & 0.29 \\
\hline C15 & 71.5 & 34.98 & 0.26 \\
\hline C15 & 72.5 & 21.85 & 0.18 \\
\hline C15 & 73.5 & 19.18 & 0.09 \\
\hline C15 & 74.5 & 22.02 & 0.38 \\
\hline C15 & 75.5 & 22.83 & 0.81 \\
\hline C15 & 76.5 & 20.74 & 1.19 \\
\hline C15 & 77.5 & 14.12 & 7.03 \\
\hline C15 & 78.5 & 16.68 & 8.16 \\
\hline C15 & 79.5 & 19.62 & 6.70 \\
\hline $\mathrm{C} 15$ & 80.5 & 21.69 & 4.24 \\
\hline $\mathrm{C} 15$ & 81.5 & 29.71 & 5.08 \\
\hline C15 & 82.5 & 37.06 & 2.89 \\
\hline
\end{tabular}




\begin{tabular}{|c|c|c|c|}
\hline C15 & 83.5 & 41.03 & 2.64 \\
\hline C15 & 84.5 & 21.60 & 7.05 \\
\hline C15 & 85.5 & 6.30 & 9.99 \\
\hline C15 & 86.5 & 9.03 & 8.51 \\
\hline C15 & 87.5 & 19.54 & 8.27 \\
\hline C15 & 88.5 & 39.13 & 5.40 \\
\hline C15 & 89.5 & 46.83 & 1.81 \\
\hline C15 & 90.5 & 27.26 & 1.60 \\
\hline C15 & 91.5 & 18.13 & 1.46 \\
\hline C15 & 92.5 & 16.01 & 2.34 \\
\hline $\mathrm{C} 15$ & 93.5 & 12.24 & 1.60 \\
\hline C15 & 94.5 & 34.81 & 3.80 \\
\hline $\mathrm{C} 15$ & 95.5 & 52.56 & 1.04 \\
\hline C15 & 96.5 & 59.41 & 0.47 \\
\hline C15 & 97.5 & 61.85 & 0.34 \\
\hline C15 & 98.5 & 62.08 & 0.60 \\
\hline C15 & 99.5 & 52.45 & 0.89 \\
\hline $\mathrm{C} 15$ & 100.5 & 57.97 & 0.31 \\
\hline C15 & 101.5 & 55.24 & 0.31 \\
\hline C15 & 102.5 & 32.37 & 0.97 \\
\hline C15 & 103.5 & 43.96 & 0.93 \\
\hline C15 & 104.5 & 47.35 & 1.45 \\
\hline C15 & 105.5 & 54.89 & 1.53 \\
\hline C15 & 106.5 & 44.61 & 2.97 \\
\hline $\mathrm{C} 15$ & 107.5 & 37.62 & 2.43 \\
\hline C15 & 108.5 & 26.00 & 1.74 \\
\hline $\mathrm{C} 15$ & 109.5 & 29.15 & 2.12 \\
\hline $\mathrm{C} 15$ & 110.5 & 26.82 & 0.61 \\
\hline C15 & 111.5 & 22.93 & 0.90 \\
\hline C15 & 112.5 & 22.97 & 1.61 \\
\hline C15 & 113.5 & 17.91 & 1.95 \\
\hline C15 & 114.5 & 26.25 & 3.59 \\
\hline C15 & 115.5 & 49.47 & 1.47 \\
\hline $\mathrm{C} 15$ & 116.5 & 46.10 & 1.13 \\
\hline C15 & 117.5 & 41.43 & 1.07 \\
\hline C15 & 118.5 & 44.36 & 1.75 \\
\hline C15 & 119.5 & 26.32 & 45.93 \\
\hline C15 & 120.5 & 47.92 & 3.28 \\
\hline C15 & 121.5 & 51.89 & 1.23 \\
\hline C15 & 122.5 & 49.49 & 0.76 \\
\hline $\mathrm{C} 15$ & 123.5 & 53.57 & 0.83 \\
\hline $\mathrm{C} 15$ & 124.5 & 58.87 & 0.86 \\
\hline C15 & 125.5 & 56.56 & 1.23 \\
\hline
\end{tabular}




\begin{tabular}{|c|c|c|c|}
\hline C15 & 126.5 & 46.54 & 1.73 \\
\hline C15 & 127.5 & 43.61 & 1.77 \\
\hline C15 & 128.5 & 48.07 & 1.22 \\
\hline C15 & 129.5 & 39.31 & 0.88 \\
\hline C15 & 130.5 & 43.49 & 1.18 \\
\hline C15 & 131.5 & 52.33 & 0.83 \\
\hline C15 & 132.5 & 45.35 & 0.61 \\
\hline C15 & 133.5 & 39.56 & 0.45 \\
\hline C15 & 134.5 & 42.60 & 1.60 \\
\hline C15 & 135.5 & 36.69 & 1.71 \\
\hline $\mathrm{C} 15$ & 136.5 & 38.95 & 1.11 \\
\hline C15 & 137.5 & 45.25 & 1.49 \\
\hline C15 & 138.5 & 41.19 & 1.09 \\
\hline $\mathrm{C} 15$ & 139.5 & 31.09 & 0.84 \\
\hline C15 & 140.5 & 41.22 & 1.21 \\
\hline C15 & 141.5 & 39.40 & 1.37 \\
\hline C15 & 142.5 & 32.99 & 1.07 \\
\hline $\mathrm{C} 15$ & 143.5 & 36.36 & 0.87 \\
\hline C15 & 144.5 & 34.95 & 0.78 \\
\hline $\mathrm{C} 15$ & 145.5 & 36.35 & 0.66 \\
\hline C15 & 146.5 & 27.46 & 0.93 \\
\hline C15 & 147.5 & 30.14 & 1.31 \\
\hline C15 & 148.5 & 35.19 & 0.66 \\
\hline $\mathrm{C} 15$ & 149.5 & 31.78 & 0.45 \\
\hline $\mathrm{C} 15$ & 150.5 & 39.74 & 0.60 \\
\hline C15 & 151.5 & 42.96 & 0.63 \\
\hline $\mathrm{C} 15$ & 152.5 & 41.65 & 0.49 \\
\hline $\mathrm{C} 15$ & 153.5 & 38.02 & 0.53 \\
\hline C15 & 154.5 & 31.73 & 0.39 \\
\hline C15 & 155.5 & 27.94 & 0.43 \\
\hline C15 & 156.5 & 30.96 & 0.57 \\
\hline C15 & 157.5 & 39.44 & 0.46 \\
\hline C15 & 158.5 & 40.50 & 0.50 \\
\hline $\mathrm{C} 15$ & 159.5 & 37.14 & 0.70 \\
\hline C15 & 160.5 & 34.54 & 0.58 \\
\hline C15 & 161.5 & 31.25 & 1.03 \\
\hline C15 & 162.5 & 39.37 & 0.49 \\
\hline C15 & 163.5 & 39.21 & 0.54 \\
\hline C15 & 164.5 & 25.07 & 0.76 \\
\hline C15 & 165.5 & 24.61 & 0.60 \\
\hline $\mathrm{C} 15$ & 166.5 & 19.18 & 0.96 \\
\hline $\mathrm{C} 15$ & 167.5 & 16.73 & 1.65 \\
\hline C15 & 168.5 & 14.81 & 3.74 \\
\hline
\end{tabular}




\begin{tabular}{|c|c|c|c|}
\hline C15 & 169.5 & 15.43 & 2.38 \\
\hline C15 & 170.5 & 12.30 & 3.56 \\
\hline C15 & 171.5 & 11.25 & 3.80 \\
\hline C15 & 172.5 & 11.22 & 4.85 \\
\hline C15 & 173.5 & 12.40 & 3.06 \\
\hline C15 & 174.5 & 13.75 & 1.78 \\
\hline C15 & 175.5 & 12.75 & 1.44 \\
\hline C15 & 176.5 & 10.87 & 2.67 \\
\hline C15 & 177.5 & 9.12 & 3.27 \\
\hline $\mathrm{C} 15$ & 178.5 & 7.38 & 4.94 \\
\hline $\mathrm{C} 15$ & 179.5 & 7.43 & 6.48 \\
\hline C15 & 180.5 & 6.97 & 6.79 \\
\hline $\mathrm{C} 15$ & 181.5 & 6.96 & 7.33 \\
\hline $\mathrm{C} 15$ & 182.5 & 6.31 & 6.17 \\
\hline C15 & 183.5 & 5.62 & 7.71 \\
\hline C15 & 184.5 & 4.83 & 6.54 \\
\hline C15 & 185.5 & 5.10 & 8.45 \\
\hline C15 & 186.5 & 4.77 & 7.27 \\
\hline C20 & 0.5 & 49.26 & 0.39 \\
\hline C20 & 1.5 & 53.85 & 0.19 \\
\hline C20 & 2.5 & 52.83 & 0.54 \\
\hline C20 & 3.5 & 71.49 & 0.31 \\
\hline C20 & 4.5 & 54.48 & 0.45 \\
\hline C20 & 5.5 & 56.48 & 0.23 \\
\hline C20 & 6.5 & 43.29 & 0.24 \\
\hline C20 & 7.5 & 50.86 & 0.22 \\
\hline C20 & 8.5 & 58.89 & 0.29 \\
\hline C20 & 9.5 & 53.82 & 0.41 \\
\hline C20 & 10.5 & 52.28 & 0.16 \\
\hline C20 & 11.5 & 45.98 & 0.20 \\
\hline C20 & 12.5 & 41.00 & 0.34 \\
\hline C20 & 13.5 & 23.70 & 3.44 \\
\hline C20 & 14.5 & 28.28 & 2.26 \\
\hline C20 & 15.5 & 35.02 & 1.64 \\
\hline C20 & 16.5 & 25.38 & 5.47 \\
\hline C20 & 17.5 & 19.85 & 12.77 \\
\hline C20 & 18.5 & 33.42 & 6.08 \\
\hline C20 & 19.5 & 39.82 & 0.51 \\
\hline C20 & 20.5 & 74.59 & 0.37 \\
\hline C20 & 21.5 & 47.64 & 1.08 \\
\hline C20 & 22.5 & 45.87 & 0.91 \\
\hline C20 & 23.5 & 41.49 & 0.66 \\
\hline C20 & 24.5 & 35.42 & 0.36 \\
\hline
\end{tabular}




\begin{tabular}{|c|c|c|c|}
\hline C20 & 25.5 & 30.76 & 0.32 \\
\hline C20 & 26.5 & 36.46 & 0.79 \\
\hline C20 & 27.5 & 35.07 & 0.65 \\
\hline C20 & 28.5 & 38.69 & 0.34 \\
\hline C20 & 29.5 & 32.06 & 0.35 \\
\hline C20 & 30.5 & 25.18 & 0.47 \\
\hline C20 & 31.5 & 23.42 & 0.23 \\
\hline C20 & 32.5 & 24.13 & 0.19 \\
\hline C20 & 33.5 & 20.83 & 0.32 \\
\hline C20 & 34.5 & 23.23 & 0.35 \\
\hline C20 & 35.5 & 25.07 & 0.46 \\
\hline C20 & 36.5 & 27.97 & 0.94 \\
\hline C20 & 37.5 & 30.28 & 0.74 \\
\hline C20 & 38.5 & 21.23 & 2.74 \\
\hline C20 & 39.5 & 18.37 & 2.76 \\
\hline C20 & 40.5 & 22.76 & 0.52 \\
\hline C20 & 41.5 & 33.57 & 0.01 \\
\hline C20 & 42.5 & 35.74 & -0.42 \\
\hline C20 & 43.5 & 37.59 & -0.08 \\
\hline C20 & 44.5 & 27.21 & 0.30 \\
\hline C20 & 45.5 & 31.46 & 0.24 \\
\hline C20 & 46.5 & 31.83 & 0.47 \\
\hline C20 & 47.5 & 33.63 & 0.39 \\
\hline C20 & 48.5 & 36.83 & 0.65 \\
\hline C20 & 49.5 & 34.65 & 0.25 \\
\hline C20 & 50.5 & 32.92 & 0.16 \\
\hline C20 & 51.5 & 36.65 & -0.04 \\
\hline C20 & 52.5 & 31.58 & -0.15 \\
\hline C20 & 53.5 & 28.58 & 0.22 \\
\hline C20 & 54.5 & 32.64 & 0.13 \\
\hline C20 & 55.5 & 32.88 & 0.15 \\
\hline C20 & 56.5 & 30.44 & 0.72 \\
\hline C20 & 57.5 & 42.20 & 0.74 \\
\hline C20 & 58.5 & 52.91 & 0.30 \\
\hline $\mathrm{C} 20$ & 59.5 & 65.90 & 0.06 \\
\hline C20 & 60.5 & 53.71 & 0.04 \\
\hline C20 & 61.5 & 42.27 & 0.55 \\
\hline C20 & 62.5 & 46.61 & 0.06 \\
\hline C20 & 63.5 & 40.60 & 0.32 \\
\hline C20 & 64.5 & 43.88 & 0.04 \\
\hline C20 & 65.5 & 39.91 & 0.25 \\
\hline C20 & 66.5 & 24.72 & 1.72 \\
\hline C20 & 67.5 & 29.98 & 0.69 \\
\hline
\end{tabular}




\begin{tabular}{|c|c|c|c|}
\hline C20 & 68.5 & 29.75 & 0.40 \\
\hline C20 & 69.5 & 27.65 & 0.43 \\
\hline C20 & 70.5 & 28.21 & 0.35 \\
\hline C20 & 71.5 & 32.68 & 0.24 \\
\hline C20 & 72.5 & 29.72 & 0.27 \\
\hline C20 & 73.5 & 29.95 & 1.22 \\
\hline C20 & 74.5 & 30.61 & 1.42 \\
\hline C20 & 75.5 & 39.45 & 0.66 \\
\hline C20 & 76.5 & 44.16 & 0.89 \\
\hline C20 & 77.5 & 36.45 & 1.13 \\
\hline C20 & 78.5 & 32.90 & 1.37 \\
\hline C20 & 79.5 & 28.53 & 1.15 \\
\hline C20 & 80.5 & 34.57 & 3.33 \\
\hline $\mathrm{C} 20$ & 81.5 & 40.23 & 1.42 \\
\hline C20 & 82.5 & 40.60 & 1.52 \\
\hline C20 & 83.5 & 38.05 & 2.71 \\
\hline $\mathrm{C} 20$ & 84.5 & 37.21 & 1.61 \\
\hline C20 & 85.5 & 35.60 & 0.39 \\
\hline C20 & 86.5 & 36.69 & 0.80 \\
\hline C20 & 87.5 & 30.94 & 2.96 \\
\hline C20 & 88.5 & 36.21 & 3.49 \\
\hline C20 & 89.5 & 35.11 & 1.13 \\
\hline C20 & 90.5 & 22.10 & 1.94 \\
\hline C20 & 91.5 & 28.48 & 1.20 \\
\hline C20 & 92.5 & 38.22 & 0.78 \\
\hline C20 & 93.5 & 36.22 & 0.74 \\
\hline C20 & 94.5 & 22.37 & 1.39 \\
\hline C20 & 95.5 & 18.24 & 1.58 \\
\hline C20 & 96.5 & 12.37 & 2.89 \\
\hline C20 & 97.5 & 9.08 & 2.66 \\
\hline C20 & 98.5 & 16.39 & 1.62 \\
\hline C20 & 99.5 & 34.72 & 0.99 \\
\hline C20 & 100.5 & 27.93 & 1.66 \\
\hline C20 & 101.5 & 16.64 & 3.66 \\
\hline $\mathrm{C} 20$ & 102.5 & 8.89 & 4.89 \\
\hline C20 & 103.5 & 8.09 & 5.10 \\
\hline C20 & 104.5 & 11.50 & 4.38 \\
\hline C20 & 105.5 & 29.41 & 1.46 \\
\hline C20 & 106.5 & 33.26 & 0.73 \\
\hline C20 & 107.5 & 27.83 & 1.88 \\
\hline C20 & 108.5 & 29.90 & 2.65 \\
\hline C20 & 109.5 & 33.61 & 1.89 \\
\hline C20 & 110.5 & 36.62 & 1.33 \\
\hline
\end{tabular}




\begin{tabular}{|c|c|c|c|}
\hline $\mathrm{C} 20$ & 111.5 & 40.17 & 1.40 \\
\hline C20 & 112.5 & 40.73 & 0.48 \\
\hline C20 & 113.5 & 27.92 & 0.95 \\
\hline $\mathrm{C} 20$ & 114.5 & 18.46 & 9.19 \\
\hline $\mathrm{C} 20$ & 115.5 & 32.74 & 2.62 \\
\hline $\mathrm{C} 20$ & 116.5 & 36.16 & 0.75 \\
\hline C20 & 117.5 & 27.98 & 2.52 \\
\hline $\mathrm{C} 20$ & 118.5 & 19.18 & 2.95 \\
\hline $\mathrm{C} 20$ & 119.5 & 8.86 & 8.35 \\
\hline $\mathrm{C} 20$ & 120.5 & 7.04 & 3.89 \\
\hline $\mathrm{C} 20$ & 121.5 & 13.96 & 2.02 \\
\hline $\mathrm{C} 20$ & 122.5 & 23.41 & 1.73 \\
\hline $\mathrm{C} 20$ & 123.5 & 34.62 & 3.33 \\
\hline $\mathrm{C} 20$ & 124.5 & 45.76 & 0.52 \\
\hline $\mathrm{C} 20$ & 125.5 & 50.99 & 0.60 \\
\hline $\mathrm{C} 20$ & 126.5 & 53.28 & 0.96 \\
\hline $\mathrm{C} 20$ & 127.5 & 58.94 & 0.44 \\
\hline $\mathrm{C} 20$ & 128.5 & 62.27 & 0.33 \\
\hline $\mathrm{C} 20$ & 129.5 & 56.32 & 0.45 \\
\hline $\mathrm{C} 20$ & 130.5 & 51.36 & 0.85 \\
\hline $\mathrm{C} 20$ & 131.5 & 50.74 & 0.63 \\
\hline $\mathrm{C} 20$ & 132.5 & 46.34 & 0.54 \\
\hline $\mathrm{C} 20$ & 133.5 & 45.96 & 0.40 \\
\hline $\mathrm{C} 20$ & 134.5 & 51.06 & 0.39 \\
\hline C20 & 135.5 & 55.45 & 0.53 \\
\hline $\mathrm{C} 20$ & 136.5 & 58.65 & -0.03 \\
\hline $\mathrm{C} 20$ & 137.5 & 57.95 & 0.40 \\
\hline $\mathrm{C} 20$ & 138.5 & 56.23 & 0.30 \\
\hline $\mathrm{C} 20$ & 139.5 & 50.37 & 0.45 \\
\hline $\mathrm{C} 20$ & 140.5 & 48.28 & 0.60 \\
\hline $\mathrm{C} 20$ & 141.5 & 52.17 & 0.51 \\
\hline C20 & 142.5 & 56.34 & 0.32 \\
\hline $\mathrm{C} 20$ & 143.5 & 56.03 & 0.49 \\
\hline $\mathrm{C} 20$ & 144.5 & 54.01 & 0.46 \\
\hline $\mathrm{C} 20$ & 145.5 & 47.20 & 0.11 \\
\hline $\mathrm{C} 20$ & 146.5 & 44.66 & 0.17 \\
\hline $\mathrm{C} 20$ & 147.5 & 45.36 & 0.51 \\
\hline $\mathrm{C} 20$ & 148.5 & 48.22 & 0.45 \\
\hline C20 & 149.5 & 48.43 & 0.48 \\
\hline C20 & 150.5 & 33.80 & 0.59 \\
\hline $\mathrm{C} 20$ & 151.5 & 32.00 & 1.16 \\
\hline $\mathrm{C} 20$ & 152.5 & 31.51 & 2.19 \\
\hline C20 & 153.5 & 34.34 & 5.31 \\
\hline
\end{tabular}




\begin{tabular}{|c|c|c|c|}
\hline $\mathrm{C} 20$ & 154.5 & 46.29 & 0.67 \\
\hline C20 & 155.5 & 44.63 & 0.46 \\
\hline C20 & 156.5 & 37.95 & 0.53 \\
\hline $\mathrm{C} 20$ & 157.5 & 26.47 & 3.68 \\
\hline $\mathrm{C} 20$ & 158.5 & 13.76 & 6.38 \\
\hline $\mathrm{C} 20$ & 159.5 & 19.73 & 4.75 \\
\hline C20 & 160.5 & 42.21 & 0.75 \\
\hline $\mathrm{C} 20$ & 161.5 & 43.98 & 0.45 \\
\hline $\mathrm{C} 20$ & 162.5 & 43.80 & 0.52 \\
\hline $\mathrm{C} 20$ & 163.5 & 48.52 & 0.45 \\
\hline C20 & 164.5 & 36.40 & 0.29 \\
\hline $\mathrm{C} 20$ & 165.5 & 34.78 & 0.42 \\
\hline $\mathrm{C} 20$ & 166.5 & 42.05 & 0.48 \\
\hline $\mathrm{C} 20$ & 167.5 & 40.73 & 0.66 \\
\hline $\mathrm{C} 20$ & 168.5 & 39.52 & 0.41 \\
\hline $\mathrm{C} 20$ & 169.5 & 40.40 & 0.80 \\
\hline $\mathrm{C} 20$ & 170.5 & 26.66 & 4.85 \\
\hline $\mathrm{C} 20$ & 171.5 & 29.81 & 6.20 \\
\hline $\mathrm{C} 20$ & 172.5 & 37.64 & 0.90 \\
\hline $\mathrm{C} 20$ & 173.5 & 37.71 & 0.27 \\
\hline $\mathrm{C} 20$ & 174.5 & 36.74 & 0.31 \\
\hline $\mathrm{C} 20$ & 175.5 & 29.79 & 0.06 \\
\hline $\mathrm{C} 20$ & 176.5 & 29.96 & 0.08 \\
\hline $\mathrm{C} 20$ & 177.5 & 29.64 & 0.14 \\
\hline C20 & 178.5 & 27.85 & 0.13 \\
\hline $\mathrm{C} 20$ & 179.5 & 28.91 & 0.13 \\
\hline $\mathrm{C} 20$ & 180.5 & 23.44 & 0.07 \\
\hline $\mathrm{C} 20$ & 181.5 & 20.39 & 0.07 \\
\hline $\mathrm{C} 20$ & 182.5 & 20.47 & 0.25 \\
\hline C20 & 183.5 & 20.18 & 0.14 \\
\hline $\mathrm{C} 20$ & 184.5 & 22.46 & 0.09 \\
\hline C20 & 185.5 & 20.87 & 0.03 \\
\hline C20 & 186.5 & 20.01 & 0.11 \\
\hline $\mathrm{C} 20$ & 187.5 & 22.64 & 0.11 \\
\hline $\mathrm{C} 20$ & 188.5 & 19.83 & 0.08 \\
\hline $\mathrm{C} 20$ & 189.5 & 15.88 & 0.32 \\
\hline $\mathrm{C} 20$ & 190.5 & 14.58 & 0.18 \\
\hline $\mathrm{C} 20$ & 191.5 & 12.94 & 0.36 \\
\hline C20 & 192.5 & 12.85 & 0.30 \\
\hline C20 & 193.5 & 13.60 & 0.21 \\
\hline $\mathrm{C} 20$ & 194.5 & 13.36 & 0.28 \\
\hline $\mathrm{C} 20$ & 195.5 & 11.99 & 0.23 \\
\hline C20 & 196.5 & 11.53 & 0.17 \\
\hline
\end{tabular}




\begin{tabular}{|l|l|l|l|}
\hline C20 & 197.5 & 11.80 & 0.21 \\
\hline C20 & 198.5 & 11.48 & 0.33 \\
\hline C20 & 199.5 & 10.68 & 0.46 \\
\hline C20 & 200.5 & 10.32 & 0.76 \\
\hline C20 & 201.5 & 10.01 & 0.71 \\
\hline C20 & 202.5 & 9.24 & 0.99 \\
\hline C20 & 203.5 & 9.83 & 1.12 \\
\hline C20 & 204.5 & 11.82 & 0.70 \\
\hline C20 & 205.5 & 9.78 & 1.09 \\
\hline C20 & 206.5 & 8.64 & 1.44 \\
\hline C20 & 207.5 & 7.31 & 1.65 \\
\hline C20 & 208.5 & 7.47 & 2.63 \\
\hline C20 & 209.5 & 6.76 & 2.74 \\
\hline C20 & 210.5 & 6.06 & 3.64 \\
\hline C20 & 211.5 & 6.02 & 3.59 \\
\hline C20 & 212.5 & 5.77 & 4.03 \\
\hline C20 & 213.5 & 5.55 & 3.22 \\
\hline C20 & 214.5 & 5.85 & 5.01 \\
\hline
\end{tabular}




\section{References}

Allen, J. R. L. (1989). Evolution of salt-marsh cliffs in muddy and sandy systems: A qualitative comparison of British West-Coast estuaries. Earth Surface Processes and Landforms, 14(1), 85-92. https://doi.org/10.1002/esp.3290140108

Allison, M. A., \& Kepple, E. (2001). Modern sediment supply to the lower delta plain of the Ganges-Brahmaputra River in Bangladesh. Geo-Marine Letters, 21(2), 66-74. https://doi.org/10.1007/s003670100069

Argow, B. A., Hughes, Z. J., \& FitzGerald, D. M. (2007). Ice Raft Formation, Dispersion and Sedimentation on New England Salt Marshes, 40926 (October 2015), 798-813.

Barbier, E. B., Georgiou, I. Y., Enchelmeyer, B., \& Reed, D. J. (2013). The Value of Wetlands in Protecting Southeast Louisiana from Hurricane Storm Surges. PLoS ONE, 8(3), 1-6. https://doi.org/10.1371/journal.pone.0058715

Barbier, E. B., Hacker, S. D., Kennedy, C., Koch, E. W., Stier, A. C., \& Silliman, B. R. (2011). The value of estuarine and coastal ecosystem services. Ecological Monographs, 81(2), 169-193. https://doi.org/10.1890/10-1510.1

Barras, J. A. (2007). Land area changes in coastal Louisiana after Hurricanes Katrina and Rita. In G. S. Farris, G. J. Smith, M. P. Crane, C. R. Demas, L. L. Robbins, \& D. L. Lavoie (Eds.), Science and the Storms: The USGS Response to the Hurricanes of 2005 (pp. 97-112). U.S. Geological Survey Circular 1306. Retrieved from http://www.scopus.com/inward/record.url?eid=2-s2.079958073367\&partnerID=40\&md5=72bc3fd526f29098fe596d213f227172

Baustian, J. J., \& Mendelssohn, I. A. (2015). Hurricane-Induced Sedimentation Improves Marsh Resilience and Vegetation Vigor under High Rates of Relative Sea Level Rise. Wetlands, 35(4), 795-802. https://doi.org/10.1007/s13157-015-0670-2

BenDor, T., Lester, T. W., Livengood, A., Davis, A., \& Yonavjak, L. (2015). Estimating the Size and Impact of the Ecological Restoration Economy. PLOS ONE, 10(6), 1-15. https://doi.org/10.1371/journal.pone.0128339

Bhatia, K., Vecchi, G., Murakami, H., Underwood, S., \& Kossin, J. (2018). Projected response of tropical cyclone intensity and intensification in a global climate model. Journal of Climate, 31(20), 8281-8303. https://doi.org/10.1175/JCLI-D-17-0898.1

Blaauw, M., \& Christen, J. A. (2011). Flexible paleoclimate age-depth models using an autoregressive gamma process. Bayesian Analysis, 6(3), 457-474. https://doi.org/10.1214/11-BA618

Blake, E. S., Kimberlain, T. B., Berg, R. J., Cangialosi, J. P., \& Beven II, J. L. (2013). Hurricane Sandy: October 22 - 29, 2012. National Hurricane Center.

Boldt, K. V., Lane, P., Woodruff, J. D., \& Donnelly, J. P. (2010). Calibrating a sedimentary record of overwash from Southeastern New England using modeled historic hurricane surges. Marine Geology, 275(1-4), 127-139. https://doi.org/10.1016/j.margeo.2010.05.002

Booij, N., Ris, R. C., \& Holthuijsen, L. H. (1999). A third-generation wave model for coastal regions: 1. Model description and validation. Journal of Geophysical Research, 104(C4), 7649-7666. https://doi.org/10.1029/98JC02622

Boose, E. R., Chamberlin, K. E., \& Foster, D. R. (2001). Landscape and Regional Impacts of 
Hurricanes in New England. Ecological Monographs, 71(1), 27-48.

Booth, J. G., Miller, R. L., McKee, B. A., \& Leathers, R. A. (2000). Wind induced sediment resuspension in a microtidal estuary. Continental Shelf Research, 20(7), 785-806.

Boothroyd, J. C., Friedrich, N. E., \& McGinn, S. R. (1985). Geology of microtidal coastal lagoons: Rhode Island. Marine Geology, 63(1-4), 35-76. https://doi.org/10.1016/0025-3227(85)90079-9

Brandon, C. M., Woodruff, J. D., Lane, D. P., \& Donnelly, J. P. (2013). Tropical cyclone wind speed constraints from resultant storm surge deposition: A 2500 year reconstruction of hurricane activity from St. Marks, FL. Geochemistry, Geophysics, Geosystems, 14(8), 2993-3008. https://doi.org/10.1002/ggge.20217

Brandon, C. M., Woodruff, J. D., Donnelly, J. P., \& Sullivan, R. M. (2014). How Unique was Hurricane Sandy? Sedimentary Reconstructions of Extreme Flooding from New York Harbor. Scientific Reports, 4(7366), 1-9. https://doi.org/10.1038/srep07366

Bregy, J. C., Wallace, D. J., Minzoni, R. T., \& Cruz, V. J. (2017). 2500-year paleotempestological record of intense storms for the northern Gulf of Mexico, United States. Marine Geology, (August 2016), 1-17. https://doi.org/10.1016/j.margeo.2017.09.009

Bruun, P. (1988). The Bruun rule of erosion by sea-level rise: a discussion on large-scale two-and three-dimensional usages. Journal of Coastal Research, 4(4), 627-648. https://doi.org/10.2307/4297466

Burkett, V., Groat, C. G., \& Reed, D. (2007). Hurricanes Not the Key to a Sustainable Coast. Science, 315, 1366-1367.

Butchart, S., Dieme-Amting, E., Gitay, H., Raaymakers, S., \& Taylor, D. (2005). Ecosystems and human well-being: Wetlands and water synthesis. Millennium Ecosystem Assessment. Washington, DC. https://doi.org/10.1017/CBO9781107415324.004

Cahoon, D. R. (2006). A review of major storm impacts on coastal wetland elevations. Estuaries and Coasts, 29(6), 889-898. https://doi.org/10.1007/BF02798648

Carper, G. L., \& Bachmann, R. W. (1984). Wind Resuspension of Sediments in a Prairie Lake. Canadian Journal of Fisheries and Aquatic Sciences, 41(12), 1763-1767. https://doi.org/10.1139/f84-217

Castagno, K. A., Jiménez-Robles, A. M., Donnelly, J. P., Wiberg, P. L., Fenster, M. S., \& Fagherazzi, S. (2018). Intense Storms Increase the Stability of Tidal Bays. Geophysical Research Letters, 45(11), 5491-5500. https://doi.org/10.1029/2018GL078208

Cheung, K. F., Tang, L., Donnelly, J. P., Scileppi, E. M., Liu, K. B., Mao, X. Z., ... Murnane, R. J. (2007). Numerical modeling and field evidence of coastal overwash in southern New England from Hurricane Bob and implications for paleotempestology. Journal of Geophysical Research: Earth Surface, 112(3), 1-24. https://doi.org/10.1029/2006JF000612

Christiansen, T., Wiberg, P. L., \& Milligan, T. G. (2000). Flow and Sediment Transport on a Tidal Salt Marsh Surface. Estuarine, Coastal and Shelf Science, 50(3), 315-331. https://doi.org/10.1006/ecss.2000.0548

Costanza, R., d'Arge, R., de Groot, R., Farber, S., Grasso, M., Hannon, B., ... van den Belt, M. (1997). The value of the world's ecosystem services and natural capital. Nature, 387(6630), 253260. https://doi.org/10.1038/387253a0 
Costanza, R., de Groot, R., Sutton, P., van der Ploeg, S., Anderson, S. J., Kubiszewski, I., ... Turner, R. K. (2014). Changes in the global value of ecosystem services. Global Environmental Change, 26(1), 152-158. https://doi.org/10.1016/j.gloenvcha.2014.04.002

Craft, C., Clough, J., Ehman, J., Jove, S., Park, R., Pennings, S., .. Machmuller, M. (2009). Forecasting the effects of accelerated sea-level rise on tidal marsh ecosystem services. Frontiers in Ecology and the Environment, 7(2), 73-78. https://doi.org/10.1890/070219

Davis, R. A., Knowles, S. C., \& Bland, M. J. (1989). Role of hurricanes in the Holocene stratigraphy of estuaries; examples from the Gulf Coast of Florida. Journal of Sedimentary Research, 59(6), 1052-1061. https://doi.org/10.1306/212F90ED-2B24-11D7-8648000102C1865D

Day, J. W., Boesch, D. F., Clairain, E. J., Kemp, G. P., Laska, S. B., Mitsch, W. J., ... Whigham, D. F. (2007). Restoration of the Mississippi Delta: Lessons from Hurricanes Katrina and Rita. Science, 315(5819), 1679-1684. https:/ / doi.org/10.1126/science.1137030

Dean, W. E. (1974). Determination of Carbonate and Organic-Matter in Calcareous Sediments and Sedimentary-Rocks by Loss on Ignition - Comparison with Other Methods. Journal of Sedimentary Petrology, 44(1), 242-248.

Deaton, C. D., Hein, C. J., \& Kirwan, M. L. (2016). Barrier island migration dominates ecogeomorphic feedbacks and drives salt marsh loss along the Virginia Atlantic Coast, USA. Geology, 1-4. https://doi.org/10.1130/G38459.1

Donnelly, C., Kraus, N., \& Larson, M. (2006). State of Knowledge on Measurement and Modeling of Coastal Overwash. Journal of Coastal Research, 22(4), 965-991. https://doi.org/10.2112/040431.1

Donnelly, J P, \& Bertness, M. D. (2001). Rapid shoreward encroachment of salt marsh cordgrass in response to accelerated sea-level rise. Proceedings of the National Academy of Sciences of the United States of America, 98(25), 14218-14223. https://doi.org/10.1073/pnas.251209298

Donnelly, Jeffrey P. (2004). Coupling instrumental and geological records of sea-level change: Evidence from southern New England of an increase in the rate of sea-level rise in the late 19th century. Geophysical Research Letters, 31(5), 2-5. https://doi.org/10.1029/2003GL018933

Donnelly, Jeffrey P., Smith Bryant, S., Butler, J., Dowling, J., Fan, L., Hausmann, N., ... Webb III, T. (2001a). $700 \mathrm{yr}$ sedimentary record of intense hurricane landfalls in southern New England. Geological Society of America Bulletin, 113(6), 714-727. https://doi.org/10.1130/00167606(2001)113<0714:YSROIH>2.0.CO;2

Donnelly, Jeffrey P., Roll, S., Wengren, M., Butler, J., Lederer, R., \& Webb, T. (2001b). Sedimentary evidence of intense hurricane strikes from New Jersey. Geology, 29(7), 615-618. https://doi.org/10.1130/0091-7613(2001)029<0615:SEOIHS>2.0.CO;2

Donnelly, Jeffrey P., Bryant, S. S., Butler, J., Dowling, J., Fan, L., Hausmann, N., ... Webb, T. I. (2001). $700 \mathrm{yr}$ sedimentary record of intense hurricane landfalls in southern New England. GSA Bulletin, 113(6), 714-727. https://doi.org/10.1130/0016-7606(2001)113<0714

Donnelly, Jeffrey P., Hawkes, A. D., Lane, P., Macdonald, D., Shuman, B. N., Toomey, M. R., ... Woodruff, J. D. (2015). Climate forcing of unprecedented intense-hurricane activity in the last 2000 years. Earth's Future, 3(2), 49-65. https://doi.org/10.1002/2014EF000274

Dunphy, P. P., \& Dibb, J. E. (1994). Cs-137 gamma-ray detection at Summit, Greenland. Journal of Glaciology, 40(134), 87-92. 
Elsey-Quirk, T. (2016). Impact of Hurricane Sandy on salt marshes of New Jersey. Estuarine, Coastal and Shelf Science, 183, 235-248. https://doi.org/10.1016/j.ecss.2016.09.006

Emanuel, K. (2008). The Hurricane-Climate Connection. Bulletin of the American Meteorological Society, 89(5), ES10-ES20.

Emanuel, K. (2013). Downscaling CMIP5 climate models shows increased tropical cyclone activity over the 21st century. Proceedings of the National Academy of Sciences of the United States of America, 110(30), 12219-24. https://doi.org/10.1073/pnas.1301293110

Emanuel, K., Ravela, S., Vivant, E., \& Risi, C. (2006). A statistical deterministic approach to hurricane risk assessment. Bulletin of the American Meteorological Society, 87(3), 299-314. https://doi.org/10.1175/BAMS-87-3-299

Emery, K. O. (1969). A coastal pond studied by oceanographic methods. Oyster Pond Environmental Trust, Falmouth, MA.

Engelhart, S. E., Horton, B. P., Douglas, B. C., Peltier, W. R., \& Törnqvist, T. E. (2009). Spatial variability of late Holocene and 20th century sea-level rise along the Atlantic coast of the United States. Geology, 37(12), 1115-1118. https://doi.org/10.1130/G30360A.1

Fagherazzi, S., Kirwan, M. L., Mudd, S. M., Guntenspergen, G. R., Temmerman, S., Rybczyk, J. M., ... Clough, J. (2012). Numerical models of salt marsh evolution: Ecological, geormorphic, and climatic factors. Reviews of Geophysics, (2011), 1-28. https://doi.org/10.1029/2011RG000359.1.INTRODUCTION

Fagherazzi, S., Mariotti, G., Wiberg, P. L., \& McGlathery, K. J. (2014). Marsh collapse does not require sea level rise. Oceanography, 26(3), 70-77. https://doi.org/10.5670/oceanog.2009.80.COPYRIGHT

Fagherazzi, S., \& Wiberg, P. L. (2009). Importance of wind conditions, fetch, and water levels on wave-generated shear stresses in shallow intertidal basins. Journal of Geophysical Research: Solid Earth, 114(3), 1-12. https://doi.org/10.1029/2008JF001139

Feagin, R. A., Lozada-Bernard, S. M., Ravens, T. M., Moller, I., Yeager, K. M., \& Baird, A. H. (2009). Does vegetation prevent wave erosion of salt marsh edges? Proceedings of the National Academy of Sciences, 106(25), 10109-10113. https://doi.org/10.1073/pnas.0901297106

Feagin, Rusty A., Sherman, D. J., \& Grant, W. E. (2005). Coastal erosion, global sea-level rise, and the loss of sand dune plant habitats. Frontiers in Ecology and the Environment, 3(7), 359-364. https://doi.org/10.1890/1540-9295(2005)003[0359:CEGSRA]2.0.CO;2

Fenster, M. S., Dolan, R., \& Smith, J. J. (2016). Grain-size distributions and coastal morphodynamics along the southern Maryland and Virginia barrier islands. Sedimentology, 809-823. https://doi.org/10.1111/sed.12239

Ferguson, R. I., \& Church, M. (2004). A simple universal equation for grain settling velosity. Journal of Sedimentary Research, 74(6), 933-937. https://doi.org/10.1306/051204740933

FitzGerald, D. M., Fenster, M. S., Argow, B. a., \& Buynevich, I. V. (2008). Coastal Impacts Due to Sea-Level Rise. Annual Review of Earth and Planetary Sciences, 36(1), 601-647. https://doi.org/10.1146/annurev.earth.35.031306.140139

French, J. (2006). Tidal marsh sedimentation and resilience to environmental change: Exploratory modelling of tidal, sea-level and sediment supply forcing in predominantly allochthonous 
systems. Marine Geology, 235(1-4 SPEC. ISS.), 119-136.

https://doi.org/10.1016/j.margeo.2006.10.009

Frey, R. W., \& Basan, P. B. (1978). Coastal Salt Marshes. In R. A. Davis Jr. (Ed.), Coastal Sedimentary Environments (pp. 225-302). New York: Springer. https://doi.org/10.1007/978-1-4612-50784_4

Ganju, N. K., Nidzieko, N. J., \& Kirwan, M. L. (2013). Inferring tidal wetland stability from channel sediment fluxes: Observations and a conceptual model. Journal of Geophysical Research: Earth Surface, 118(4), 2045-2058. https://doi.org/10.1002/jgrf.20143

Ganju, N. K., Kirwan, M. L., Dickhudt, P. J., Guntenspergen, G. R., Cahoon, D. R., \& Kroeger, K. D. (2015). Sediment transport-based metrics of wetland stability. Geophysical Research Letters, 42(19), 7992-8000. https://doi.org/10.1002/2015GL065980

Gardner, L. R., Michener, W. K., Kjerve, B., \& Lipscomb, D. J. (1992). Disturbance Effects of Hurricane Hugo on a Pristine Coastal. Netherlands Journal of Sea Reasearch, 30, 249-263.

Gedan, K. B., Altieri, A. H., \& Bertness, M. D. (2011). Uncertain future of New England salt marshes. Marine Ecology Progress Series, 434, 229-237. https://doi.org/10.3354/meps09084

Gleason, M. L., Elmer, D. A., Pien, N. C., \& Fisher, J. S. (1979). Effects of stem density upon sediment retention by salt marsh cord grass, Spartina alterniflora loisel. Estuaries, 2(4), 271-273. https://doi.org/10.2307/1351574

Goodbred, S. L., \& Hine, A. C. (1995). Coastal storm deposition: salt-marsh response to a severe extratropical storm, March 1993, west-central Florida. Geology, 23(8), 679-682. https://doi.org/10.1130/0091-7613(1995)023<0679:CSDSMR>2.3.CO;2

Griswold, E., Zinsser, A., Calabrese, D., Picchi, V., Barrett, M., \& Silver, W. (1975). An Ecological Inventory of Pattagansett Marshes Preserve, East Lyme, Connecticut. New Haven, CT.

Grossi, P., Aachi, N., Bellone, E., Bingi, S., Boissonnade, A., Colette, A., ... Ziehmann, C. (2008). The 1938 Great New England Hurricane: Looking to the Past to Understand Today's Risk. Newark, CA.

Hardwick-Witman, M. N. (1986). Aerial survey of a salt marsh: Ice rafting to the lower intertidal zone. Estuarine, Coastal and Shelf Science, 22(3), 379-383. https://doi.org/10.1016/02727714(86)90050-8

van Hengstum, P. J., Donnelly, J. P., Toomey, M. R., Albury, N. A., Lane, P., \& Kakuk, B. (2014). Heightened hurricane activity on the Little Bahama Bank from 1350 to 1650 AD. Continental Shelf Research, 86, 103-115. https://doi.org/10.1016/j.csr.2013.04.032

Hennessy, J. T., \& Zarillo, G. A. (1987). The interrelation and distinction between flood-tidal delta and washover deposits in a transgressive barrier island. Marine Geology, 78(1-2), 35-56. https://doi.org/10.1016/0025-3227(87)90067-3

Hippensteel, S. P. (2008). Preservation Potential of Storm Deposits in South Carolina Back-Barrier Marshes. Journal of Coastal Research, 243, 594-601. https://doi.org/10.2112/05-0624.1

Hippensteel, S. P., \& Martin, R. E. (1999). Foraminifera as an indicator of overwash deposits, Barrier Island sediment supply, and Barrier Island evolution: Folly Island, South Carolina. Palaeogeography, Palaeoclimatology, Palaeoecology, 149(1-4), 115-125. https://doi.org/10.1016/S0031-0182(98)00196-5

Hodge, J., \& Williams, H. (2016). Deriving spatial and temporal patterns of coastal marsh 
aggradation from hurricane storm surge marker beds. Geomorphology, 274, 50-63. https://doi.org/10.1016/j.geomorph.2016.09.005

Holland, G. J., \& Webster, P. J. (2007). Heightened tropical cyclone activity in the North Atlantic: natural variability or climate trend? Philosophical Transactions. Series A, Mathematical, Physical, and Engineering Sciences, 365(1860), 2695-716. https://doi.org/10.1098/rsta.2007.2083

Hong, I., Pilarczyk, J. E., Horton, B. P., Fritz, H. M., Kosciuch, T. J., Wallace, D. J., ... Jockley, F. R. (2018). Sedimentological characteristics of the 2015 Tropical Cyclone Pam overwash sediments from Vanuatu, South Pacific. Marine Geology, 396(May 2017), 205-214. https://doi.org/10.1016/j.margeo.2017.05.011

Howes, N. C., FitzGerald, D. M., Hughes, Z. J., Georgiou, I. Y., Kulp, M. A., Miner, M. D., ... Barras, J. A. (2010). Hurricane-induced failure of low salinity wetlands. Proceedings of the National Academy of Sciences of the United States of America, 107(32), 14014-14019. https://doi.org/10.1073/pnas.0914582107

Hu, K., Chen, Q., Wang, H., Hartig, E. K., \& Orton, P. M. (2018). Numerical modeling of salt marsh morphological change induced by Hurricane Sandy. Coastal Engineering, 132(October 2017), 63-81. https://doi.org/10.1016/j.coastaleng.2017.11.001

ICAT Damage Estimator. Accessed 2019 at http://www.icatdamageestimator.com/.

Jarvinen, B., Neuman, C., \& Davis, M. (1988). A Tropical Cyclone Data Tape for the North Atlantic Basin 1886-1977: Contents, Limitations, and Uses. NOAA Tech. Memo. NWS NHC-22.

Jarvinen, B. R. (2006). Storm Tides in Twelve Tropical Cyclones (including Four Intense New England Hurricanes). Miami, Florida.

Jelesnianski, C., Chen, J., \& Shaffer, W. (1992). SLOSH: Sea, lake, and overland surges from hurricanes. NOAA Tech. Rep. NWS ,NOAA AOML Library, Miami, Fla., 48(April).

Kemp, A. C., Bernhardt, C. E., Horton, B. P., Kopp, R. E., Vane, C. H., Peltier, W. R., ... Cahill, N. (2014). Late Holocene sea- and land-level change on the U.S. southeastern Atlantic coast. Marine Geology, 357, 90-100. https://doi.org/10.1016/j.margeo.2014.07.010

Kemp, A. C., Hawkes, A. D., Donnelly, J. P., Vane, C. H., Horton, B. P., Hill, T. D., ... Cahill, N. (2015). Relative sea - level change in Connecticut (USA) during the last 2200 yrs. Earth and Planetary Science Letters, 428, 217-229. https://doi.org/10.1016/j.epsl.2015.07.034

Kirwan, M. L., Temmerman, S., Skeehan, E. E., Guntenspergen, G. R., \& Faghe, S. (2016). Overestimation of marsh vulnerability to sea level rise. Nature Climate Change, 6(3), 253-260. https://doi.org/10.1038/nclimate2909

Kirwan, M. L., Guntenspergen, G. R., D’Alpaos, A., Morris, J. T., Mudd, S. M., \& Temmerman, S. (2010). Limits on the adaptability of coastal marshes to rising sea level. Geophysical Research Letters, 37(23), 1-5. https://doi.org/10.1029/2010GL045489

Klotzbach, P. J., Bowen, S. G., Pielke Jr, R., \& Bell, M. (2018). Continental U.S. Hurricane Landfall Frequency and Associated Damage: Observations and Future Risks. Bulletin of the American Meteorological Society, (99), 1359-1376. https://doi.org/10.1175/BAMS-D-17-0184.1

Kolker, A. S., Goodbred, S. L., Hameed, S., \& Cochran, J. K. (2009). High-resolution records of the response of coastal wetland systems to long-term and short-term sea-level variability. Estuarine, Coastal and Shelf Science, 84(4), 493-508. https://doi.org/10.1016/j.ecss.2009.06.030 
Kopp, R. E., Kemp, A. C., Bittermann, K., Horton, B. P., Donnelly, J. P., Gehrels, W. R., ... Rahmstorf, S. (2016). Temperature-driven global sea-level variability in the Common Era. Proceedings of the National Academy of Sciences, 113(38), 1-8. https://doi.org/10.1073/pnas.1517056113

van de Koppel, J., van der Wal, D., Bakker, J. P., \& Herman, P. M. J. (2005). Self-organization and vegetation collapse in salt marsh ecosystems. The American Naturalist, 165(1), E1-E12. https://doi.org/10.1086/426602

Korty, R. L., Emanuel, K. A., Huber, M., \& Zamora, R. A. (2017). Tropical cyclones downscaled from simulations with very high carbon dioxide levels. Journal of Climate. https://doi.org/10.1175/JCLI-D-16-0256.1

Lane, P., Donnelly, J. P., Woodruff, J. D., \& Hawkes, A. D. (2011). A decadally-resolved paleohurricane record archived in the late Holocene sediments of a Florida sinkhole. Marine Geology, 287(1-4), 14-30. https://doi.org/10.1016/j.margeo.2011.07.001

Leatherman, S. P. (1983). Barrier dynamics and landward migration with Holocene sea-level rise. Nature, 301(5899), 415-417. https://doi.org/10.1038/301415a0

Leatherman, S. P., Zhang, K., \& Douglas, B. C. (2000). Sea level rise shown to drive coastal erosion. Eos, 81(6), 55-57. https://doi.org/10.1029/00EO00034

Leonard, L. A., \& Luther, M. E. (1995). Flow hydrodynamics in tidal marsh canopies. Limnology and Oceanography, 40(8), 1474-1484. https://doi.org/10.4319/lo.1995.40.8.1474

Leonard, L. A., Hine, A. C., \& Luther, M. E. (1995). Surficial Sediment Transport and Deposition Processes in a Juncus roemerianus Marsh. Journal of Coastal Research, 11(2), 322-336.

Leonardi, N., \& Fagherazzi, S. (2014). How waves shape salt marshes. Geology, 42(10), 887-890. https://doi.org/10.1130/G35751.1

Leonardi, Nicoletta, \& Fagherazzi, S. (2015). Effect of local variability in erosional resistance on large-scale morphodynamic response of salt marshes to wind waves and extreme events. Geophysical Research Letters, 42, 5872-5879. https://doi.org/10.1002/2015GL064730.Received

Leonardi, Nicoletta, Ganju, N. K., \& Fagherazzi, S. (2016). A linear relationship between wave power and erosion determines salt-marsh resilience to violent storms and hurricanes. Proceedings of the National Academy of Sciences, 113(1), 64-68. https://doi.org/10.1073/pnas.1510095112

Leonardi, Nicoletta, Defne, Z., Ganju, N. K., \& Fagherazzi, S. (2016). Salt marsh erosion rates and boundary features in a shallow Bay. Journal of Geophysical Research: Earth Surface, 121, 1861-1875. https://doi.org/10.1002/2014JF003432.Received

Lesser, G. R., Roelvink, J. A., van Kester, J. A. T. M., \& Stelling, G. S. (2004). Development and validation of a three-dimensional morphological model. Coastal Engineering, 51(8-9), 883-915. https://doi.org/10.1016/j.coastaleng.2004.07.014

Lin, N., Emanuel, K., Oppenheimer, M., \& Vanmarcke, E. (2012). Physically based assessment of hurricane surge threat under climate change. Nature Climate Change, 2(6), 462-467. https://doi.org/10.1038/nclimate1389

List, J. H., Hansen, M. E., Sallenger, A. H., \& Jaffe, B. E. (2001). The impact of an extreme event on the sediment budget: Hurricane Andrew in the Louisiana barrier islands. Coastal Engineering Proceedings, 25, 2756-2769. 
Liu, K., \& Fearn, M. L. (1993). Lake-sediment record of late Holocene hurricane. Geology, 21, 793796. https://doi.org/10.1130/0091-7613(1993)021<0793

Loder, N. M., Irish, J. L., Cialone, M. A., \& Wamsley, T. V. (2009). Sensitivity of hurricane surge to morphological parameters of coastal wetlands. Estuarine, Coastal and Shelf Science, 84(4), 625-636. https://doi.org/10.1016/j.ecss.2009.07.036

Long, A. J., Waller, M. P., \& Stupples, P. (2006). Driving mechanisms of coastal change: Peat compaction and the destruction of late Holocene coastal wetlands. Marine Geology, 225(1-4), 63-84. https://doi.org/10.1016/j.margeo.2005.09.004

Lorenzo-Trueba, J., \& Ashton, A. D. (2010). Rollover, drowning, and discontinuous retreat: Distinct modes of barrier response to sea-level rise arising from a simple morphodynamic model. Journal of Geophysical Research: Earth Surface, 119(4), 779-801. https://doi.org/10.1002/2013JF002941

Ludlum, D. M. (1963). Early American hurricanes. Boston, MA: American Meterological Society.

Luettich, R. A., Harleman, D. R. F., \& SomlyÓdy, Lá. (1990). Dynamic behavior of suspended sediment concentrations in a shallow lake perturbed by episodic wind events. Limnology and Oceanography, 35(5), 1050-1067. https://doi.org/10.4319/lo.1990.35.5.1050

Mariotti, G., Fagherazzi, S., Wiberg, P. L., McGlathery, K. J., Carniello, L., \& Defina, A. (2010). Influence of storm surges and sea level on shallow tidal basin erosive processes. Journal of Geophysical Research: Oceans, 115(11), 1-17. https://doi.org/10.1029/2009JC005892

Mariotti, Giulio, \& Fagherazzi, S. (2010). A numerical model for the coupled long-term evolution of salt marshes and tidal flats. Journal of Geophysical Research, 115(F1), F01004. https://doi.org/10.1029/2009JF001326

Marsooli, R., Orton, P. M., Georgas, N., \& Blumberg, A. F. (2016). Three-dimensional hydrodynamic modeling of coastal flood mitigation by wetlands. Coastal Engineering, 111, 83-94. https://doi.org/10.1016/j.coastaleng.2016.01.012

Massachusetts Shoreline Change Browser. MassGIS. Accessed 2019 at http://maps.massgis.state.ma.us/map ol/czm shorelines.php.

McBride, R. A., Anderson, J. B., Buynevich, I. V., Cleary, W., Fenster, M. S., FitzGerald, D. M., ... Wang, P. (2013). Morphodynamics of Barrier Systems: A Synthesis. Treatise on Geomorphology (Vol. 10). Elsevier Ltd. https://doi.org/10.1016/B978-0-12-374739-6.00279-7

McKee, K. L., \& Cherry, J. A. (2009). Hurricane Katrina sediment slowed elevation loss in subsiding brackish marshes of the Mississippi River delta. Wetlands, 29(1), 2-15. https://doi.org/10.1672/08-32.1

McLoughlin, S. M., Wiberg, P. L., Safak, I., \& McGlathery, K. J. (2015). Rates and Forcing of Marsh Edge Erosion in a Shallow Coastal Bay. Estuaries and Coasts, 38, 620-638. https://doi.org/10.1007/s12237-014-9841-2

Mcowen, C., Weatherdon, L., Bochove, J.-W., Sullivan, E., Blyth, S., Zockler, C., ... Fletcher, S. (2017). A global map of saltmarshes. Biodiversity Data Journal, 5, e11764. https://doi.org/10.3897/BDJ.5.e11764

Mendelsohn, R., Emanuel, K., Chonabayashi, S., \& Bakkensen, L. (2012). The impact of climate change on global tropical cyclone damage. Nature Climate Change, 2(3), 205-209.

https://doi.org/10.1038/nclimate1357 
Miller, K. G., Sugarman, P. J., Browning, J. V., Horton, B. P., Stanley, A., Kahn, A., .. Aucott, M. (2009). Sea-level rise in New Jersey over the past 5000 years: Implications to anthropogenic changes. Global and Planetary Change, 66(1-2), 10-18. https://doi.org/10.1016/j.gloplacha.2008.03.008

Möller, I. (2012). Bio-physical linkages in coastal wetlands - implications for coastal protection. Crossing Borders in Coastal Research: Jubilee Conference Proceedings. https://doi.org/10.3990/2.170

Möller, Iris, Kudella, M., Rupprecht, F., Spencer, T., Paul, M., van Wesenbeeck, B. K., ... Schimmels, S. (2014). Wave attenuation over coastal salt marshes under storm surge conditions. Nature Geoscience, 7(September), 727-731. https://doi.org/10.1038/ngeo2251

Morgan, P. A., Burdick, D. M., \& Short, F. T. (2009). The functions and values of fringing salt marshes in northern New England, USA. Estuaries and Coasts, 32(3), 483-495. https://doi.org/10.1007/s12237-009-9145-0

Morton, R. A., \& Barras, J. A. (2011). Hurricane Impacts on Coastal Wetlands: A Half-Century Record of Storm-Generated Features from Southern Louisiana Hurricane Impacts on Coastal Wetlands: A Half -Century Record of Storm-Generated Features from Southern Louisiana. Journal of Coastal Research, 27(6A), 27-43. https://doi.org/10.2112/jcoastres-d-10-00185.1

Morton, R. A., \& Donaldson, A. C. (1973). Sediment distribution and evolution of tidal deltas along a tide-dominated shoreline, Wachapreague, Virginia. Sedimentary Geology, 10(4), 285-299. https://doi.org/10.1016/0037-0738(73)90053-5

Muller, J., Collins, J.M., Gibson, S. and Paxton, L. (2017). Recent Advances in the Emerging Field of Paleotempestology. In Hurricanes and Climate Change (pp. 1-33). Springer, Cham.

Myers, V. A., \& Jordan, E. S. (1956). Winds and Pressures Over the Sea in the Hurricane of September 1938. Monthly Weather Review, (July), 261-270.

Nepf, H. M. (2012). Flow and Transport in Regions with Aquatic Vegetation. Annual Review of Fluid Mechanics, 44(1), 123-142. https://doi.org/10.1146/annurev-fluid-120710-101048

Niering, W. A., \& Warren, R. S. (2006). Vegetation Patterns and Processes in New England Salt Marshes. BioScience, 30(5), 301-307. https://doi.org/10.2307/1307853

Nikitina, D. L., Kemp, A. C., Horton, B. P., Vane, C. H., van de Plassche, O., \& Engelhart, S. E. (2014). Storm erosion during the past 2000 years along the north shore of Delaware Bay, USA. Geomorphology, 208, 160-172. https://doi.org/10.1016/j.geomorph.2013.11.022

Ochi,M. K., 2005. Ocean Waves: The Stochastic Approach. Cambridge University Press 6, New York.

Oertel, G. F. (2001). Hypsographic, Hydro-Hypsographic and Hydrological Analysis of Coastal Bay Environments, Great Machipongo Bay, Virginia. Journal of Coastal Research, 17(4), 775-783. Retrieved from http://www.jstor.org/stable/4300238

Olabarrieta, M., Warner, J. C., \& Kumar, N. (2011). Wave-current interaction in Willapa Bay. Journal of Geophysical Research: Oceans, 116(12), 1-27. https://doi.org/10.1029/2011JC007387

Oliva, F., Viau, A. E., Peros, M. C., \& Bouchard, M. (2018). Paleotempestology database for the western North Atlantic basin. Holocene, 28(10), 1664-1671. https://doi.org/10.1177/0959683618782598

Orson, R.A., Warren, R. S., \& Niering, W. A. (1998). Interpreting Sea Level Rise and Rates of 
Vertical Marsh Accretion in a Southern New England Tidal Salt Marsh. Estuarine, Coastal and Shelf Science, 47, 419-429. https://doi.org/10.1006/ecss.1998.0363

Orson, Richard A., Warren, R. S., \& Niering, W. A. (1987). Development of a Tidal Marsh in a New England River Valley. Estuaries, 10(1), 20-27.

Orton, P., Talke, S., Jay, D., Yin, L., Blumberg, A., Georgas, N., .. MacManus, K. (2015). Channel Shallowing as Mitigation of Coastal Flooding. Journal of Marine Science and Engineering, 3(3), 654 673. https://doi.org/10.3390/jmse3030654

Parris, A., Bromirski, P., Burkett, V., Cayan, D., Culver, M., Hall, J., ... Weiss, J. (2012). Global Sea Level Rise Scenarios for the US National Climate Assessment. NOAA Tech Memo OAR CPO, 1-37. Retrieved from http://cpo.noaa.gov/sites/cpo/Reports/2012/NOAA_SLR_r3.pdf

Pedersen, J. B. T., \& Bartholdy, J. (2006). Budgets for fine-grained sediment in the Danish Wadden Sea. Marine Geology, 235(1-4 SPEC. ISS.), 101-117. https://doi.org/10.1016/j.margeo.2006.10.008

Pielke Jr, R., Gratz, J., \& Landsea, C. (2008). Normalized hurricane damage in the United States: 1900-2005. Natural Hazards Review, 29-42. Retrieved from http://ascelibrary.org/doi/abs/10.1061/(ASCE)1527-6988(2008)9:1(29)

van de Plassche, O., van der Borg, K., \& de Jong, A. F. M. (1999). Sea level - climate correlation during the past 1400 yr. Geology, 26(6), 319-322.

van de Plassche, O., Wright, A. J., van der Borg, K., \& de Jong, A. F. M. (2004). On the erosive trail of a 14th and 15th century hurricane in Connecticut (USA) salt marshes. Radiocarbon, 46(1), 1111-1150. https://doi.org/10.2458/azu_js_rc.46.4183

van de Plassche, O., Erkens, G., van Vliet, F., Brandsma, J., van der Borg, K., \& de Jong, A. F. M. (2006). Salt-marsh erosion associated with hurricane landfall in southern New England in the fifteenth and seventeenth centuries. Geology, 34(10), 829-832. https://doi.org/10.1130/G22598.1

Podlaha, A., Bowen, S., \& Lörinc, M. (2017). Weather, Climate \& Catastrophe Insight: 2017 Annual Report. Boston, MA.

Postma, H. (1961). Transport and accumulation of suspended matter in the Dutch Wadden Sea. Netherlands Journal of Sea Reasearch, 1, 148-190. https://doi.org/10.1017/CBO9781107415324.004

Priestas, A., Mariotti, G., Leonardi, N., \& Fagherazzi, S. (2015). Coupled Wave Energy and Erosion Dynamics along a Salt Marsh Boundary, Hog Island Bay, Virginia, USA. Journal of Marine Science and Engineering, 3, 1041-1065. https://doi.org/10.3390/jmse3031041

Rappaport, E. N. (2014). Fatalities in the United States from Atlantic Tropical Cyclones: New Data and Interpretation. Bulletin of the American Meteorological Society, 95(3), 341-346. https://doi.org/10.1175/BAMS-D-12-00074.1

Redfield, A. C. (1972). Development of a New England Salt Marsh. Ecological Monographs, 42(2), 201237. Retrieved from http://www.jstor.org/stable/10.2307/1942263

Redfield, A. C. (1965). Ontogeny of a Salt Marsh Estuary. Science, 147(3653), 50-55. https://doi.org/10.1126/science.147.3653.50

Redfield, A. C. (1972). Development of a New England Salt Marsh. Ecological Monographs, 42(2), 201- 
237.

Resio, D. T., \& Westerink, J. J. (2008). Modeling the physics of storm surges. Physics Today, 61(9), 33-38. https://doi.org/10.1063/1.2982120

Rodriguez, A. B., Fegley, S. R., Ridge, J. T., VanDusen, B. M., \& Anderson, N. (2013). Contribution of aeolian sand to backbarrier marsh sedimentation. Estuarine, Coastal and Shelf Science, 117, 248259. https://doi.org/10.1016/j.ecss.2012.12.001

Sallenger, A. H., Doran, K. S., \& Howd, P. A. (2012). Hotspot of accelerated sea-level rise on the Atlantic coast of North America. Nature Climate Change, 2(12), 884-888. https://doi.org/10.1038/nclimate1597

Schuerch, M., Vafeidis, A., Slawig, T., \& Temmerman, S. (2013). Modeling the influence of changing storm patterns on the ability of a salt marsh to keep pace with sea level rise. Journal of Geophysical Research: Earth Surface, 118(1), 84-96. https://doi.org/10.1029/2012JF002471

Schwimmer, R. A., \& Pizzuto, J. E. (2000). A model for the evolution of marsh shorelines. Journal of Sedimentary Research, 70(1981), 1026-1035. https://doi.org/10.1306/030400701026

Shennan, I., \& Horton, B. (2002). Holocene land- and sea-level changes in Great Britain. Journal of Quaternary Science, 17(5-6), 511-526. https://doi.org/10.1002/jqs.710

Shepard, C. C., Crain, C. M., \& Beck, M. W. (2011). The Protective Role of Coastal Marshes: A Systematic Review and Meta-analysis. Plos One, 6(11), e27374. https://doi.org/10.1371/journal.pone.0027374

Small, C., and Nicholls, R., 2003, A Global Analysis of Human Settlement in Coastal Zones: Journal of Coastal Research, v. 19, no. 3, p. 584-599.

Smith, J. E., Bentley, S. J., Snedden, G. A., \& White, C. (2015). What Role do Hurricanes Play in Sediment Delivery to Subsiding River Deltas? Scientific Reports, 5, 17582.

https://doi.org/10.1038/srep17582

Smith-Johnson, R. (2014). 61 years ago: Hurricane Carol, Cape Cod Online.

Snedden, G. A., Cretini, K., \& Patton, B. (2014). Inundation and salinity impacts to above- and belowground productivity in Spartina patens and Spartina alterniflora in the Mississippi River deltaic plain: Implications for using river diversions as restoration tools. Ecological Engineering, 81, 133-139. https://doi.org/10.1016/j.ecoleng.2015.04.035

Sobel, A. H., Camargo, S. J., Hall, T. M., Lee, C., Tippett, M. K., \& Wing, A. a. (2016). Human influence on tropical cyclone intensity. Science, 353(6296), 242-246.

Sopkin, K. L., Stockdon, H. F., Doran, B. K. S., Plant, N. G., Morgan, K. L. M., Guy, K. K., \& Smith, K. E. L. (2014). Hurricane Sandy: observations and analysis of coastal change. U.S. Geological Survey Open-File Report 2014-1088, 54. https://doi.org/10.3133/ofr20141088

Stanhope, J. W., Anderson, I. C., \& Reay, W. G. (2009). Base flow nutrient discharges from lower Delmarva peninsula watersheds of Virginia, USA. Journal of Environmental Quality, 38(5), 2070_ 2083. https://doi.org/10.2134/jeq2008.0358

Stark, J., Van Oyen, T., Meire, P., \& Temmerman, S. (2015). Observations of tidal and storm surge attenuation in a large tidal marsh. Limnology and Oceanography, 60(4), 1371-1381. https://doi.org/10.1002/lno.10104 
Stockdon, H. F., Holman, R. A., Howd, P. A., \& Sallenger, A. H. (2006). Empirical parameterization of setup, swash, and runup. Coastal Engineering, 53(7), 573-588.

https://doi.org/10.1016/j.coastaleng.2005.12.005

Stumpf, R. P. (1983). The process of sedimentation on the surface of a salt marsh. Estuarine, Coastal and Shelf Science, 17(5), 495-508. https://doi.org/10.1016/0272-7714(83)90002-1

Tate, A. S., \& Battaglia, L. L. (2013). Community disassembly and reassembly following experimental storm surge and wrack application. Journal of Vegetation Science, 24(1), 46-57. https://doi.org/10.1111/j.1654-1103.2012.01447.x

Temmerman, S., Bouma, T. J., Govers, G., Wang, Z. B., De Vries, M. B., \& Herman, P. M. J. (2005). Impact of vegetation on flow routing and sedimentation patterns: Three-dimensional modeling for a tidal marsh. Journal of Geophysical Research: Earth Surface, 110(4), 1-18. https://doi.org/10.1029/2005JF000301

Temmerman, Stijn, Moonen, P., Schoelynck, J., Govers, G., \& Bouma, T. J. (2012). Impact of vegetation die-off on spatial flow patterns over a tidal marsh. Geophysical Research Letters, 39(3), 1-5. https://doi.org/10.1029/2011GL050502

Temmerman, Stijn, Meire, P., Bouma, T. J., Herman, P. M. J., Ysebaert, T., \& De Vriend, H. J. (2013). Ecosystem-based coastal defence in the face of global change. Nature, 504(7478), 79-83. https://doi.org/10.1038/nature12859

Thomas, C. R., \& Blum, L. K. (2010). Importance of the fiddler crab Uca pugnax to salt marsh soil organic matter accumulation. Marine Ecology Progress Series, 414, 167-177. https://doi.org/10.3354/meps08708

Turner, R. E., Baustian, J. J., Swenson, E. M., \& Spicer, J. S. (2006). Wetland sedimentation from hurricanes Katrina and Rita. Science, 314(5798), 449-452. https://doi.org/10.1126/science.1129116

Tweel, A. W., \& Turner, R. E. (2012). Landscape-Scale Analysis of Wetland Sediment Deposition from Four Tropical Cyclone Events. PLoS ONE, 7(11). https://doi.org/10.1371/journal.pone.0050528

Vallee, D.R., Dion, M.R., 1998. Southern New England tropical storms and hurricanes, a ninetyeight year summary (1909-1997). National Weather Service, Taunton, MA.

Wallace, D. J., \& Anderson, J. B. (2010). Evidence of similar probablility of intense hurricane strikes for the gulf of Mexico over the late Holocene. Geology, 38(6), 511-514. https://doi.org/10.1130/G30729.1

Walsh, K. J. E., McBride, J. L., Klotzbach, P. J., Balachndran, S., Camargo, S. J., Holland, G. J., ... Sugi, M. (2016). Tropical cyclones and climate change. Wiley Interdisciplinary Reviews: Climate Change, 7(February/February), 65-89. https://doi.org/10.1002/wcc.371

Walters, D. C., \& Kirwan, M. L. (2016). Optimal hurricane overwash thickness for maximizing marsh resilience to sea level rise. Ecology and Evolution, 6(9), 2948-2956. https://doi.org/10.1002/ece3.2024

Walters, D., Moore, L. J., Vinent, O. D., Fagherazzi, S., \& Mariotti, G. (2014). Interactions between barrier islands and marshes affect island system response to sea level rise: Insights from a coupled model. Journal of Geophysical Research: Earth Surface, 119(9), 2013-2031. https://doi.org/10.1002/2014JF003091.Received 
Wamsley, T. V., Cialone, M. A., Smith, J. M., Ebersole, B. A., \& Grzegorzewski, A. S. (2009). Influence of landscape restoration and degradation on storm surge and waves in southern Louisiana. Natural Hazards, 51(1), 207-224. https://doi.org/10.1007/s11069-009-9378-z

Warren, R. S., \& Niering, W. A. (1993). Vegetation Change on a Northeast Tidal Marsh: Interaction of Sea-Level Rise and Marsh Accretion. Ecology, 74(1), 96-103. https://doi.org/10.2307/1939504

Watson, E. B., Wigand, C., Davey, E. W., Andrews, H. M., Bishop, J., \& Raposa, K. B. (2017). Wetland Loss Patterns and Inundation-Productivity Relationships Prognosticate Widespread Salt Marsh Loss for Southern New England. Estuaries and Coasts, 40(3), 662-681. https://doi.org/10.1007/s12237-016-0069-1

Wells, J. T. (1995). Tide-Dominated Estuaries and Tidal Rivers. In G. M. E. Perillo (Ed.), Geomorphology and Sedimentology of Estuaries (Vol. 53, pp. 179-205). https://doi.org/10.1016/S0070-4571(05)80026-3

Wiberg, P. L., Carr, J. A., Safak, I., \& Anutaliya, A. (2015). Quantifying the distribution and influence of non-uniform bed properties in shallow coastal bays. Limnology and Oceanography: Methods, 13, 746-762. https://doi.org/10.1002/lom3.10063

Williams, H. F. L. (2012). Magnitude of Hurricane Ike storm surge sedimentation: Implications for coastal marsh aggradation. Earth Surface Processes and Landforms, 37(8), 901-906. https://doi.org/10.1002/esp.3252

Wilson, K. R., Kelley, J. T., Croitoru, A., Dionne, M., Belknap, D. F., \& Steneck, R. (2009). Stratigraphic and ecophysical characterizations of salt pools: Dynamic landforms of the Webhannet salt marsh, Wells, ME, USA. Estuaries and Coasts, 32(5), 855-870. https://doi.org/10.1007/s12237-009-9203-7

Wood, M. E., Kelley, J. T., \& Belknap, D. F. (2006). Patterns of Sediment Accumulation in the Tidal Marshes of Maine. Estuaries, 12(4), 237. https://doi.org/10.2307/1351903

Woodruff, J. D., Irish, J. L., \& Camargo, S. J. (2013). Coastal flooding by tropical cyclones and sealevel rise. Nature, 504(7478), 44-52. https://doi.org/10.1038/nature12855

Woodruff, J. D., Donnelly, J. P., Mohrig, D., \& Geyer, W. R. (2008). Reconstructing relative flooding intensities responsible for hurricane-induced deposits from Laguna Playa Grande, Vieques, Puerto Rico. Geology, 36(5), 391-394. https://doi.org/10.1130/G24731A.1

Yang, J. Q., Kerger, F., \& Nepf, H. M. (2015). Estimation of the bed shear stress in vegetated and bare channels with smooth beds. Water Resources Research, 51, 3647-3663. https://doi.org/10.1002/2014WR016042.Received 